\title{
Diverse Types of Diterpenoids with an Aromatized C Ring from the Twigs of Podocarpus imbricatus
}

Bin Zhou, ${ }^{\dagger, \star}$ Yu-Hao Ren, ${ }^{\dagger \neq}$ Ying-Shan Han, ${ }^{\S}$ Thibault Mesplède, ${ }^{\S}$ and Jian-Min Yue, ${ }^{\dagger, \hbar * *}$

†State Key Laboratory of Drug Research, Shanghai Institute of Materia Medica, Chinese Academy of Sciences, 555 Zuchongzhi Road, Shanghai 201203, People's Republic of China

tUniversity of Chinese Academy of Sciences, No.19A Yuquan Road, Beijing 100049, People's Republic of China

${ }^{\S}$ McGill University AIDS Centre, Lady Davis Institute for Medical Research, Jewish General Hospital, Montreal, Quebec H3T 1E2, Canada

*Corresponding authors

Tel.: +86 21 50806718. Email: jmyue@ simm.ac.cn 


\section{Contents}

General Experimental Procedures ..........................................................1

Figure S1. ${ }^{1} \mathrm{H}$ NMR spectrum of (15S), 16-hydroxylambertic acid (1) in $\mathrm{CD}_{3} \mathrm{OD} .2$ Figure S2. ${ }^{13} \mathrm{C}$ NMR spectrum of (15S), 16-hydroxylambertic acid (1) in $\mathrm{CD}_{3} \mathrm{OD} .3$ Figure S3. ${ }^{1} \mathrm{H}^{-1} \mathrm{H}$ COSY spectrum of (15S), 16-hydroxylambertic acid (1) in $\mathrm{CD}_{3} \mathrm{OD}$

Figure S4. HSQC spectrum of (15S), 16-hydroxylambertic acid (1) in $\mathrm{CD}_{3} \mathrm{OD}$.....5 Figure S5. HMBC spectrum of (15S), 16-hydroxylambertic acid (1) in $\mathrm{CD}_{3} \mathrm{OD}$....6 Figure S6. NOESY spectrum of (15S), 16-hydroxylambertic acid (1) in $\mathrm{CD}_{3} \mathrm{OD}$...7 Figure S7. (+)-ESIMS spectrum of (15S),16-hydroxylambertic acid (1) ..................8 Figure S8. (-)-ESIMS spectrum of (15S),16-hydroxylambertic acid (1) .................9 Figure S9. (-)-HRESIMS spectrum of (15S),16-hydroxylambertic acid (1) .........10 Figure S10. IR spectrum of (15S),16-hydroxylambertic acid (1)..........................11 Figure S11. ${ }^{1} \mathrm{H}$ NMR spectrum of (15R), 16-hydroxylambertic acid (2) in $\mathrm{CD}_{3} \mathrm{OD}$

Figure S12. ${ }^{13} \mathrm{C}$ NMR spectrum of (15R), 16-hydroxylambertic acid (2) in $\mathrm{CD}_{3} \mathrm{OD}$

Figure S13. HSQC spectrum of (15R), 16-hydroxylambertic acid (2) in $\mathrm{CD}_{3} \mathrm{OD} .14$ Figure S14. HMBC spectrum of (15R), 16-hydroxylambertic acid (2) in $\mathrm{CD}_{3} \mathrm{OD} 15$ Figure S15. NOESY spectrum of (15R), 16-hydroxylambertic acid (2) in $\mathrm{CD}_{3} \mathrm{OD}$

Figure S16. ESIMS spectrum of (15R),16-hydroxylambertic acid (2) ..................17

Figure S17. (-)-HRESIMS spectrum of (15R),16-hydroxylambertic acid (2) ......18

Figure S18. IR spectrum of (15R),16-hydroxylambertic acid (2) ..........................19

Figure S19. ${ }^{1} \mathrm{H}$ NMR spectrum of 12-deoxypicrosalvin (3) in $\mathrm{CDCl}_{3}$....................20

Figure S20. ${ }^{13} \mathrm{C}$ NMR spectrum of 12-deoxypicrosalvin (3) in $\mathrm{CDCl}_{3}$..................21

Figure S21. HSQC spectrum of 12-deoxypicrosalvin (3) in $\mathrm{CDCl}_{3} \ldots . . . . . . . . . . . . . . . . . . .22$

Figure S22. HMBC spectrum of 12-deoxypicrosalvin (3) in $\mathrm{CDCl}_{3}$.....................23

Figure S23. NOESY spectrum of 12-deoxypicrosalvin (3) in $\mathrm{CDCl}_{3}$......................24

Figure S24. ESIMS spectrum of 12-deoxypicrosalvin (3) .......................................25

Figure S25. (-)-HRESIMS spectrum of 12-deoxypicrosalvin (3) .............................26

Figure S26. IR spectrum of 12-deoxypicrosalvin (3) ..........................................27

Figure S27. ${ }^{1} \mathrm{H}$ NMR spectrum of 18-hydroxysempervirol (4) in $\mathrm{CDCl}_{3}$...............28

Figure S28 ${ }^{13} \mathrm{C}$ NMR spectrum of 18-hydroxysempervirol (4) in $\mathrm{CDCl}_{3}$..............29

Figure S29. HSQC spectrum of 18-hydroxysempervirol (4) in $\mathrm{CDCl}_{3}$...................30

Figure S30. HMBC spectrum of 18-hydroxysempervirol (4) in $\mathrm{CDCl}_{3}$.................31

Figure S31. NOESY spectrum of 18-hydroxysempervirol (4) in $\mathrm{CDCl}_{3}$................32

Figure S32. (+)-ESIMS spectrum of 18-hydroxysempervirol (4)..............................33

Figure S33. (-)-ESIMS spectrum of 18-hydroxysempervirol (4)...........................34

Figure S34. (-)-HRESIMS spectrum of 18-hydroxysempervirol (4).....................35

Figure S35. IR spectrum of 18-hydroxysempervirol (4) ....................................36

Figure S36. ${ }^{1} \mathrm{H}$ NMR spectrum of $6 \beta$-hydroxysempervirol (5) in $\mathrm{CDCl}_{3} \ldots . . . . . . . . . . . . .37$ 
Figure S37. ${ }^{13} \mathrm{C}$ NMR spectrum of $6 \beta$-hydroxysempervirol (5) in $\mathrm{CDCl}_{3} \ldots . . . . . . . . . .38$

Figure S38. HSQC spectrum of $6 \beta$-hydroxysempervirol (5) in $\mathrm{CDCl}_{3} \ldots . . . . . . . . . . . . . .39$

Figure S39. HMBC spectrum of $6 \beta$-hydroxysempervirol (5) in $\mathrm{CDCl}_{3}$..................40

Figure S40. NOESY spectrum of $6 \beta$-hydroxysempervirol (5) in $\mathrm{CDCl}_{3}$................41

Figure S41. (-)-ESIMS spectrum of $6 \beta$-hydroxysempervirol (5) ........................42

Figure S42. (-)-HRESIMS spectrum of $6 \beta$-hydroxysempervirol (5) ....................43

Figure S43. IR spectrum of $6 \beta$-hydroxysempervirol (5)..........................................44

Figure S44. ${ }^{1} \mathrm{H}$ NMR spectrum of 6-hydroxy-7-oxosempervirol (6) in $\mathrm{CDCl}_{3} \ldots . . .45$

Figure S45. ${ }^{13} \mathrm{C}$ NMR spectrum of 6-hydroxy-7-oxosempervirol (6) in $\mathrm{CDCl}_{3} . . .46$

Figure S46. HSQC spectrum of 6-hydroxy-7-oxosempervirol (6) in $\mathrm{CDCl}_{3} \ldots . . . . . .47$

Figure S47. HMBC spectrum of 6-hydroxy-7-oxosempervirol (6) in $\mathrm{CDCl}_{3} \ldots . . . . . .48$

Figure S48. NOESY spectrum of 6-hydroxy-7-oxosempervirol (6) in $\mathrm{CDCl}_{3} \ldots . . .49$

Figure S49. (+)-ESIMS spectrum of 6-hydroxy-7-oxosempervirol (6) ...................50

Figure S50. (-)-ESIMS spectrum of 6-hydroxy-7-oxosempervirol (6) ..................51

Figure S51. (+)-HRESIMS spectrum of 6-hydroxy-7-oxosempervirol (6) ............52

Figure S52. IR spectrum of 6-hydroxy-7-oxosempervirol (6) ...............................53

Figure S53. ${ }^{1} \mathrm{H}$ NMR spectrum of $6 \beta, 7 \beta$-dihydroxysempervirol (7) in $\mathrm{CDCl}_{3} \ldots . .54$

Figure S54. ${ }^{13} \mathrm{C}$ NMR spectrum of $6 \beta, 7 \beta$-dihydroxysempervirol (7) in $\mathrm{CDCl}_{3} \ldots . .55$

Figure S55. HSQC spectrum of $6 \beta, 7 \beta$-dihydroxysempervirol (7) in $\mathrm{CDCl}_{3} \ldots . . . . . .56$

Figure S56. HMBC spectrum of $6 \beta, 7 \beta$-dihydroxysempervirol (7) in $\mathrm{CDCl}_{3} \ldots . . . . .57$

Figure S57. NOESY spectrum of $6 \beta, 7 \beta$-dihydroxysempervirol (7) in $\mathrm{CDCl}_{3} \ldots . . .58$

Figure S58. (+)-ESIMS spectrum of $6 \beta, 7 \beta$-dihydroxysempervirol (7) ..................59

Figure S59. (-)-ESIMS spectrum of $6 \beta, 7 \beta$-dihydroxysempervirol (7) ....................60

Figure S60. (-)-HRESIMS spectrum of $6 \beta, 7 \beta$-dihydroxysempervirol (7)............61

Figure S61. IR spectrum of $6 \beta, 7 \beta$-dihydroxysempervirol (7) ...............................62

Figure S62. ${ }^{1} \mathrm{H}$ NMR spectrum of 6,7-dioxosempervirol (8) in $\mathrm{CDCl}_{3} \ldots . . . . . . . . . . . . . . . .663$

Figure S63. ${ }^{13} \mathrm{C}$ NMR spectrum of 6,7-dioxosempervirol (8) in $\mathrm{CDCl}_{3}$................64

Figure S64. HSQC spectrum of 6,7-dioxosempervirol (8) in $\mathrm{CDCl}_{3}$.....................65

Figure S65. HMBC spectrum of 6,7-dioxosempervirol (8) in $\mathrm{CDCl}_{3}$....................66

Figure S66. NOESY spectrum of 6,7-dioxosempervirol (8) in $\mathrm{CDCl}_{3}$..................67

Figure S67. (+)-ESIMS spectrum of 6,7-dioxosempervirol (8) ................................68

Figure S68. (-)-ESIMS spectrum of 6,7-dioxosempervirol (8) ..............................69

Figure S69. (+)-HRESIMS spectrum of 6,7-dioxosempervirol (8) ..........................70

Figure S70. IR spectrum of 6,7-dioxosempervirol (8).........................................71

Figure S71. ${ }^{1} \mathrm{H}$ NMR spectrum of $6 \beta$-hydroxy-7 $\alpha$-methoxysempervirol (9) in

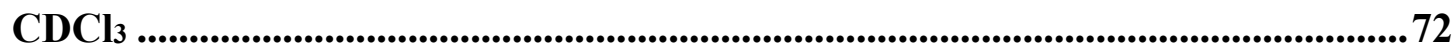

Figure S72. ${ }^{13} \mathrm{C}$ NMR spectrum of $6 \beta$-hydroxy-7 $\alpha$-methoxysempervirol (9) in

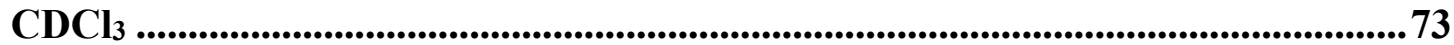

Figure S73. HSQC spectrum of $6 \beta$-hydroxy-7 $\alpha$-methoxysempervirol (9) in $\mathrm{CDCl}_{3}$ . .74

Figure S74. HMBC spectrum of $6 \beta$-hydroxy-7 $\alpha$-methoxysempervirol (9) in $\mathrm{CDCl}_{3}$

Figure S75. NOESY spectrum of $6 \beta$-hydroxy-7 $\alpha$-methoxysempervirol (9) in $\mathrm{CDCl}_{3}$ . .76 
Figure S76. (+)-ESIMS spectrum of $6 \beta$-hydroxy-7 $\alpha$-methoxysempervirol (9).....77

Figure S77. (-)-ESIMS spectrum of $6 \beta$-hydroxy-7 $\alpha$-methoxysempervirol (9).....78

Figure S78. (-)-HRESIMS spectrum of $6 \beta$-hydroxy-7 $\alpha$-methoxysempervirol (9)

Figure S79. IR spectrum of $6 \beta$-hydroxy-7 $\alpha$-methoxysempervirol $(9)$

Figure S80. ${ }^{1} \mathrm{H}$ NMR spectrum of $1 \beta, 18$-dihydroxytotarol $(10)$ in $\mathrm{CDCl}_{3} \ldots . . . . . . . . .81$

Figure S81. ${ }^{13} \mathrm{C}$ NMR spectrum of $1 \beta, 18$-dihydroxytotarol (10) in $\mathrm{CDCl}_{3} \ldots . . . . . . . . .82$

Figure S82. ${ }^{1} \mathrm{H}-{ }^{1} \mathrm{H}$ COSY spectrum of $1 \beta, 18$-dihydroxytotarol (10) in $\mathrm{CDCl}_{3} \ldots . .83$

Figure S83. HSQC spectrum of $1 \beta, 18$-dihydroxytotarol (10) in $\mathrm{CDCl}_{3}$.................84

Figure S84. HMBC spectrum of $1 \beta, 18$-dihydroxytotarol (10) in $\mathrm{CDCl}_{3} . . . . . . . . . . . . . . .885$

Figure S85. NOESY spectrum of $1 \beta, 18$-dihydroxytotarol (10) in $\mathrm{CDCl}_{3} \ldots . . . . . . . . . . .86$

Figure S86. (-)-ESIMS spectrum of $1 \beta$,18-dihydroxytotarol (10) ........................87

Figure S87. (-)-HRESIMS spectrum of 1 $\beta, 18$-dihydroxytotarol (10) ...................88

Figure S88. IR spectrum of $1 \beta, 18$-dihydroxytotarol (10) ...................................89

Figure S89. ${ }^{1} \mathrm{H}$ NMR spectrum of $2 \alpha$-hydroxytotarol (11) in $\mathrm{CDCl}_{3} \ldots . . . . . . . . . . . . . . .90$

Figure S90. ${ }^{13} \mathrm{C}$ NMR spectrum of $2 \alpha$-hydroxytotarol (11) in $\mathrm{CDCl}_{3} \ldots . . . . . . . . . . . . . .991$

Figure S91. HSQC spectrum of $2 \alpha$-hydroxytotarol (11) in $\mathrm{CDCl}_{3}$......................92

Figure S92. HMBC spectrum of $2 \alpha$-hydroxytotarol (11) in $\mathrm{CDCl}_{3} \ldots \ldots . . . . . . . . . . . . . . . .93$

Figure S93. NOESY spectrum of $2 \alpha$-hydroxytotarol (11) in $\mathrm{CDCl}_{3} \ldots . . . . . . . . . . . . . . . . .994$

Figure S94. (+)-ESIMS spectrum of $2 \alpha$-hydroxytotarol (11) ...............................95

Figure S95. (-)-ESIMS spectrum of $2 \alpha$-hydroxytotarol (11) ...............................96

Figure S96. (-)-HRESIMS spectrum of $2 \alpha$-hydroxytotarol (11) ..........................97

Figure S97. IR spectrum of $2 \alpha$-hydroxytotarol (11) .................................................98

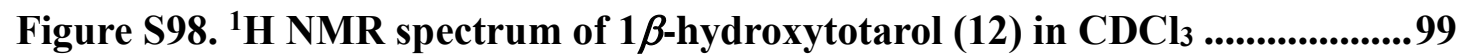

Figure S99. ${ }^{13} \mathrm{C}$ NMR spectrum of $1 \beta$-hydroxytotarol (12) in $\mathrm{CDCl}_{3}$..................100

Figure S100. HSQC spectrum of $1 \beta$-hydroxytotarol (12) in $\mathrm{CDCl}_{3} \ldots . . . . . . . . . . . . . . .101$

Figure S101. HMBC spectrum of $1 \beta$-hydroxytotarol (12) in $\mathrm{CDCl}_{3} \ldots . . . . . . . . . . . . . . .102$

Figure S102. NOESY spectrum of $1 \beta$-hydroxytotarol (12) in $\mathrm{CDCl}_{3} \ldots . . . . . . . . . . . . . .103$

Figure S103. (+)-ESIMS spectrum of $1 \beta$-hydroxytotarol (12) ...............................104

Figure S104. (-)-ESIMS spectrum of $1 \beta$-hydroxytotarol (12) ...............................105

Figure S105. (+)-HRESIMS spectrum of $1 \beta$-hydroxytotarol (12) ..........................106

Figure S106. IR spectrum of $1 \beta$-hydroxytotarol (12) .........................................107

Figure S107. ${ }^{1} \mathrm{H}$ NMR spectrum of 16-hydroxy-17-norlambertic acid (13) in $\mathrm{CDCl}_{3}$ 108

Figure S108. ${ }^{13} \mathrm{C}$ NMR spectrum of 16-hydroxy-17-norlambertic acid (13) in $\mathrm{CDCl}_{3}$....................................................................................................................109

Figure S109. HSQC spectrum of 16-hydroxy-17-norlambertic acid (13) in $\mathrm{CDCl}_{3}$ 110

Figure S110. HMBC spectrum of 16-hydroxy-17-norlambertic acid in $\mathrm{CDCl}_{3}$. 111 Figure S111. NOESY spectrum of 16-hydroxy-17-norlambertic acid (13) in $\mathrm{CDCl}_{3}$

Figure S112. ESIMS spectrum of 16-hydroxy-17-norlambertic acid (13) 112 Figure S113. (-)-HRESIMS spectrum of 16-hydroxy-17-norlambertic acid (13) 
Figure S114. IR spectrum of 16-hydroxy-17-norlambertic acid (13) .................... 115

Figure S115. ${ }^{1} \mathrm{H}$ NMR spectrum of 3-oxopisiferanol (14) in $\mathrm{CDCl}_{3}$...................... 116

Figure S116. ${ }^{13} \mathrm{C}$ NMR spectrum of 3-oxopisiferanol (14) in $\mathrm{CDCl}_{3}$.................... 117

Figure S117. HSQC spectrum of 3-oxopisiferanol (14) in $\mathrm{CDCl}_{3} \ldots . . . . . . . . . . . . . . . . . .118$

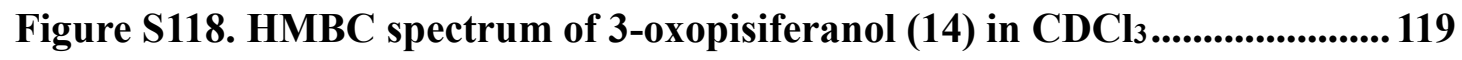

Figure S119. NOESY spectrum of 3-oxopisiferanol (14) in $\mathrm{CDCl}_{3} . . . . . . . . . . . . . . . . . . .120$

Figure S120. ESIMS spectrum of 3-0xopisiferanol (14) .....................................121

Figure S121. (-)-HRESIMS spectrum of 3-oxopisiferanol (14) ..............................122

Figure S122. IR spectrum of 3-oxopisiferanol (14) ......................................................123 


\section{General Experimental Procedures}

The melting points were measured on an SGM X-4 analyzer (Shanghai Precision \& Scientific Instrument Co. Ltd.) and were uncorrected. The X-ray crystallography was performed on a Bruker APEX-II CCD diffractometer equipped with graphitemonochromated $\mathrm{Cu} \mathrm{K} \alpha$ radiation $(\lambda=1.54178 \AA$ ). Optical rotations were measured on an Autopol VI polarimeter at room temperature; concentrations were reported in $\mathrm{g} / 100$ mL. UV data were obtained by using a Shimadzu UV-2550 spectrophotometer. ECD spectra were obtained on a JASCO J-815 spectrometer using a $0.1 \mathrm{~cm}$ path length sample cell. IR spectra were acquired on a Thermo IS5 spectrometer with KBr disks. NMR spectra were run on a Bruker AM-500 NMR spectrometer with TMS as internal standard. ESIMS data were recorded via a Bruker Daltonics Esquire 3000 plus/Shimadzu LC-MS-2020/Thermo Fisher Finnigan LCQ-DECA mass spectrometer, and HRESIMS were carried out on a Waters-Micromass Q-TQF Ultima Global mass spectrometer. Semi-preparative HPLC was performed on a Waters 1525 binary pump system with a Waters 2489 detector $(210 \mathrm{~nm})$ and equipped with a YMC-Pack ODS-A (250 $\times 10 \mathrm{~mm}, S-5 \mu \mathrm{m})$. Silica gel (200-300 mesh, Qingdao Haiyang Chemical Co., Ltd., China), $\mathrm{C}_{18}$ reversed-phase (RP-18) silica gel (20-45 $\mu \mathrm{m}$, Fuji Silysia Chemical Ltd., Japan), CHP20P MCI gel (75-150 $\mu \mathrm{m}$, Mitsubishi Chemical Corporation), and Sephadex LH-20 gel (Amersham Biosciences) were used for column chromatography (CC). Pre-coated silica gel GF 254 plates (Qingdao Haiyang Chemical Co., Ltd.) were used for TLC detection. All solvents used for CC were of analytical grade (Shanghai Chemical Reagents Co., Ltd.), and solvents used for HPLC were of HPLC grade (J \& K Scientific Ltd.). 
Figure S1. ${ }^{1} \mathrm{H}$ NMR spectrum of (15S), 16-hydroxylambertic acid (1) in $\mathrm{CD}_{3} \mathrm{OD}$

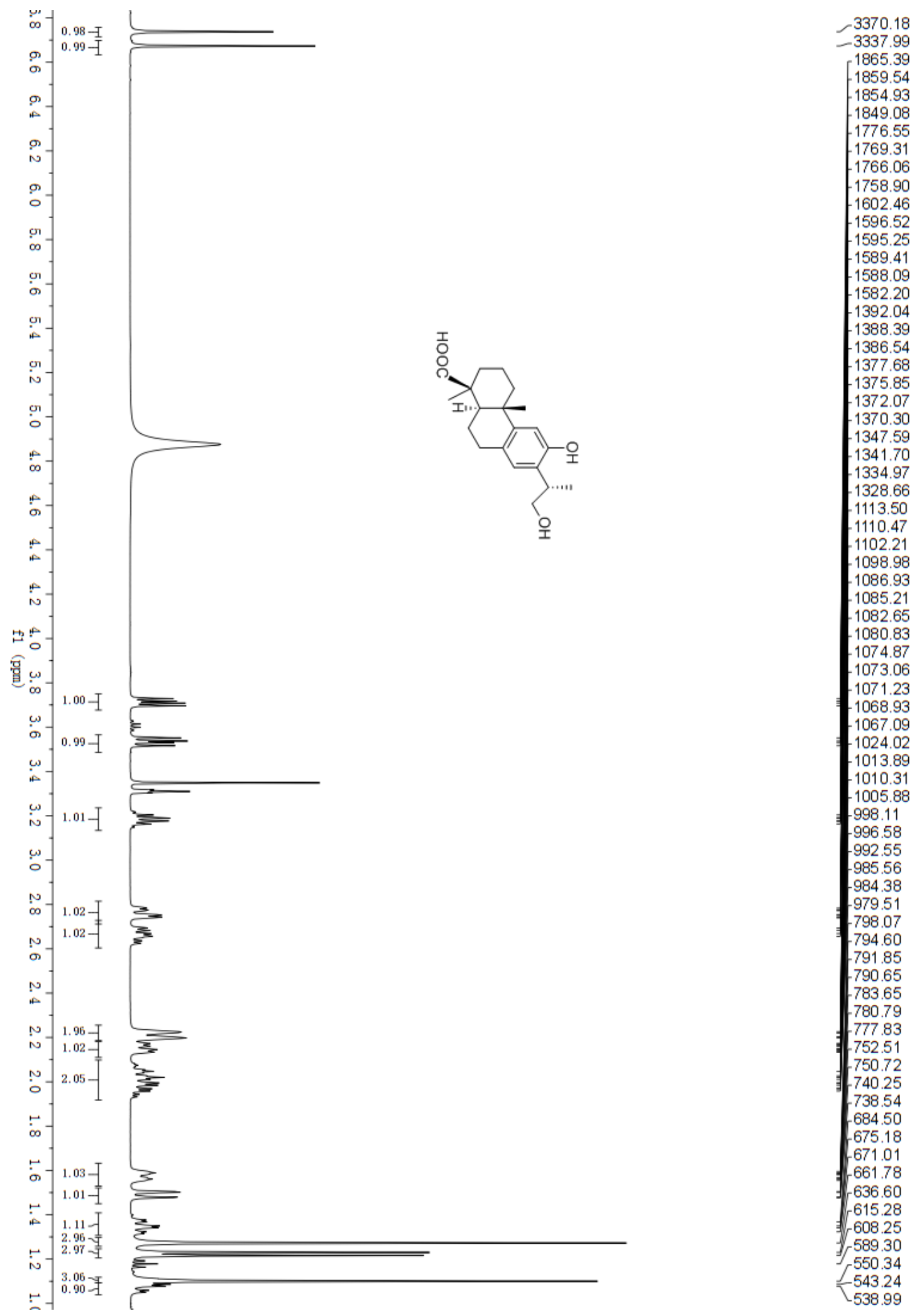


Figure S2. ${ }^{13} \mathrm{C}$ NMR spectrum of (15S), 16-hydroxylambertic acid (1) in $\mathrm{CD}_{3} \mathrm{OD}$

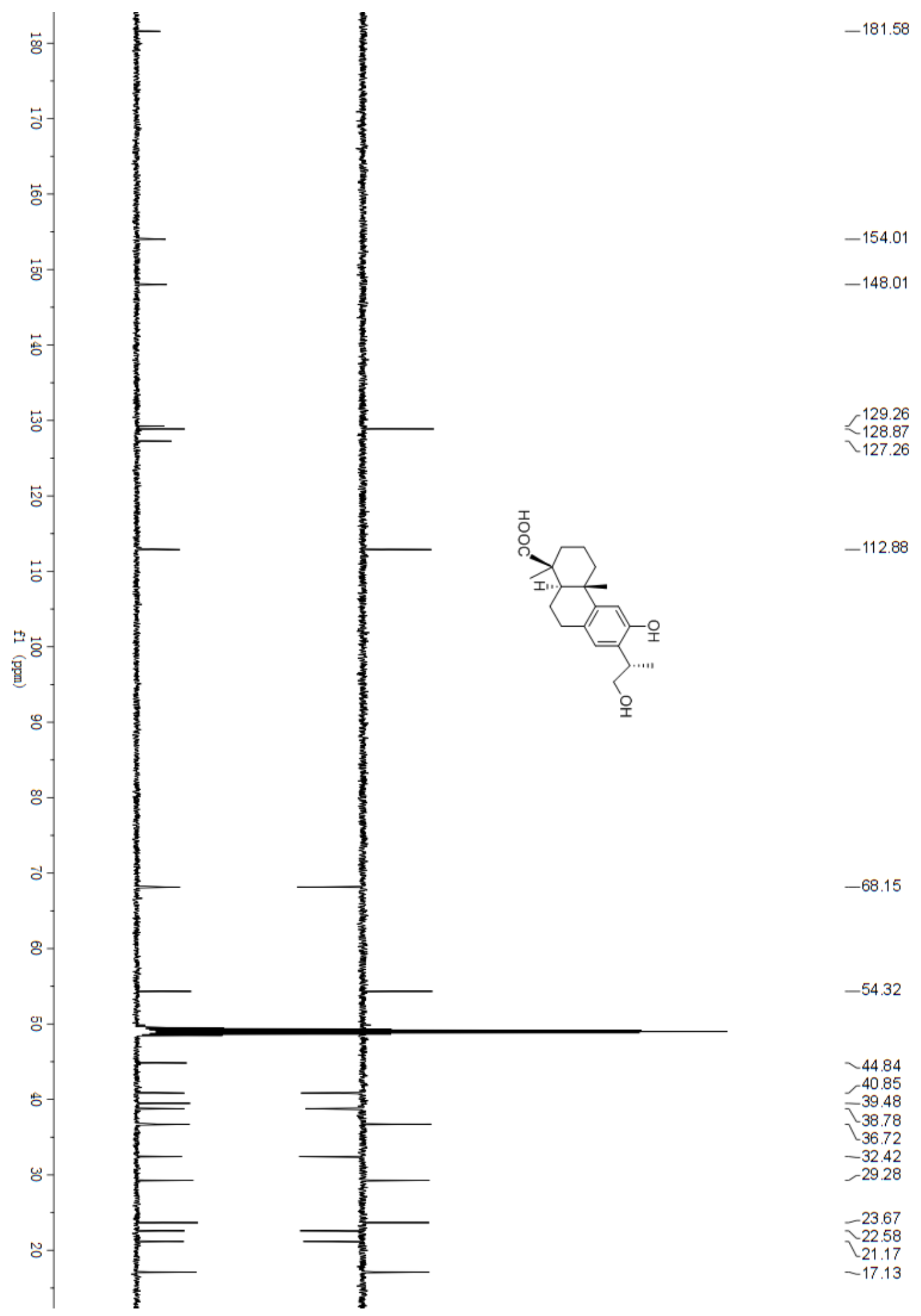




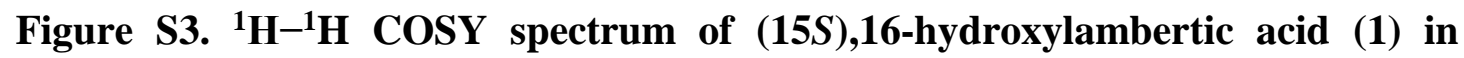
$\mathrm{CD}_{3} \mathrm{OD}$

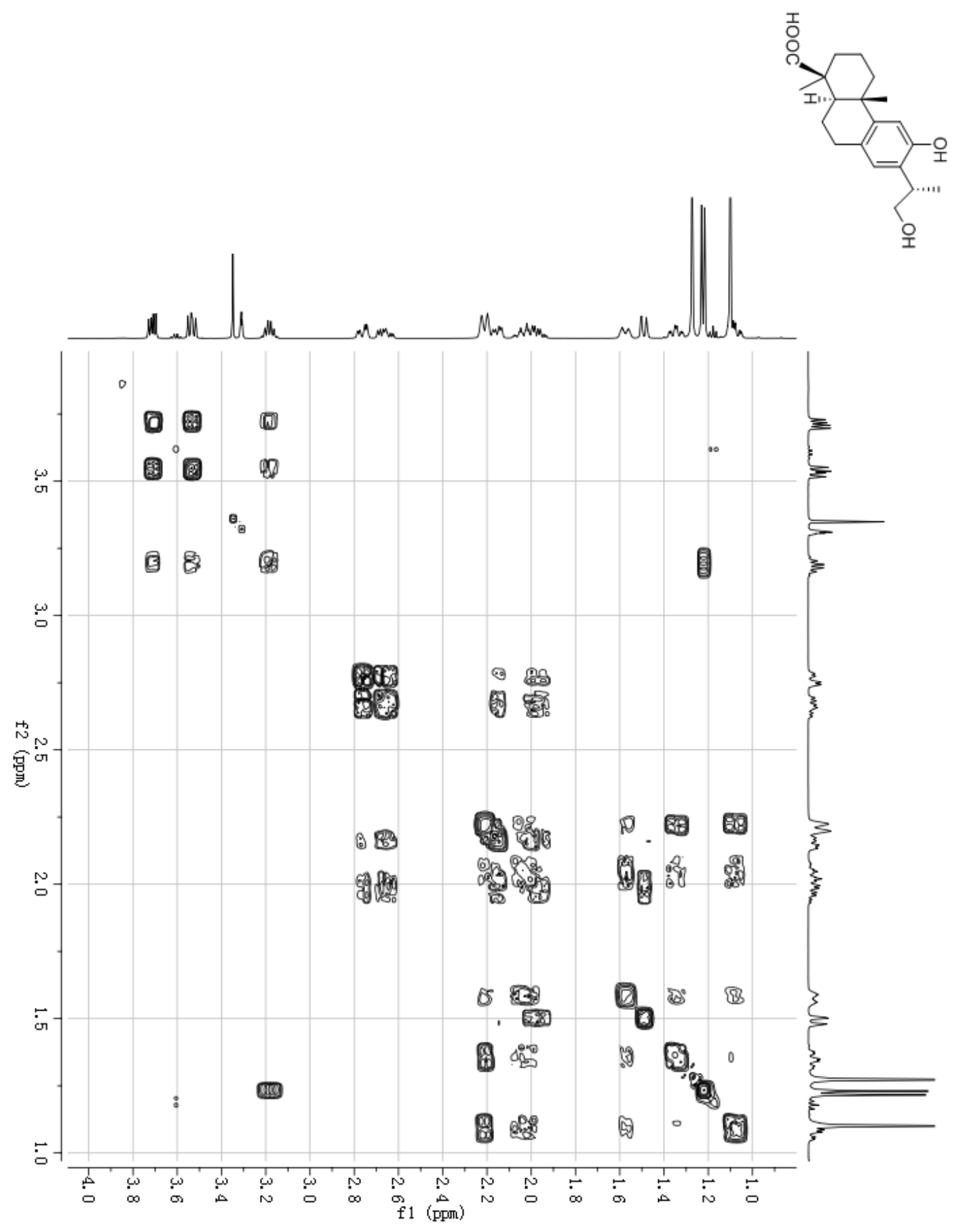


Figure S4. HSQC spectrum of (15S), 16-hydroxylambertic acid (1) in $\mathrm{CD}_{3} \mathrm{OD}$

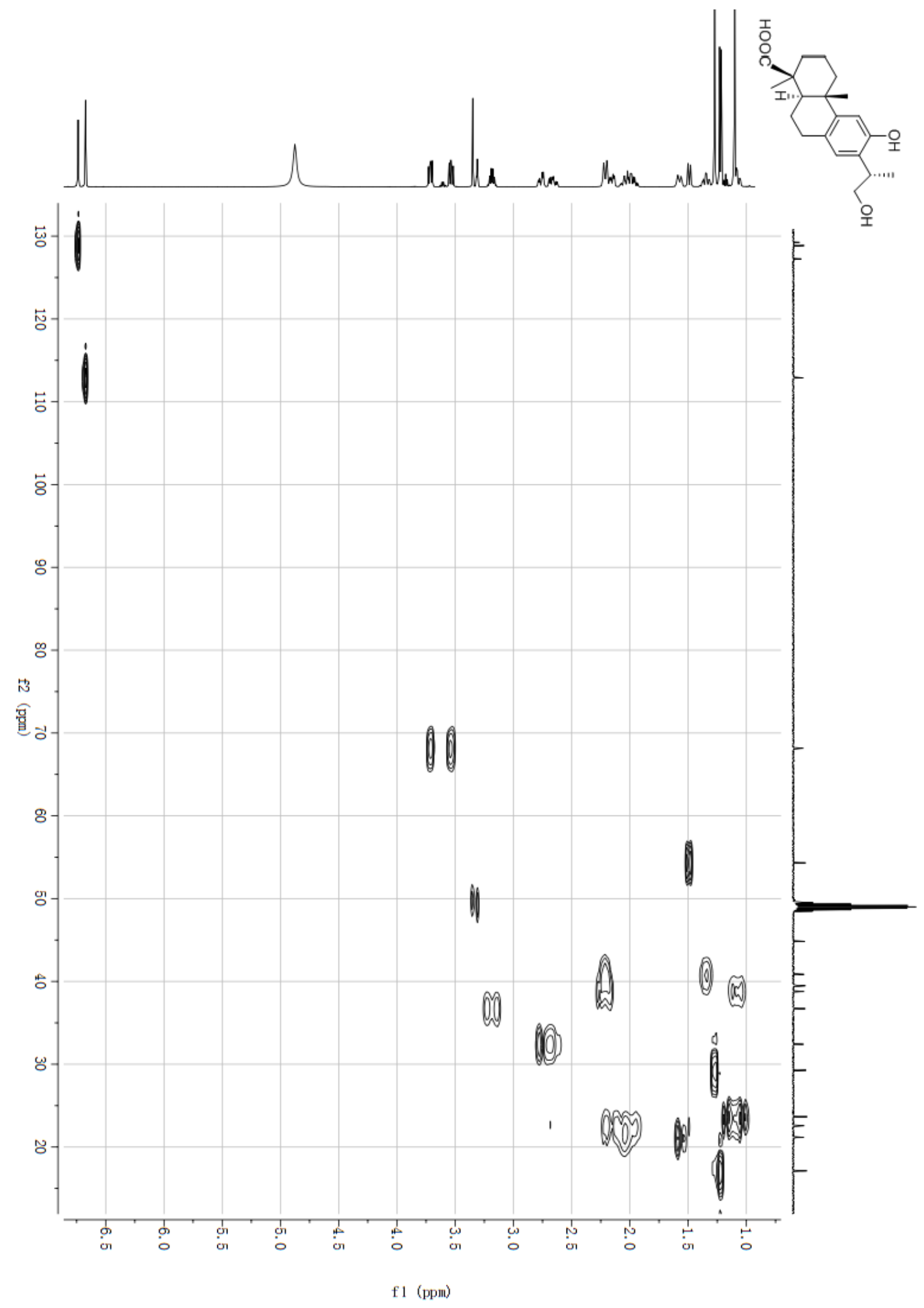


Figure S5. HMBC spectrum of (15S), 16-hydroxylambertic acid (1) in $\mathrm{CD}_{3} \mathrm{OD}$

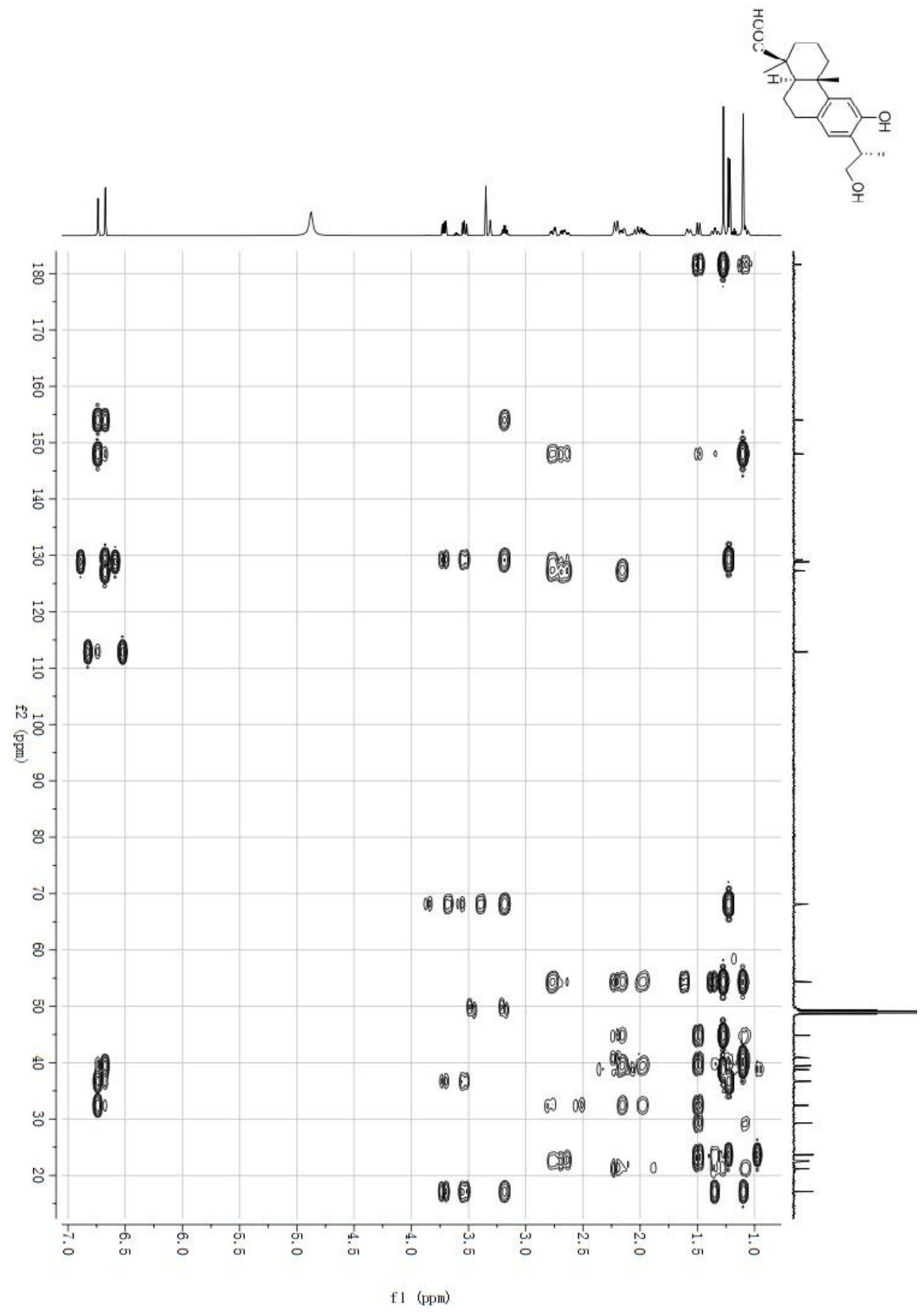


Figure S6. NOESY spectrum of (15S), 16-hydroxylambertic acid (1) in $\mathrm{CD}_{3} \mathrm{OD}$

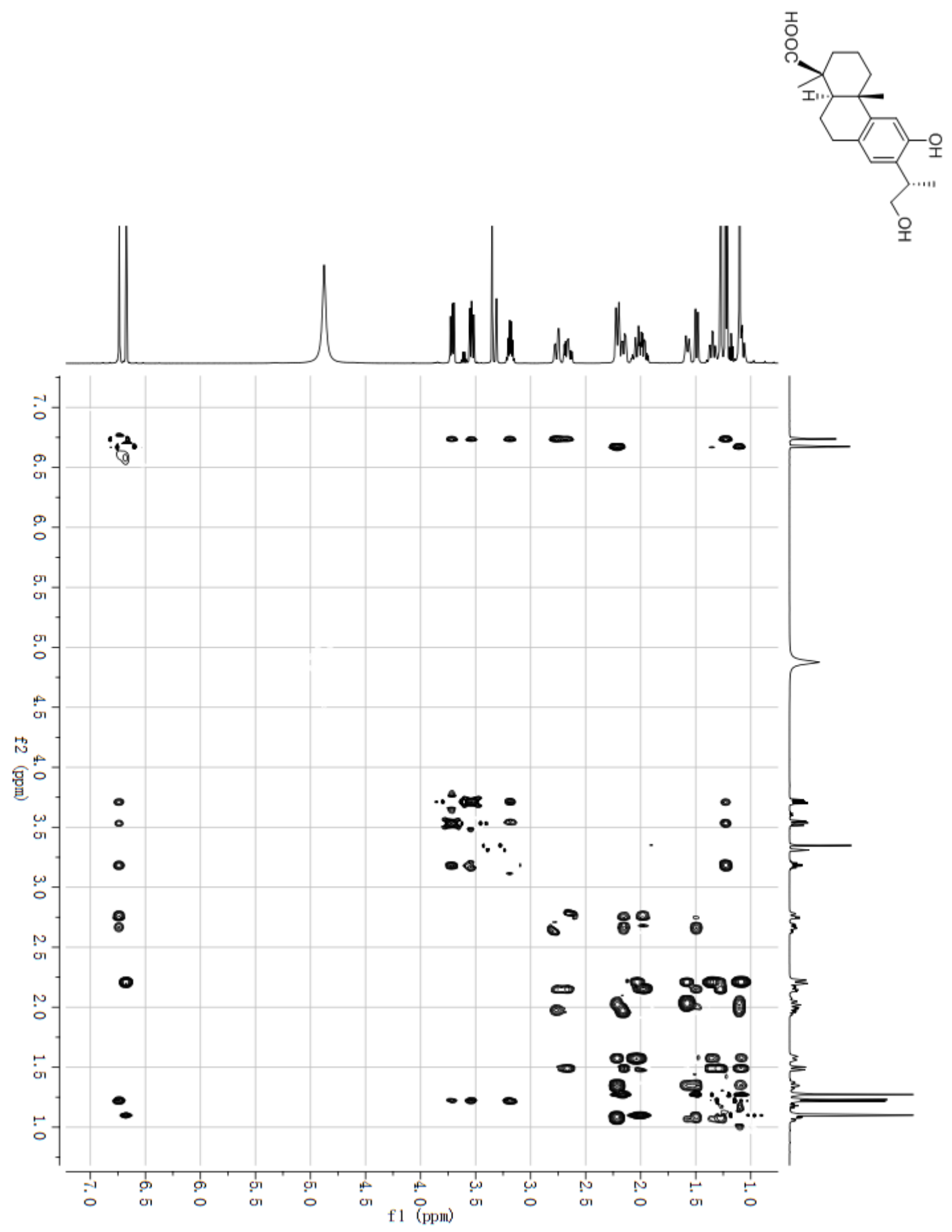


Figure S7. (+)-ESIMS spectrum of (15S),16-hydroxylambertic acid (1)

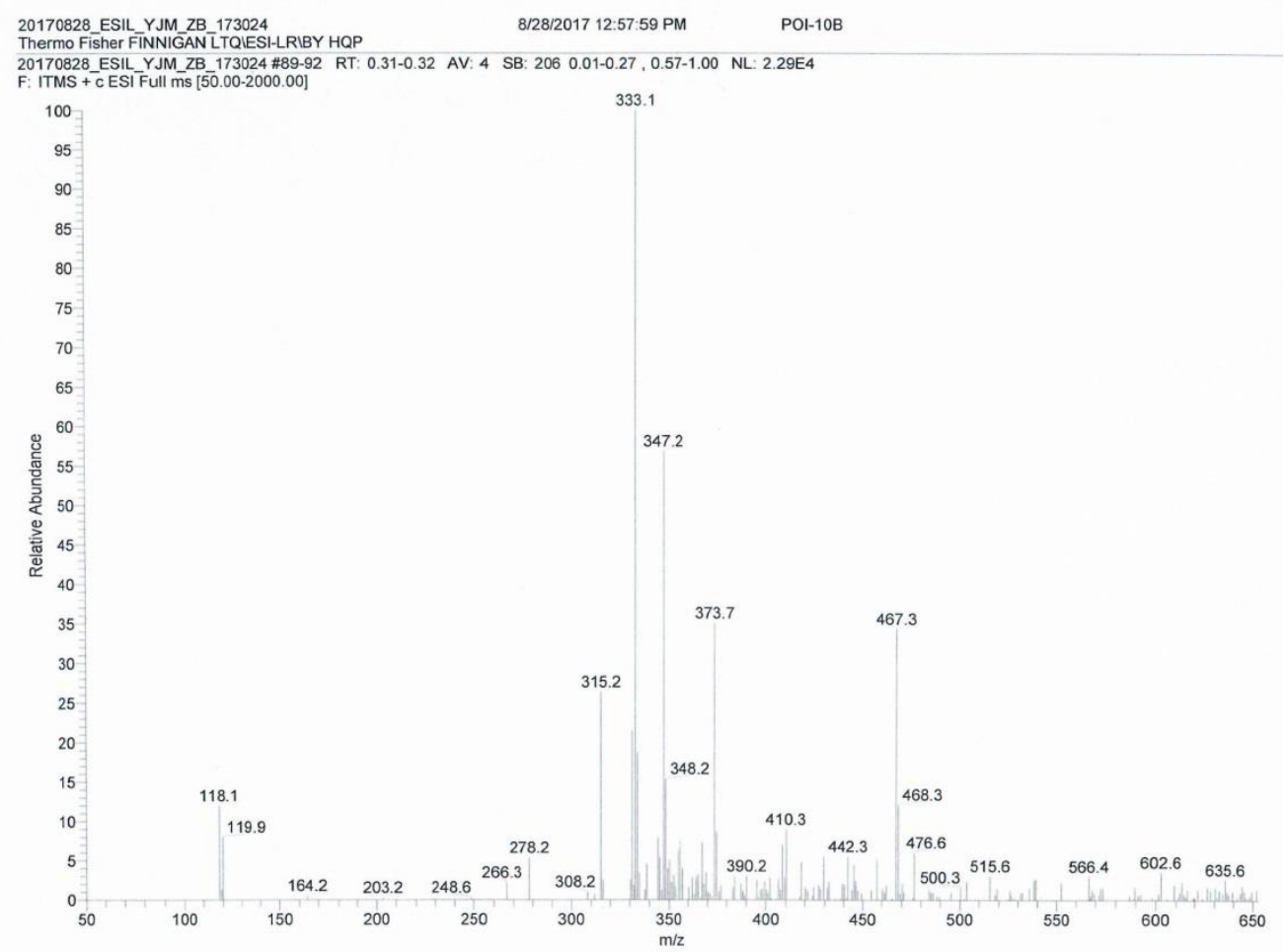


Figure S8. (-)-ESIMS spectrum of (15S),16-hydroxylambertic acid (1)

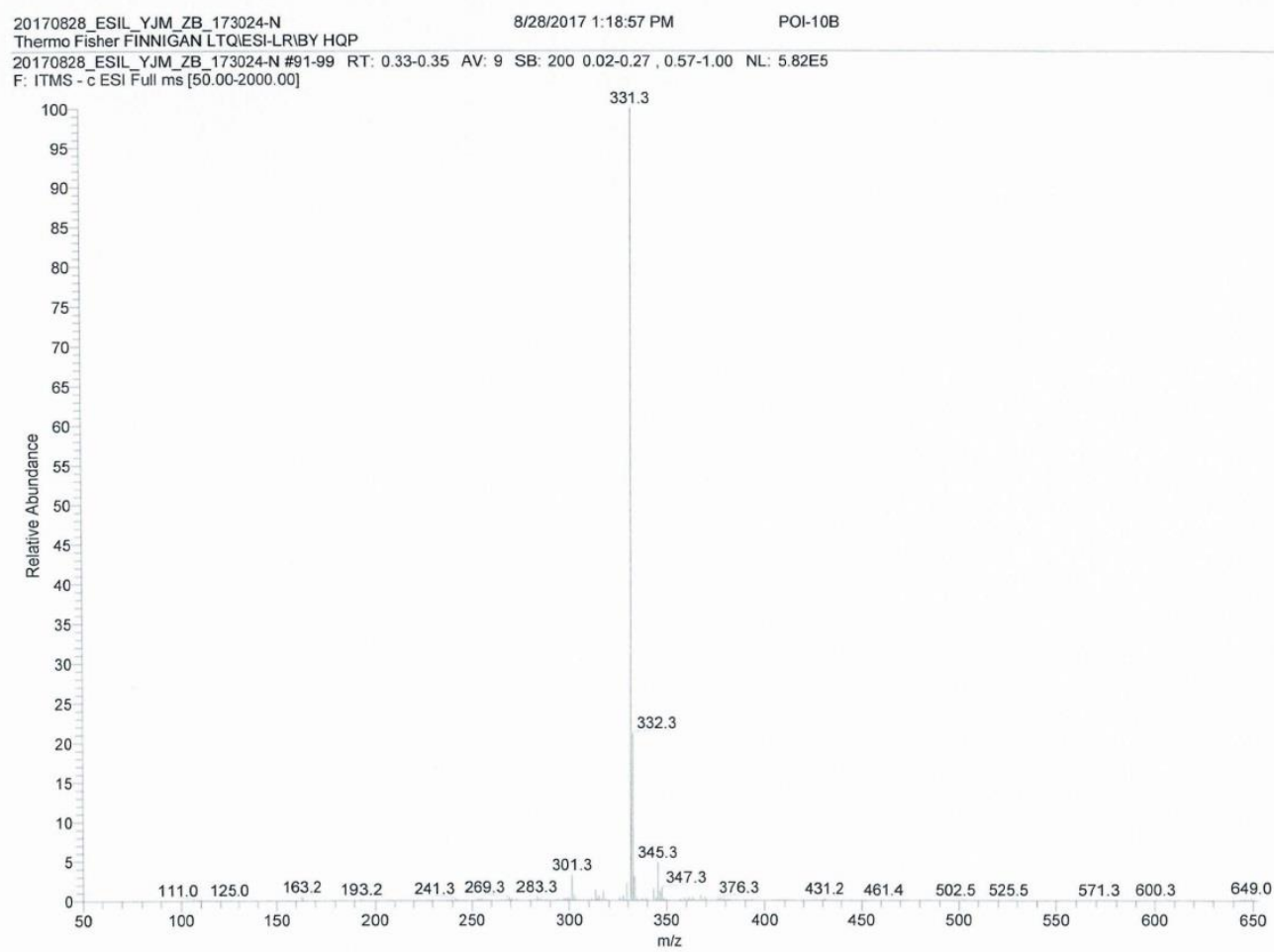


Figure S9. (-)-HRESIMS spectrum of (15S),16-hydroxylambertic acid (1)

\section{Elemental Composition Report}

Page 1

Single Mass Analysis

Tolerance $=3.0$ PPM I DBE: $\min =-1.5, \max =50.0$

Element prediction: Off

Number of isotope peaks used for $\mathrm{i}-\mathrm{FIT}=3$

Monoisotopic Mass, Even Electron lons

348 formula(e) evaluated with 1 results within limits (up to 50 closest results for each mass)

Elements

$\begin{array}{llll}\text { C: } 5-80 & \text { H: } 2-120 & \text { O: } 0-30 & \mathrm{Na}: 0-1\end{array}$

LCT PXE KE324

POI-10B 70 (1.534) AM2 (Ar, 11000.0,0.00,0.70); ABS; Cm (70:79)

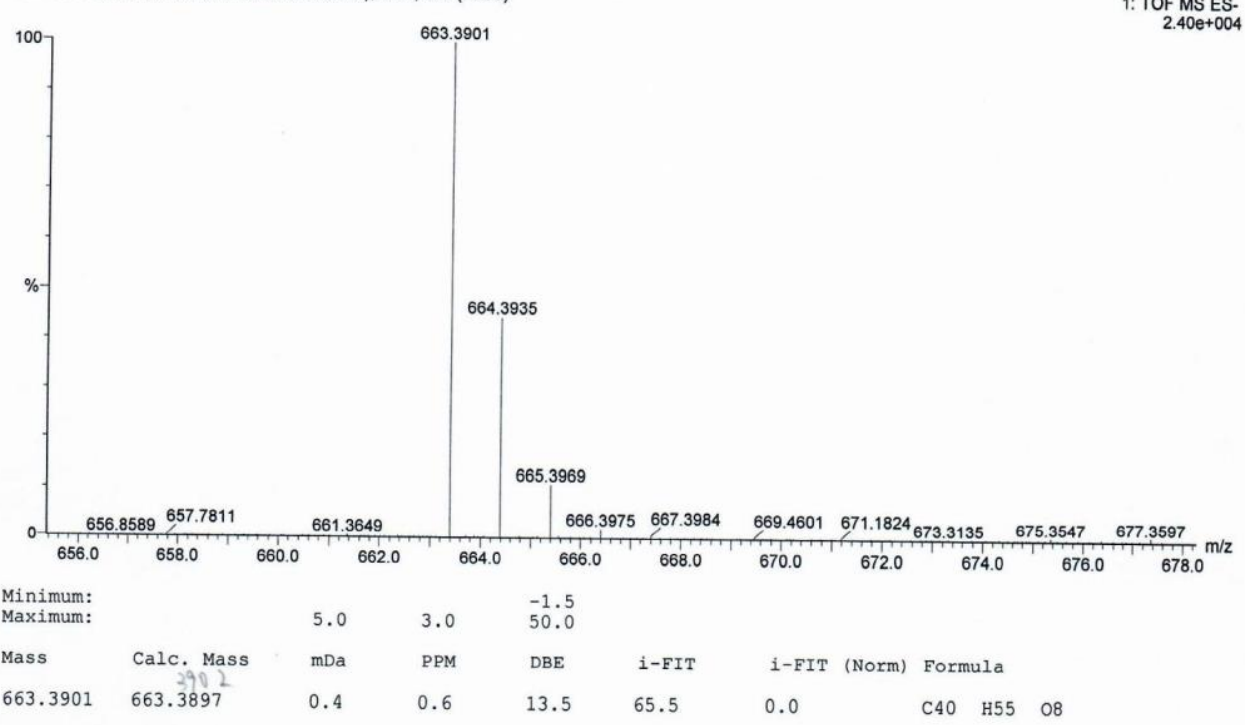


Figure S10. IR spectrum of (15S),16-hydroxylambertic acid (1)

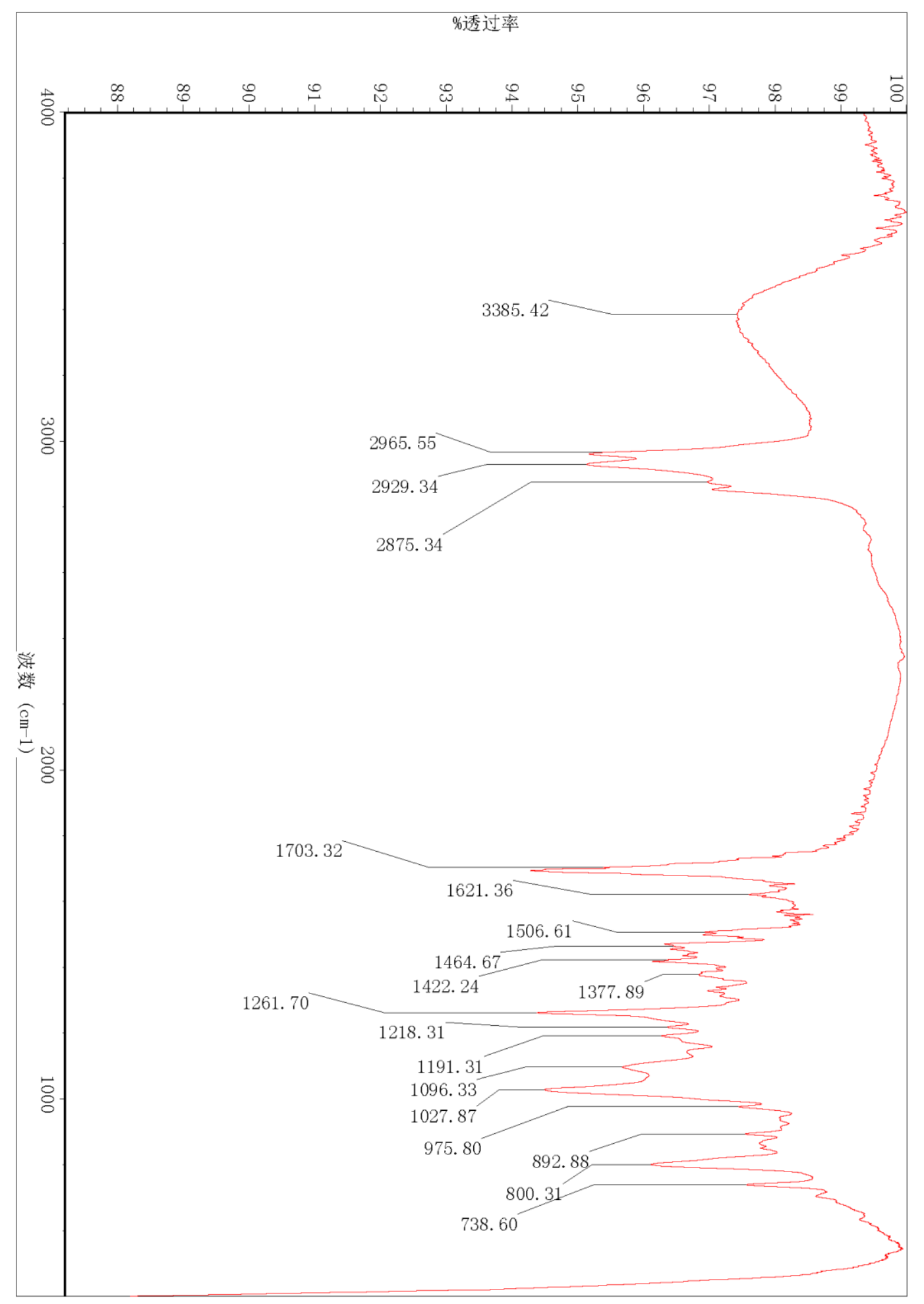


Figure S11. ${ }^{1} \mathrm{H}$ NMR spectrum of $(15 R), 16$-hydroxylambertic acid (2) in $\mathrm{CD}_{3} \mathrm{OD}$

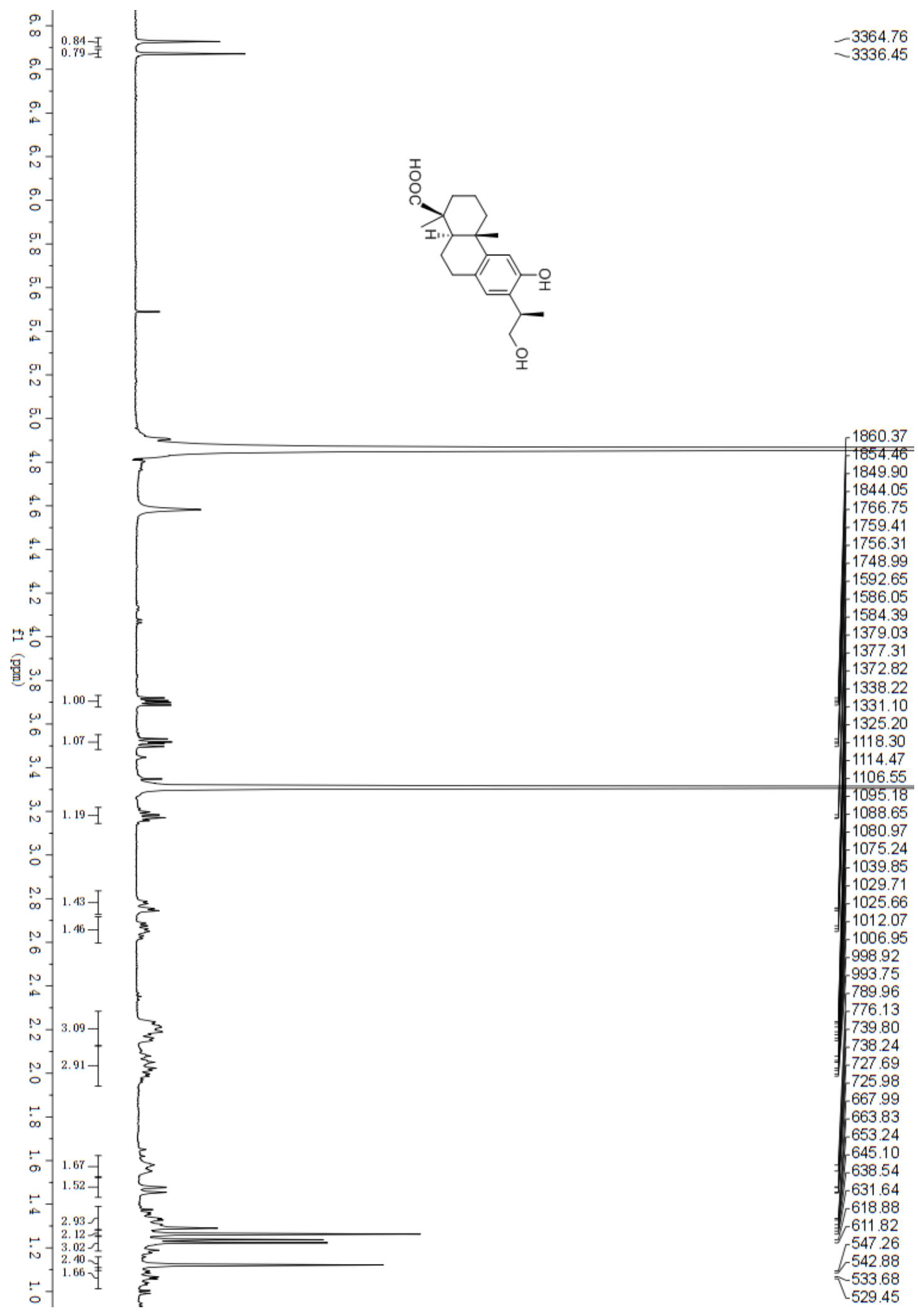


Figure S12. ${ }^{13} \mathrm{C}$ NMR spectrum of $(15 R), 16$-hydroxylambertic acid (2) in $\mathrm{CD}_{3} \mathrm{OD}$

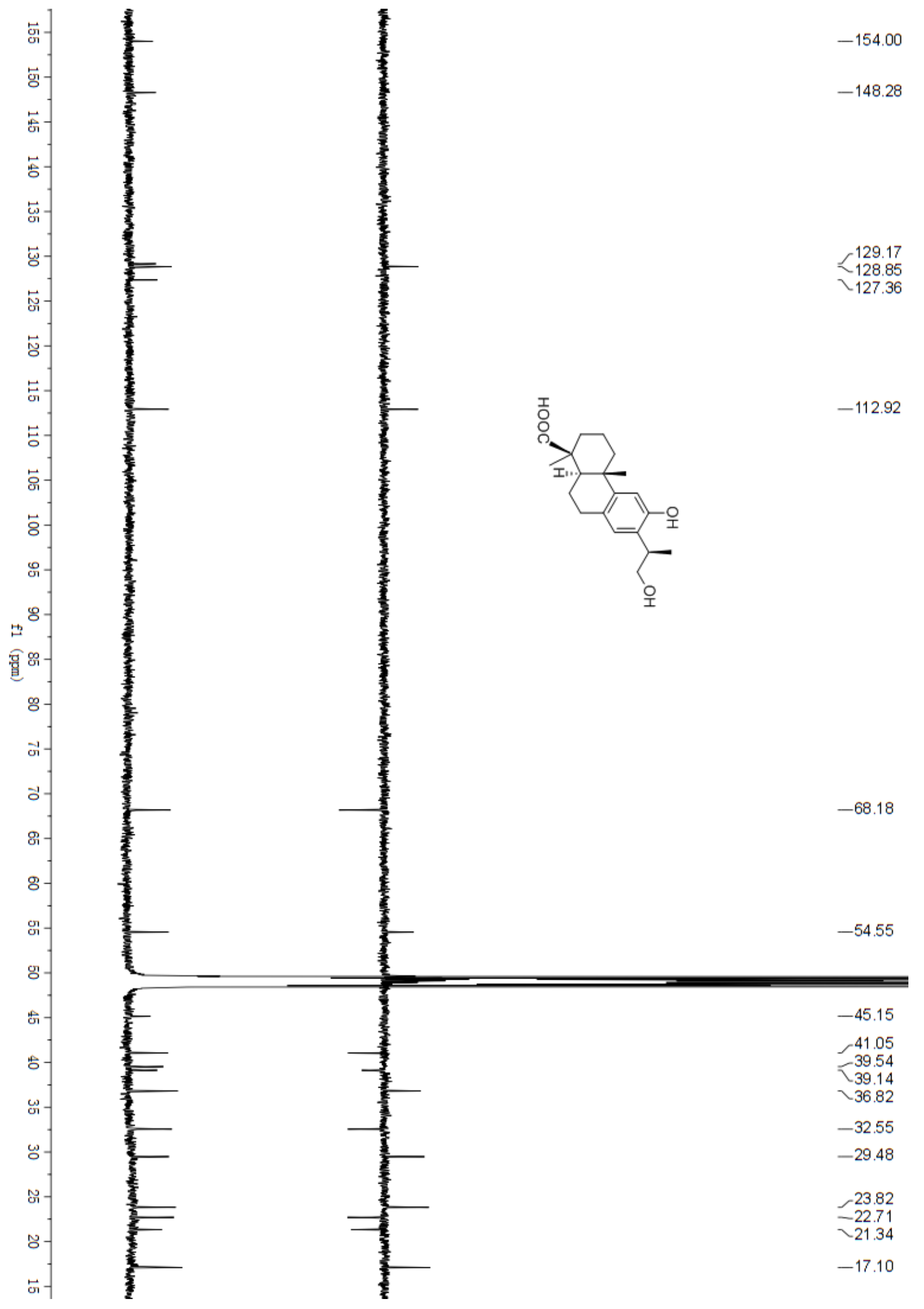


Figure S13. HSQC spectrum of (15R), 16-hydroxylambertic acid (2) in CD3OD

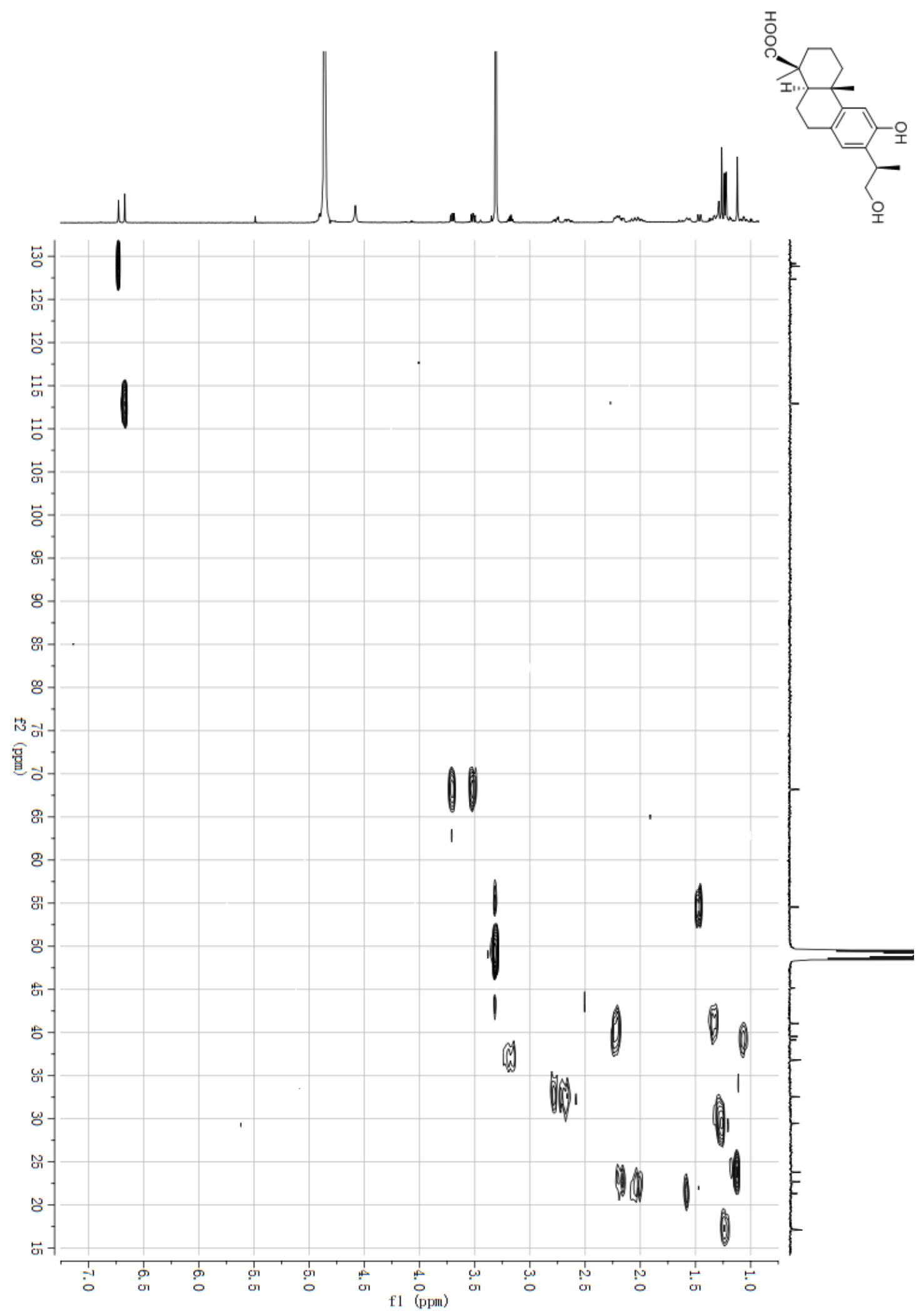


Figure S14. HMBC spectrum of (15R), 16-hydroxylambertic acid (2) in $\mathrm{CD}_{3} \mathrm{OD}$

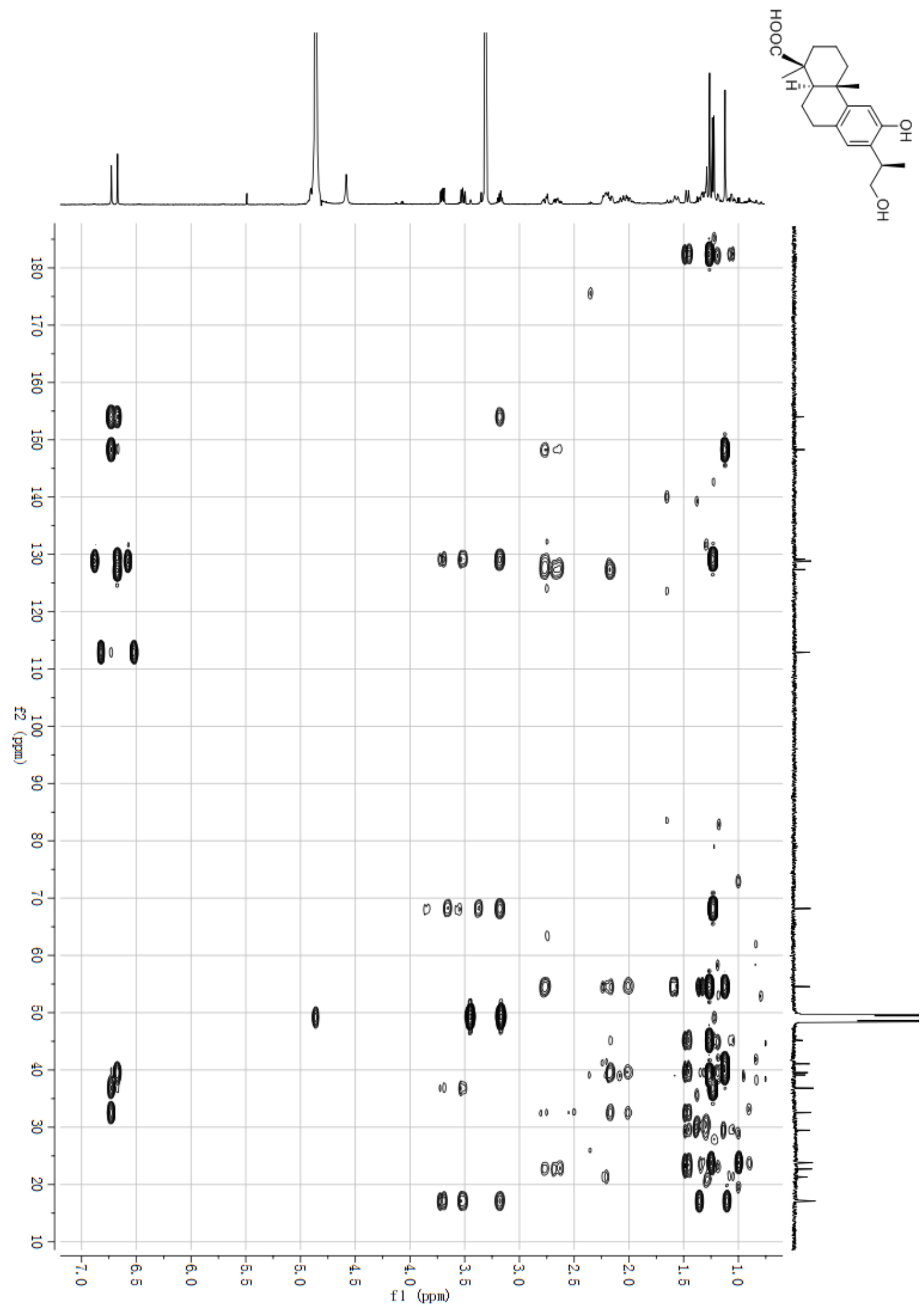


Figure S15. NOESY spectrum of (15R),16-hydroxylambertic acid (2) in $\mathrm{CD}_{3} \mathrm{OD}$

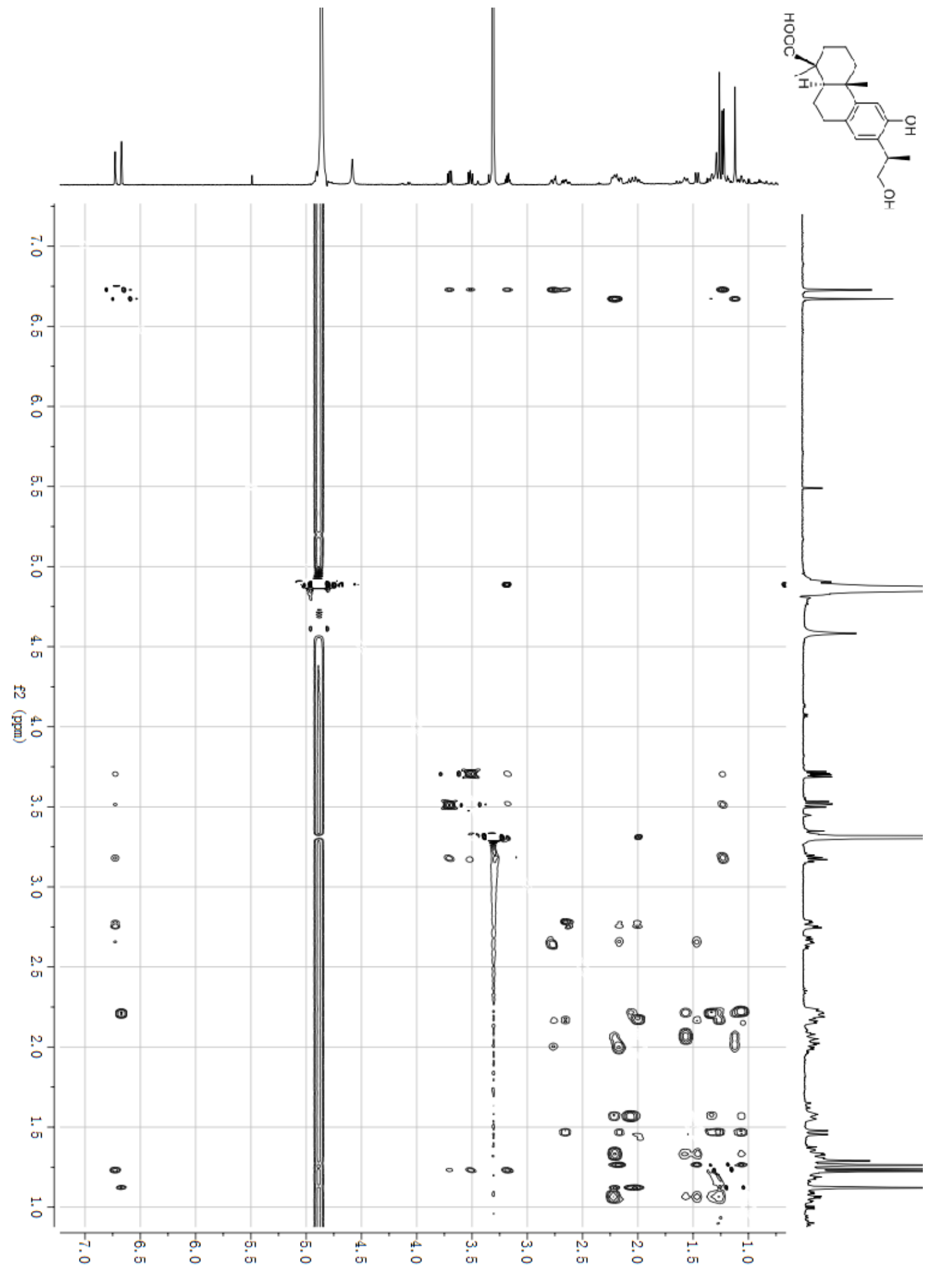

f1 (ppin) 
Figure S16. ESIMS spectrum of (15R),16-hydroxylambertic acid (2)

2017/7/16 21:13:15 2/2
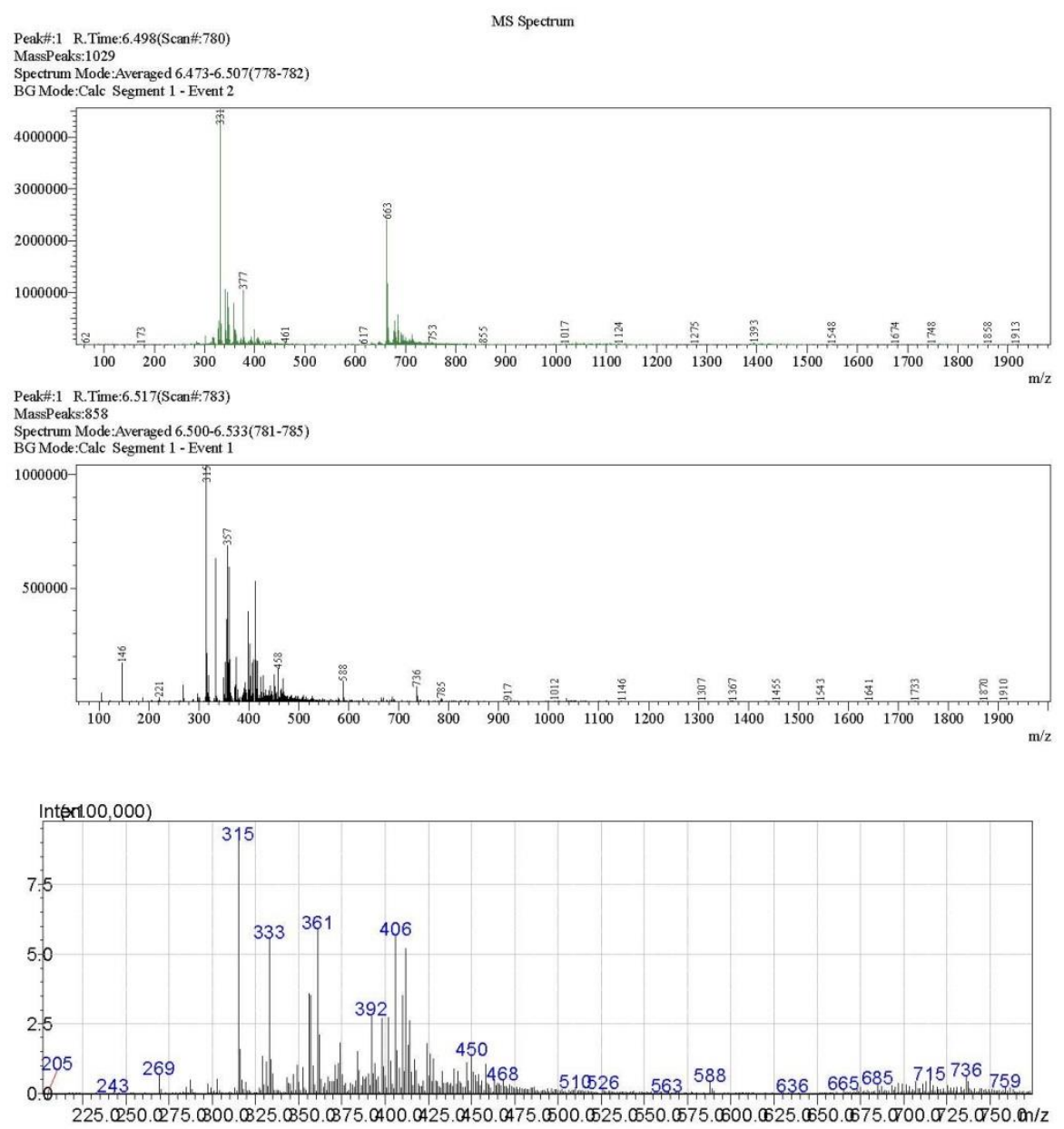
Figure S17. (-)-HRESIMS spectrum of (15R),16-hydroxylambertic acid (2)

Elemental Composition Report

Page 1

Single Mass Analysis

Tolerance $=3.0$ PPM / DBE: $\min =-1.5, \max =50.0$

Element prediction: Off

Number of isotope peaks used for i-FIT $=3$

Monoisotopic Mass, Even Electron Ions

107 formula(e) evaluated with 1 results within limits (up to 50 closest results for each mass)

$\begin{array}{llll}\text { C: } 5-80 & \text { H: } 2-120 & \text { O: } 0-30 & \text { Na: } 0-1\end{array}$

POI-10D

LCT PXE KE324

POI-10D 26 (0.566) AM2 (Ar, 10000.0,0.00,1.00); ABS; Cm (19:26)

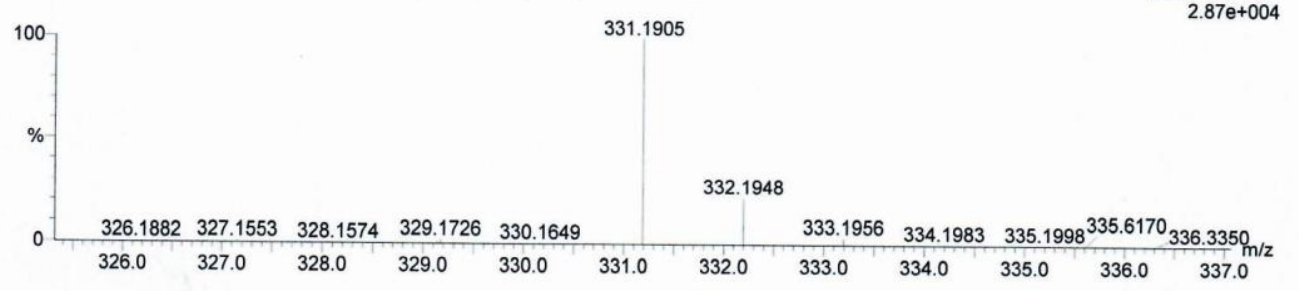

Minimum: $\quad-1.5$

$\begin{array}{lll}5.0 & 3.0 & 50.0\end{array}$

Mass Calc. Mass $\mathrm{mDa}$ PPM DBE i-FIT i-FIT (Norm) Formula

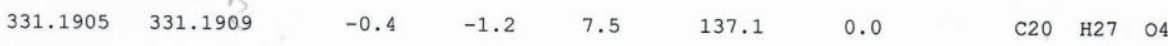


Figure S18. IR spectrum of (15R),16-hydroxylambertic acid (2)

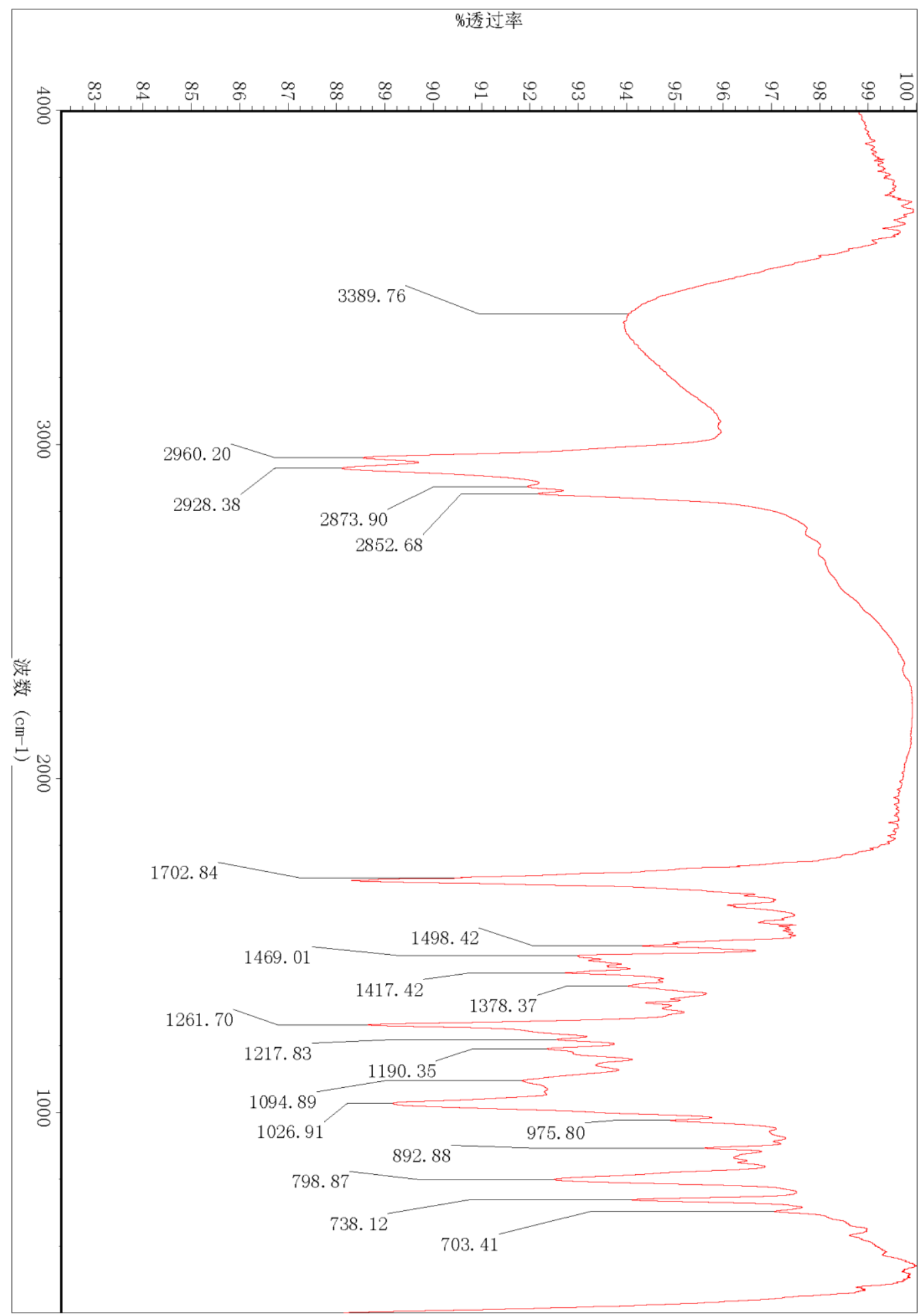


Figure S19. ${ }^{1} \mathrm{H}$ NMR spectrum of 12-deoxypicrosalvin (3) in $\mathrm{CDCl}_{3}$

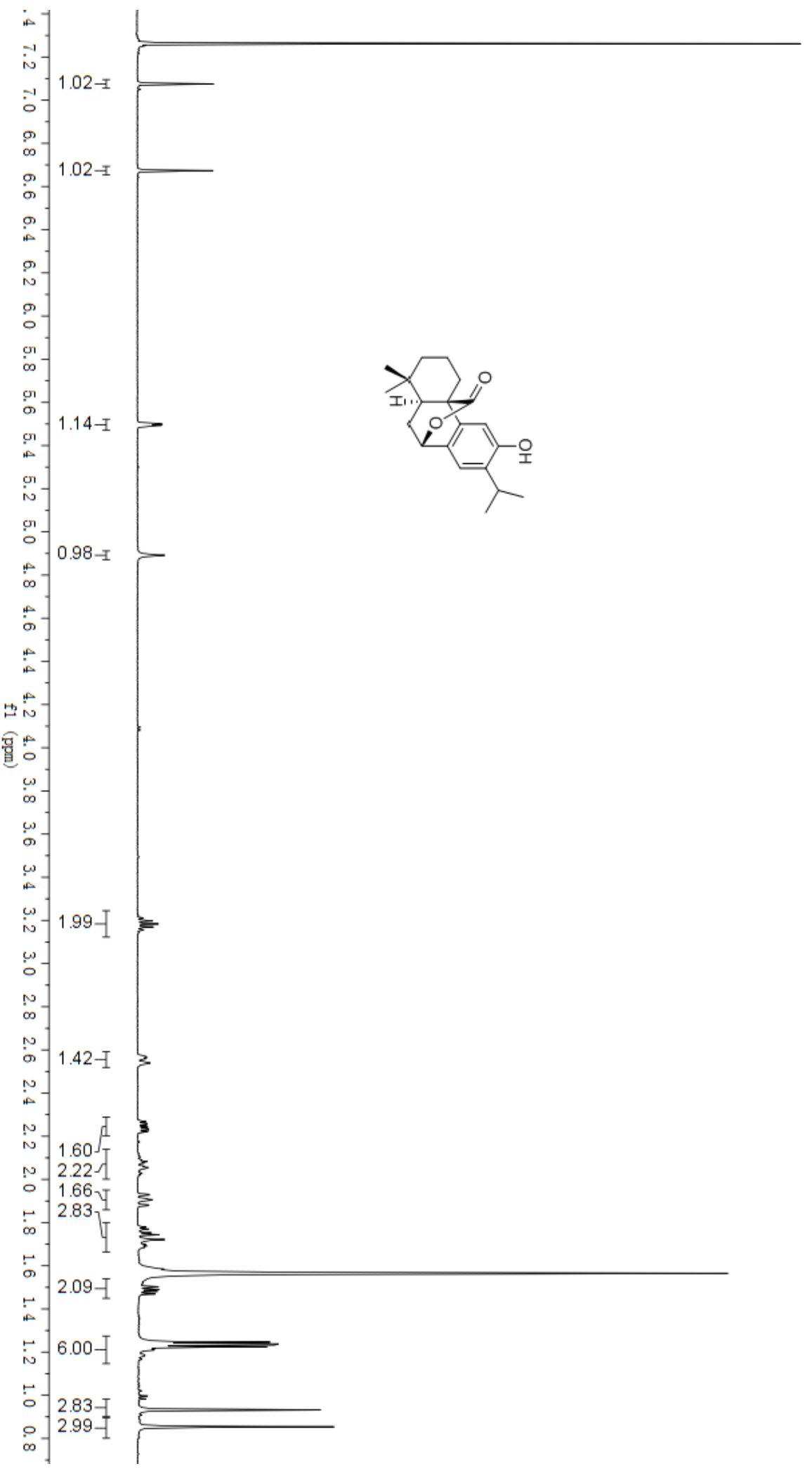


Figure S20. ${ }^{13} \mathrm{C}$ NMR spectrum of 12-deoxypicrosalvin (3) in $\mathrm{CDCl}_{3}$

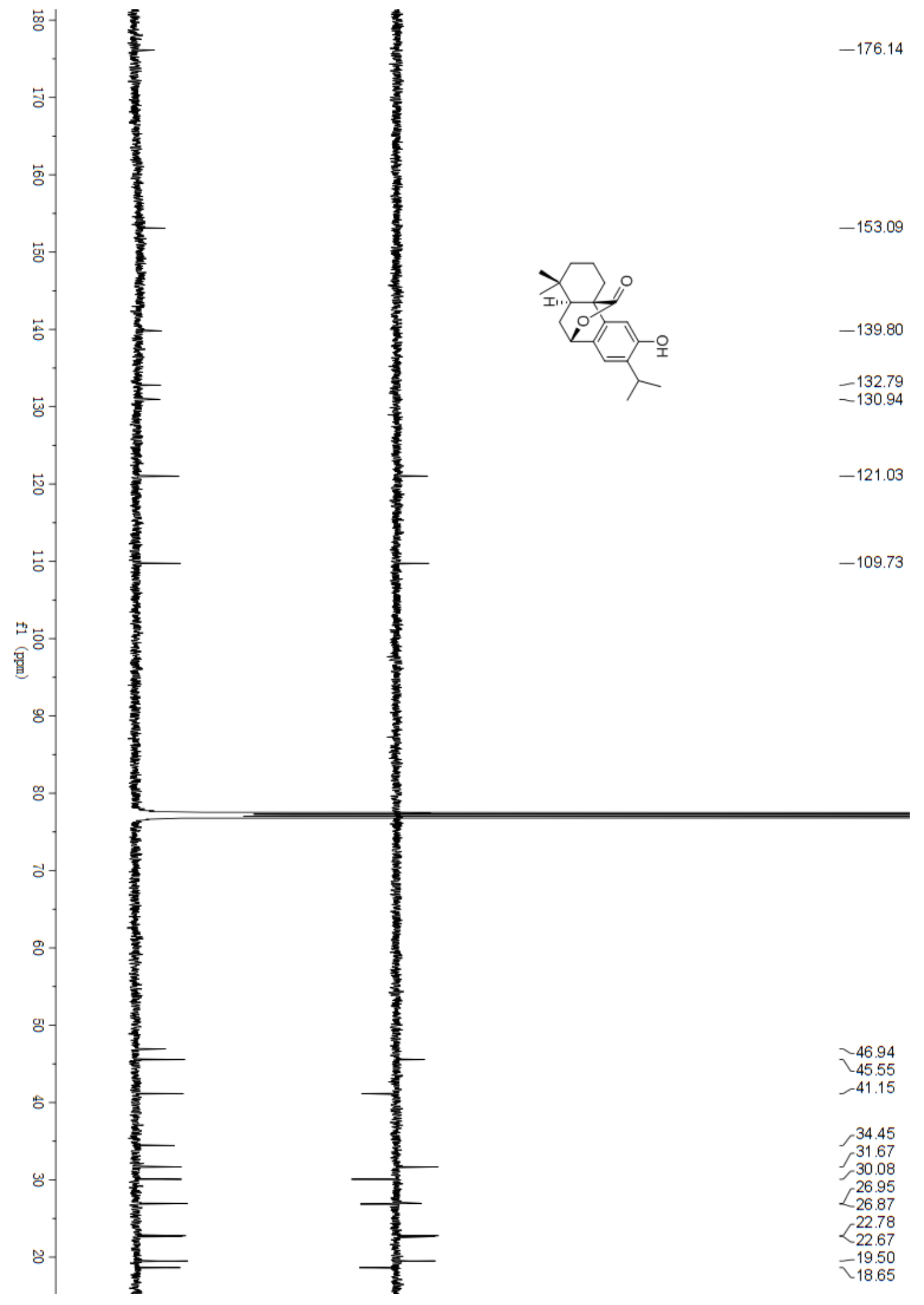


Figure S21. HSQC spectrum of 12-deoxypicrosalvin (3) in $\mathrm{CDCl}_{3}$

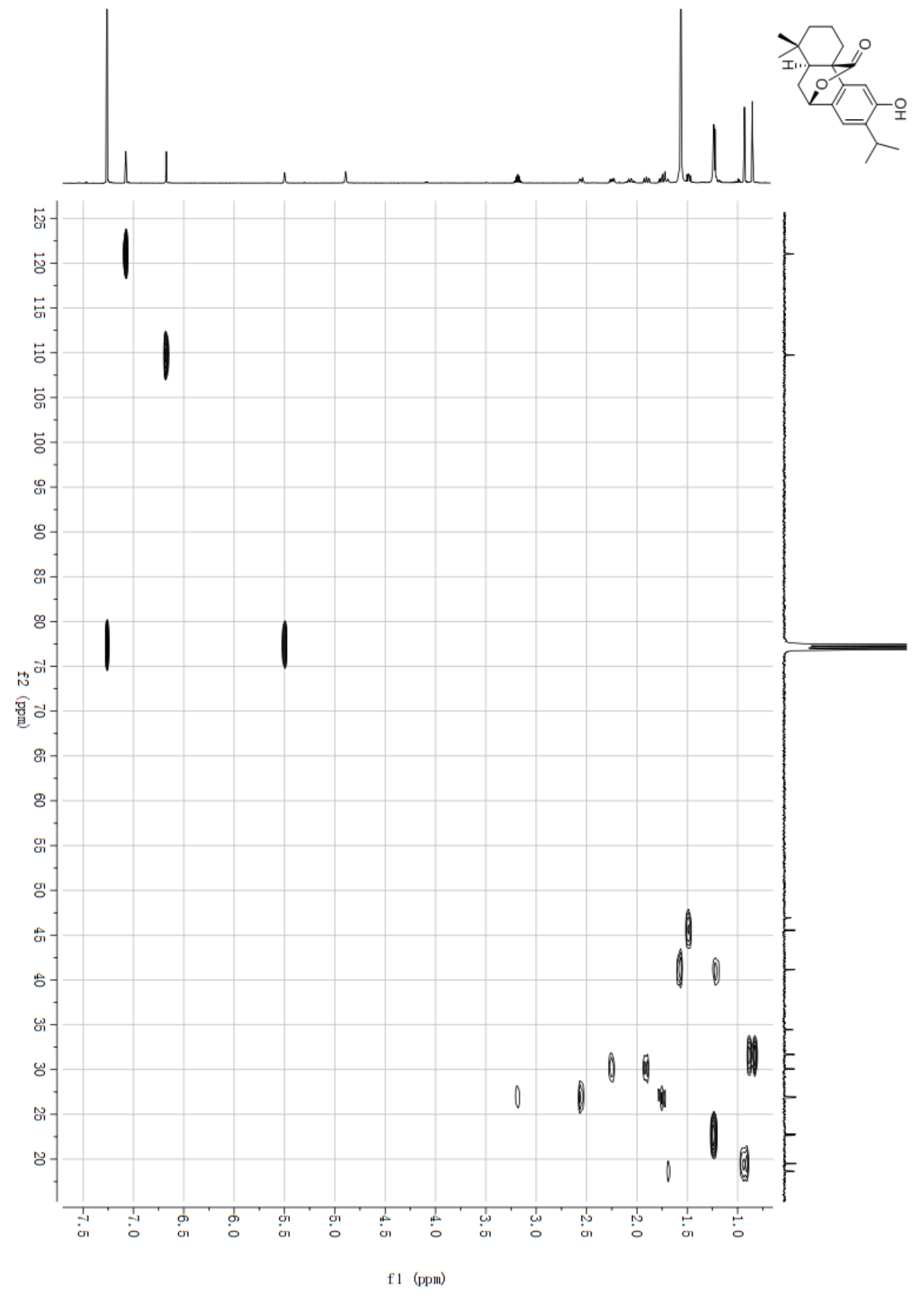


Figure S22. HMBC spectrum of 12-deoxypicrosalvin (3) in $\mathrm{CDCl}_{3}$

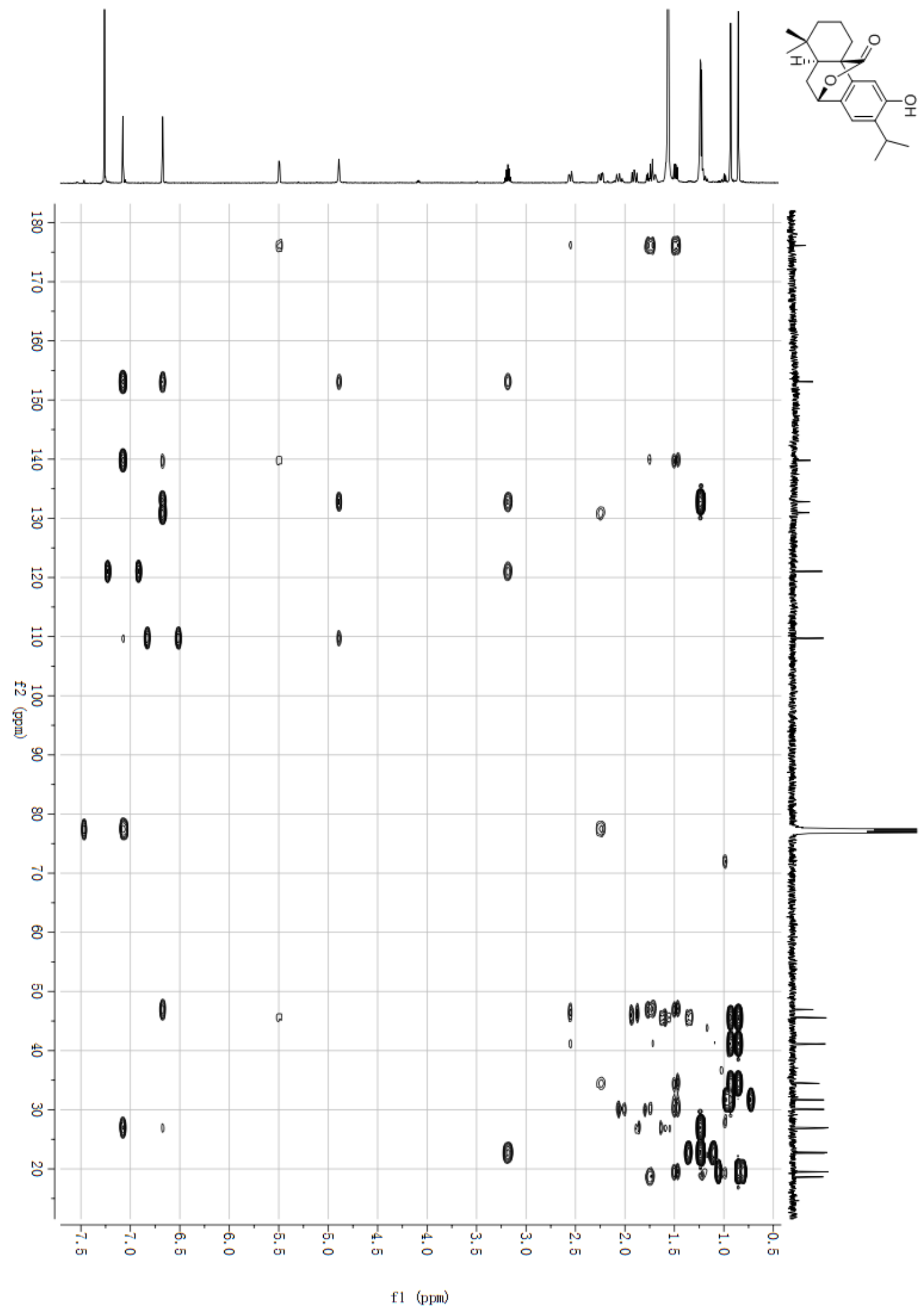


Figure S23. NOESY spectrum of 12-deoxypicrosalvin (3) in $\mathrm{CDCl}_{3}$

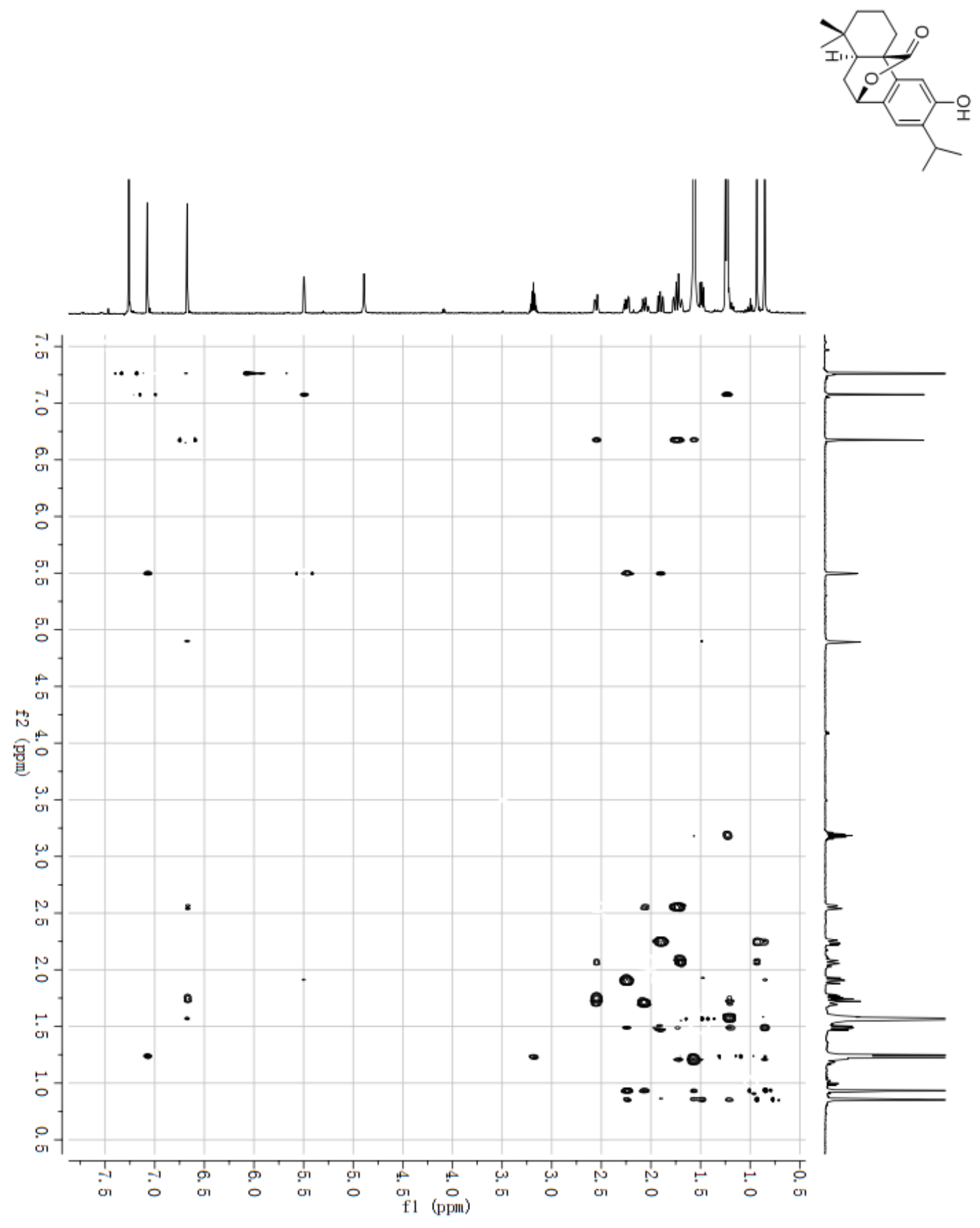


Figure S24. ESIMS spectrum of 12-deoxypicrosalvin (3)

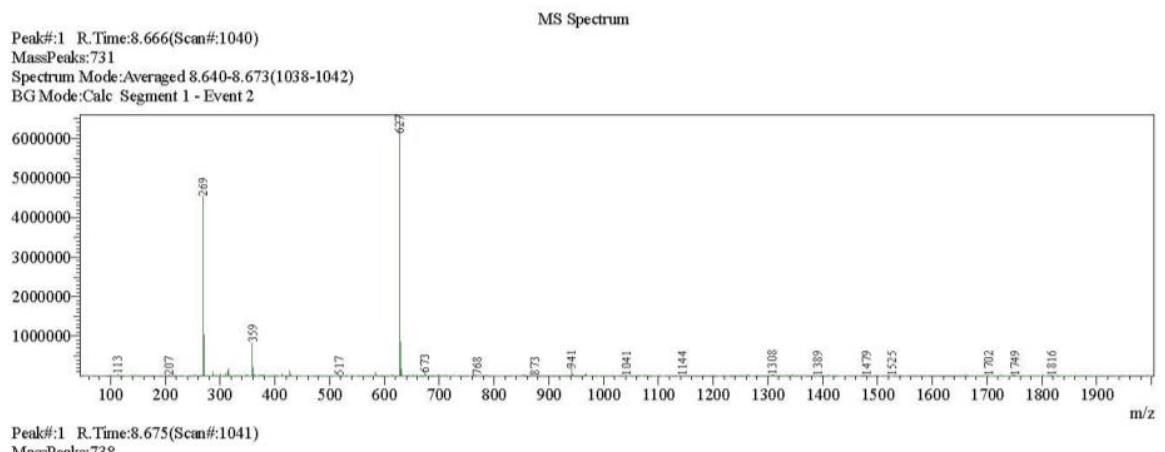
PeakH: 1 R.Time:8.675(Scan $1: 1041)$

Spectrum Mode:Averaged 8.650-8.683(1039-1043)

BG Mode:Calc Segment 1 - Event 1
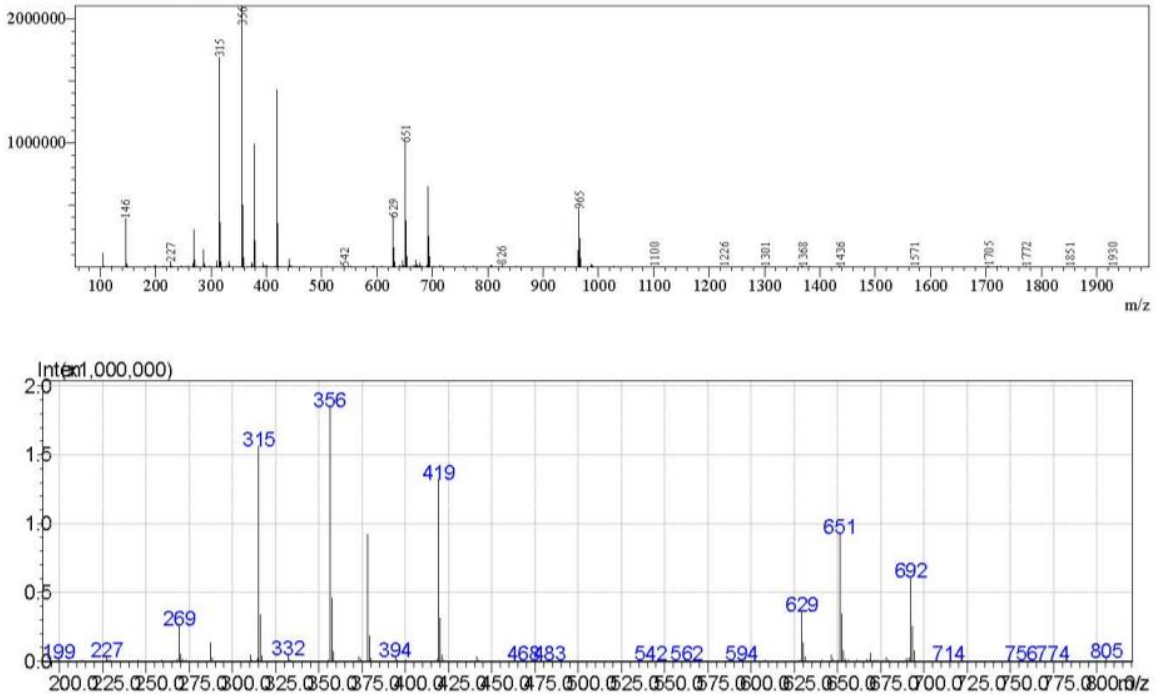
Figure S25. (-)-HRESIMS spectrum of 12-deoxypicrosalvin (3)

Elemental Composition Report

Page 1

Single Mass Analysis

Tolerance $=1.0$ PPM / DBE: $\min =-1.5, \max =50.0$

Element prediction: Off

Number of isotope peaks used for $\mathrm{i}-\mathrm{FIT}=3$

Monoisotopic Mass, Even Electron Ions

168 formula(e) evaluated with 1 results within limits (up to 50 best isotopic matches for each mass)

$\begin{array}{llll}C: 5-52 & \mathrm{H}: 2-120 & \mathrm{O}: 0-11 \quad \mathrm{Na}: 0-1\end{array}$

LCT PXE KE324

19-Sep-2017

16:17:08

1: TOF MS ES-

POI-11D 8 (0.175) Cm (8)

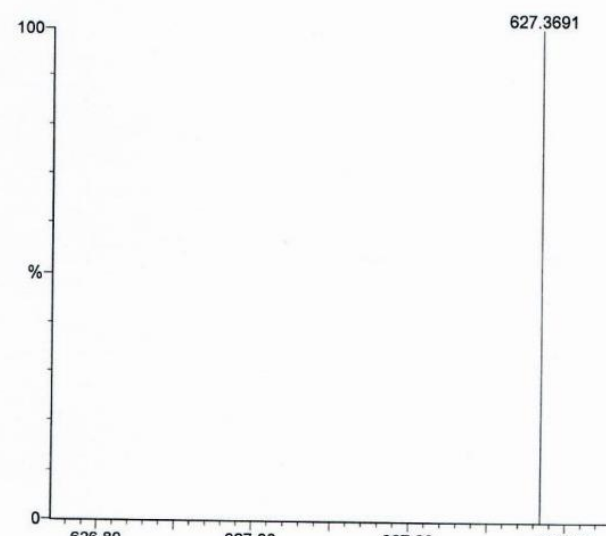

$6.81 \mathrm{e}+003$

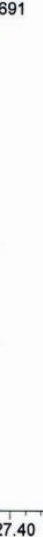

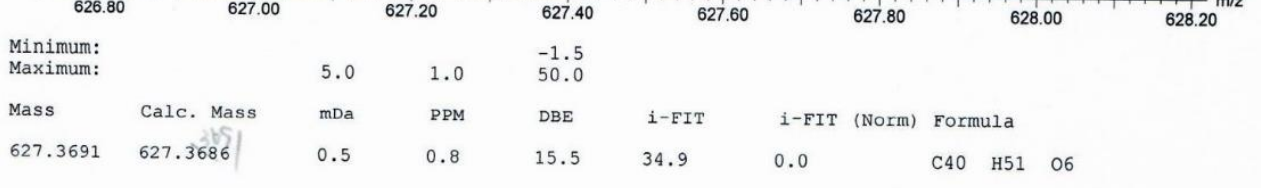


Figure S26. IR spectrum of 12-deoxypicrosalvin (3)

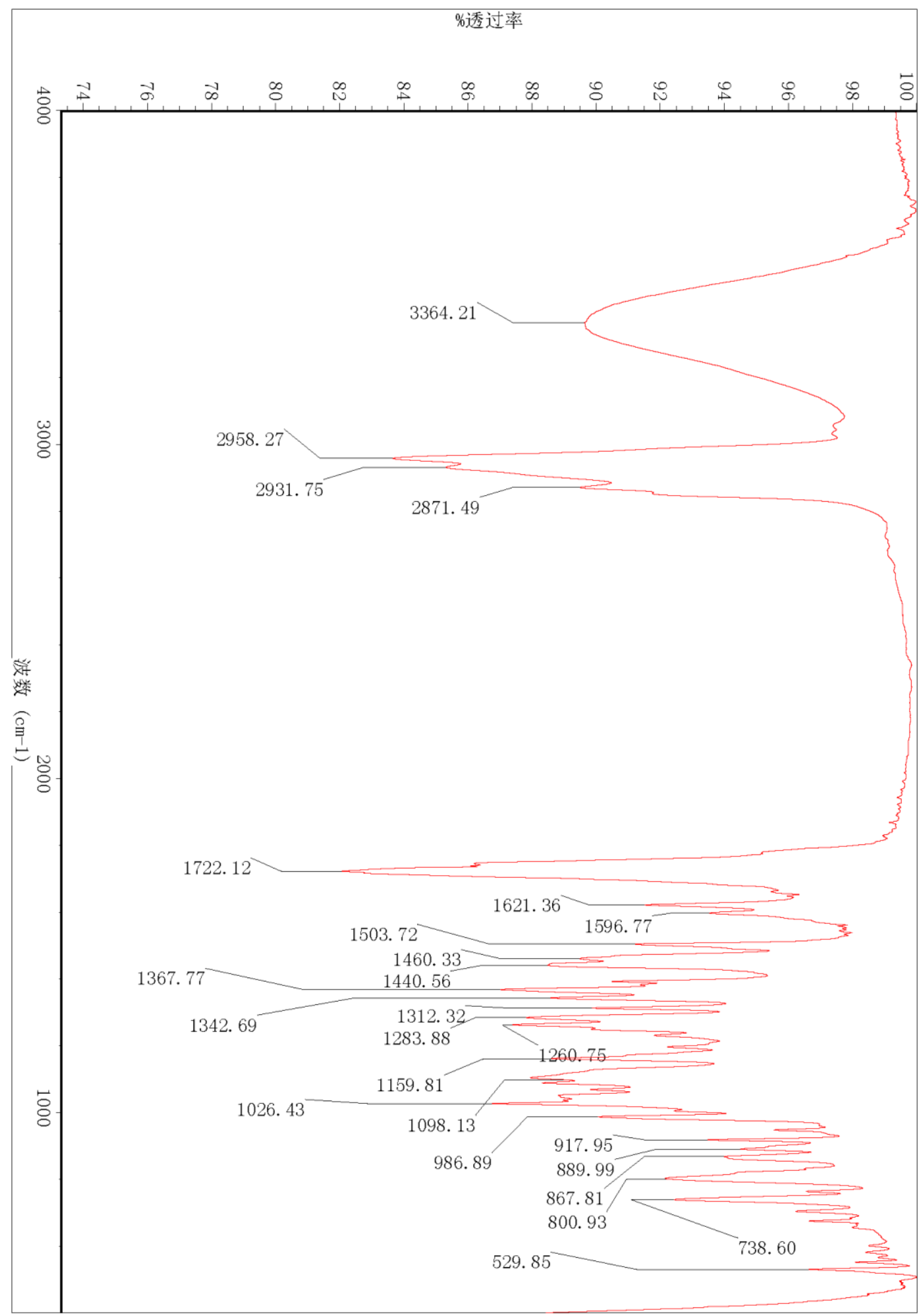


Figure S27. ${ }^{1} \mathrm{H}$ NMR spectrum of 18-hydroxysempervirol (4) in $\mathrm{CDCl}_{3}$
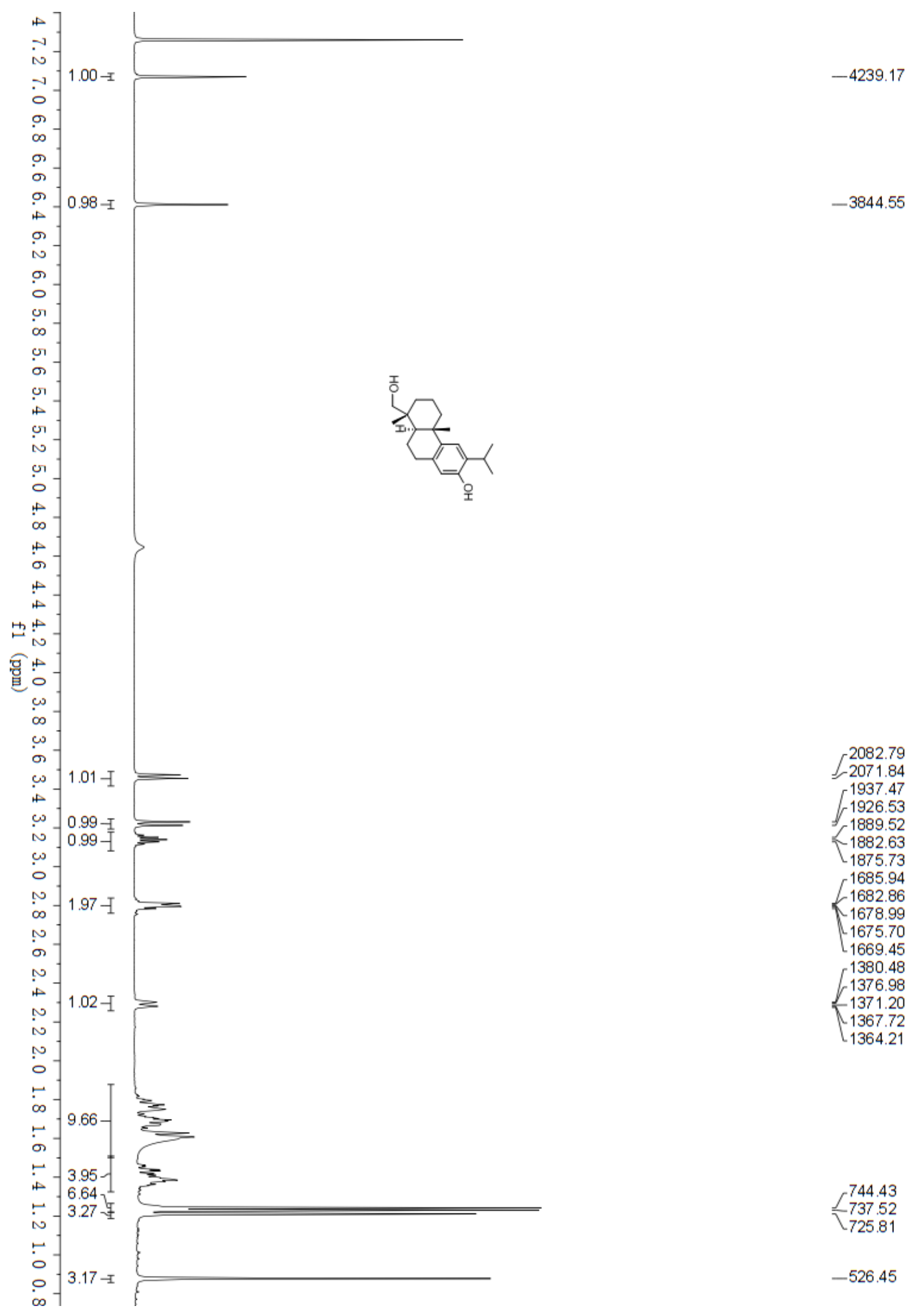

2082.79

2071.84

1937.47

1926.53

1889.52

1882.63

1875.73

1685.94

1682.86
1678.99

-1678.99

1675.70

$-1669.45$

1380.48

r 1376.98

$-1371.20$

1367.72

1364.21

744.43

737.52

725.81

$-526.45$ 
Figure S28 ${ }^{13} \mathrm{C}$ NMR spectrum of 18-hydroxysempervirol (4) in $\mathrm{CDCl}_{3}$

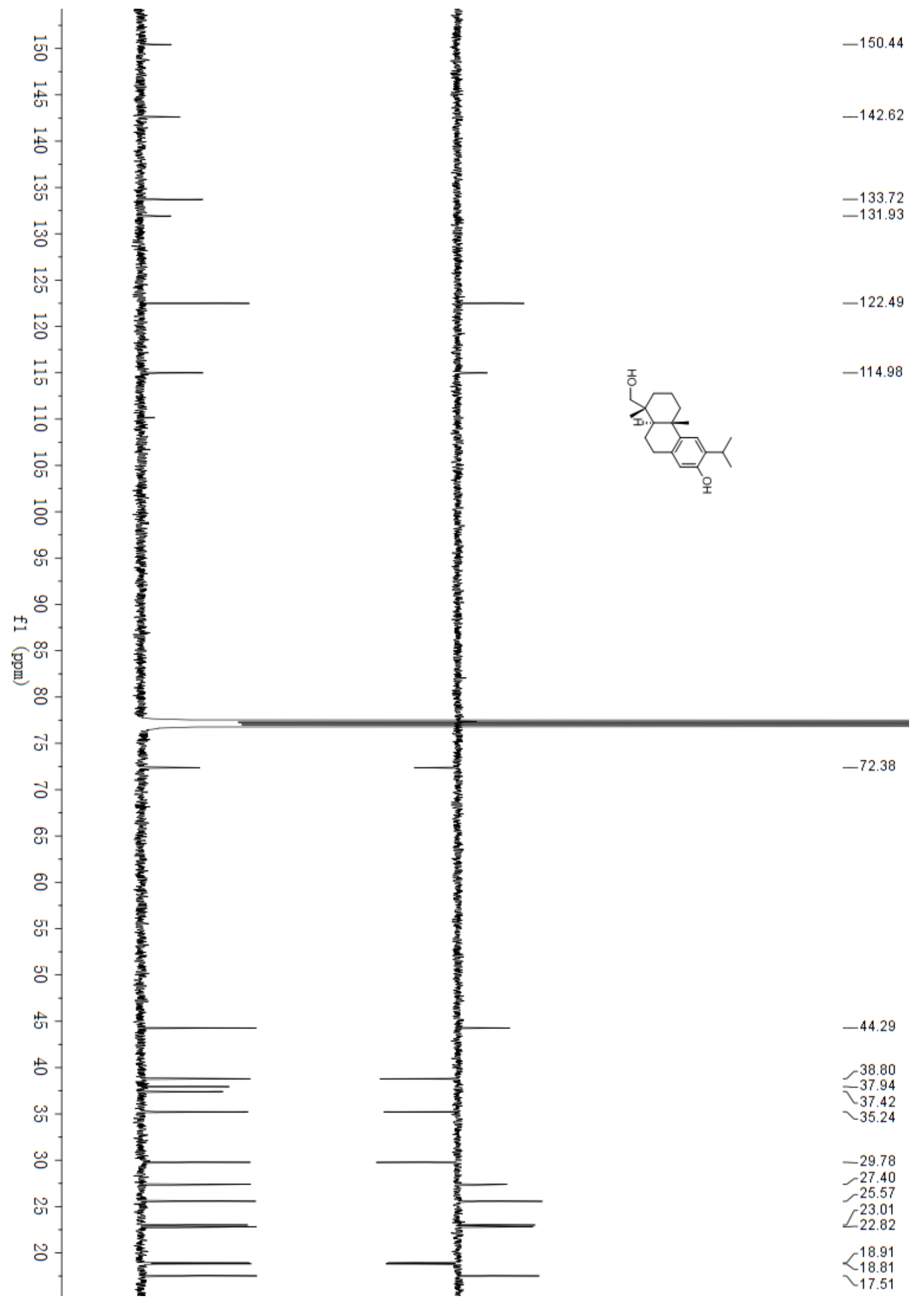


Figure S29. HSQC spectrum of 18-hydroxysempervirol (4) in $\mathrm{CDCl}_{3}$

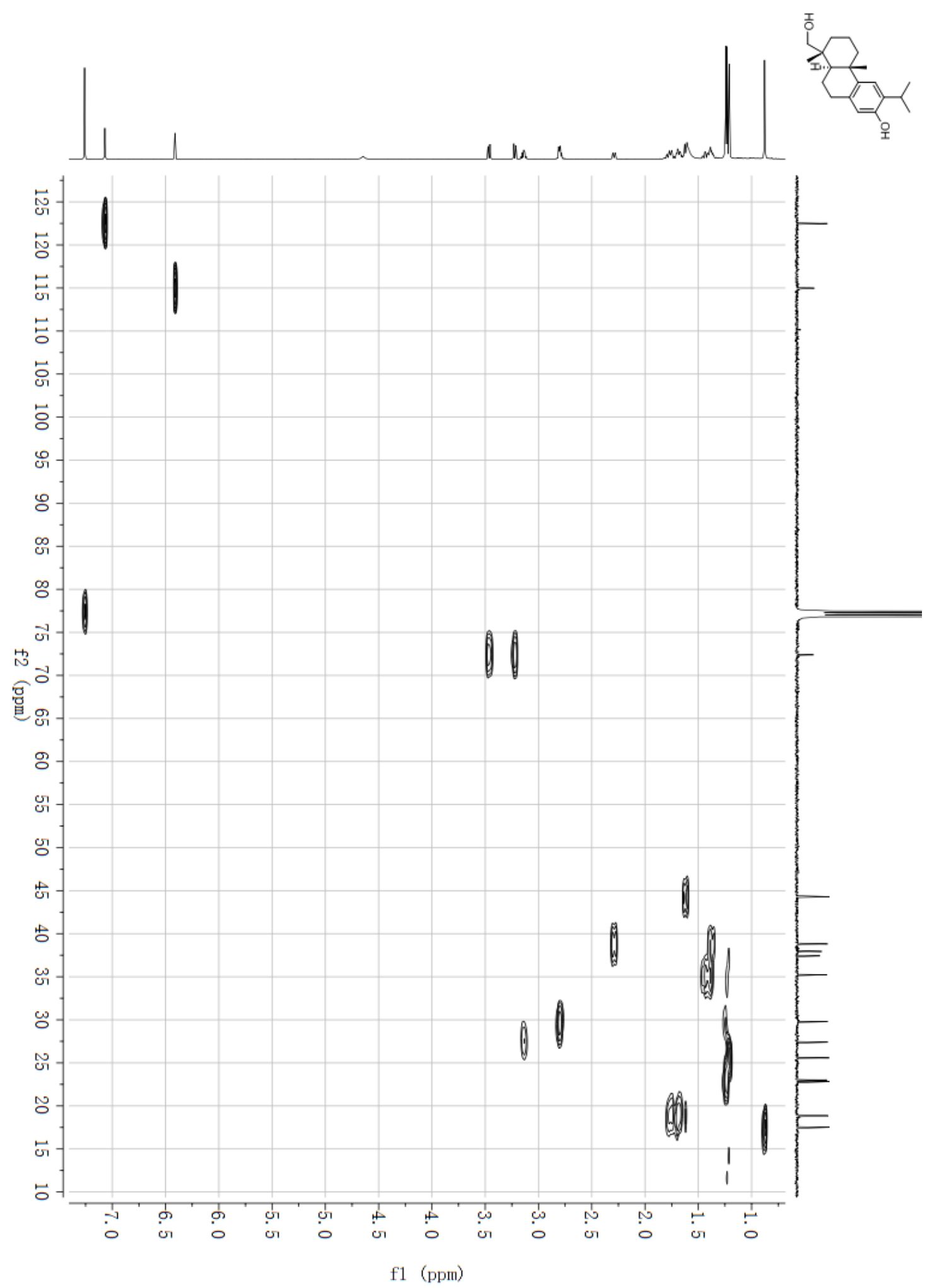


Figure S30. HMBC spectrum of 18-hydroxysempervirol (4) in $\mathrm{CDCl}_{3}$

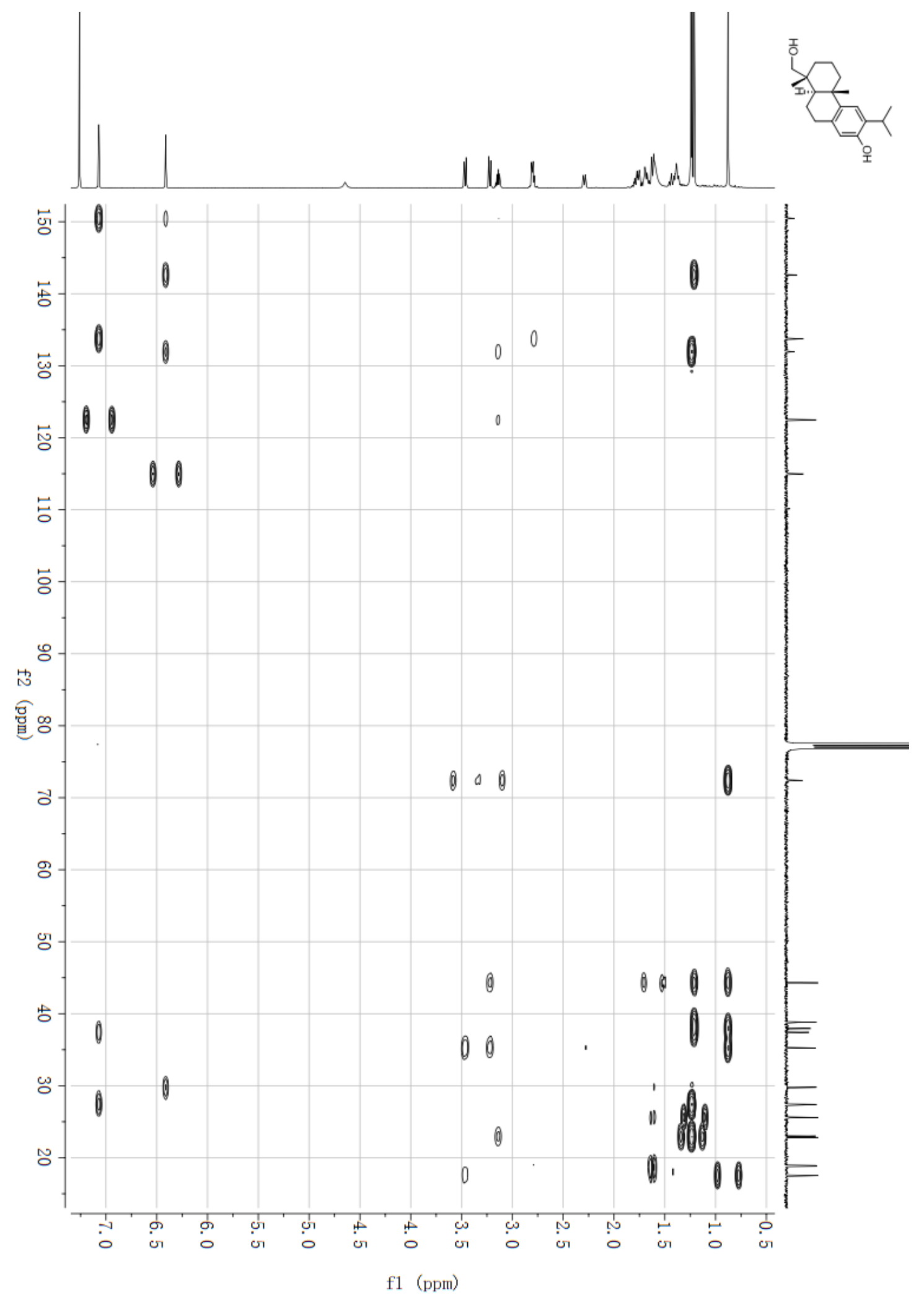


Figure S31. NOESY spectrum of 18-hydroxysempervirol (4) in $\mathrm{CDCl}_{3}$
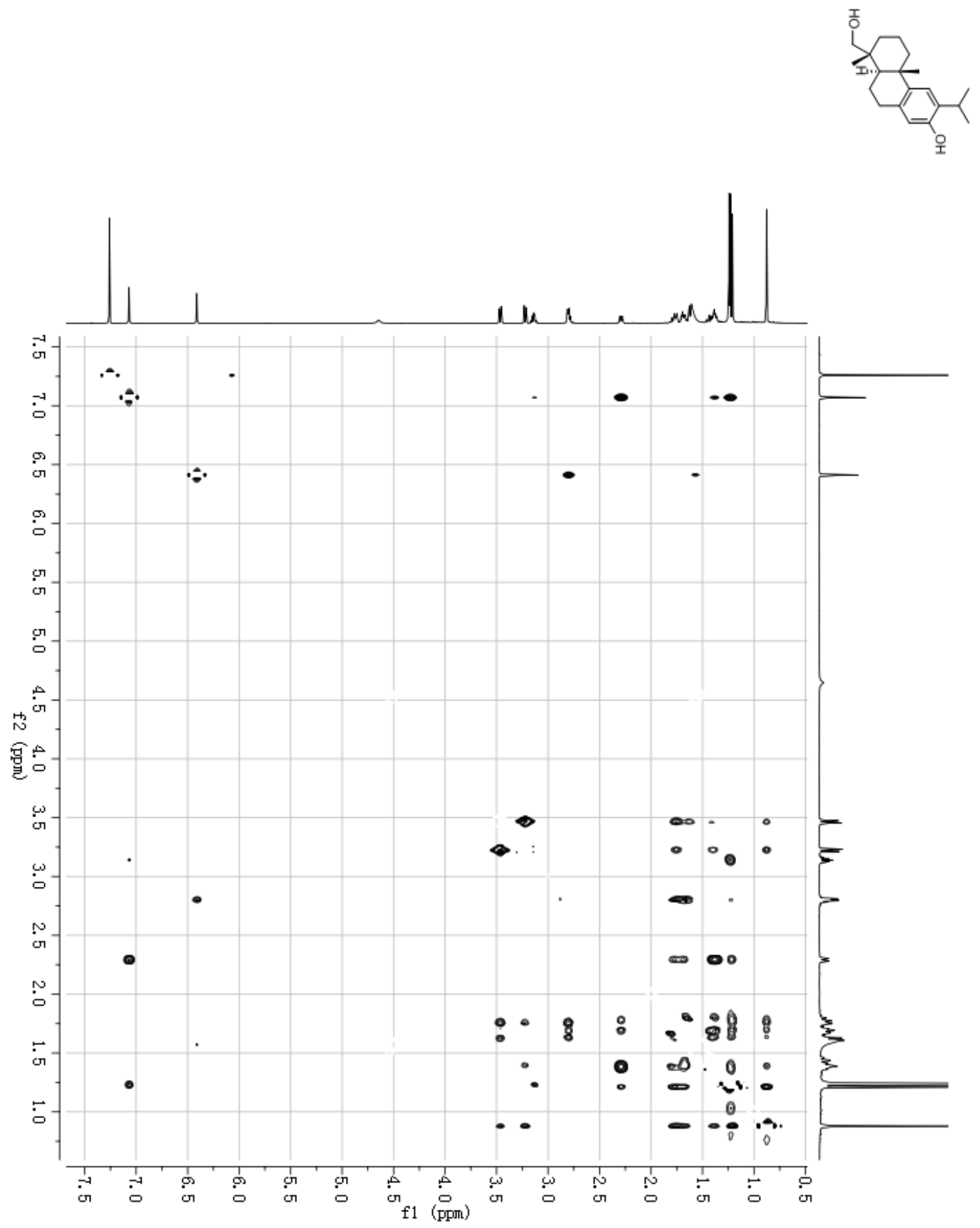
Figure S32. (+)-ESIMS spectrum of 18-hydroxysempervirol (4)

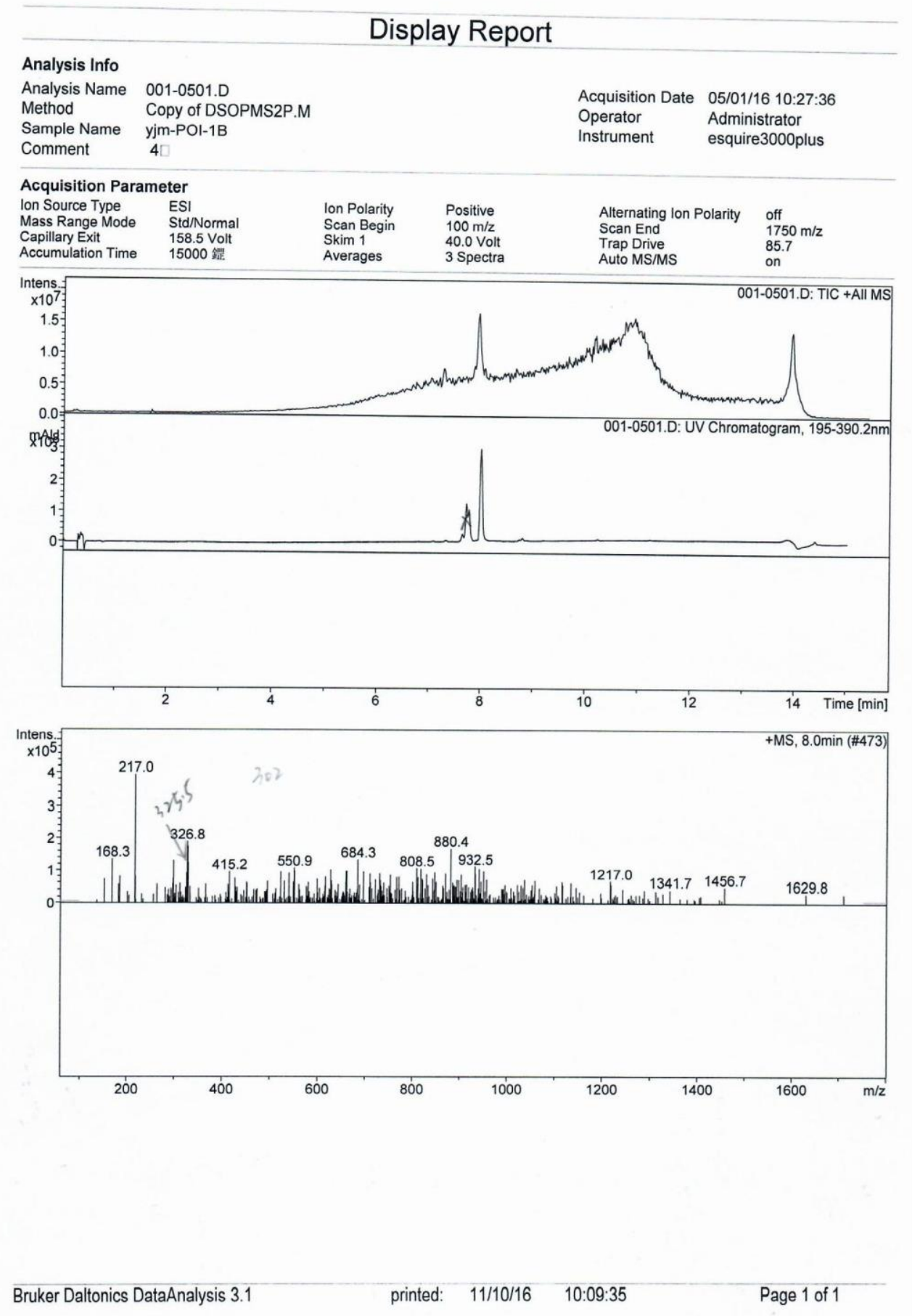


Figure S33. (-)-ESIMS spectrum of 18-hydroxysempervirol (4)

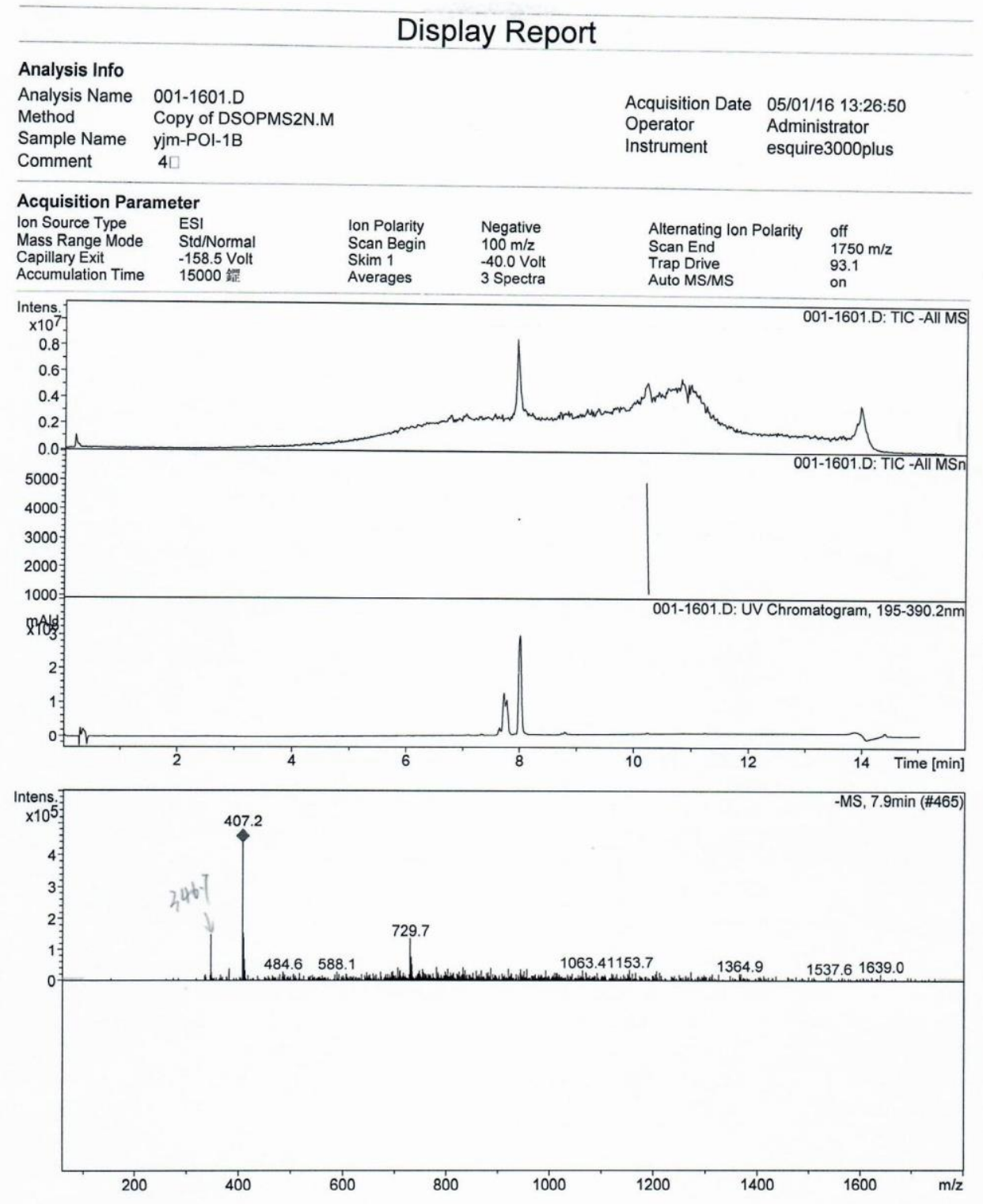


Figure S34. (-)-HRESIMS spectrum of 18-hydroxysempervirol (4)

Elemental Composition Report

Page 1

Single Mass Analysis

Tolerance $=3.0$ PPM / DBE: $\min =-1.5, \max =50.0$

Element prediction: Off

Number of isotope peaks used for i-FIT $=3$

Monoisotopic Mass, Even Electron lons

343 formula(e) evaluated with 1 results within limits (up to 50 closest results for each mass)

Elements Used:

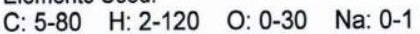

POI-1B LCT PXE KE324

POI-1B 14 (0.284) AM2 (Ar, 10000.0,0.00,1.00); ABS; Cm (11:17)

13:59:03

1: TOF MS ES-

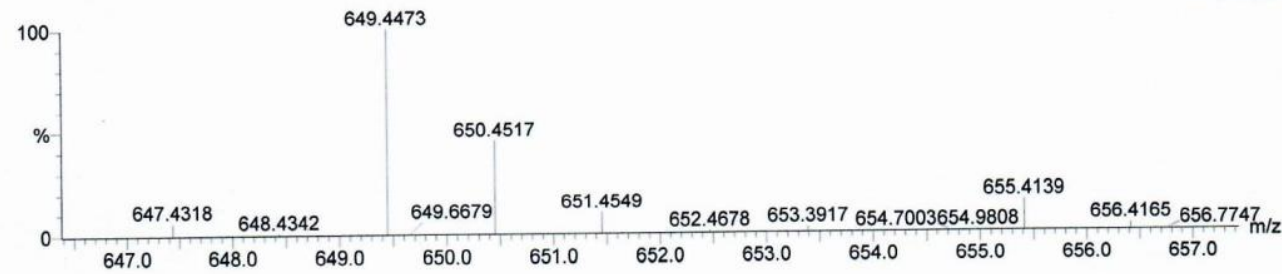

Maximum:

$\begin{array}{lll}5.0 & 3.0 & -1.5 \\ 50.0\end{array}$

Mass Calc. Mass mDa PPM DBE

$\begin{array}{lllll}649.4473 & 649.4468 & 0.5 & 0.8 & 11.5\end{array}$

11.5

$85.9 \quad 0.0$

C41 H61 06 
Figure S35. IR spectrum of 18-hydroxysempervirol (4)

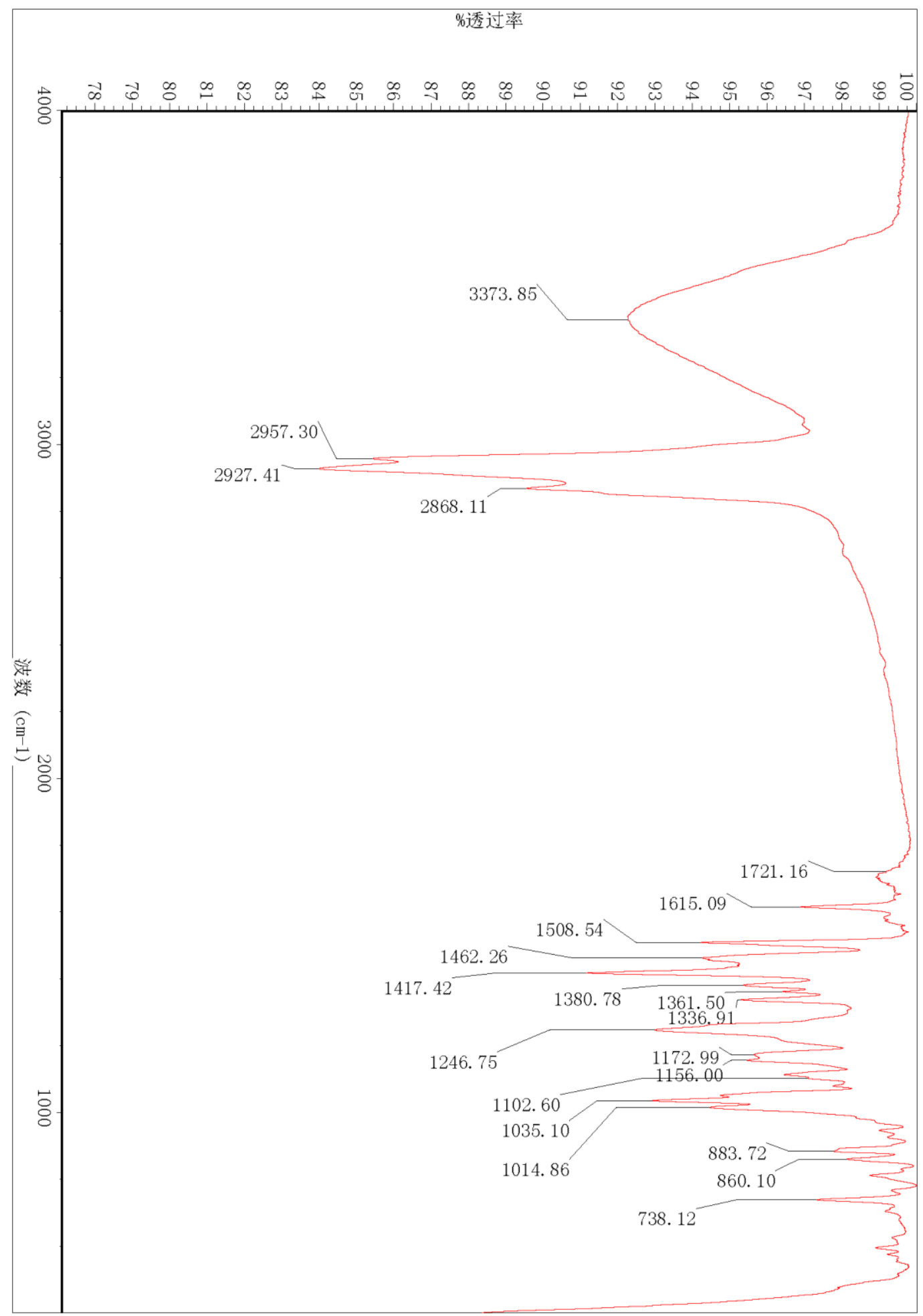


Figure S36. ${ }^{1} \mathrm{H}$ NMR spectrum of $6 \beta$-hydroxysempervirol (5) in $\mathrm{CDCl}_{3}$

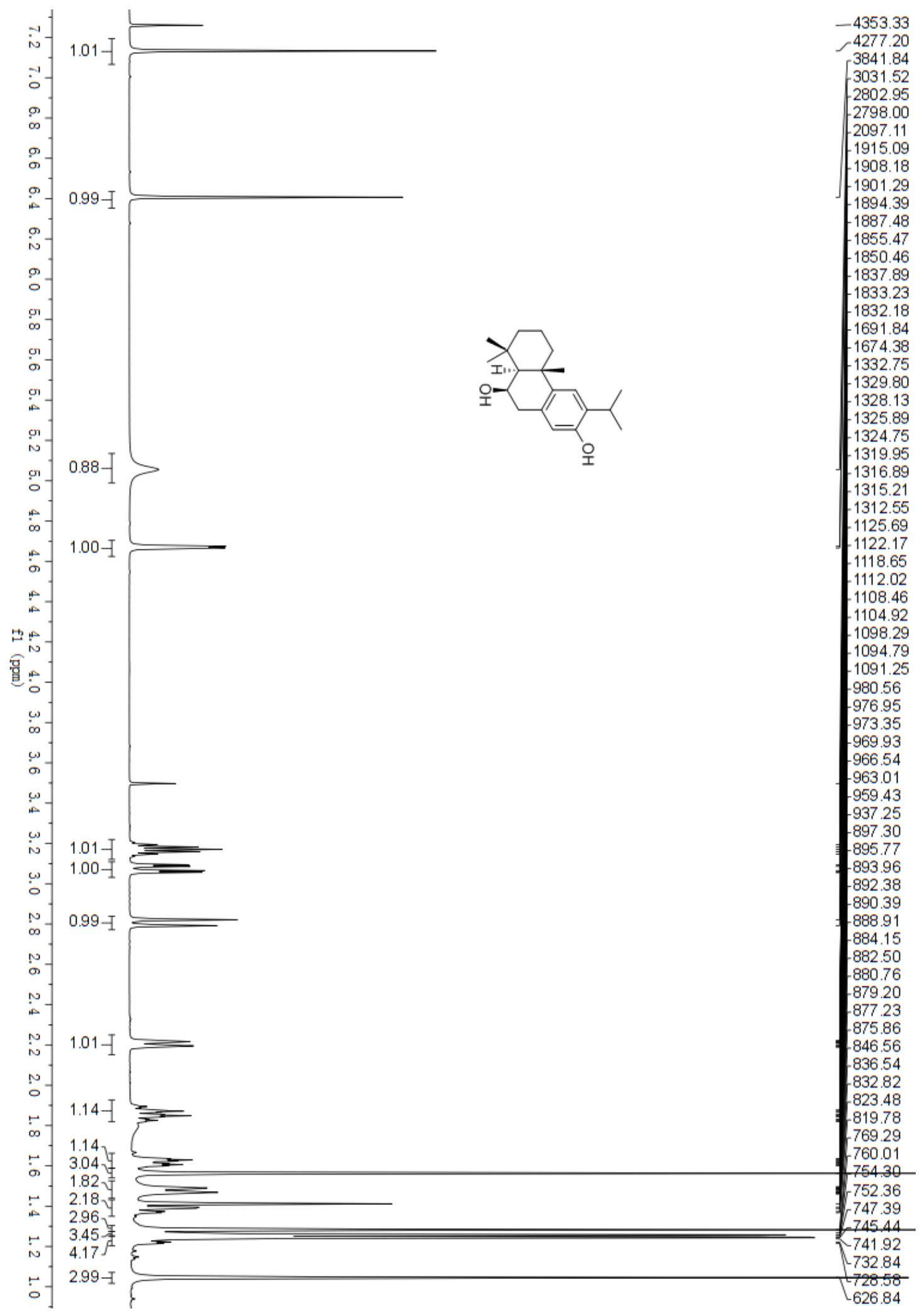


Figure S37. ${ }^{13} \mathrm{C}$ NMR spectrum of $6 \beta$-hydroxysempervirol (5) in $\mathrm{CDCl}_{3}$

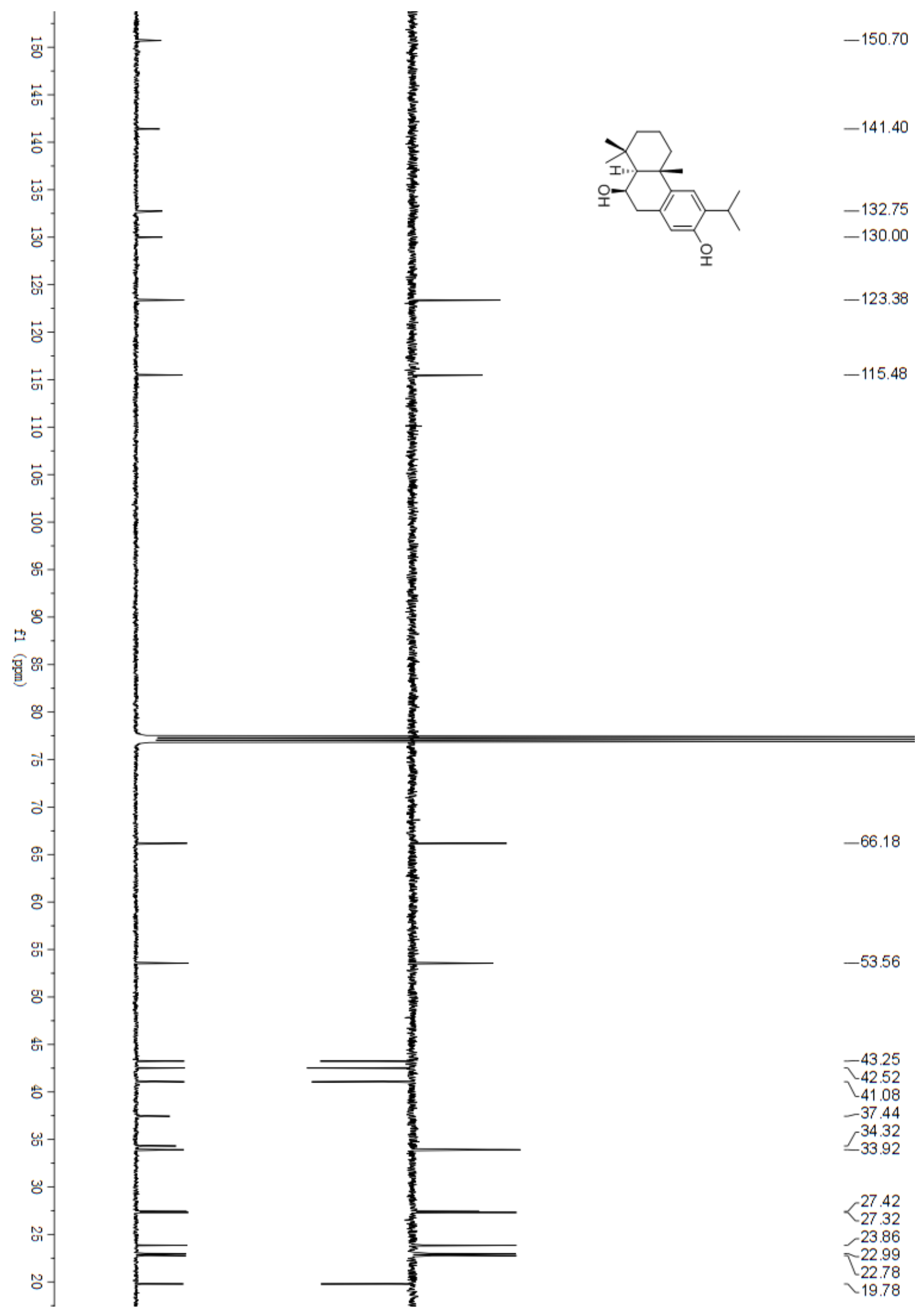


Figure S38. HSQC spectrum of $6 \beta$-hydroxysempervirol (5) in $\mathrm{CDCl}_{3}$

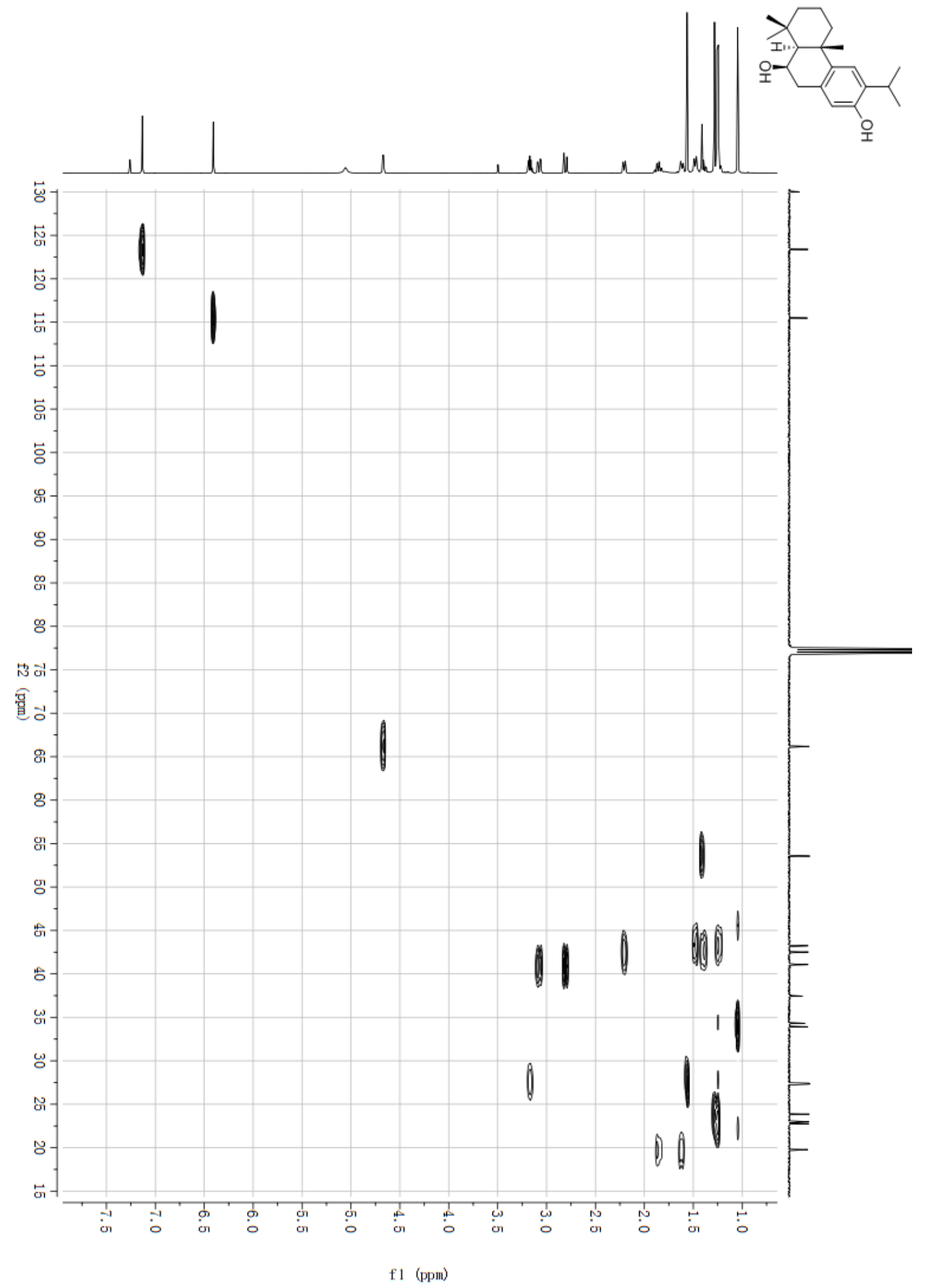


Figure S39. HMBC spectrum of $6 \beta$-hydroxysempervirol (5) in $\mathrm{CDCl}_{3}$

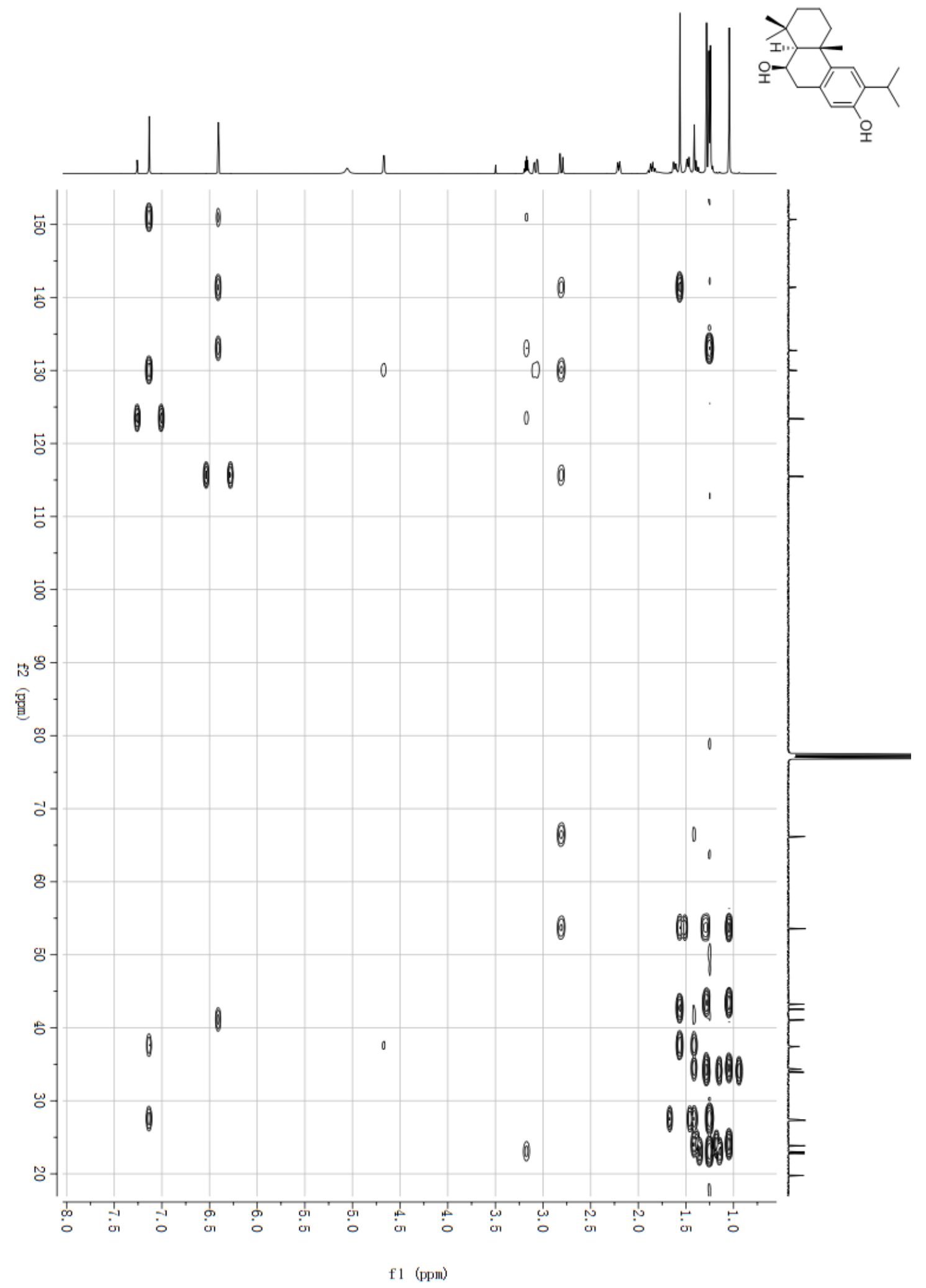


Figure S40. NOESY spectrum of $6 \beta$-hydroxysempervirol (5) in $\mathrm{CDCl}_{3}$
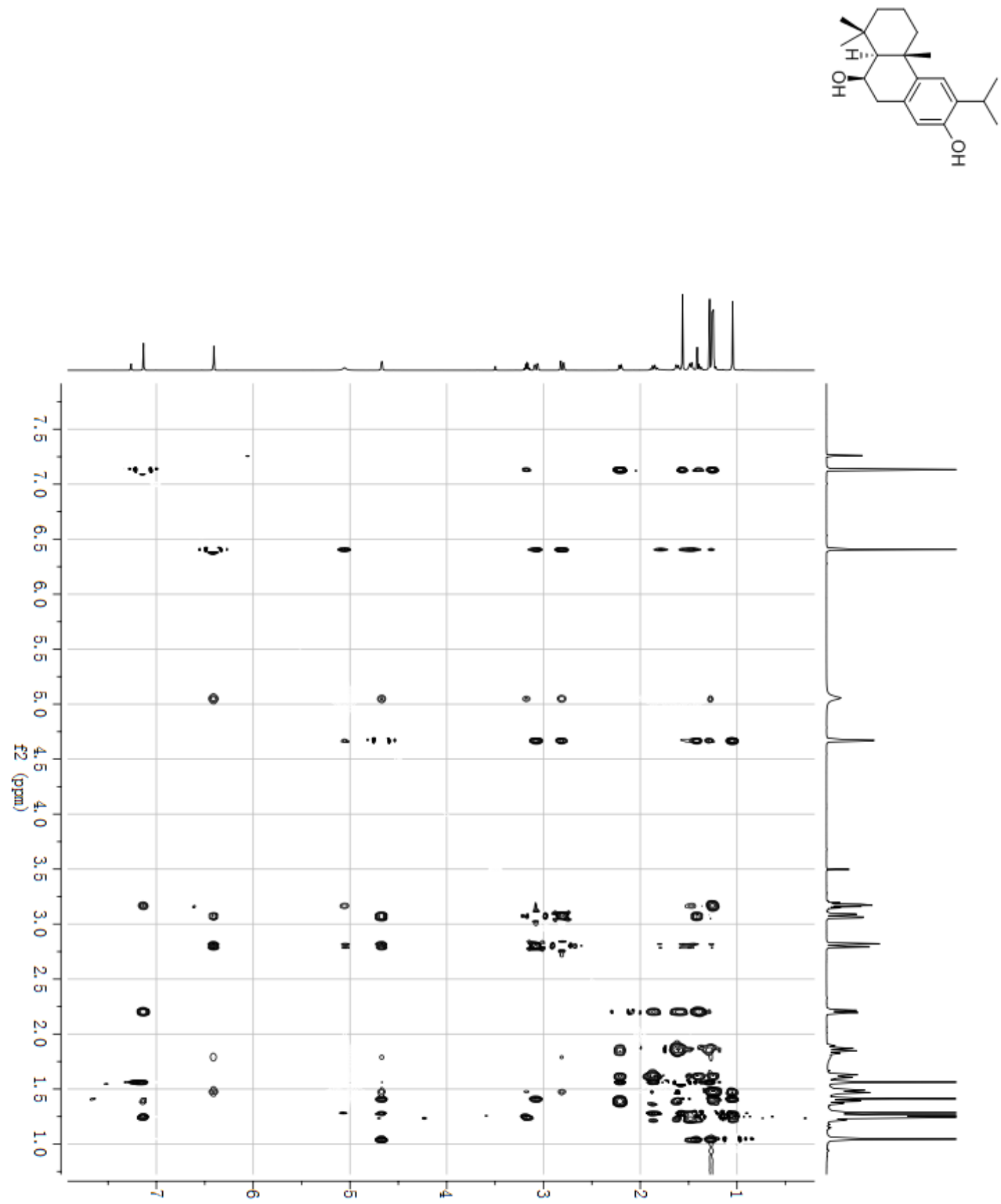

f1 (ppmi) 
Figure S41. (-)-ESIMS spectrum of $6 \beta$-hydroxysempervirol (5)

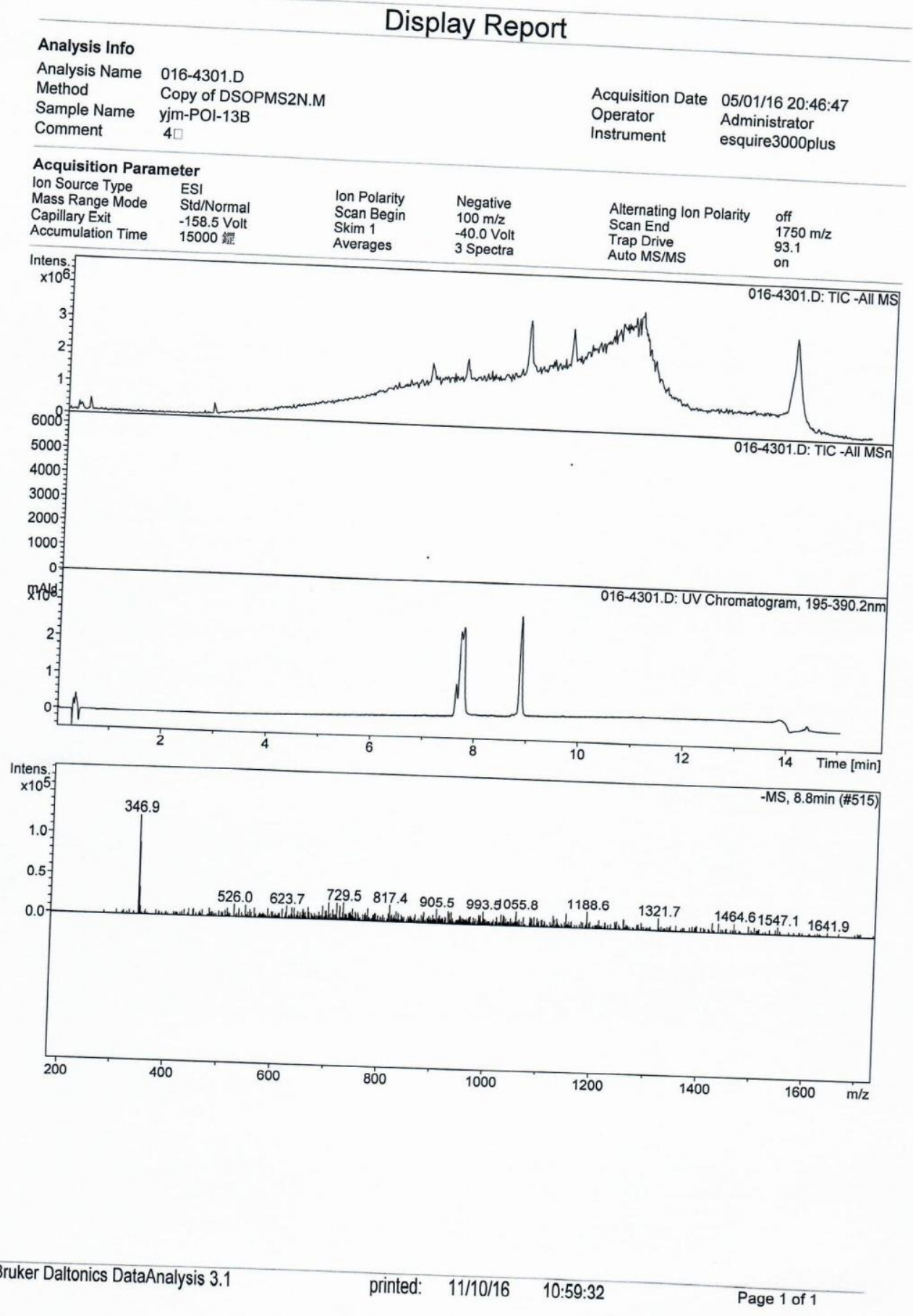


Figure S42. (-)-HRESIMS spectrum of $6 \beta$-hydroxysempervirol (5)

\section{Elemental Composition Report}

Single Mass Analysis

Tolerance $=3.0$ PPM I DBE: $\min =-1.5, \max =50.0$

Element prediction: Off

Number of isotope peaks used for i-FIT $=3$

Monoisotopic Mass, Even Electron lons

343 formula(e) evaluated with 1 results within limits (up to 50 closest results for each mass)

Elements Used:

$\begin{array}{llll}\text { C: } 5-80 & \mathrm{H}: 2-120 & \text { O: } 0-30 \quad \mathrm{Na}: 0-1\end{array}$

POI-13B

LCT PXE KE324

29-Oct-2016

POI-13B 7 (0.141) AM2 (Ar, 10000.0,0.00,1.00); ABS; Cm (6:10)

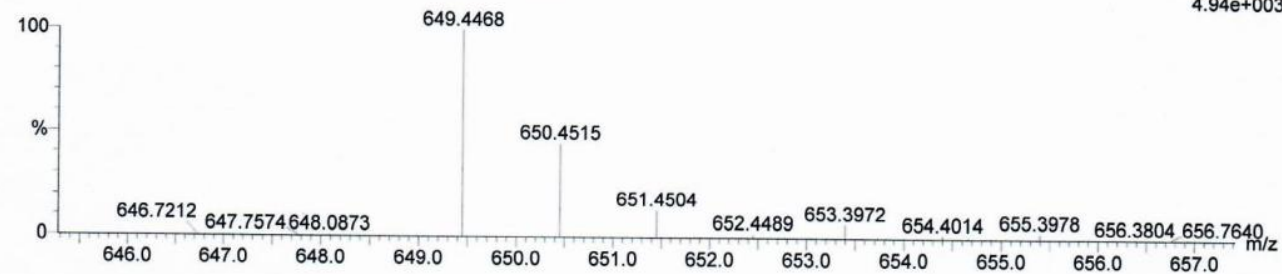

Minimum:

Maximum:

$\begin{array}{lll}5.0 & 3.0 \quad & -1.5 \\ & 50.0\end{array}$

Mass Calc. Mass mDa PPM DBE

$\begin{array}{lllllllll}649.4468 & 649.4468 & 0.0 & 0.0 & 11.5 & 69.0 & 0.0 & \text { C41 H61 } & \text { O6 }\end{array}$ 
Figure S43. IR spectrum of $6 \beta$-hydroxysempervirol (5)

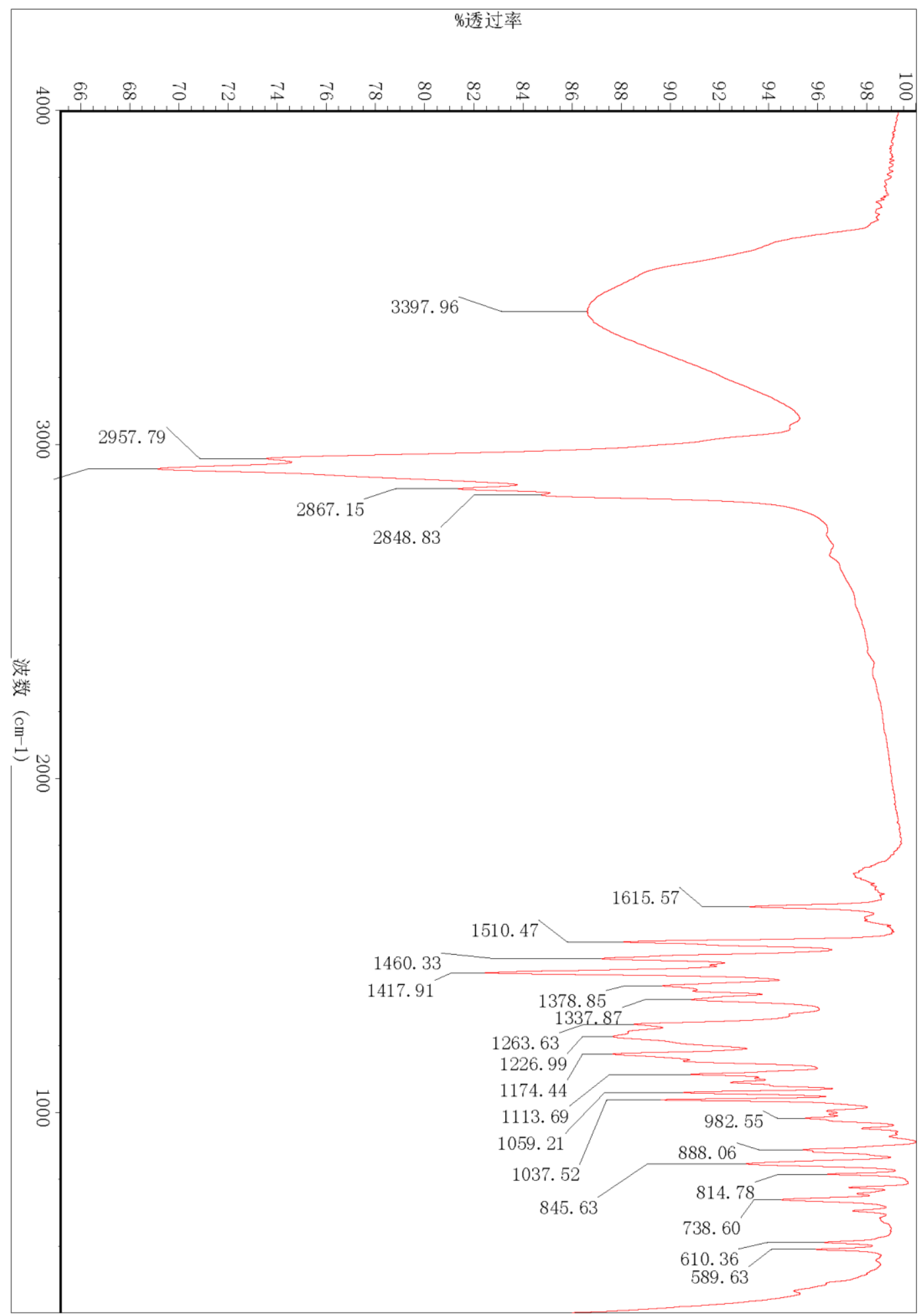


Figure S44. ${ }^{1} \mathrm{H}$ NMR spectrum of 6-hydroxy-7-oxosempervirol (6) in $\mathrm{CDCl}_{3}$

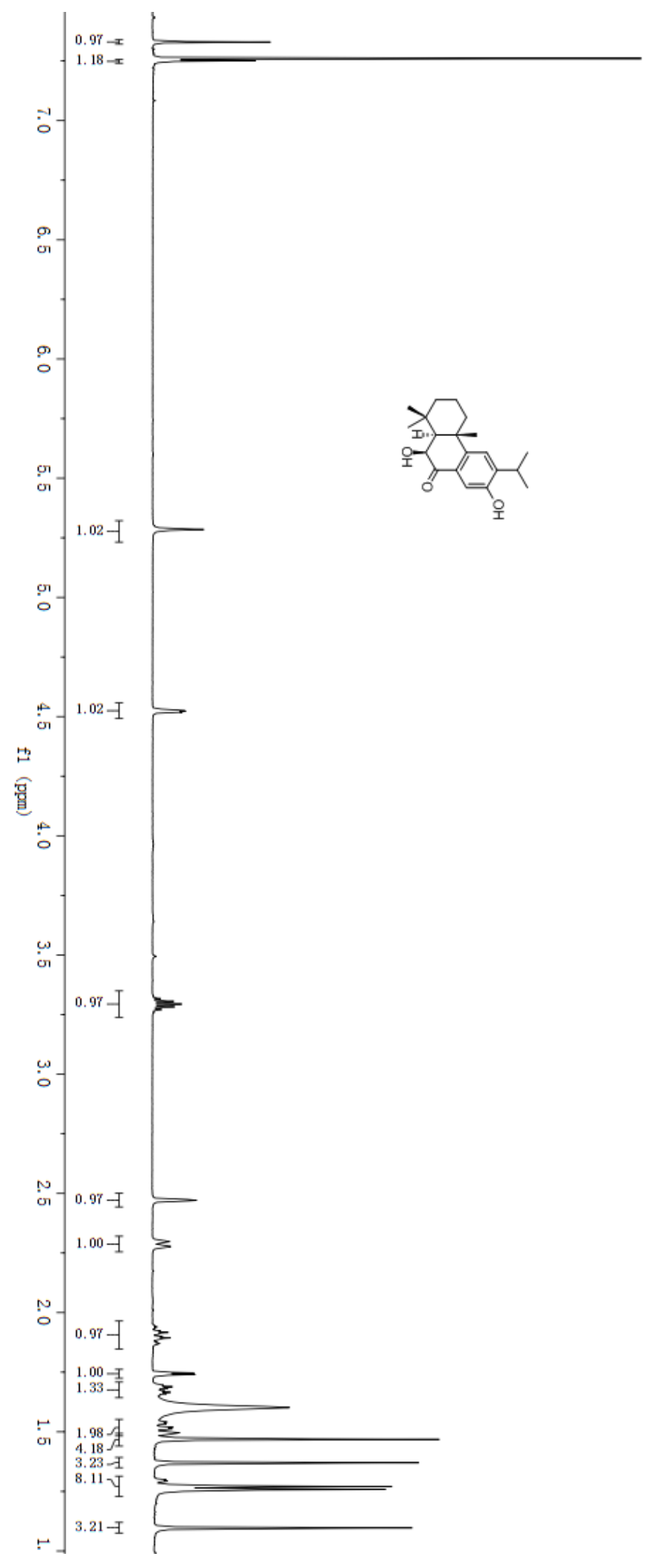

-4395.04
-4348.23

$-3168.98$

2715.88

2713.65

2711.68

$-2709.58$

1982.26

1975.36

1968.47

$-1483.57$

$-1481.76$

1480.38

1381.96

$-1379.04$

$-1377.22$

1374.50

$-1366.20$

$-1364.43$

1361.65

$-1152.74$

1149.33

$-1145.93$

$-1138.98$

$-1135.56$

$-1132.16$

$-1121.80$

$-1047.64$

1043.55

-1016.36

1012.83

$-1009.31$

1002.39

998.85

99529

924.00

$-920.03$

$-910.81$

906.93

897.49

$-895.55$

893.43

887.17

880.44

821.60

762.52

$-76116$

755.58

755.58
754.22

$\checkmark 657.61$ 
Figure S45. ${ }^{13} \mathrm{C}$ NMR spectrum of 6-hydroxy-7-oxosempervirol (6) in $\mathrm{CDCl}_{3}$

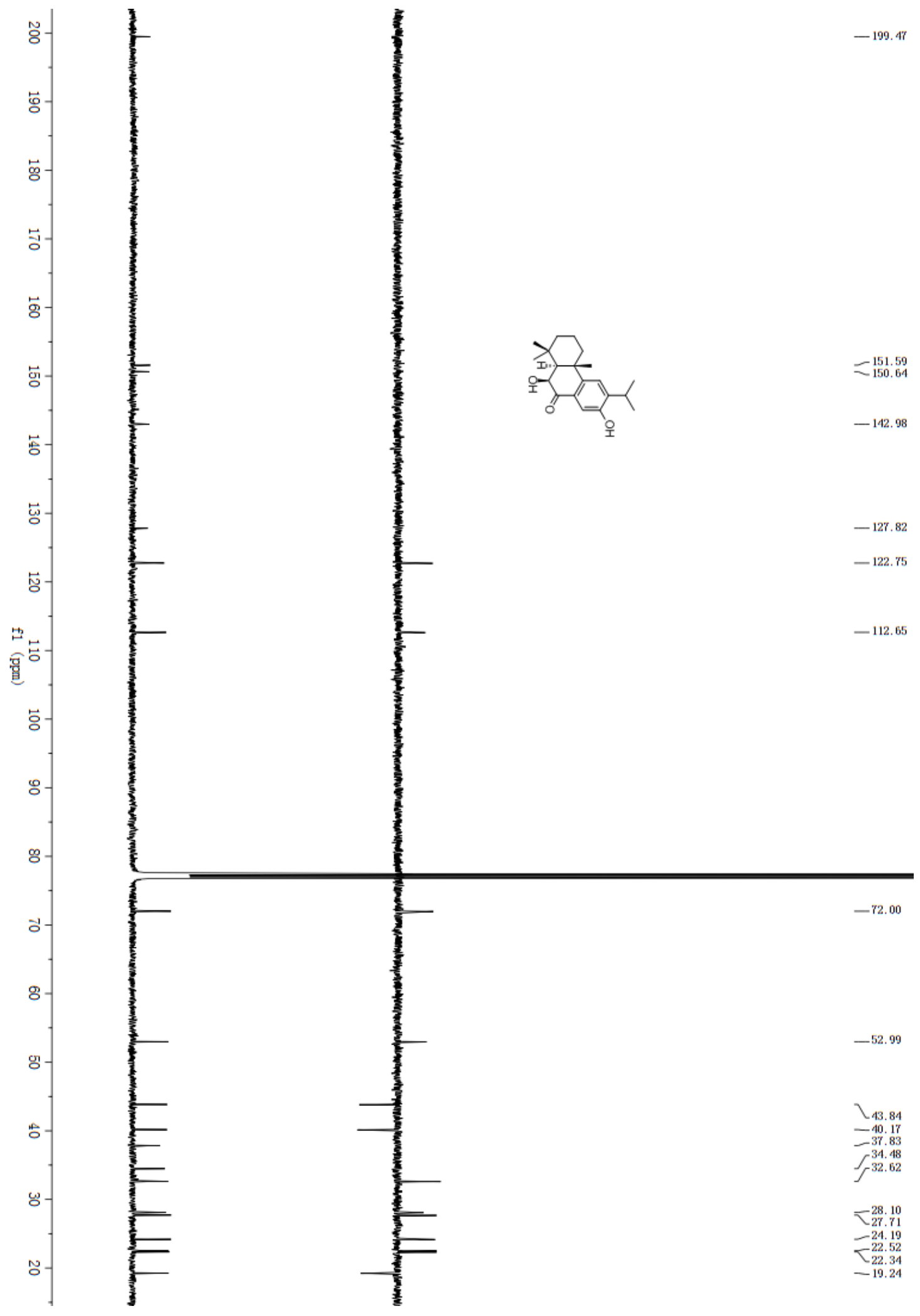


Figure S46. HSQC spectrum of 6-hydroxy-7-oxosempervirol (6) in $\mathrm{CDCl}_{3}$

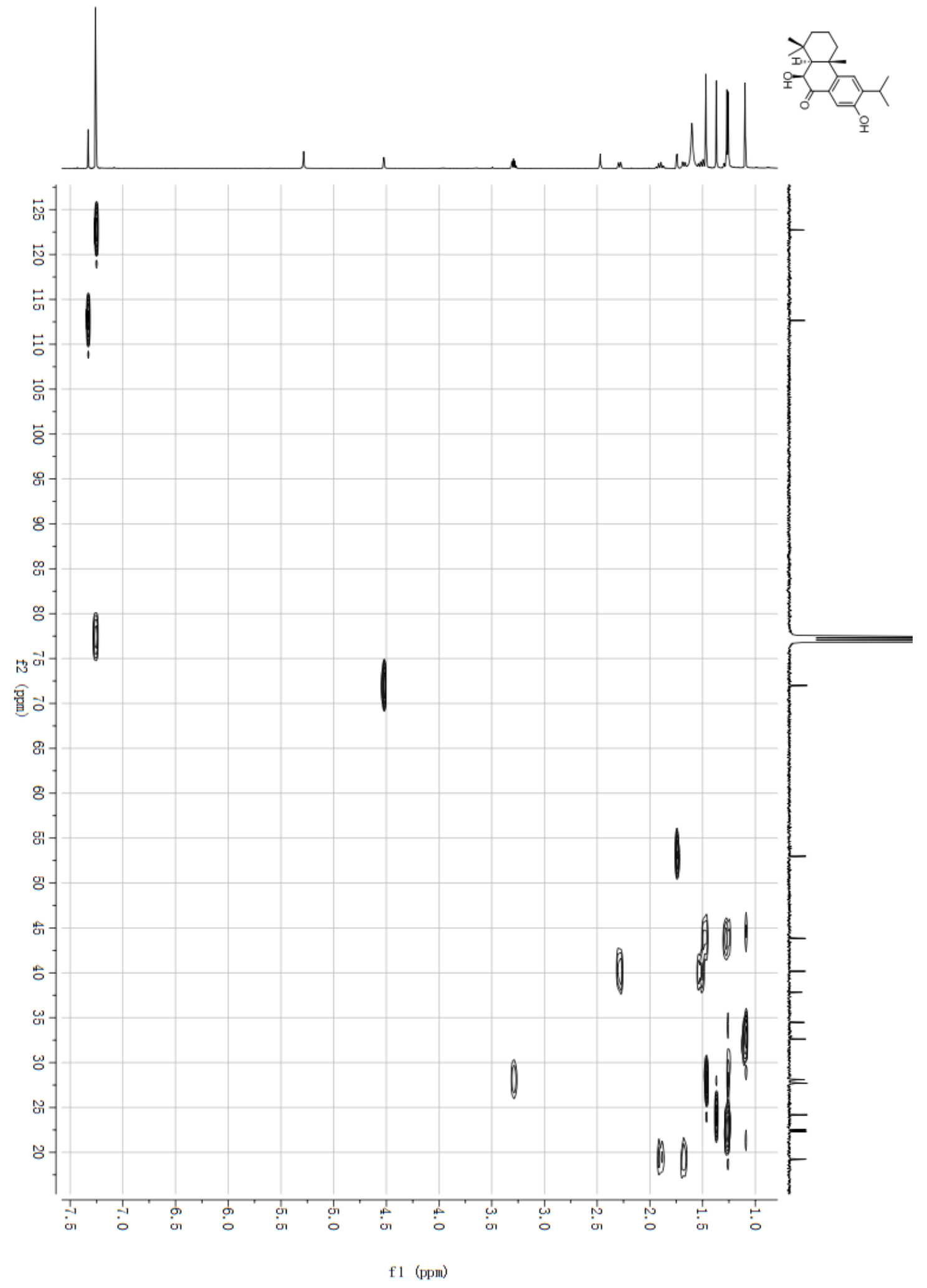


Figure S47. HMBC spectrum of 6-hydroxy-7-oxosempervirol (6) in $\mathrm{CDCl}_{3}$

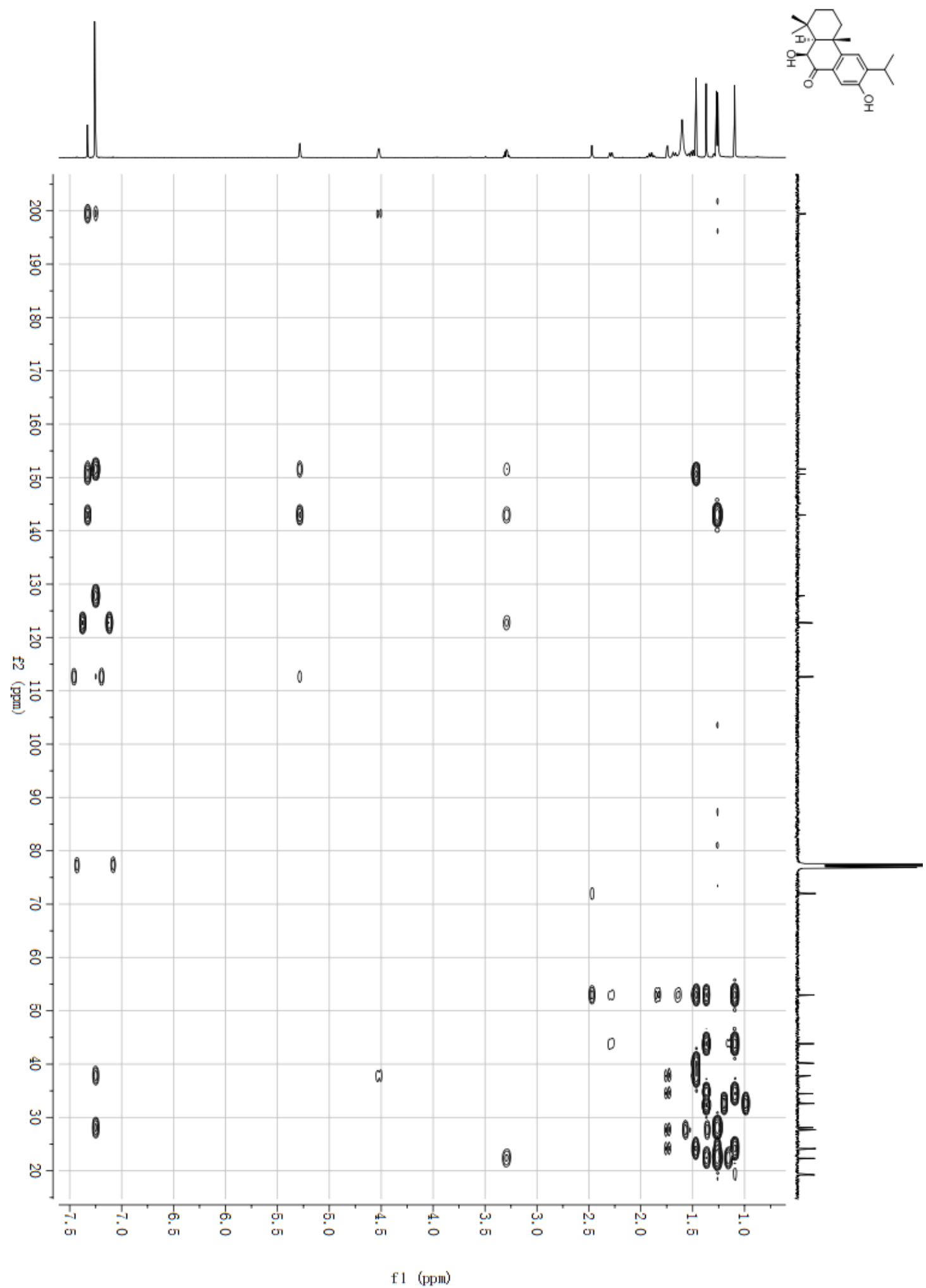


Figure S48. NOESY spectrum of 6-hydroxy-7-oxosempervirol (6) in $\mathrm{CDCl}_{3}$
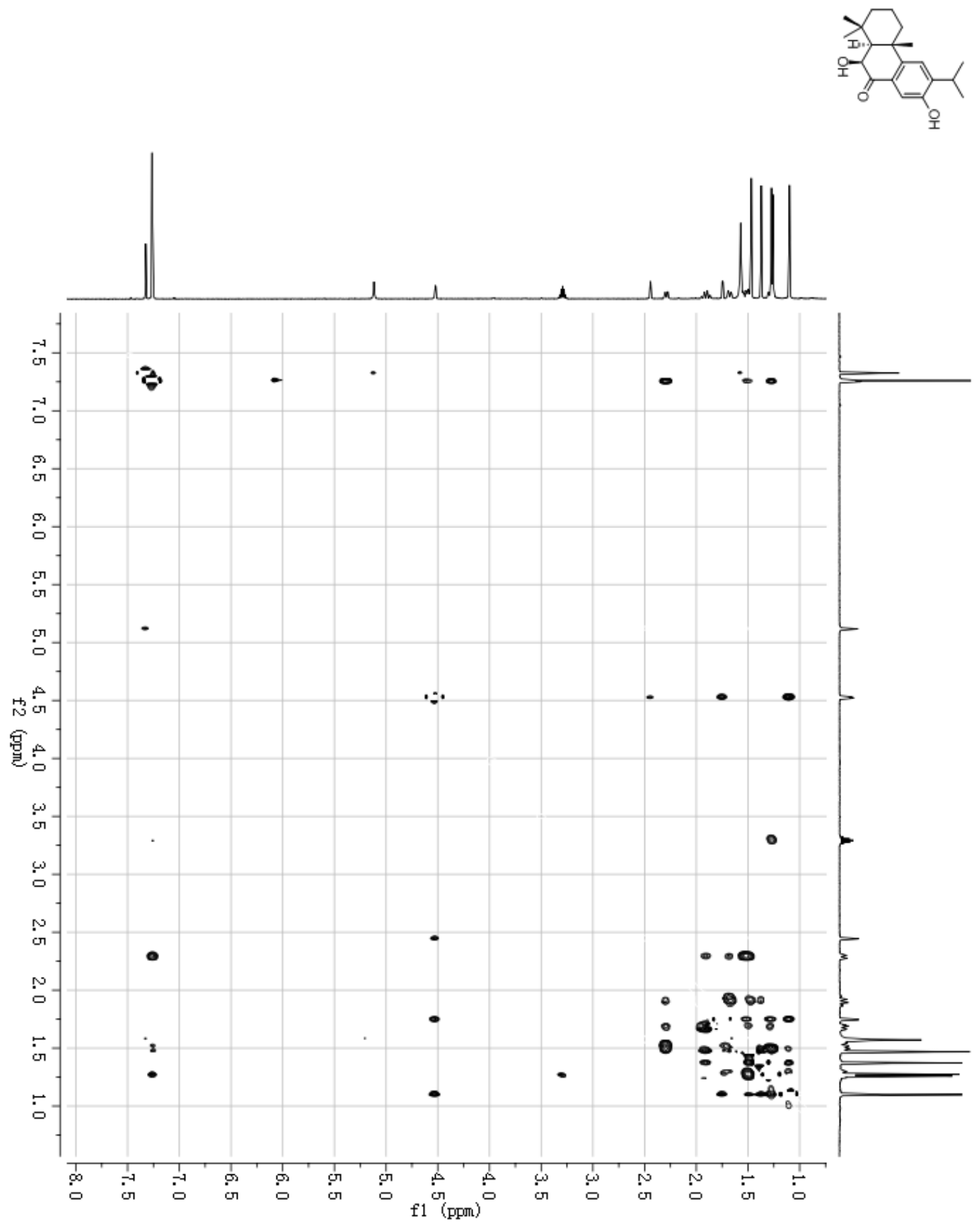
Figure S49. (+)-ESIMS spectrum of 6-hydroxy-7-oxosempervirol (6)
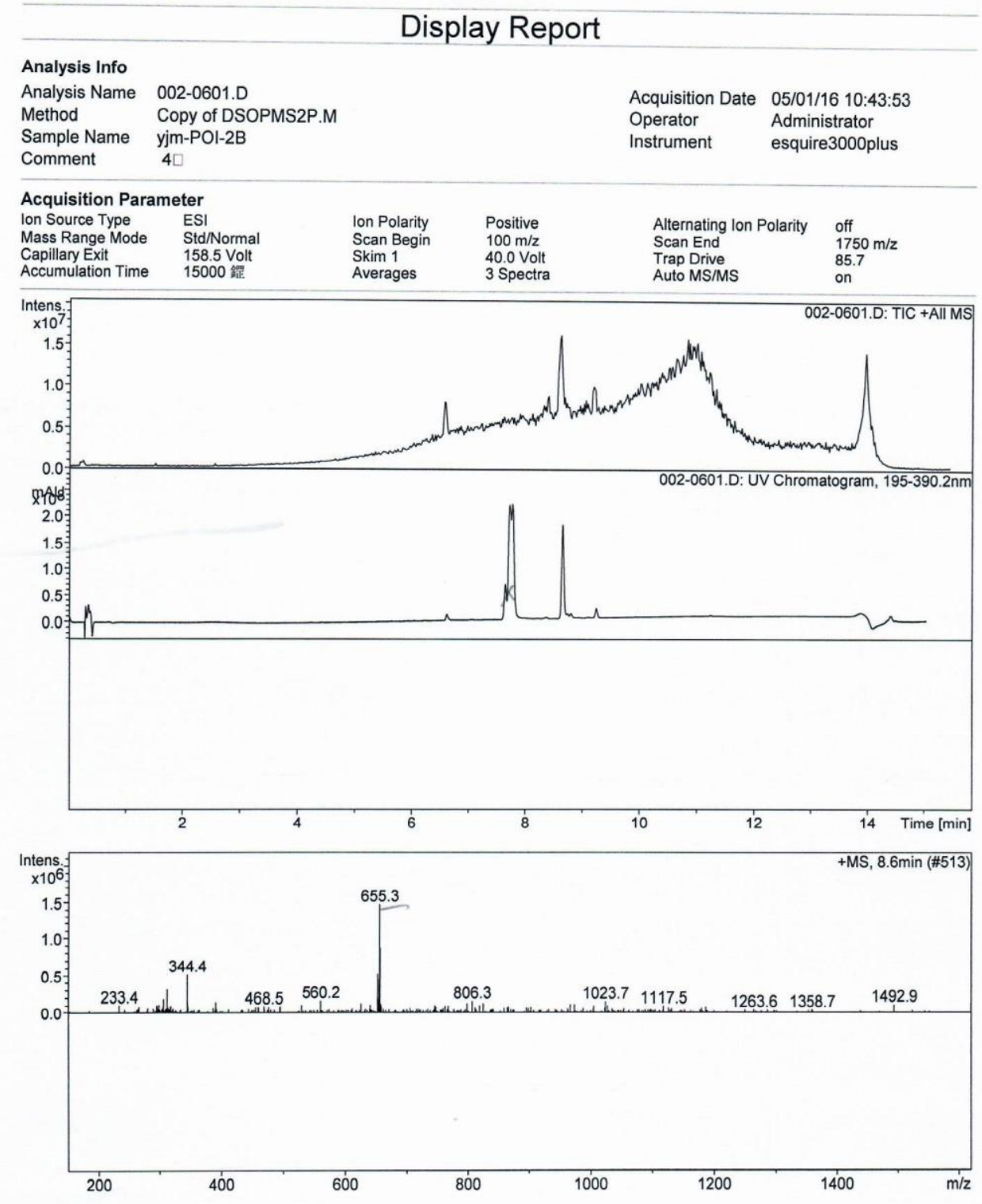
Figure S50. (-)-ESIMS spectrum of 6-hydroxy-7-oxosempervirol (6)

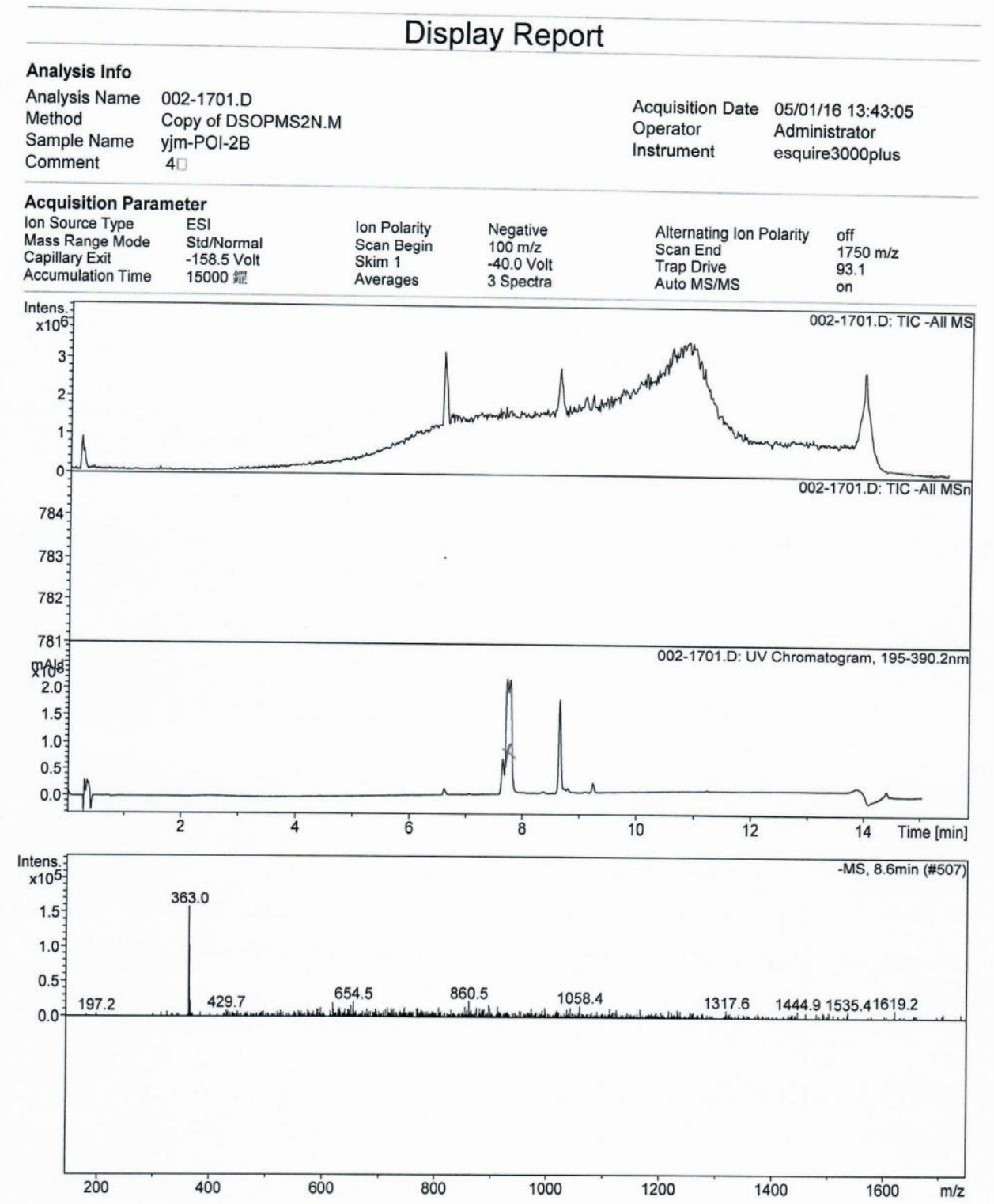


Figure S51. (+)-HRESIMS spectrum of 6-hydroxy-7-oxosempervirol (6)

\section{Elemental Composition Report}

Page 1

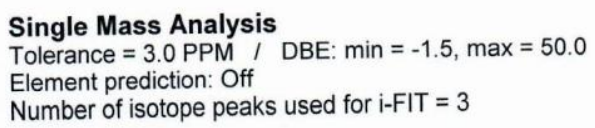

$\begin{array}{lllllllllll}655.3973 & 655.3975 & -0.2 & -0.3 & 12.5 & 96.2 & 0.0 & \text { C40 } & \text { H56 } & \text { O6 } & \text { Na }\end{array}$


Figure S52. IR spectrum of 6-hydroxy-7-oxosempervirol (6)

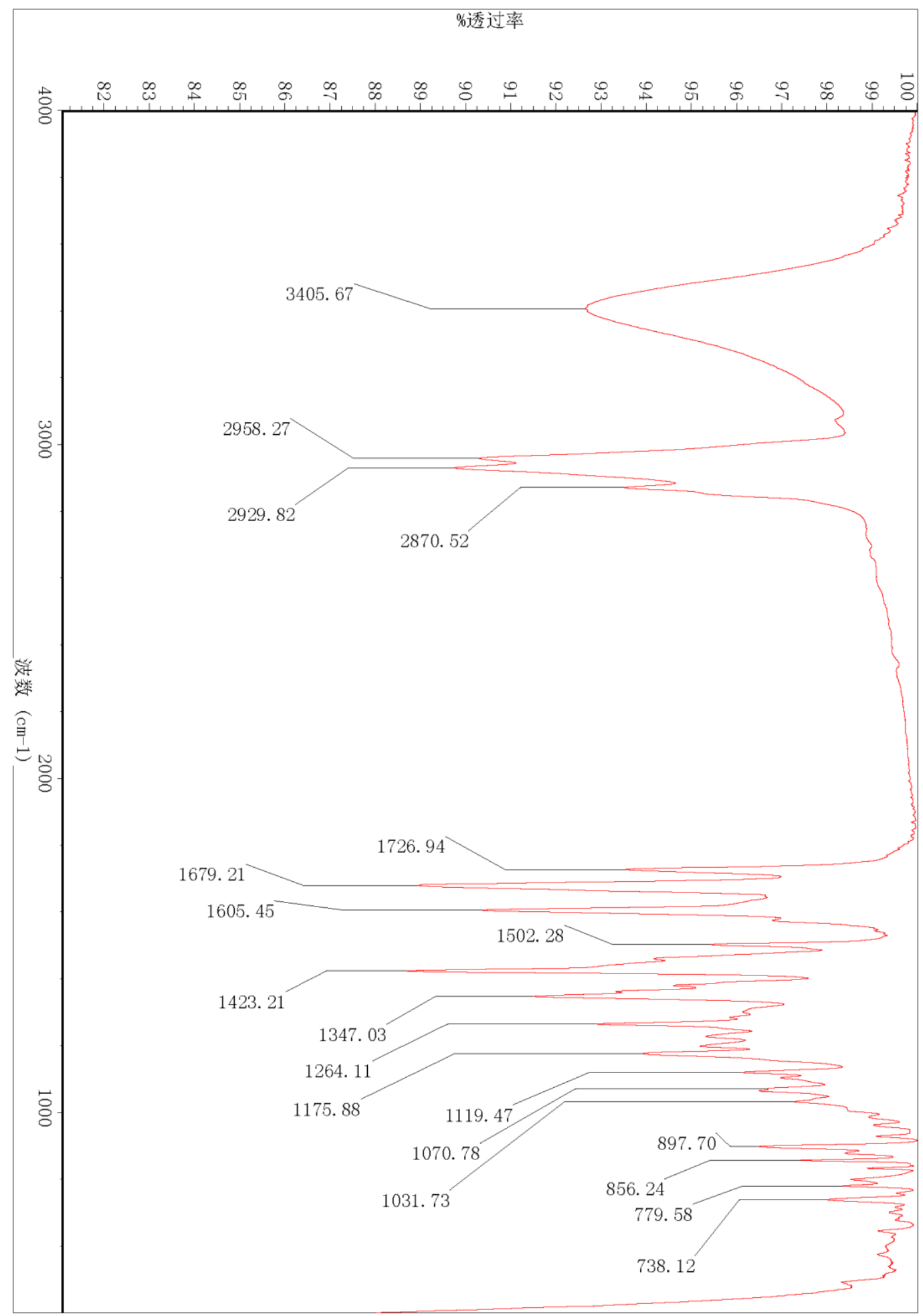


Figure S53. ${ }^{1} \mathrm{H}$ NMR spectrum of $6 \beta, 7 \beta$-dihydroxysempervirol (7) in $\mathrm{CDCl}_{3}$

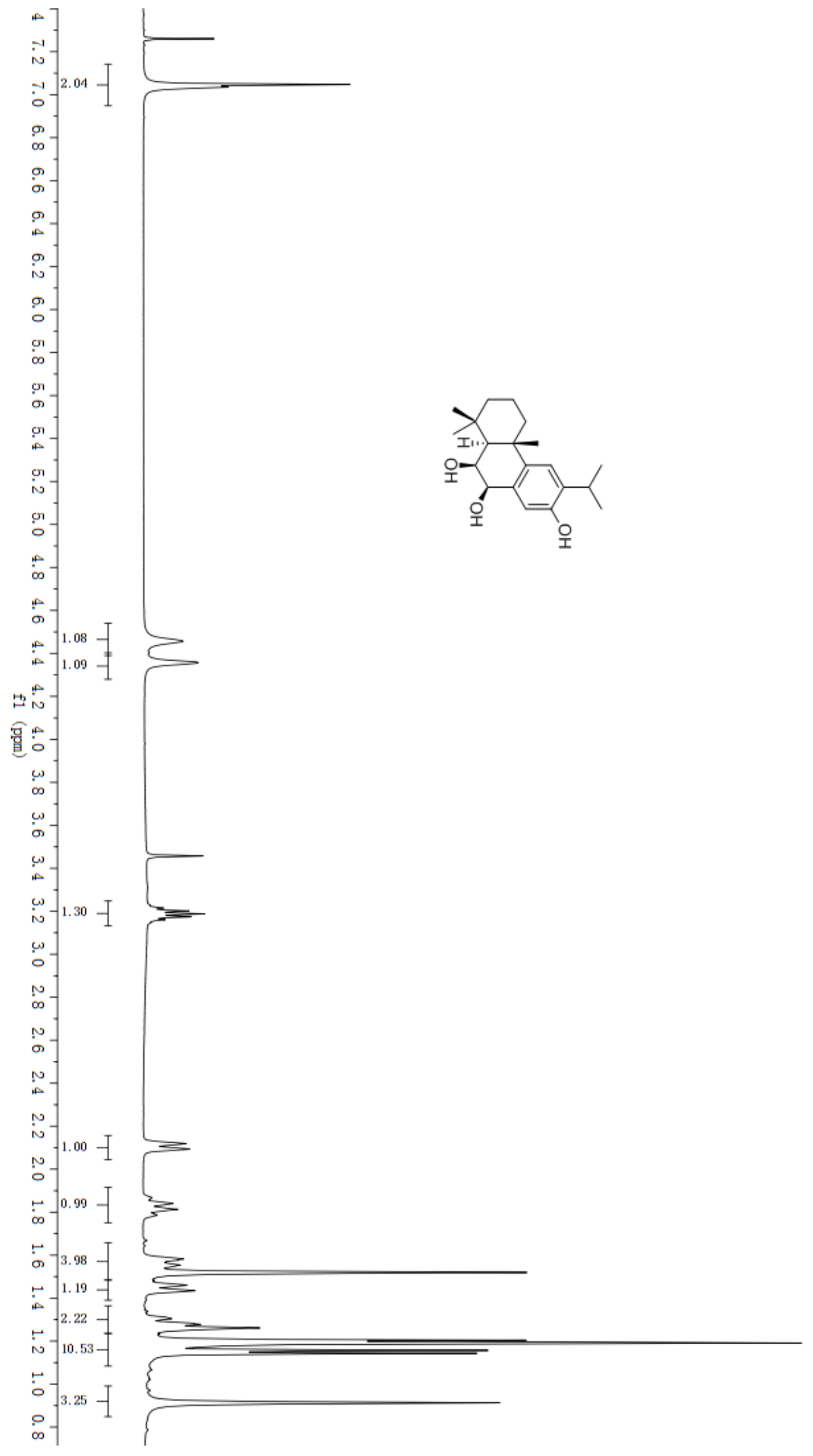


Figure S54. ${ }^{13} \mathrm{C}$ NMR spectrum of $6 \beta, 7 \beta$-dihydroxysempervirol (7) in $\mathrm{CDCl}_{3}$

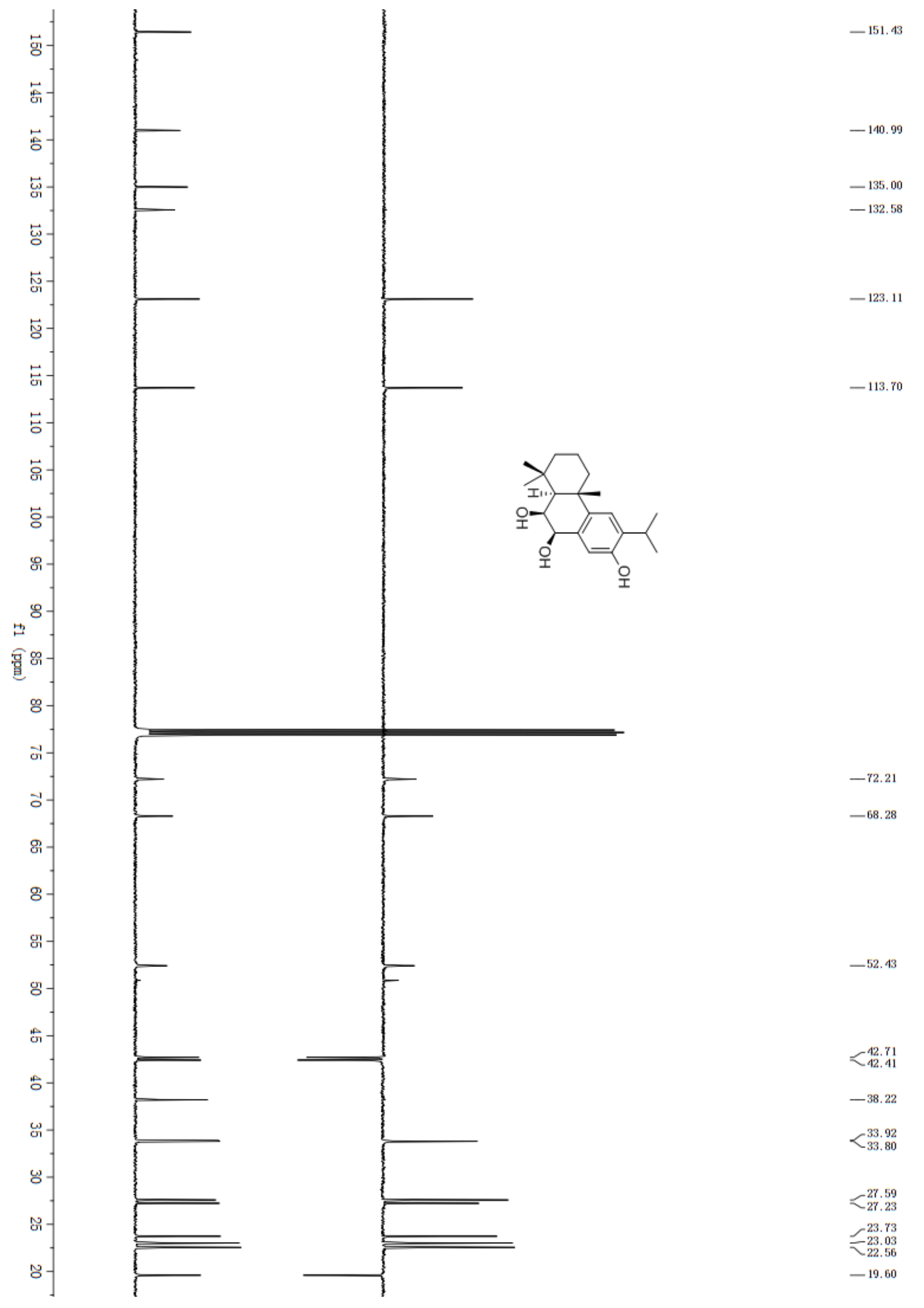


Figure S55. HSQC spectrum of $6 \beta, 7 \beta$-dihydroxysempervirol (7) in $\mathrm{CDCl}_{3}$

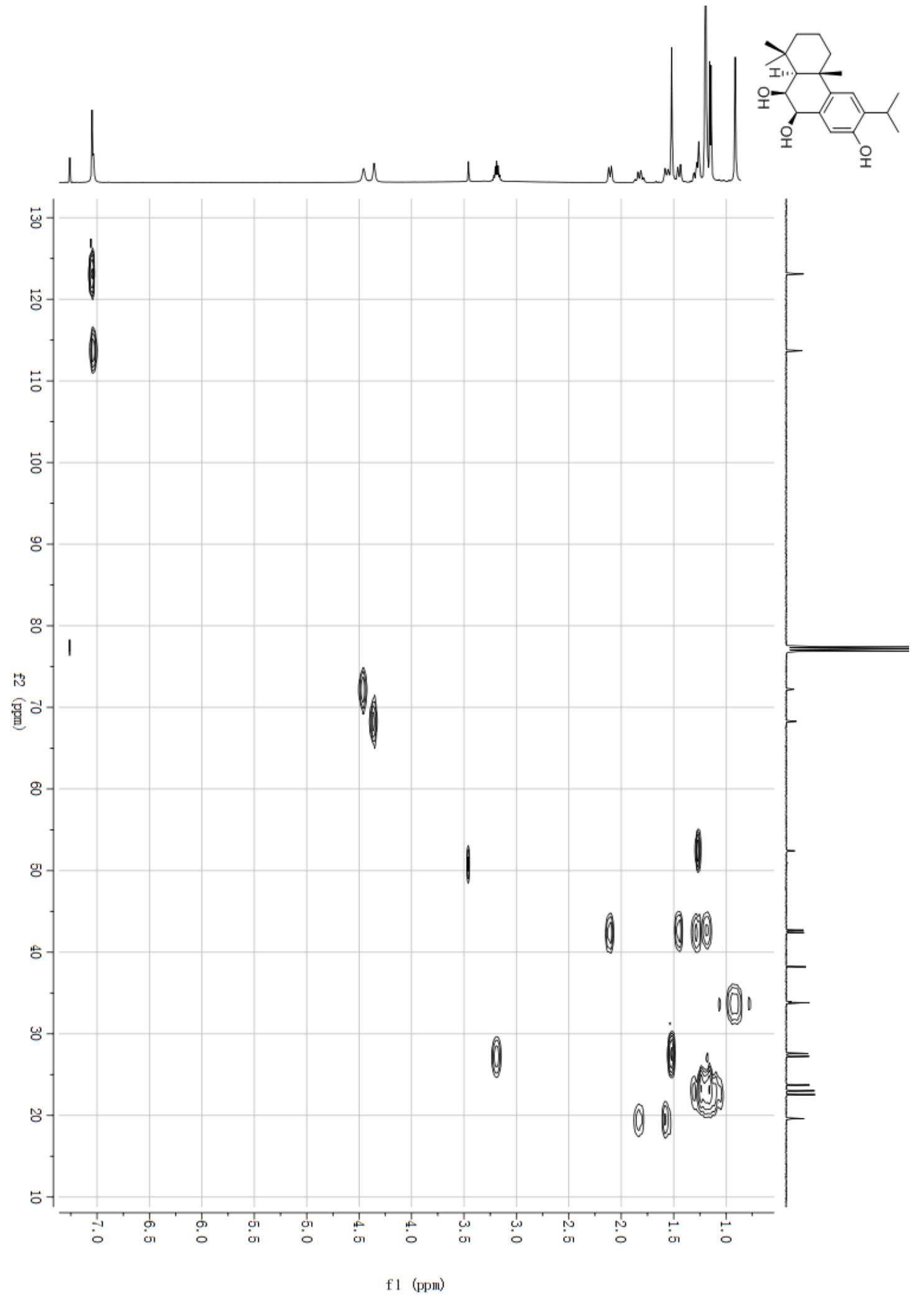


Figure S56. HMBC spectrum of $6 \beta, 7 \beta$-dihydroxysempervirol (7) in $\mathrm{CDCl}_{3}$

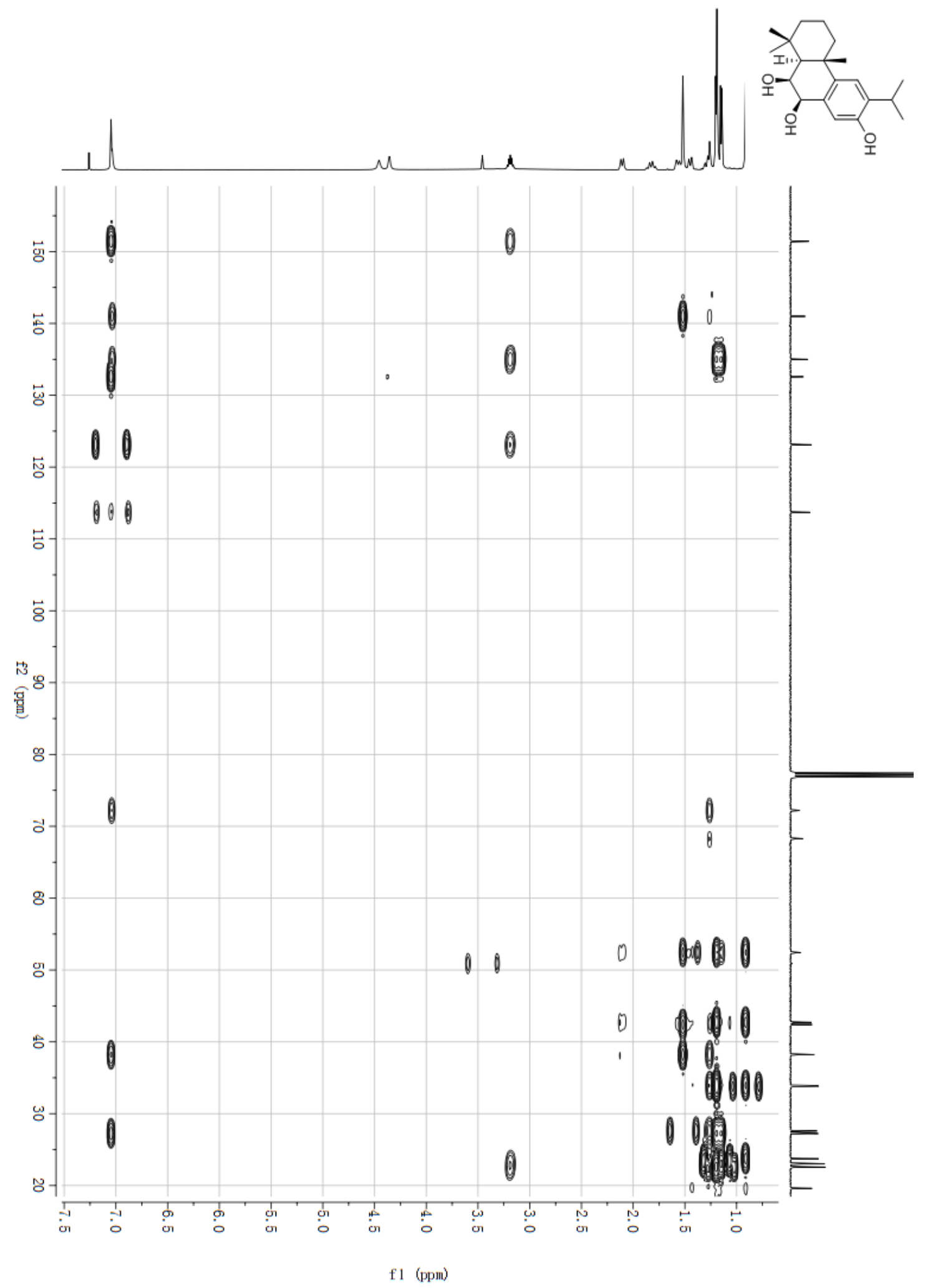


Figure S57. NOESY spectrum of $6 \beta, 7 \beta$-dihydroxysempervirol (7) in $\mathrm{CDCl}_{3}$

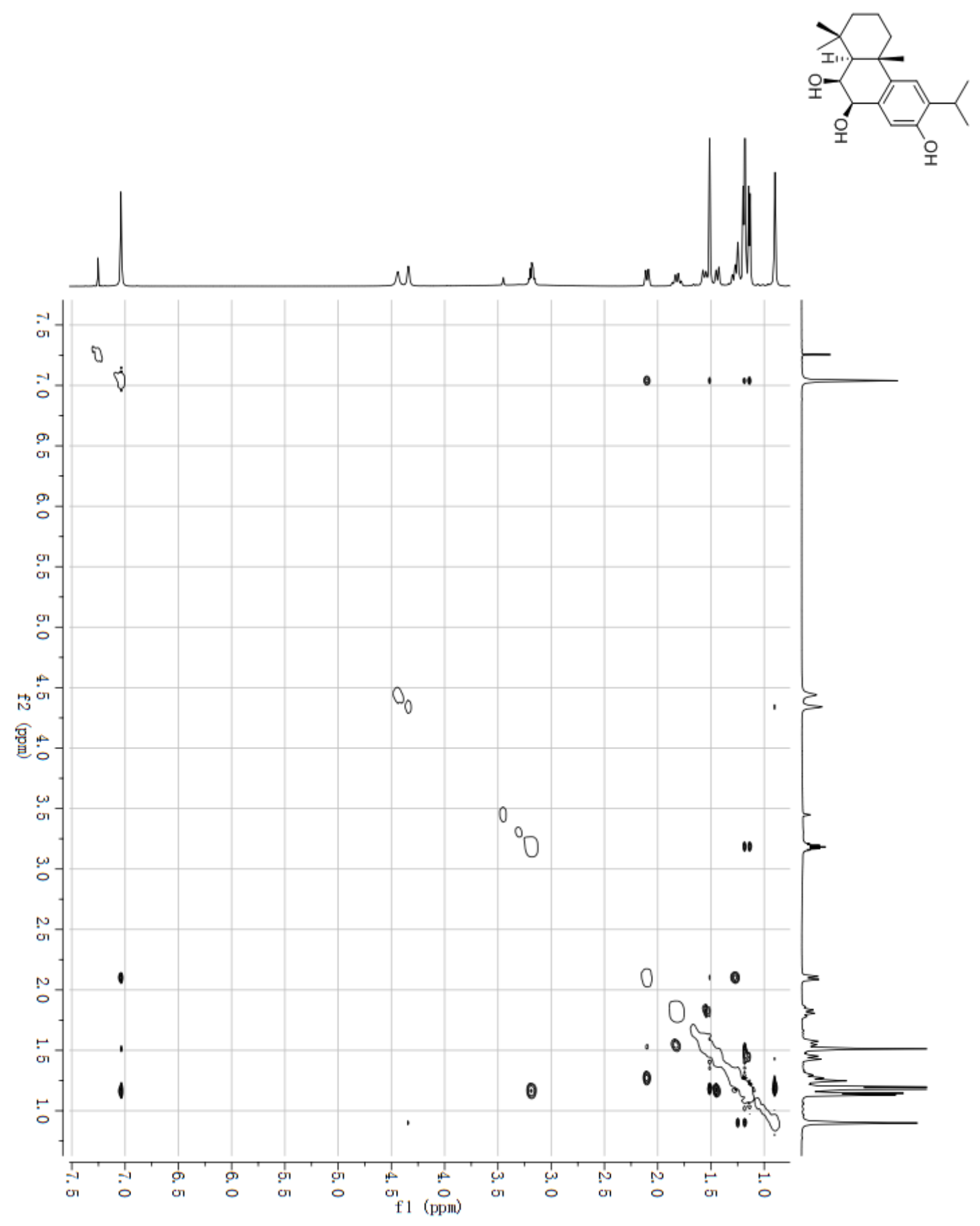


Figure S58. (+)-ESIMS spectrum of $6 \beta, 7 \beta$-dihydroxysempervirol (7)

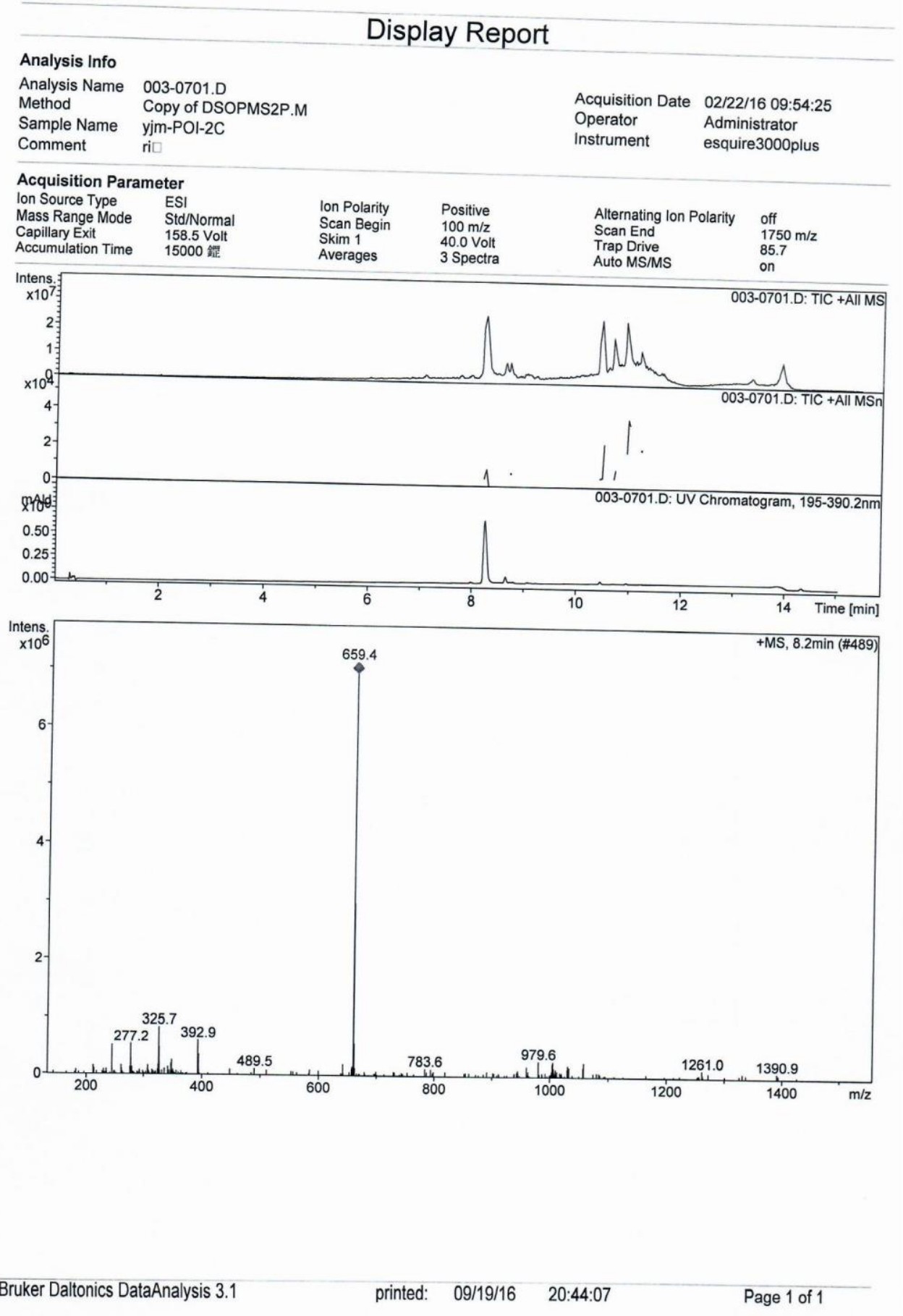


Figure S59. (-)-ESIMS spectrum of $6 \beta, 7 \beta$-dihydroxysempervirol (7)

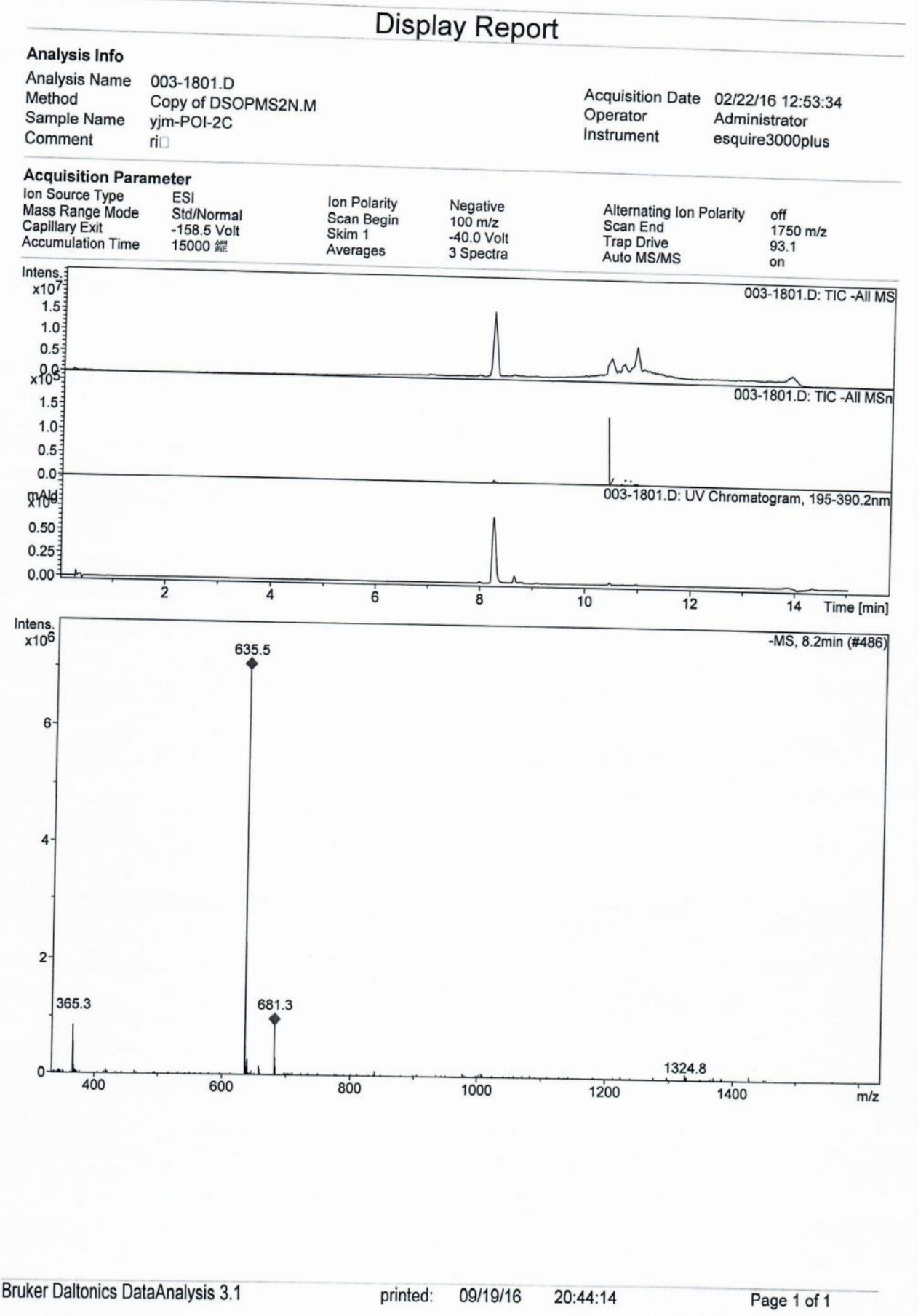


Figure S60. (-)-HRESIMS spectrum of $6 \beta, 7 \beta$-dihydroxysempervirol (7)

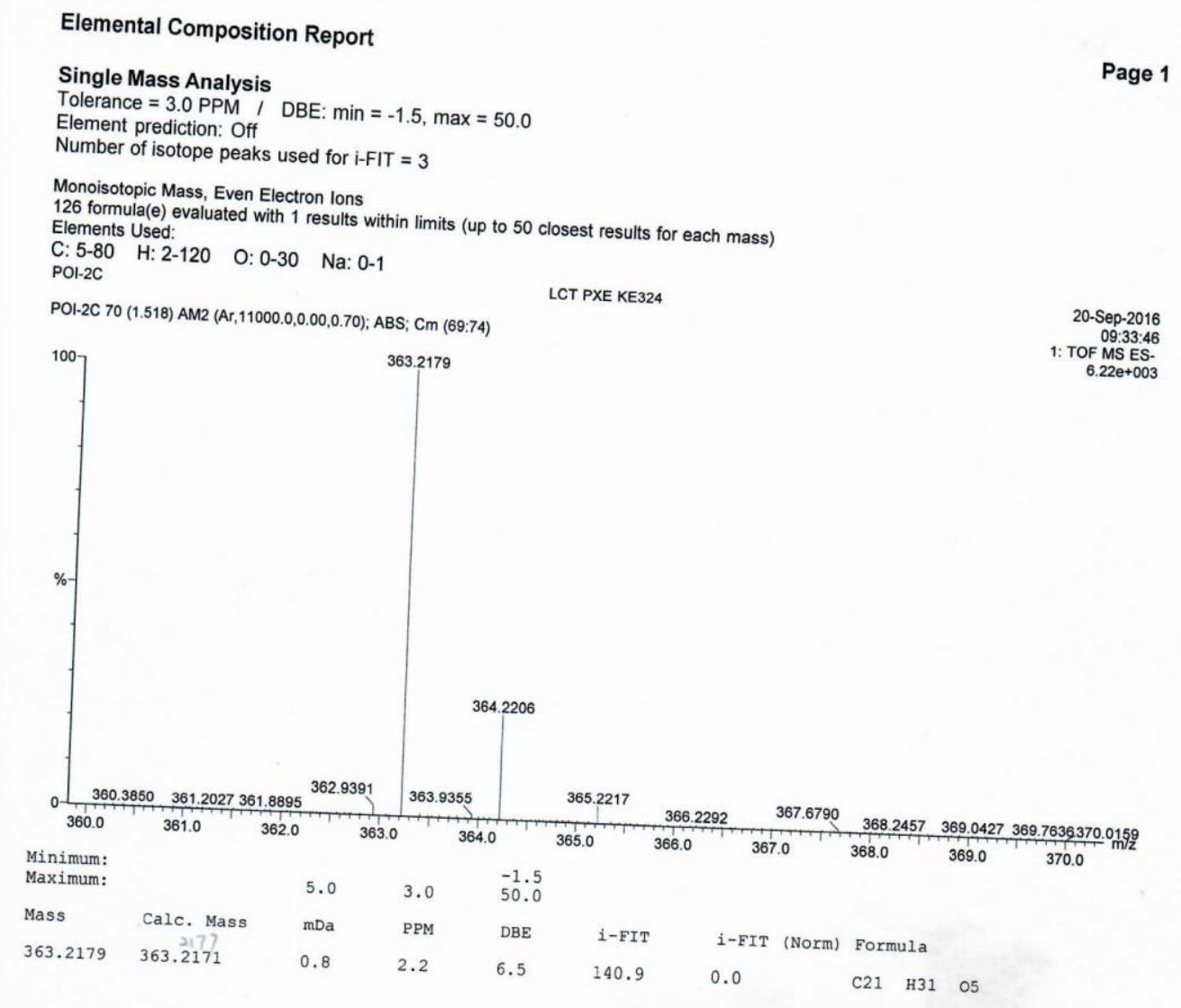


Figure S61. IR spectrum of $6 \beta, 7 \beta$-dihydroxysempervirol (7)

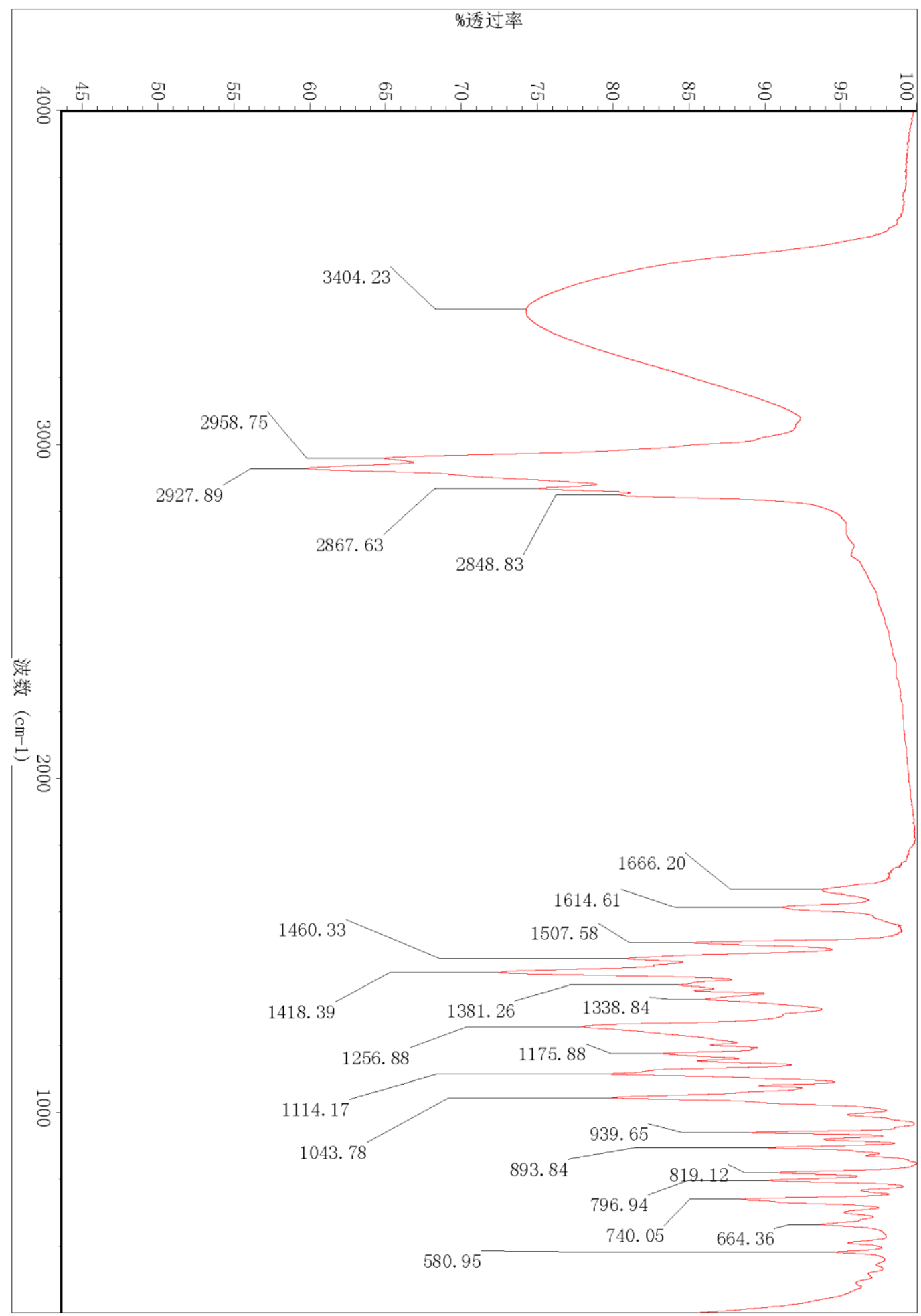


Figure S62. ${ }^{1} \mathrm{H}$ NMR spectrum of 6,7-dioxosempervirol (8) in $\mathrm{CDCl}_{3}$

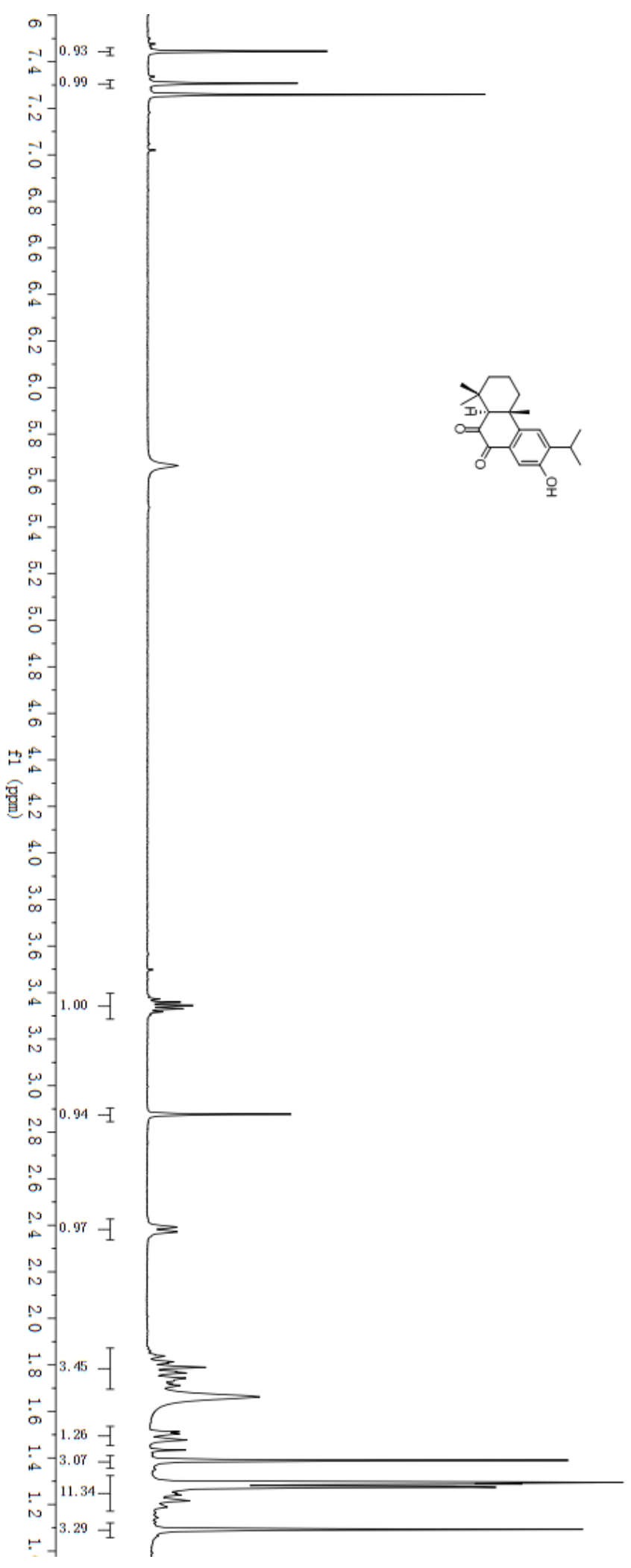

-3724.13
-3655.15

$-648.02$

$-646.19$

$-644.19$

639.28

$-637.32$

$-624.91$

620.83

- 611.31

608.04

5595.31

$\backslash 546.80$ 
Figure S63. ${ }^{13} \mathrm{C}$ NMR spectrum of 6,7-dioxosempervirol (8) in $\mathrm{CDCl}_{3}$

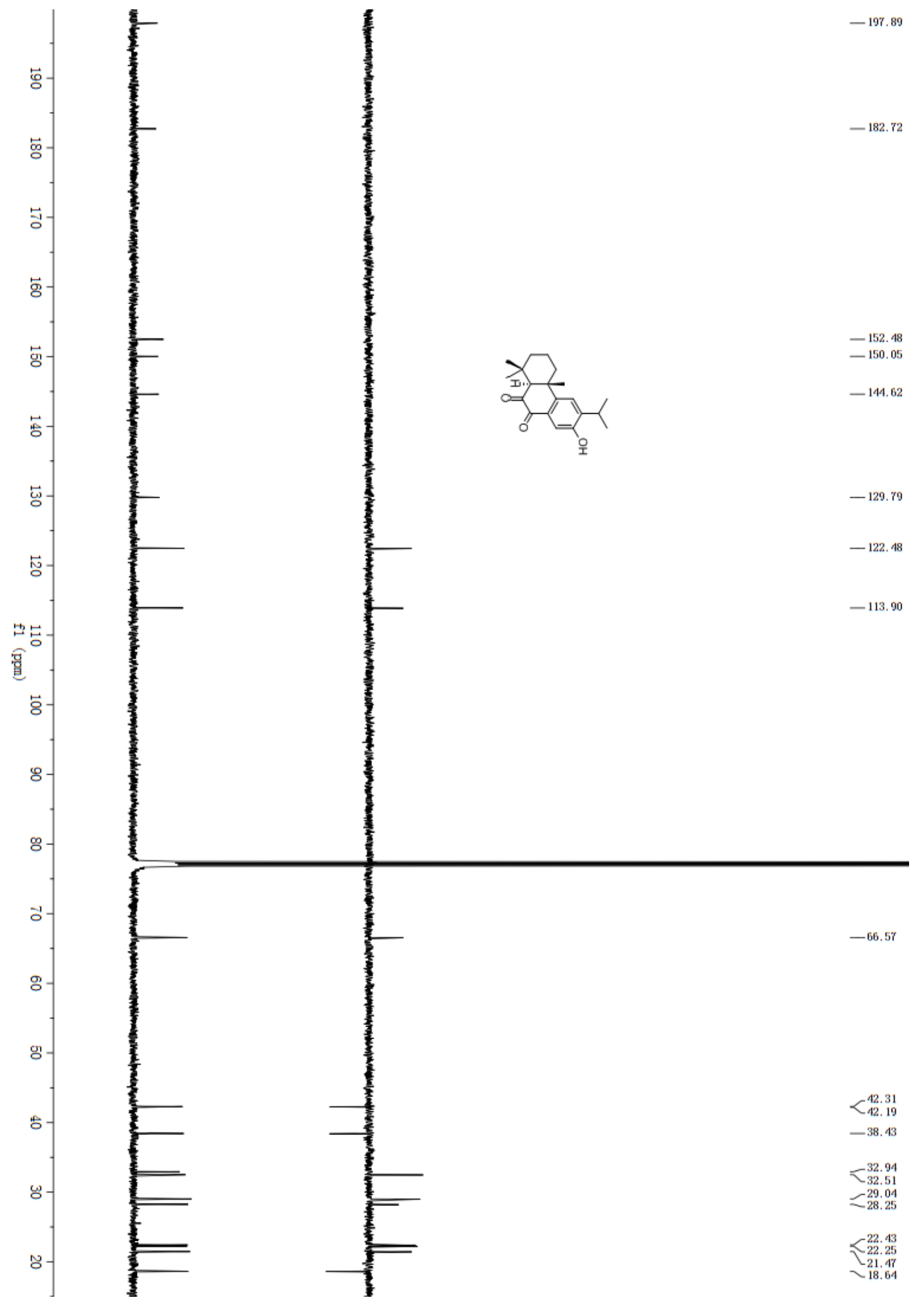


Figure S64. HSQC spectrum of 6,7-dioxosempervirol (8) in $\mathrm{CDCl}_{3}$

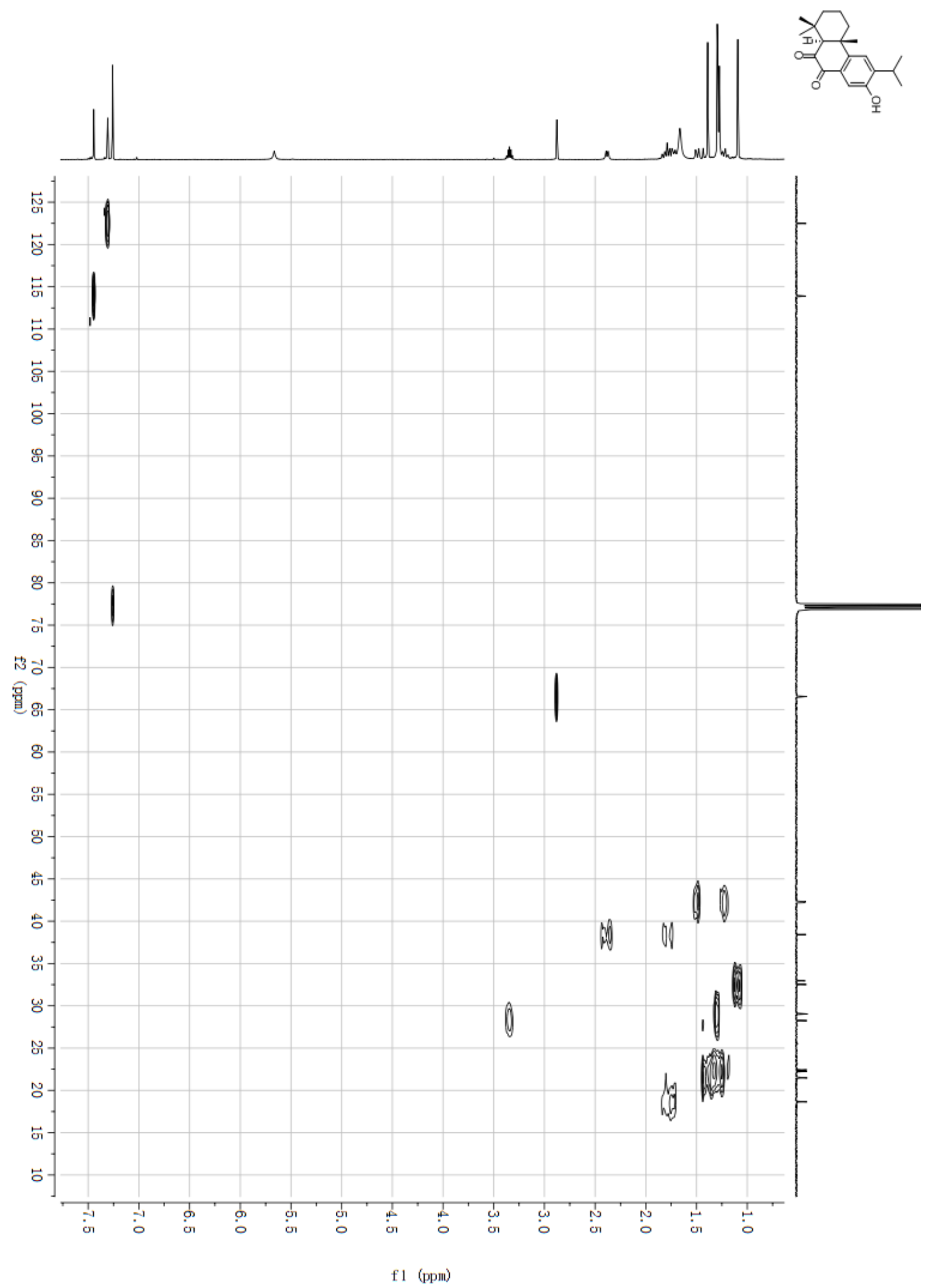


Figure S65. HMBC spectrum of 6,7-dioxosempervirol (8) in $\mathrm{CDCl}_{3}$

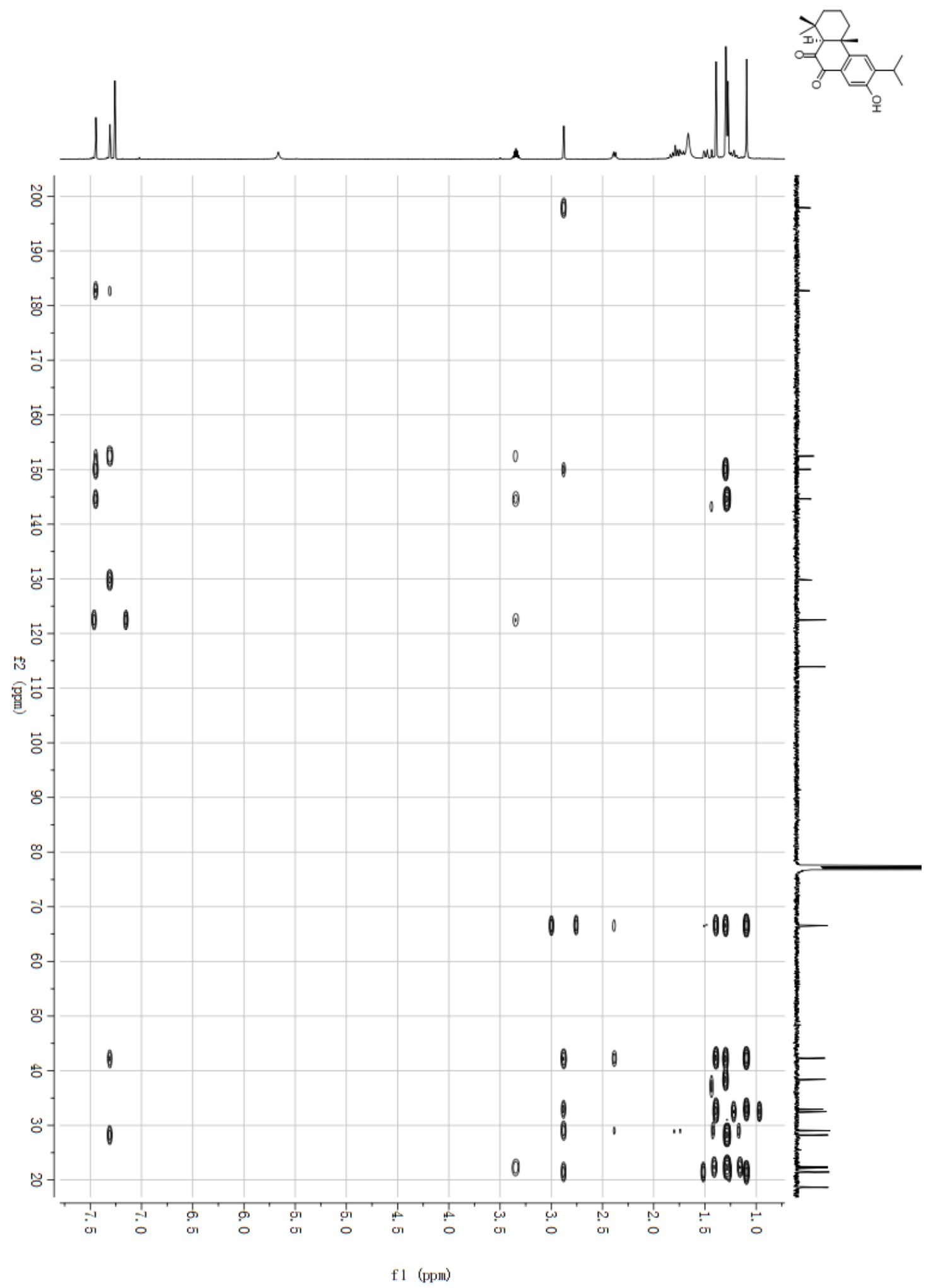


Figure S66. NOESY spectrum of 6,7-dioxosempervirol (8) in $\mathrm{CDCl}_{3}$
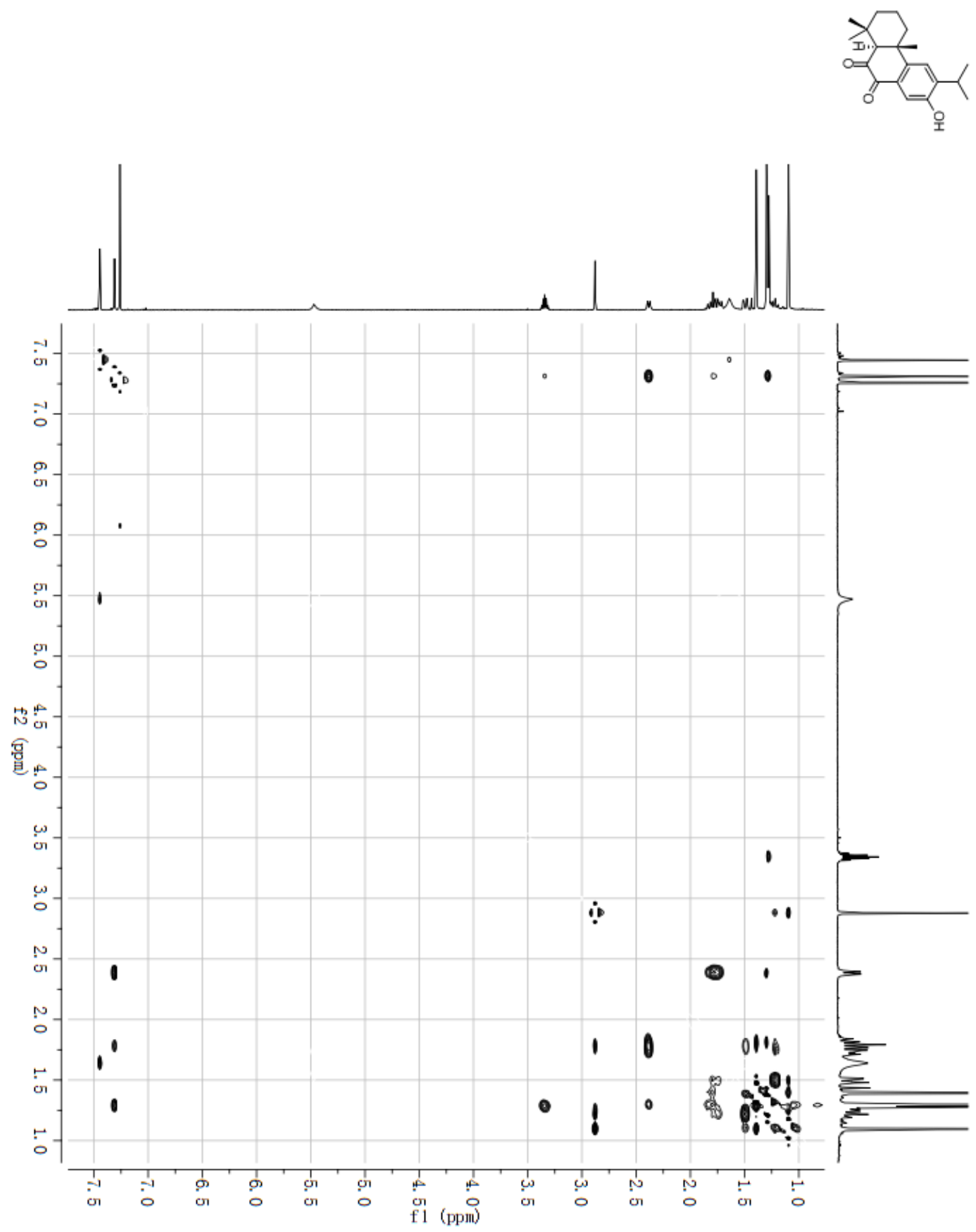
Figure S67. (+)-ESIMS spectrum of 6,7-dioxosempervirol (8)

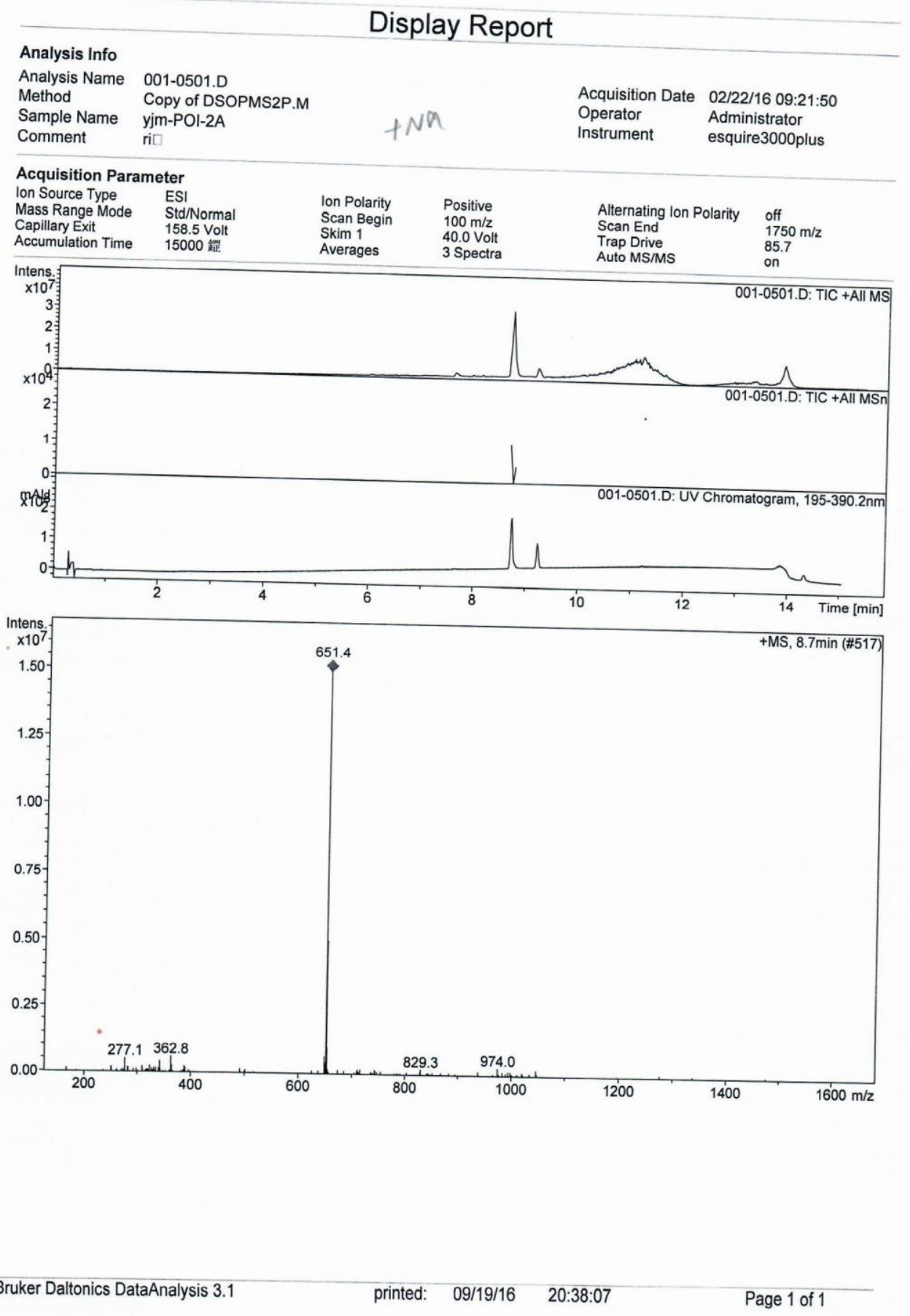


Figure S68. (-)-ESIMS spectrum of 6,7-dioxosempervirol (8)
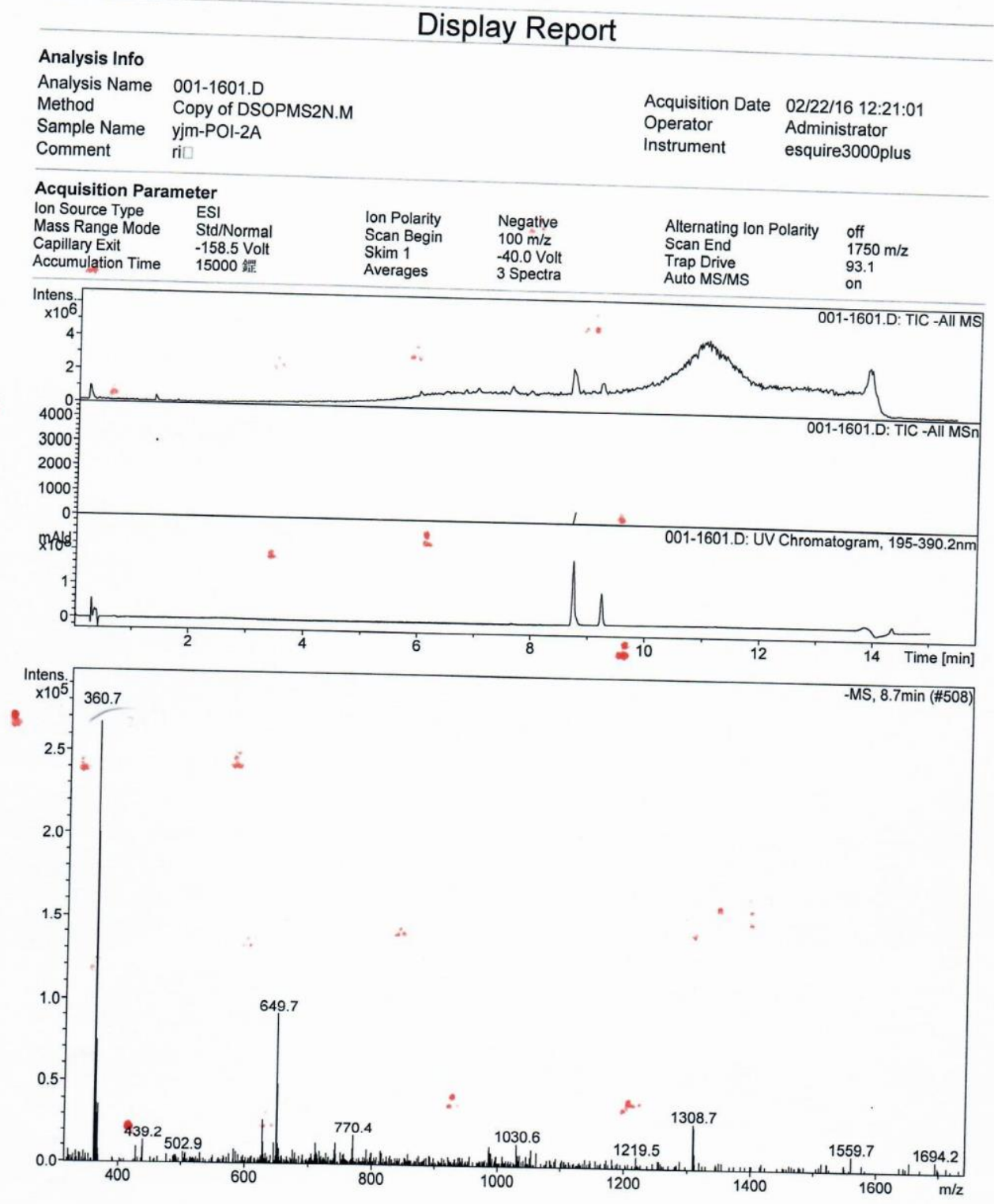
Figure S69. (+)-HRESIMS spectrum of 6,7-dioxosempervirol (8)

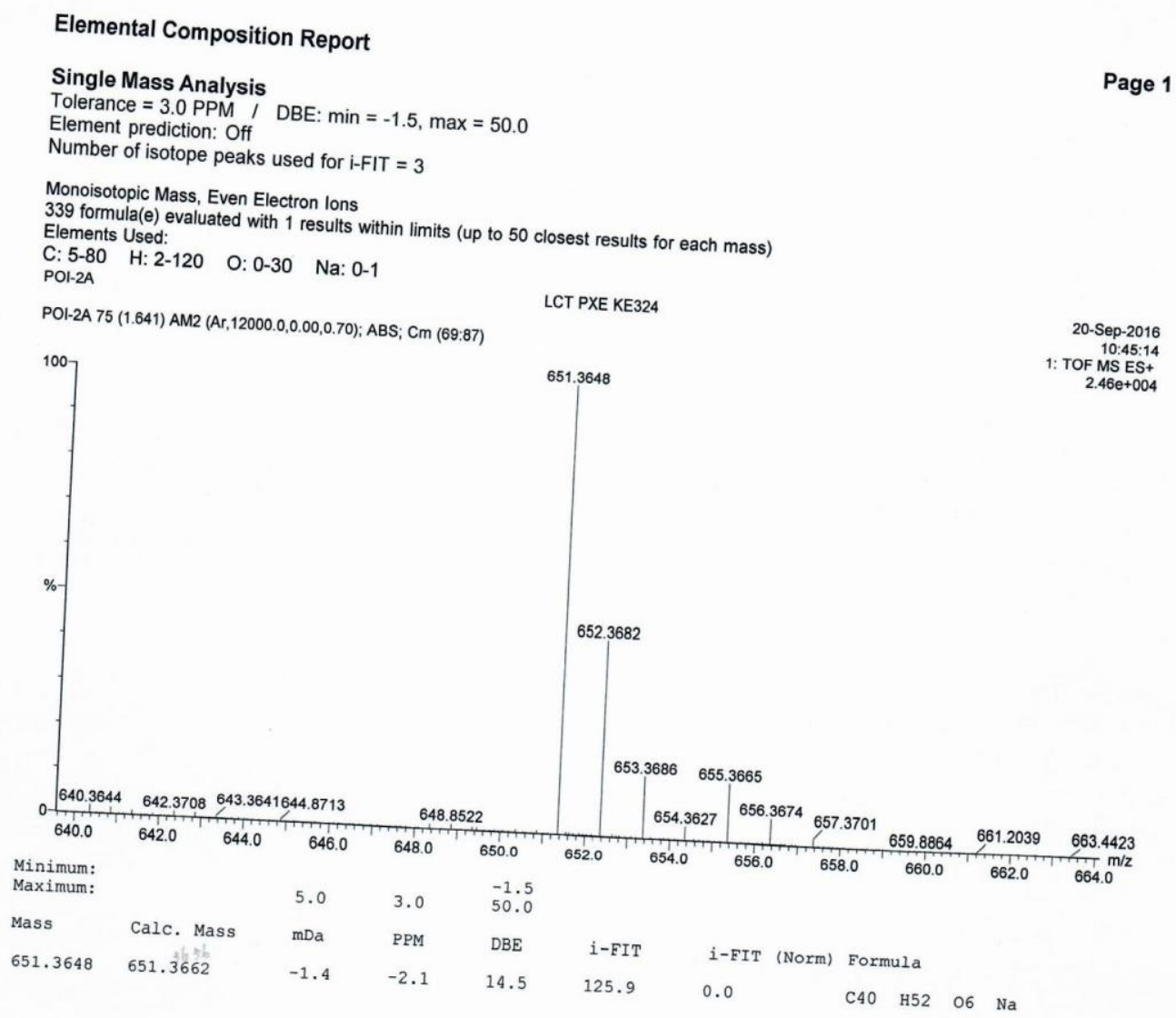


Figure S70. IR spectrum of 6,7-dioxosempervirol (8)

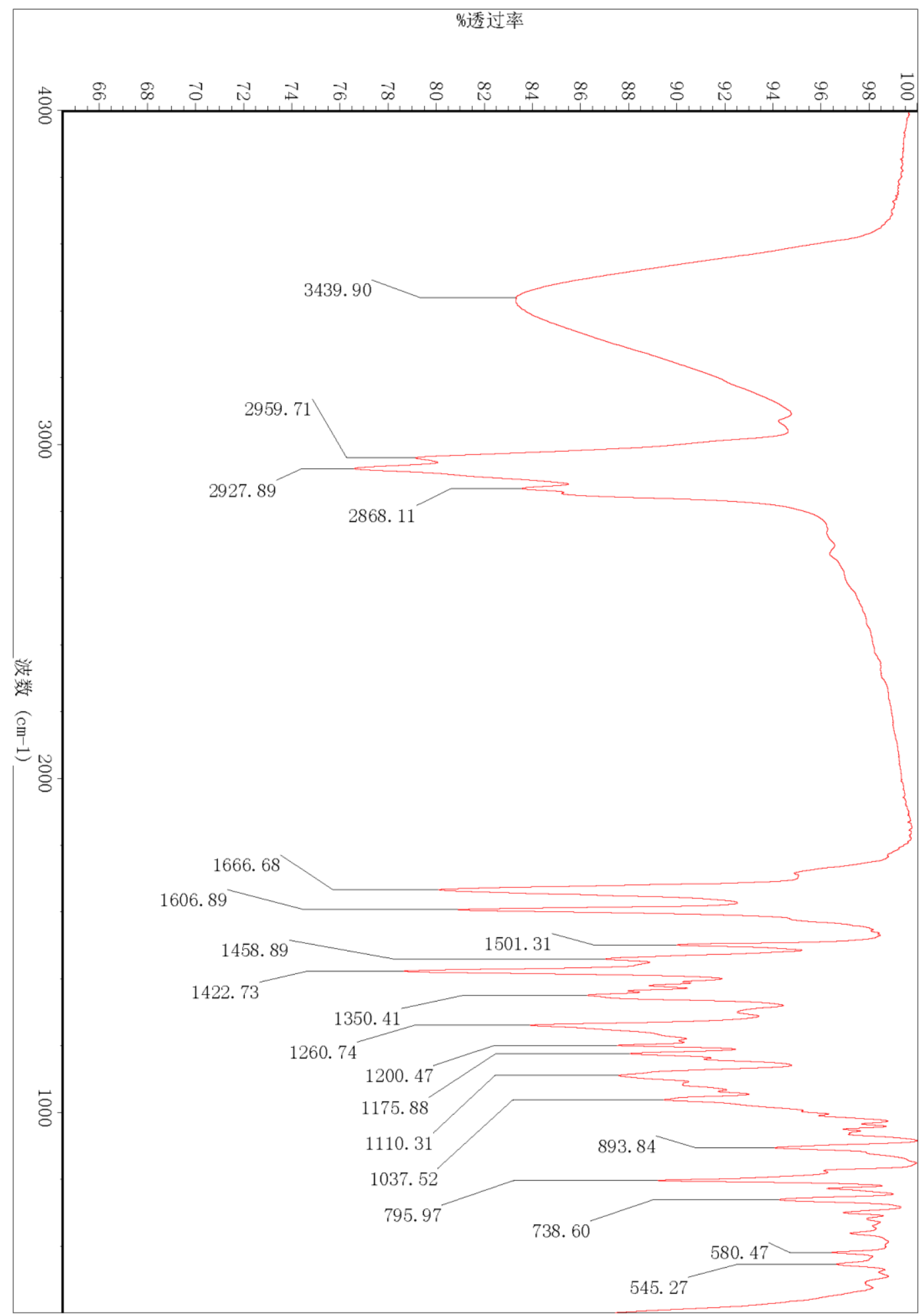


Figure S71. ${ }^{1} \mathrm{H}$ NMR spectrum of $6 \beta$-hydroxy-7 $\alpha$-methoxysempervirol (9) in $\mathrm{CDCl}_{3}$
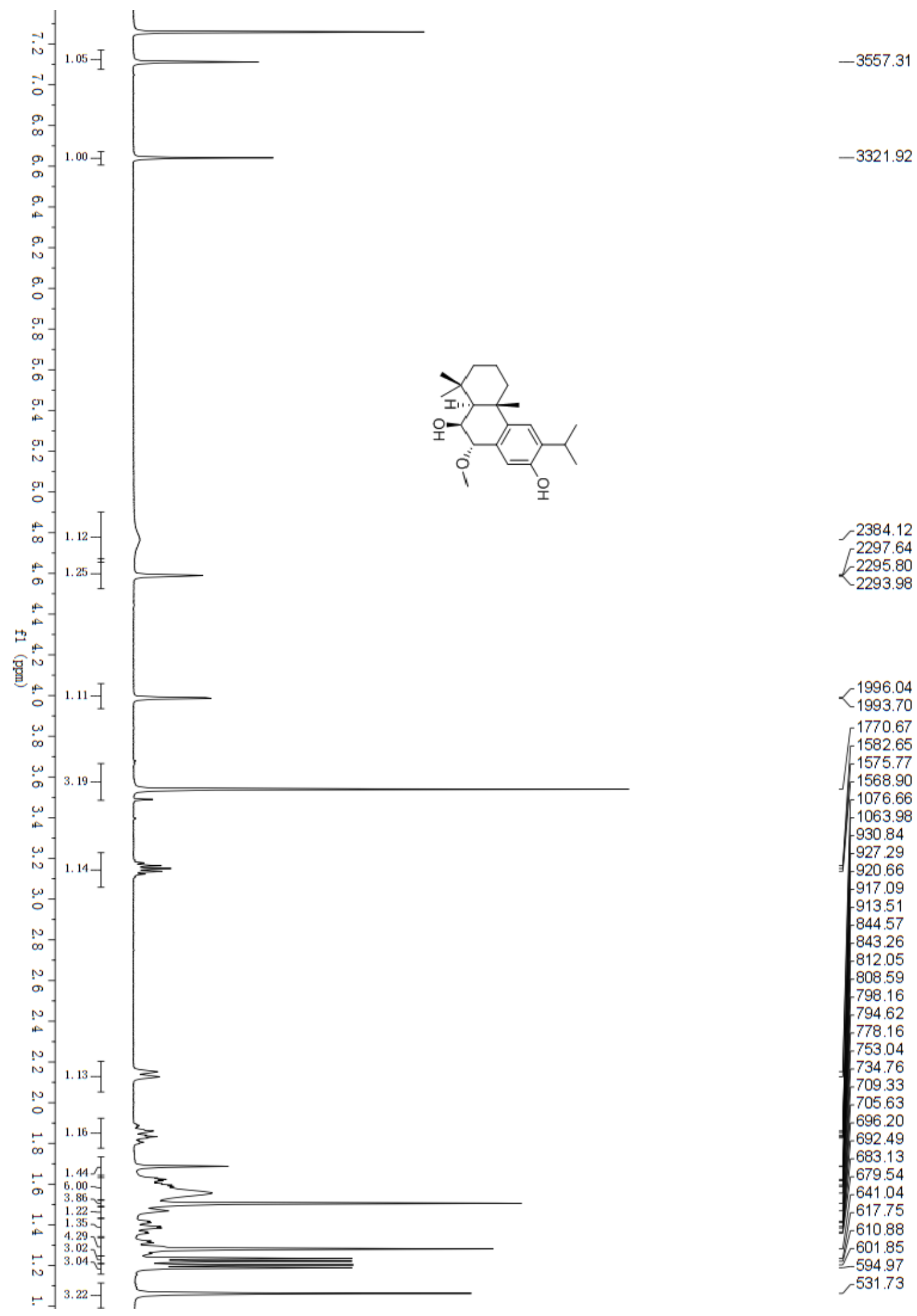

$-2384.12$

$-2295.80$

$<2293.98$

1996.04

1993.70

1770.67

1582.65

1575.77

$-1568.90$

$-1076.66$

1063.98

$-930.84$

$-927.29$

$-920.66$

$-917.09$

$-913.51$

$-844.57$

$-843.26$

$-812.05$

808.59

$-798.16$

$-794.62$

$-778.16$

$-753.04$

73476

$-709.33$

$-705.63$

$-696.20$

$-692.49$

$-683.13$

$-679.54$

.641 .04

617.75

-610.88

+ 601.85

$-594.97$

$-531.73$ 
Figure S72. ${ }^{13} \mathrm{C}$ NMR spectrum of $6 \beta$-hydroxy-7 $\alpha$-methoxysempervirol (9) in $\mathrm{CDCl}_{3}$

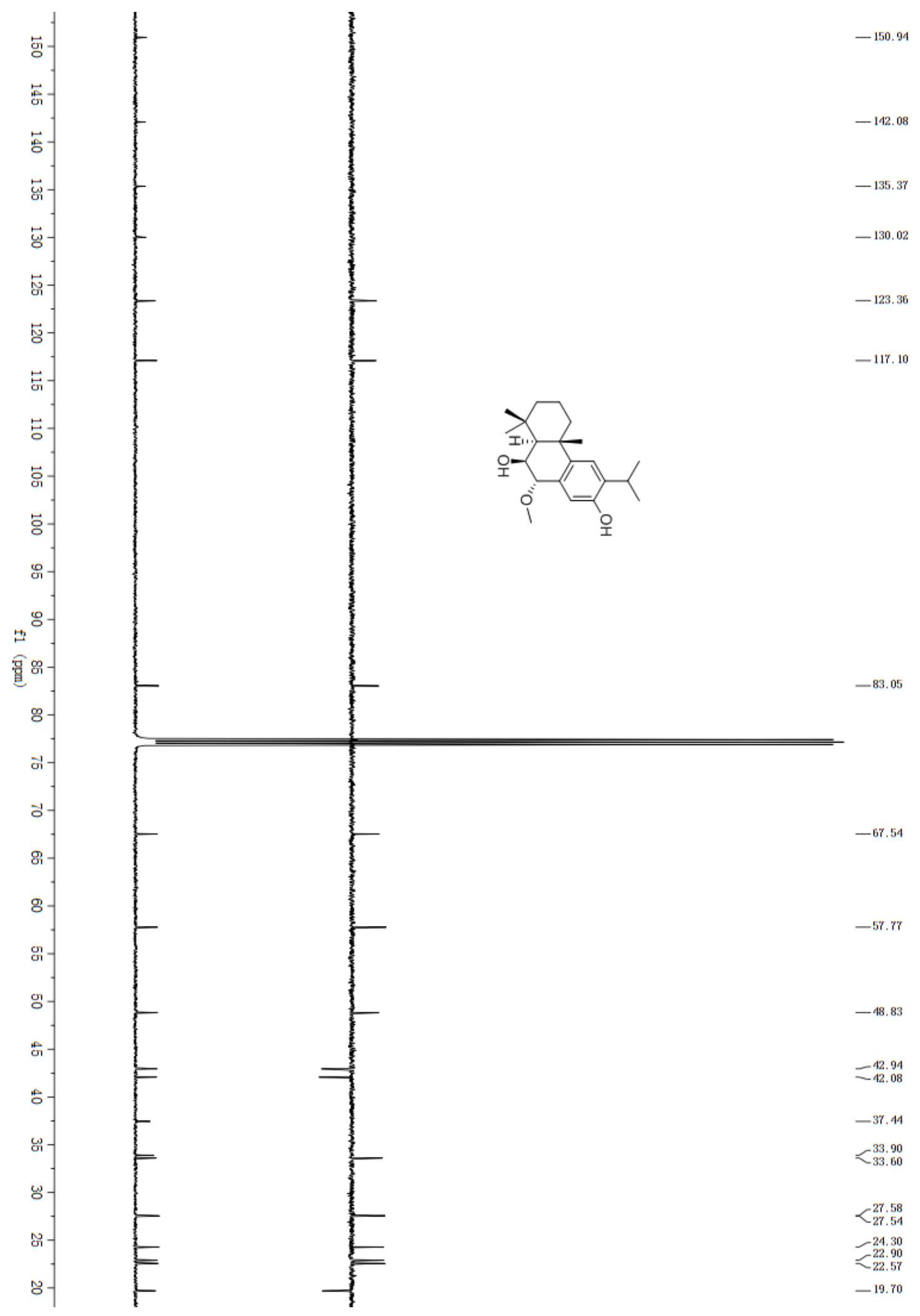


Figure S73. HSQC spectrum of $6 \beta$-hydroxy-7 $\alpha$-methoxysempervirol (9) in $\mathrm{CDCl}_{3}$

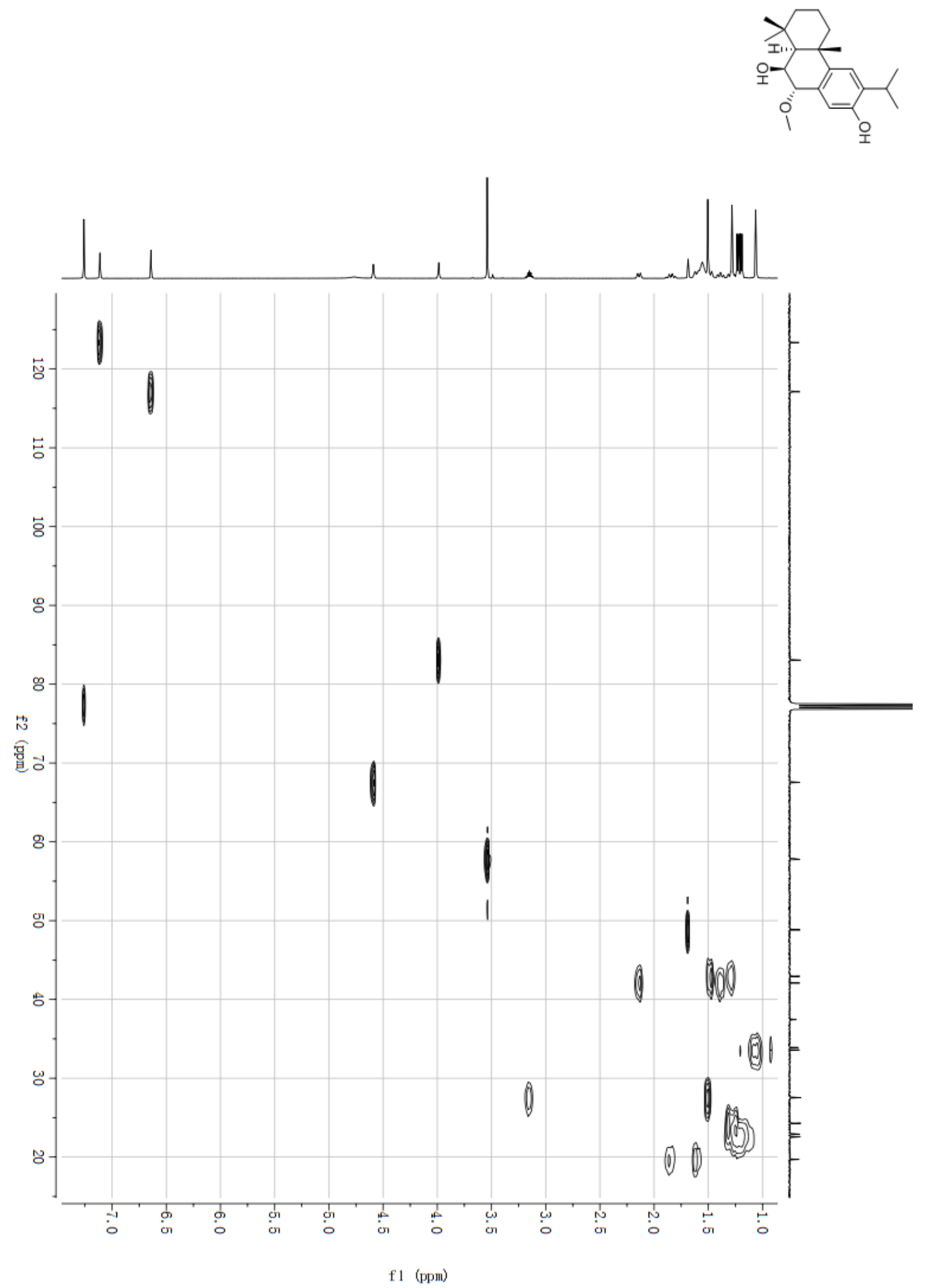


Figure S74. HMBC spectrum of $6 \beta$-hydroxy-7 $\alpha$-methoxysempervirol (9) in $\mathrm{CDCl}_{3}$

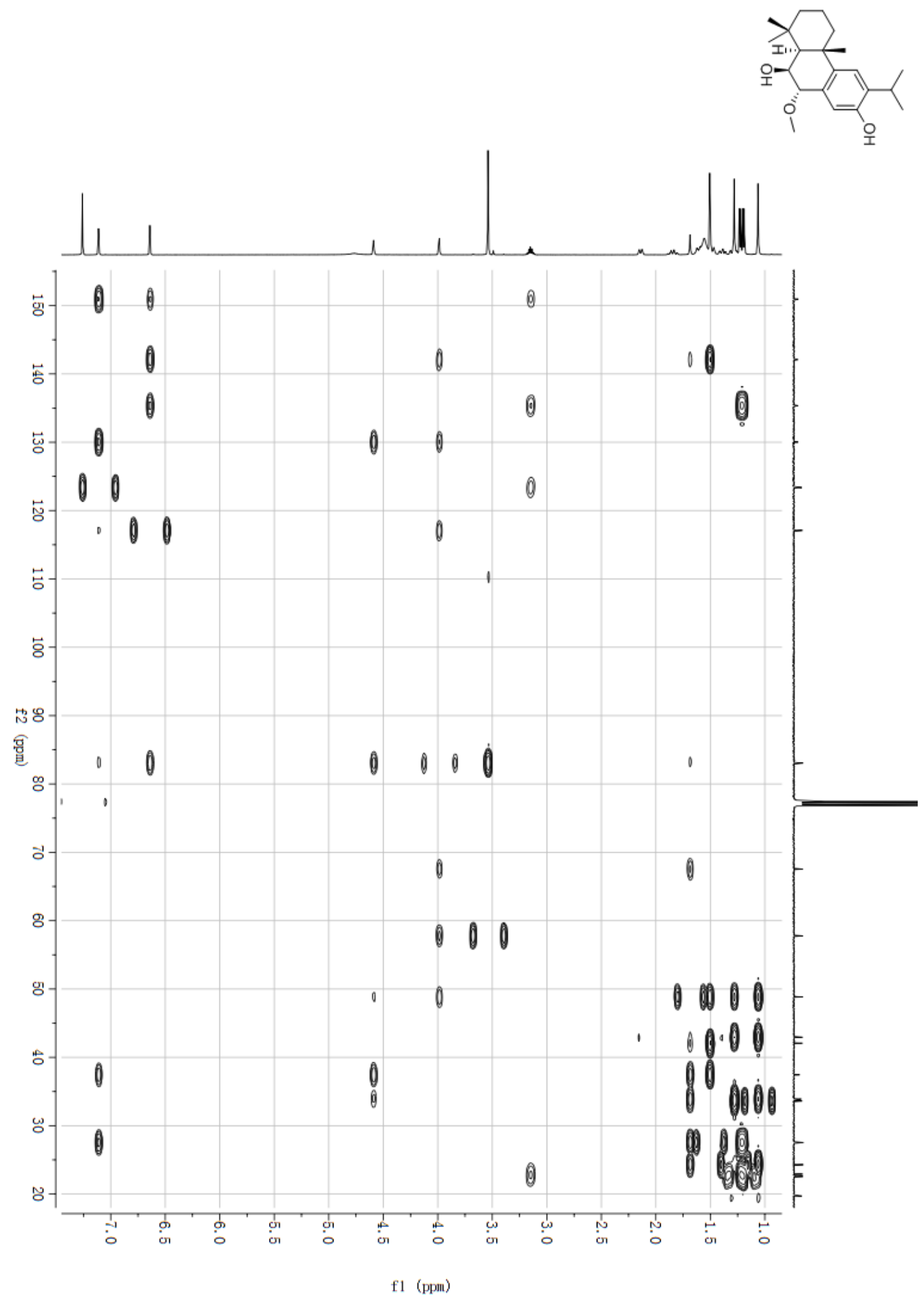


Figure S75. NOESY spectrum of $6 \beta$-hydroxy-7 $\alpha$-methoxysempervirol (9) in $\mathrm{CDCl}_{3}$

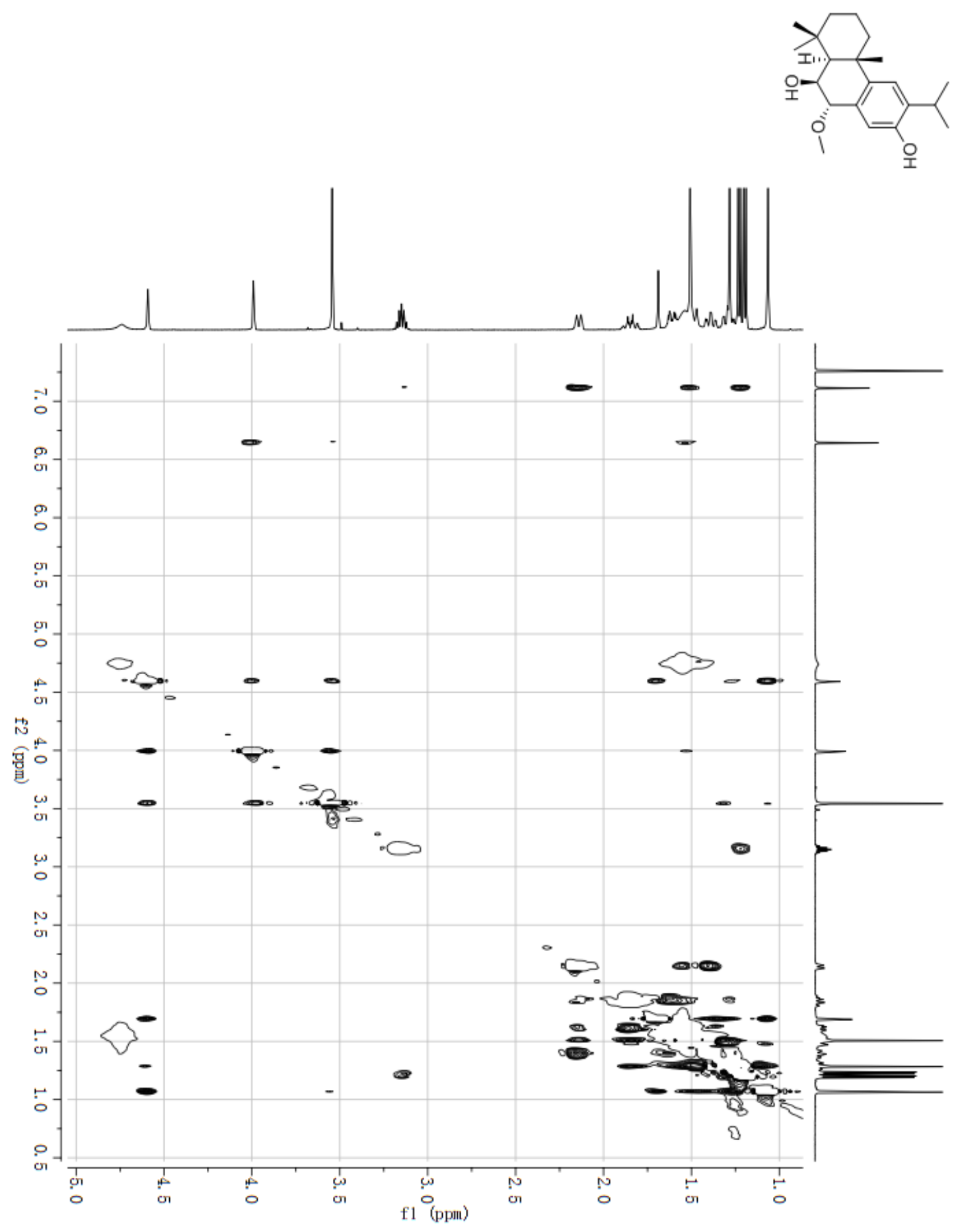


Figure S76. (+)-ESIMS spectrum of $6 \beta$-hydroxy-7 $\alpha$-methoxysempervirol (9)

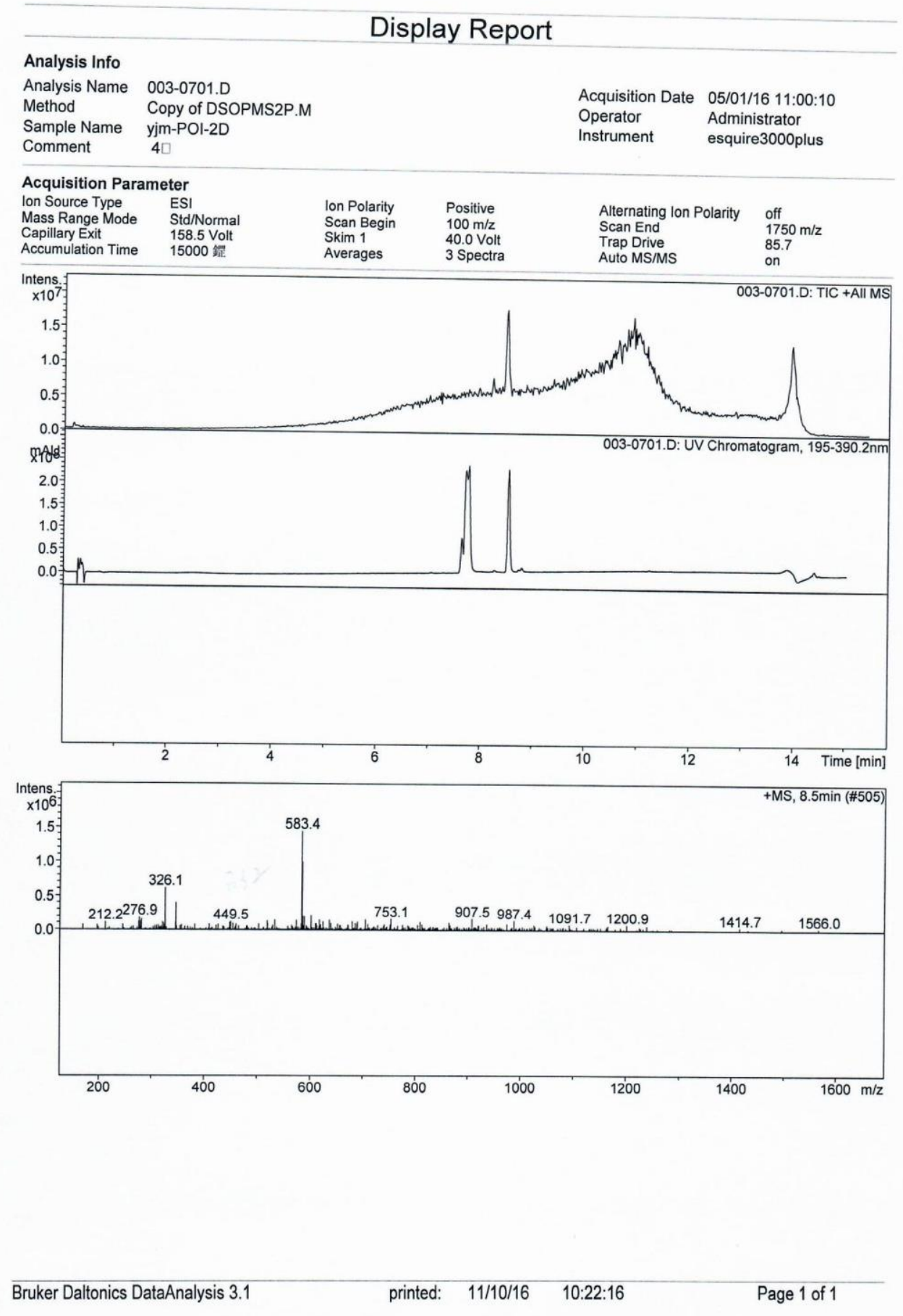


Figure S77. (-)-ESIMS spectrum of $6 \beta$-hydroxy-7 $\alpha$-methoxysempervirol (9)

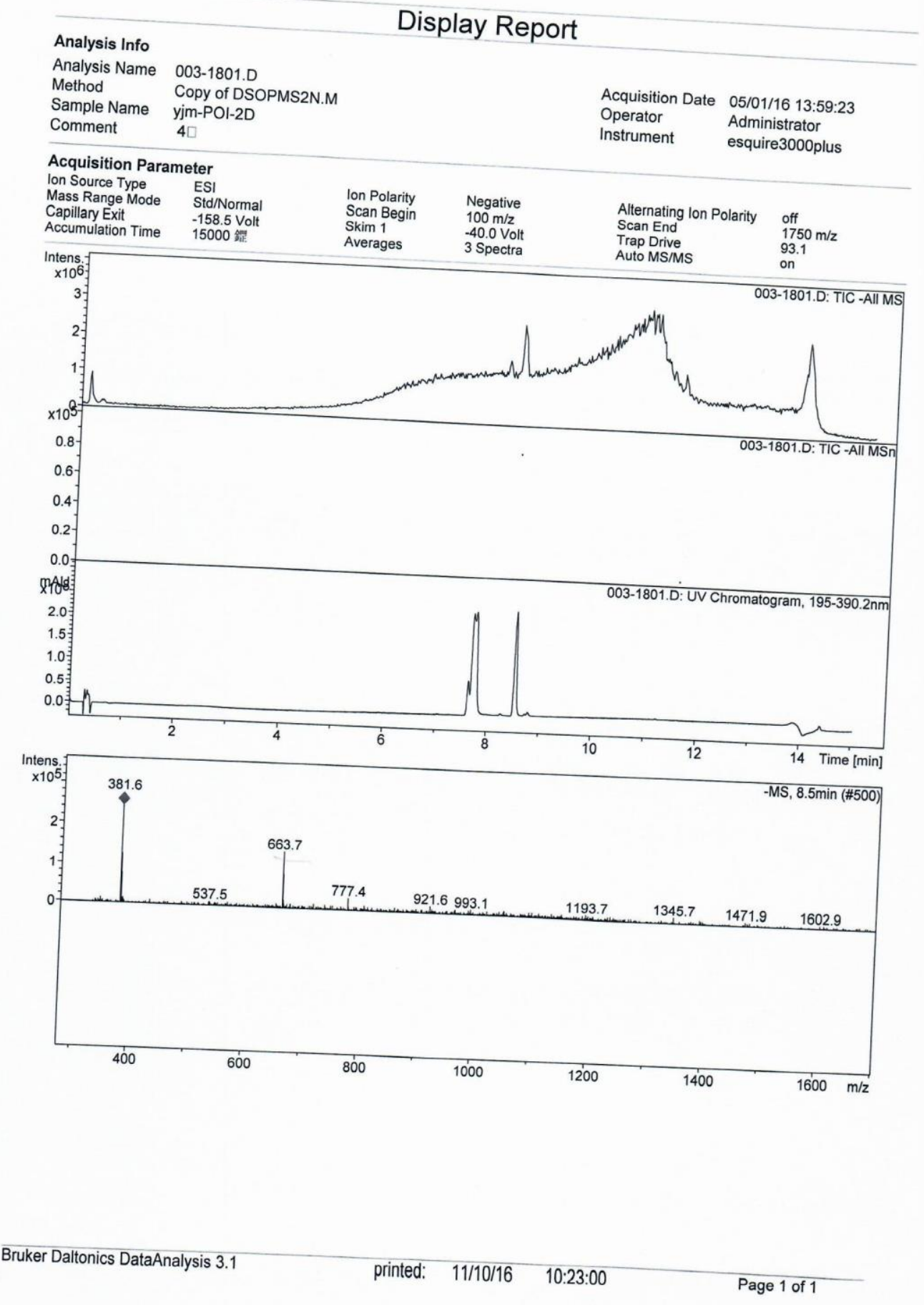


Figure S78. (-)-HRESIMS spectrum of $6 \beta$-hydroxy-7 $\alpha$-methoxysempervirol (9)

Elemental Composition Report

Page 1

Single Mass Analysis

Tolerance $=3.0$ PPM / DBE: $\min =-1.5, \max =50.0$

Element prediction: Off

Number of isotope peaks used for i-FIT $=3$

Monoisotopic Mass, Even Electron lons

107 formula(e) evaluated with 1 results within limits (up to 50 closest results for each mass)

Elements Used:

$\begin{array}{llll}\text { C: } 5-80 & \text { H: } 2-120 & \text { O: } 0-30 & \mathrm{Na}: 0-1\end{array}$

LCT PXE KE324

29-Oct-2016

13:35:48

POI-2D $13(0.246)$ AM2 (Ar, 10000.0,0.00,1.00); ABS; Cm (13:22)

1: TOF MS ES-
$4.78 \mathrm{e}+003$

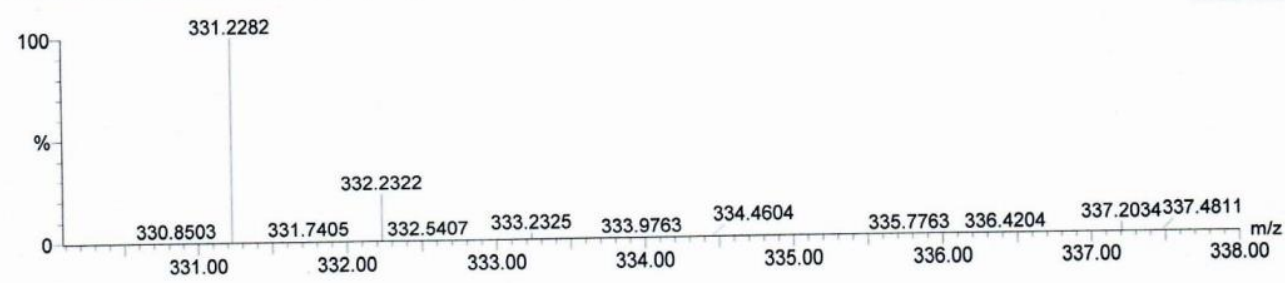

Minimum:

331.00

332.00

$333.00 \quad 334.00$

Maximum:

$5.0 \quad 3.0$

-1.5
50.0

Mass

Calc. Mass

$\mathrm{mDa} \quad \mathrm{PPM}$

DBE

331.2282

331.2273

0.9

2.7

6.5

97.9

0.0

$\begin{array}{lll}\mathrm{C} 21 & \mathrm{H} 31 & \mathrm{O} 3\end{array}$ 
Figure S79. IR spectrum of $6 \beta$-hydroxy-7 $\alpha$-methoxysempervirol (9)

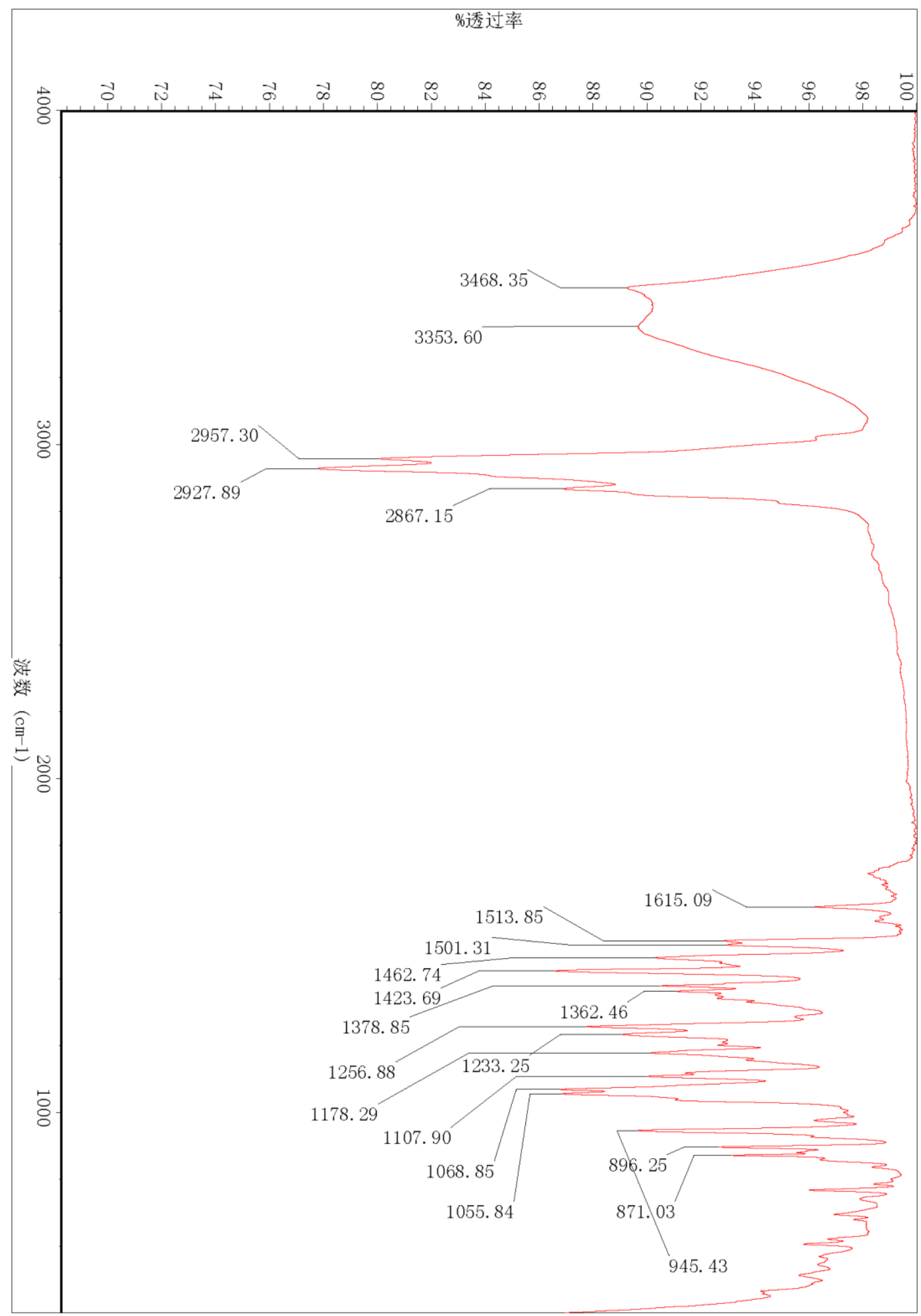


Figure S80. ${ }^{1} \mathrm{H}$ NMR spectrum of $1 \beta, 18$-dihydroxytotarol (10) in $\mathrm{CDCl}_{3}$

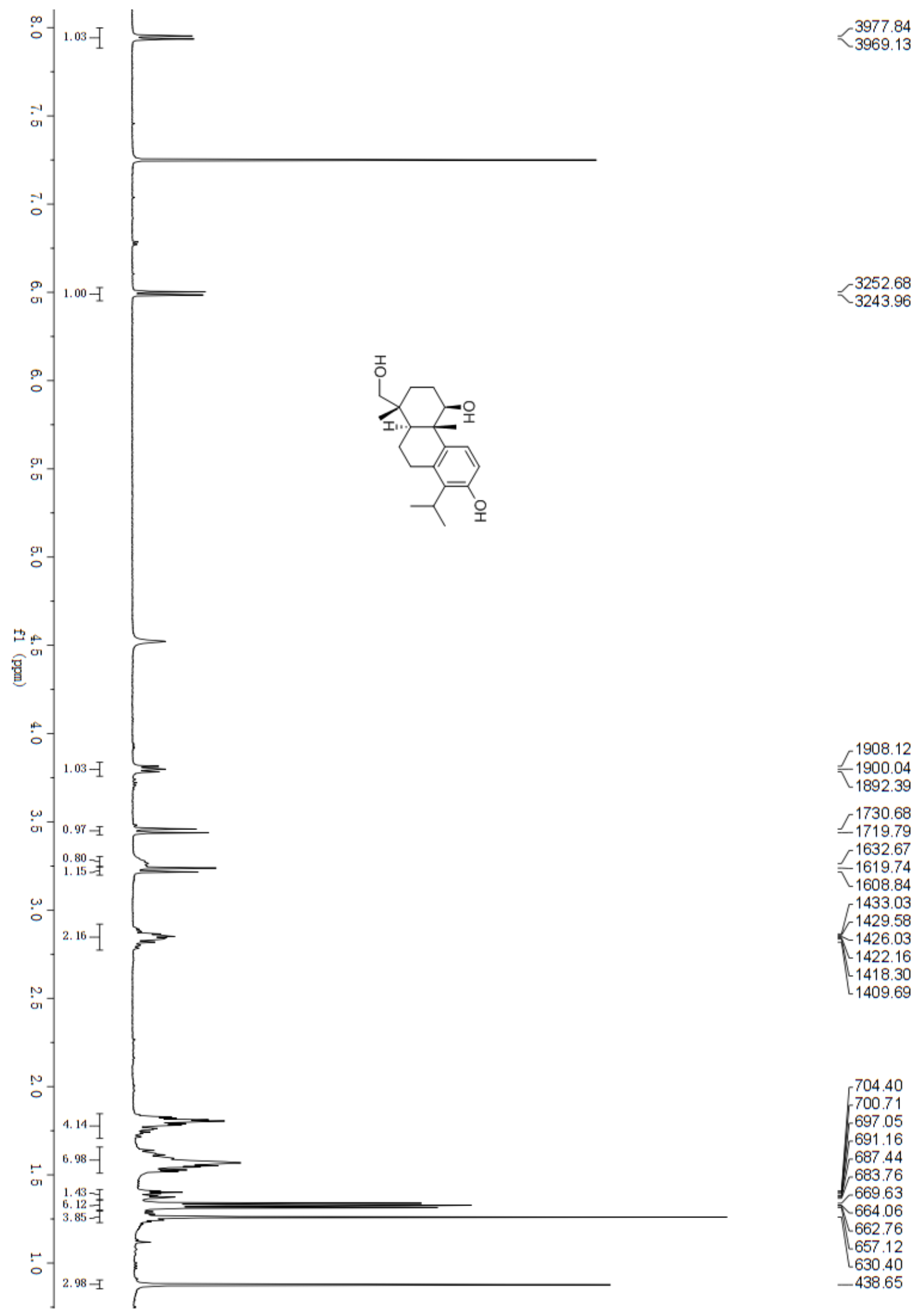


Figure S81. ${ }^{13} \mathrm{C}$ NMR spectrum of $1 \beta, 18$-dihydroxytotarol (10) in $\mathrm{CDCl}_{3}$

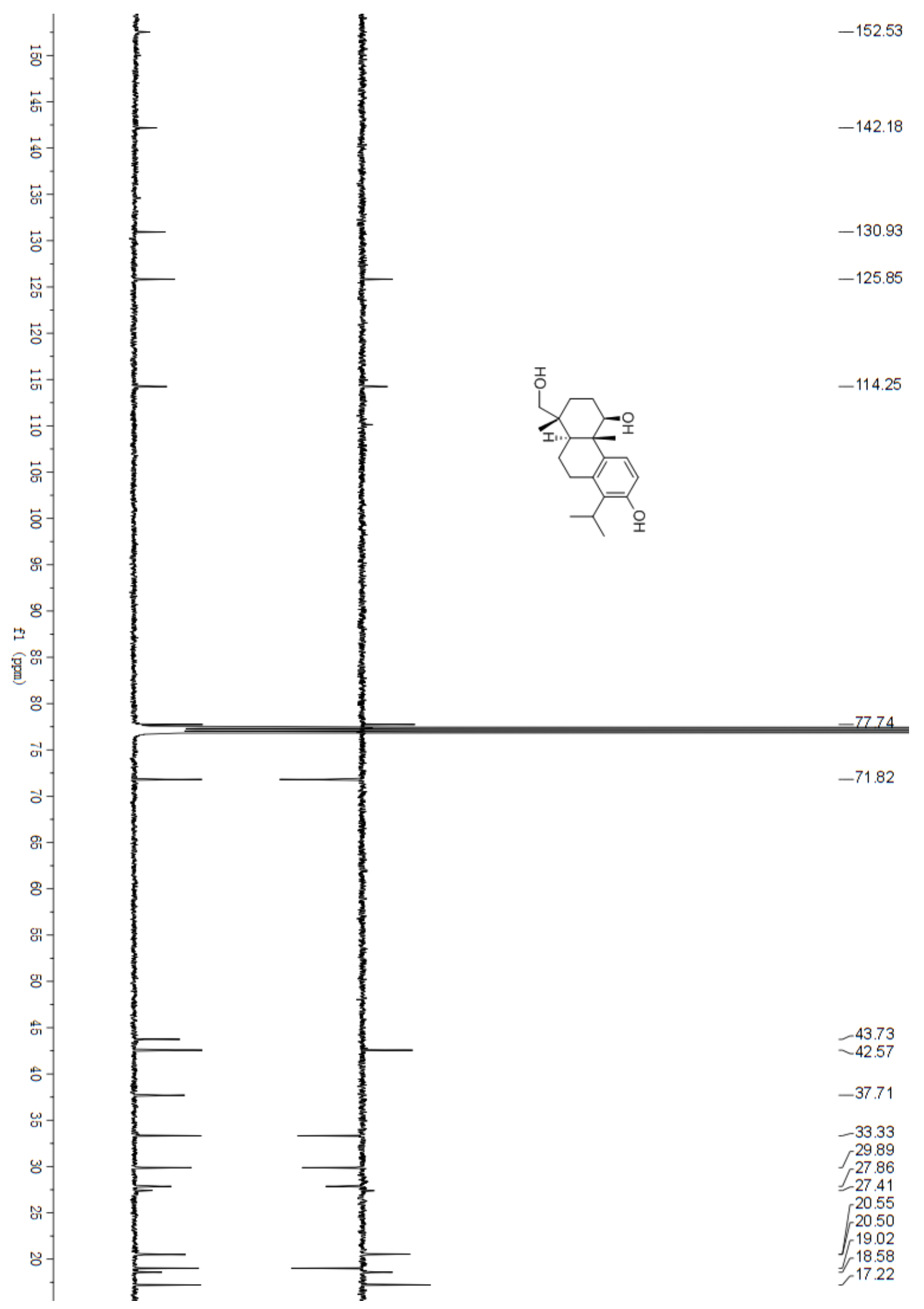


Figure S82. ${ }^{1} \mathrm{H}-{ }^{1} \mathrm{H}$ COSY spectrum of $1 \beta, 18$-dihydroxytotarol (10) in $\mathrm{CDCl}_{3}$

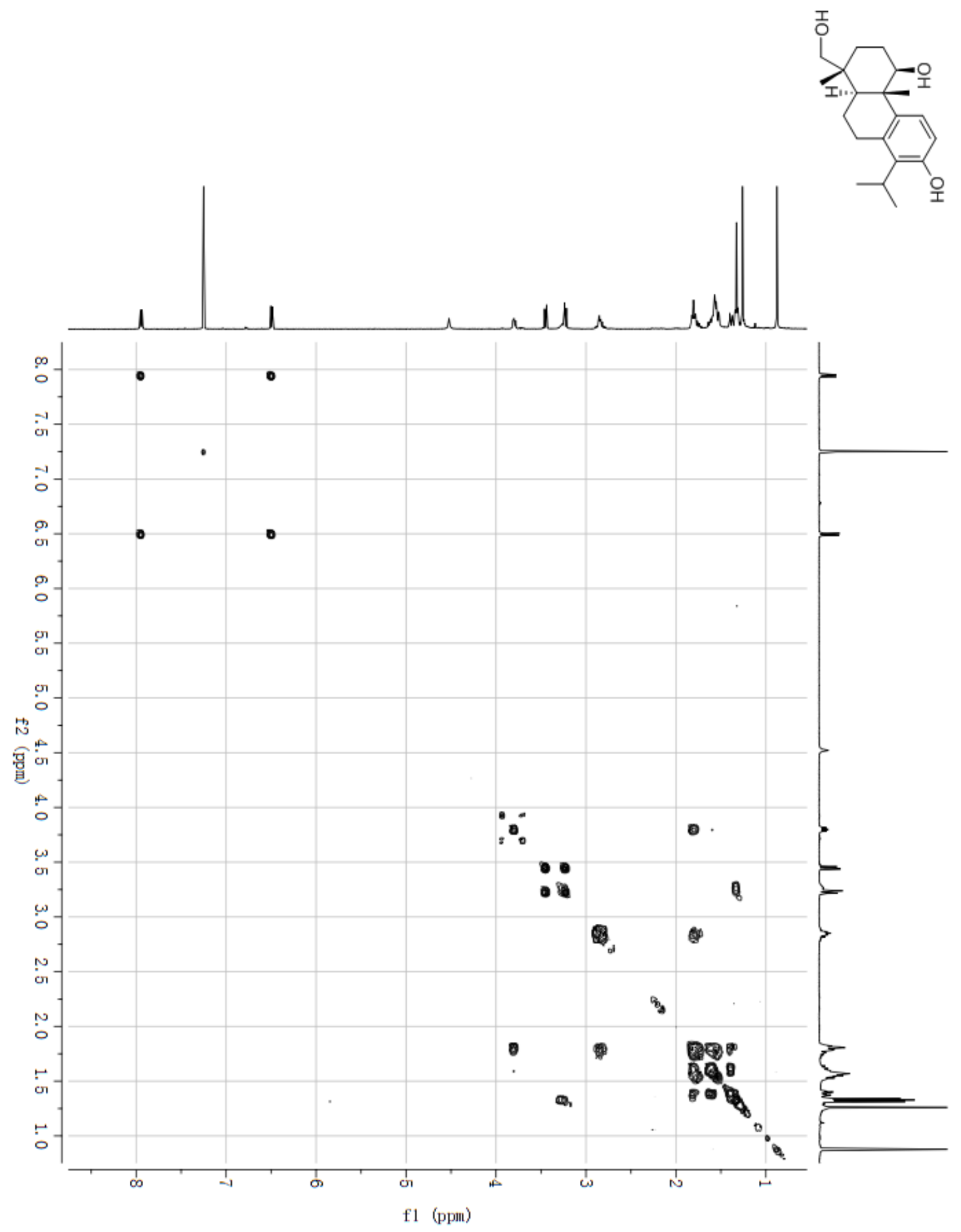


Figure S83. HSQC spectrum of $1 \beta$,18-dihydroxytotarol (10) in $\mathrm{CDCl}_{3}$

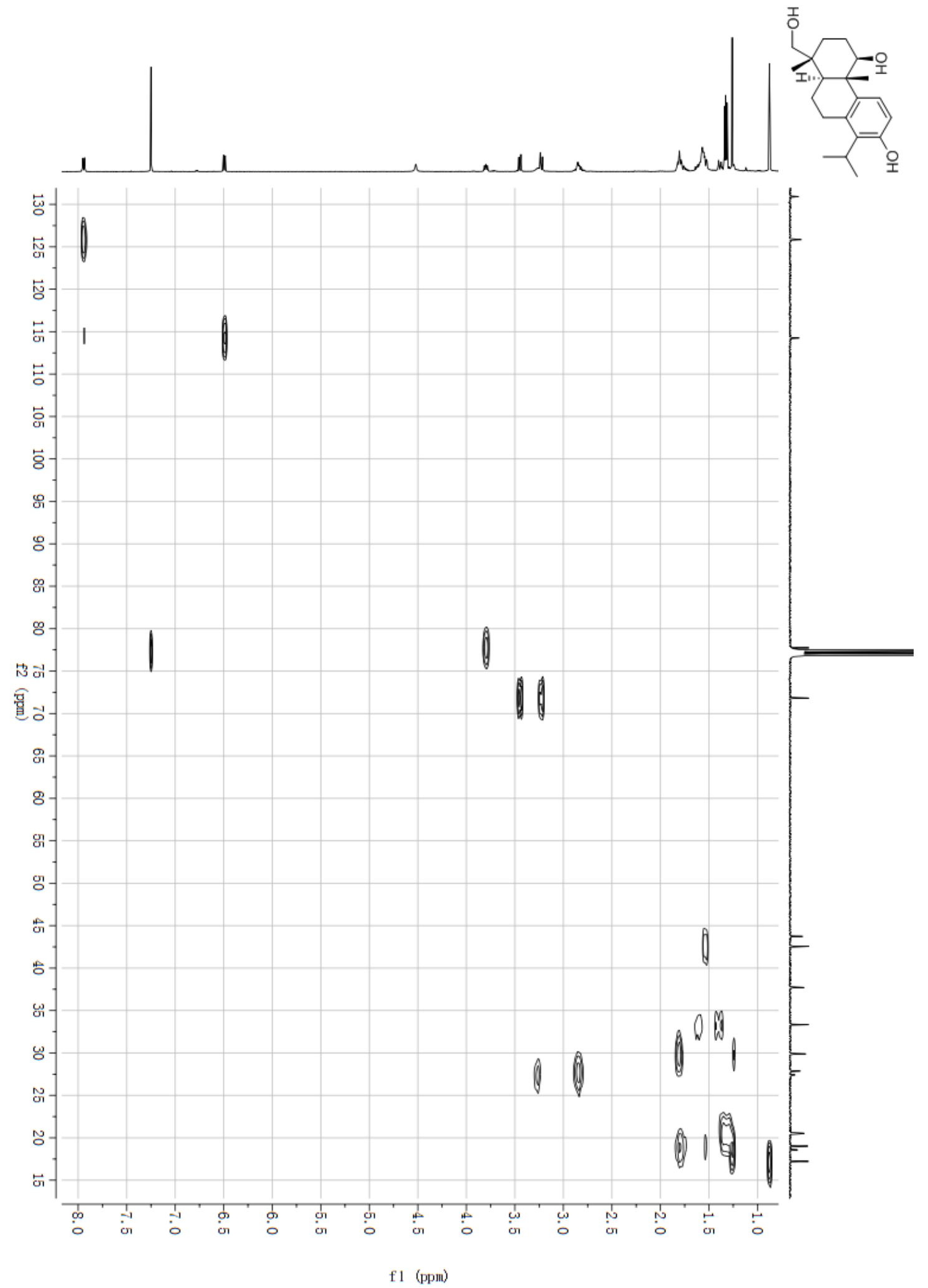


Figure S84. HMBC spectrum of $1 \beta, 18$-dihydroxytotarol (10) in $\mathrm{CDCl}_{3}$

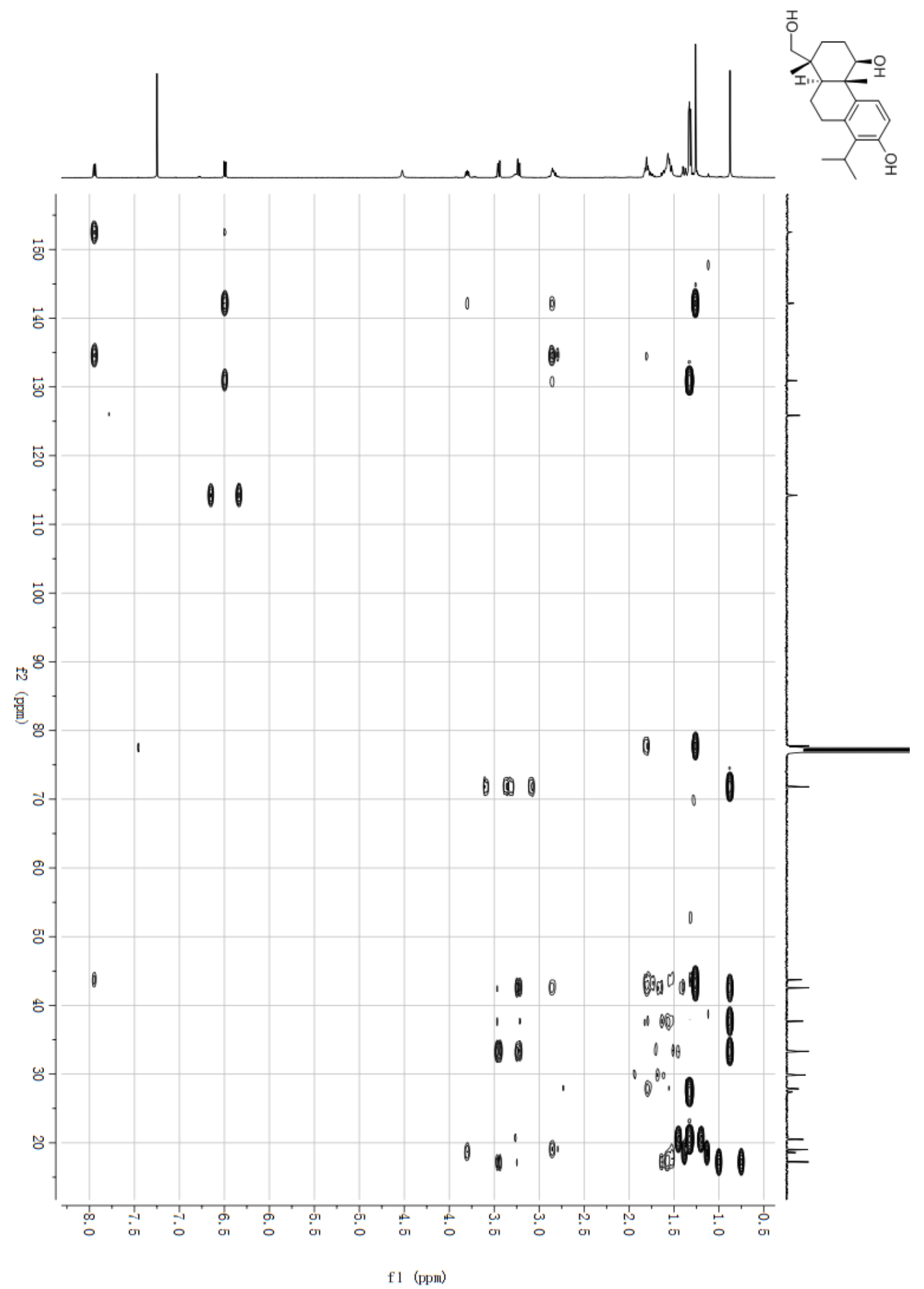


Figure S85. NOESY spectrum of $1 \beta, 18$-dihydroxytotarol (10) in $\mathrm{CDCl}_{3}$

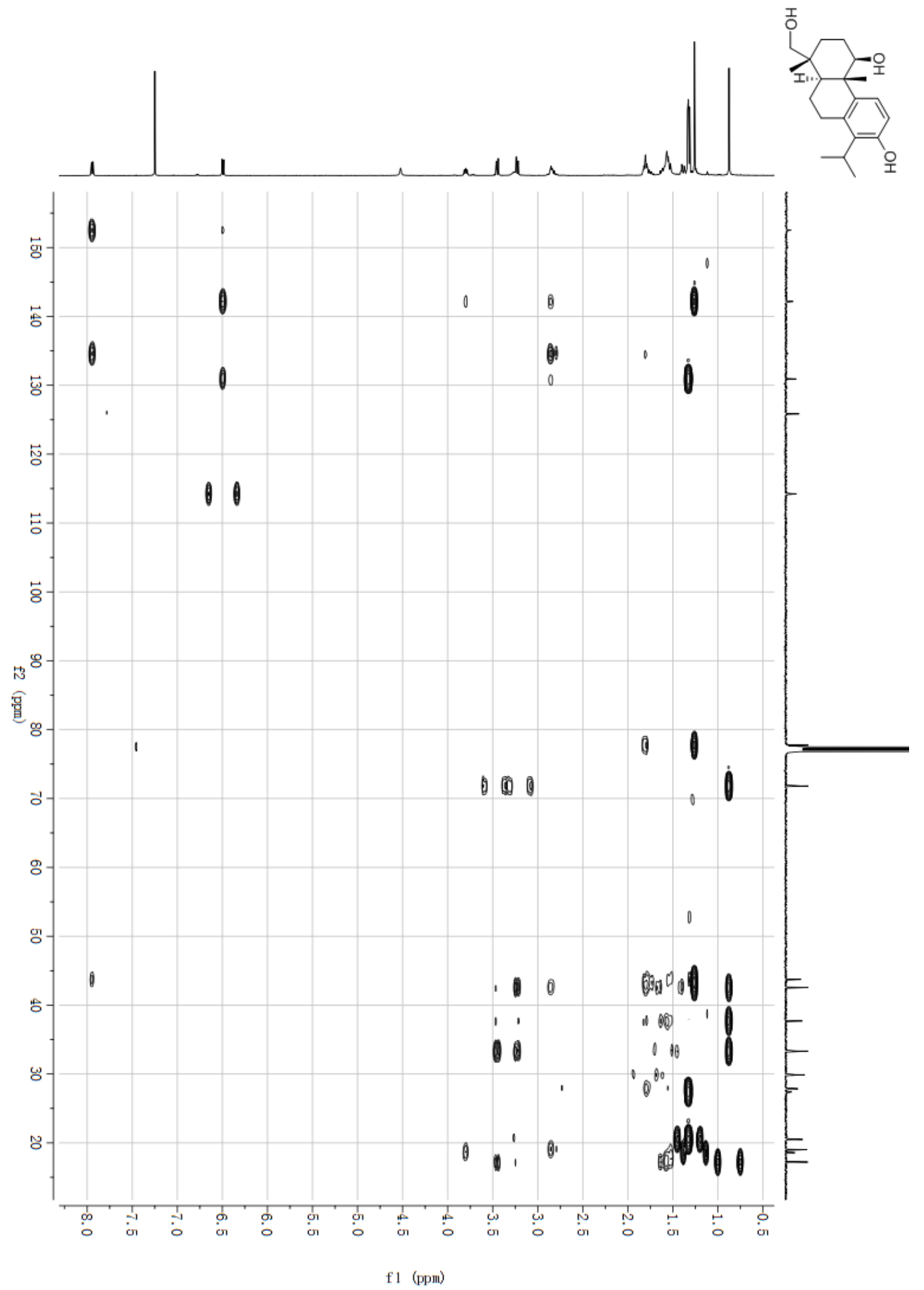


Figure S86. (-)-ESIMS spectrum of $1 \beta, 18$-dihydroxytotarol (10)

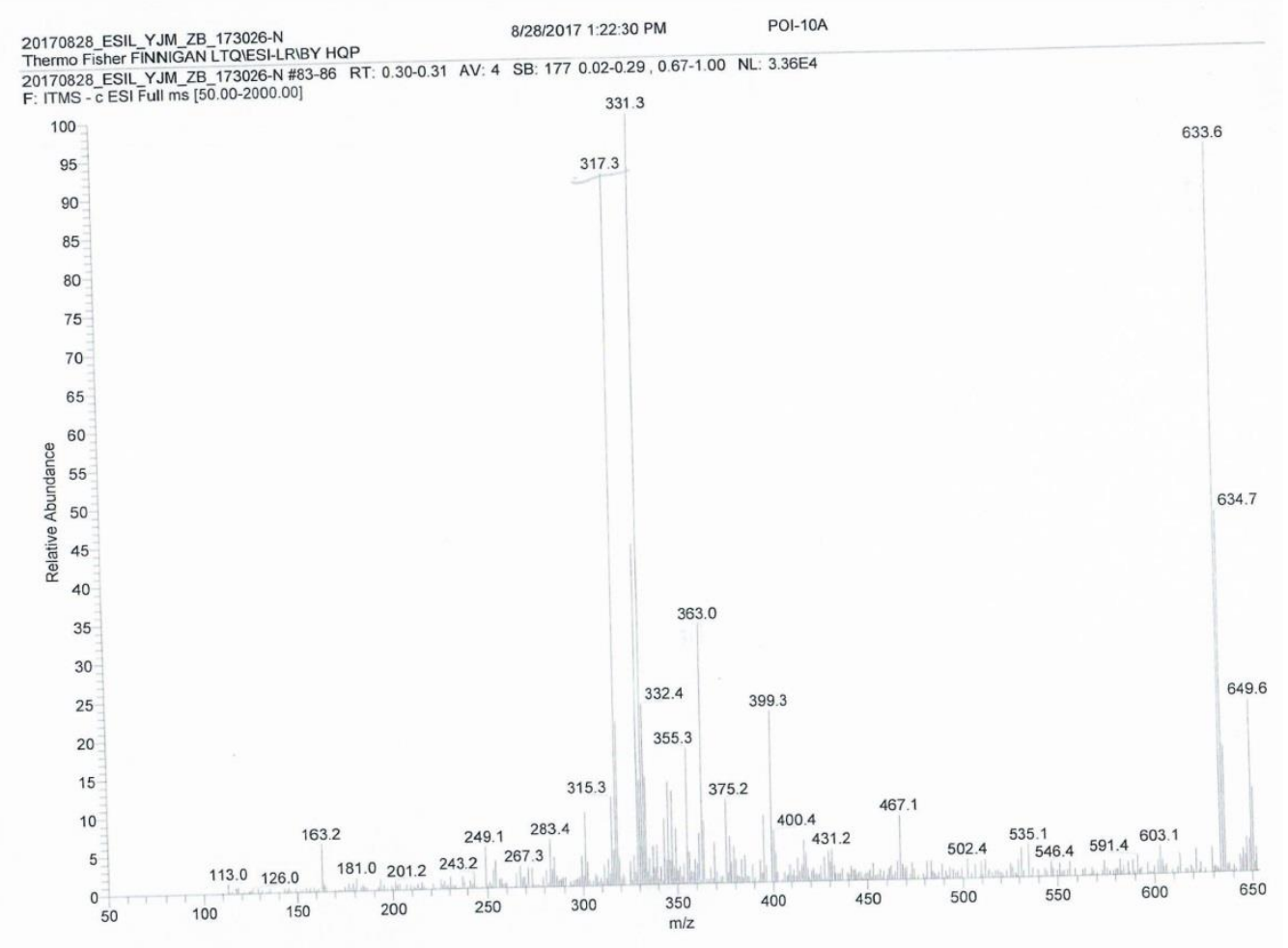


Figure S87. (-)-HRESIMS spectrum of $1 \beta, 18$-dihydroxytotarol (10)

Elemental Composition Report

Page 1

Single Mass Analysis

Tolerance $=10.0$ PPM / DBE: $\min =-1.5, \max =50.0$

Element prediction: Off

Number of isotope peaks used for $\mathrm{i}-\mathrm{FIT}=3$

Monoisotopic Mass, Even Electron Ions

98 formula(e) evaluated with 1 results within limits (up to 50 closest results for each mass)

Elements Used:

$\begin{array}{llll}\text { C: } 5-80 & \text { H: } 2-120 & \text { O: } 0-30 & \mathrm{Na}: 0-1\end{array}$

POI-10A

LCT PXE KE324

20-Sep-2016

POI-10A 25 (0.548) AM2 (Ar, 11000.0,0.00,0.70); ABS; Cm (25:36)

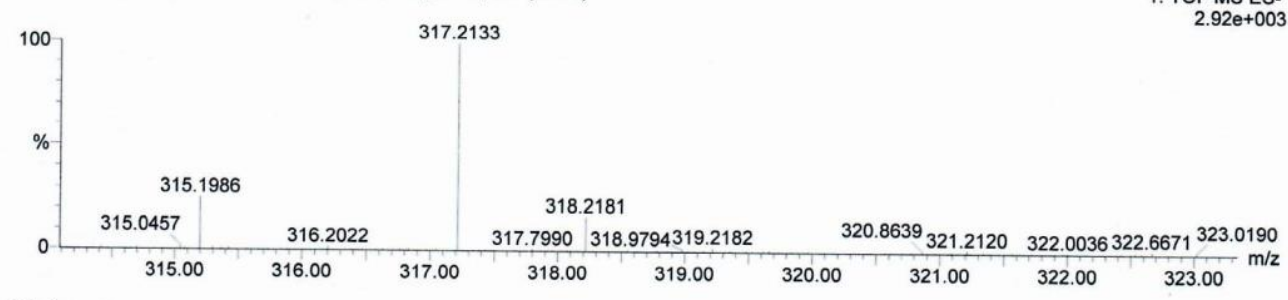

Minimum: $\quad-1.5$

$\begin{array}{lll}5.0 & 10.0 & 50.0\end{array}$

Mass Calc. Mass mDa PPM DBE i-FIT i-FIT (Norm) Formula

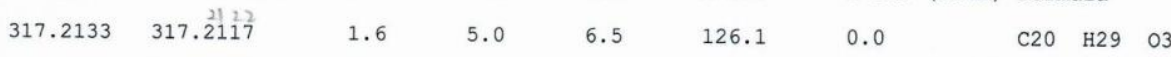


Figure S88. IR spectrum of $1 \beta, 18$-dihydroxytotarol (10)

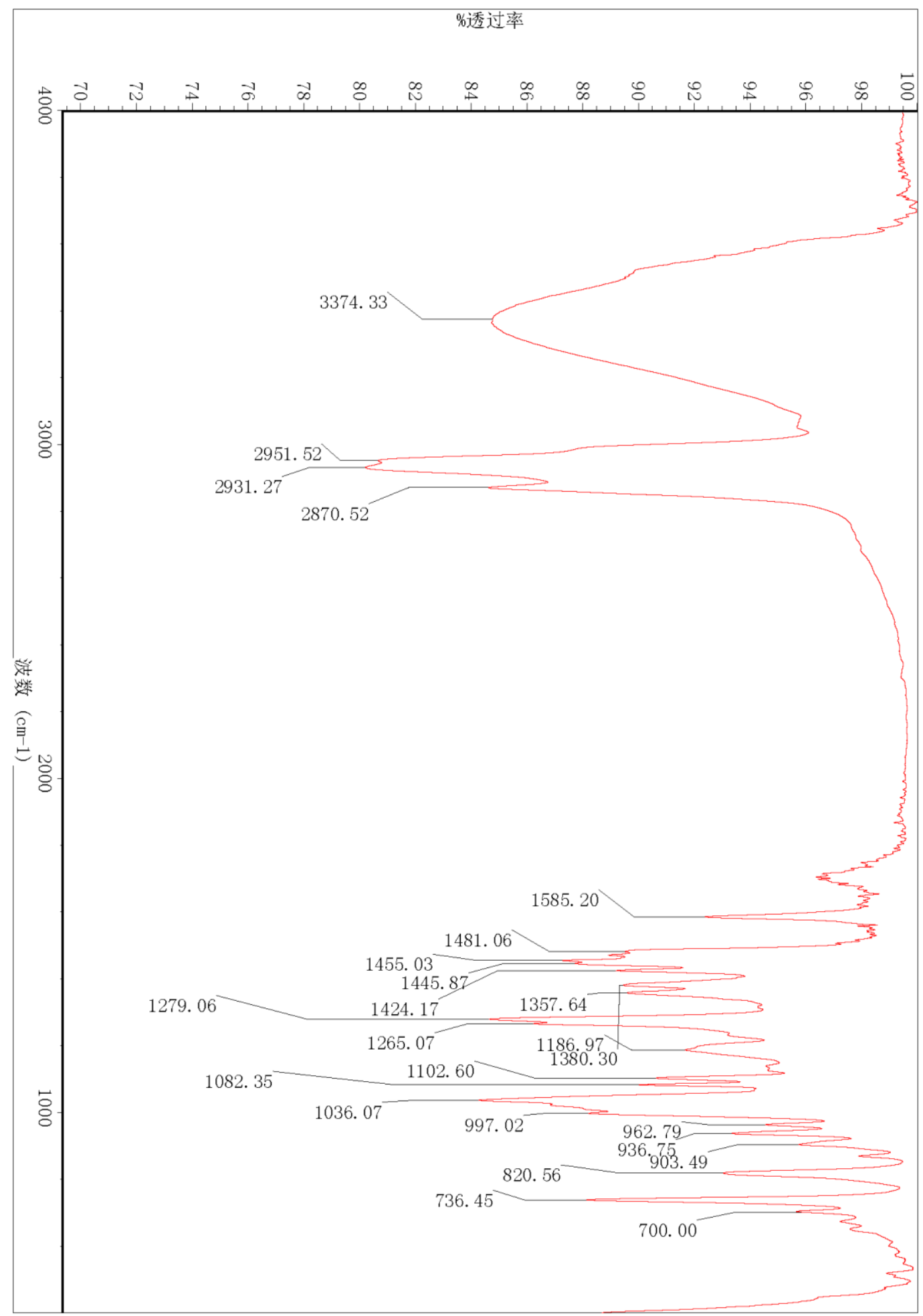


Figure S89. ${ }^{1} \mathrm{H}$ NMR spectrum of $2 \alpha$-hydroxytotarol (11) in $\mathrm{CDCl}_{3}$

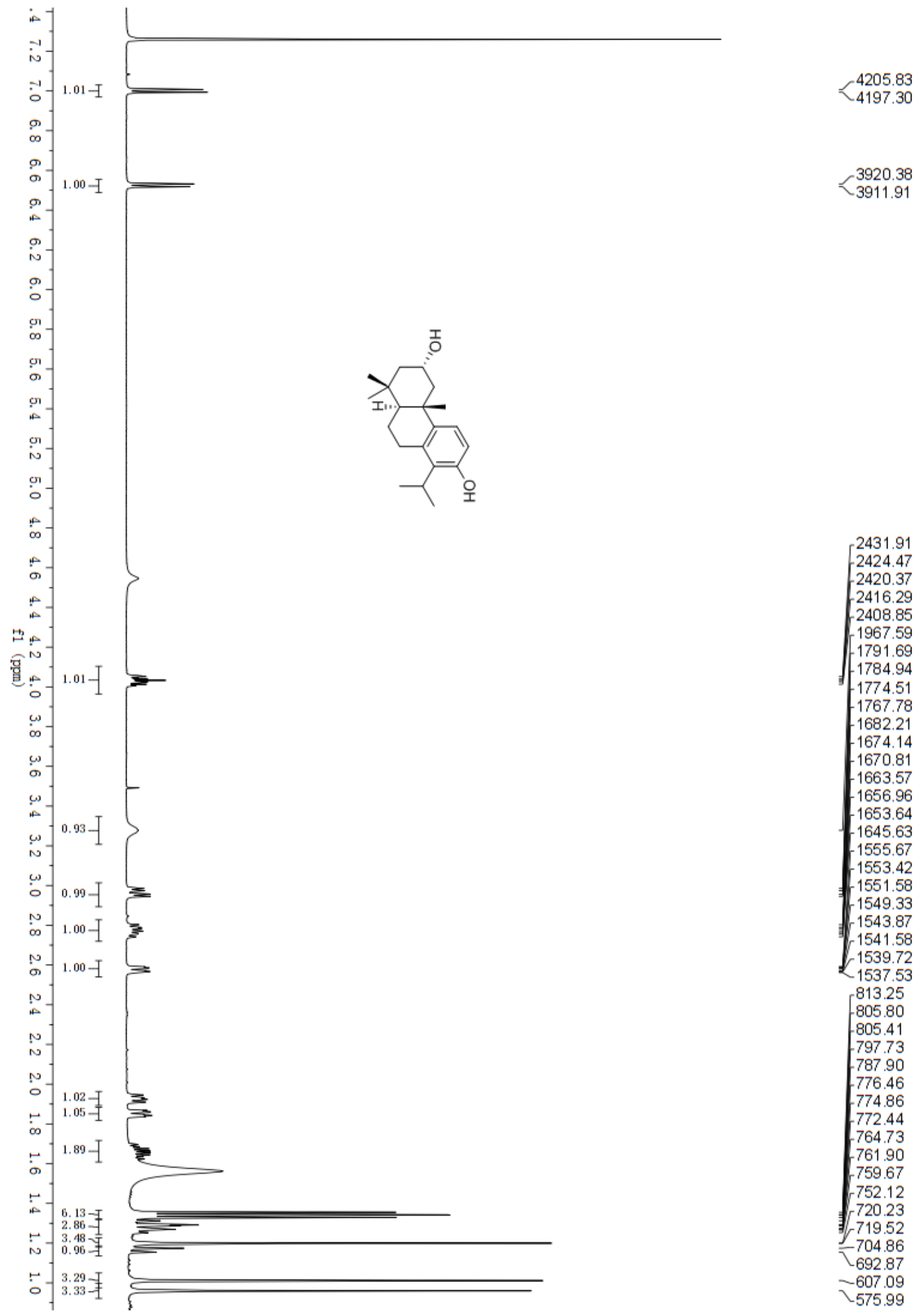


Figure S90. ${ }^{13} \mathrm{C}$ NMR spectrum of $2 \alpha$-hydroxytotarol (11) in $\mathrm{CDCl}_{3}$

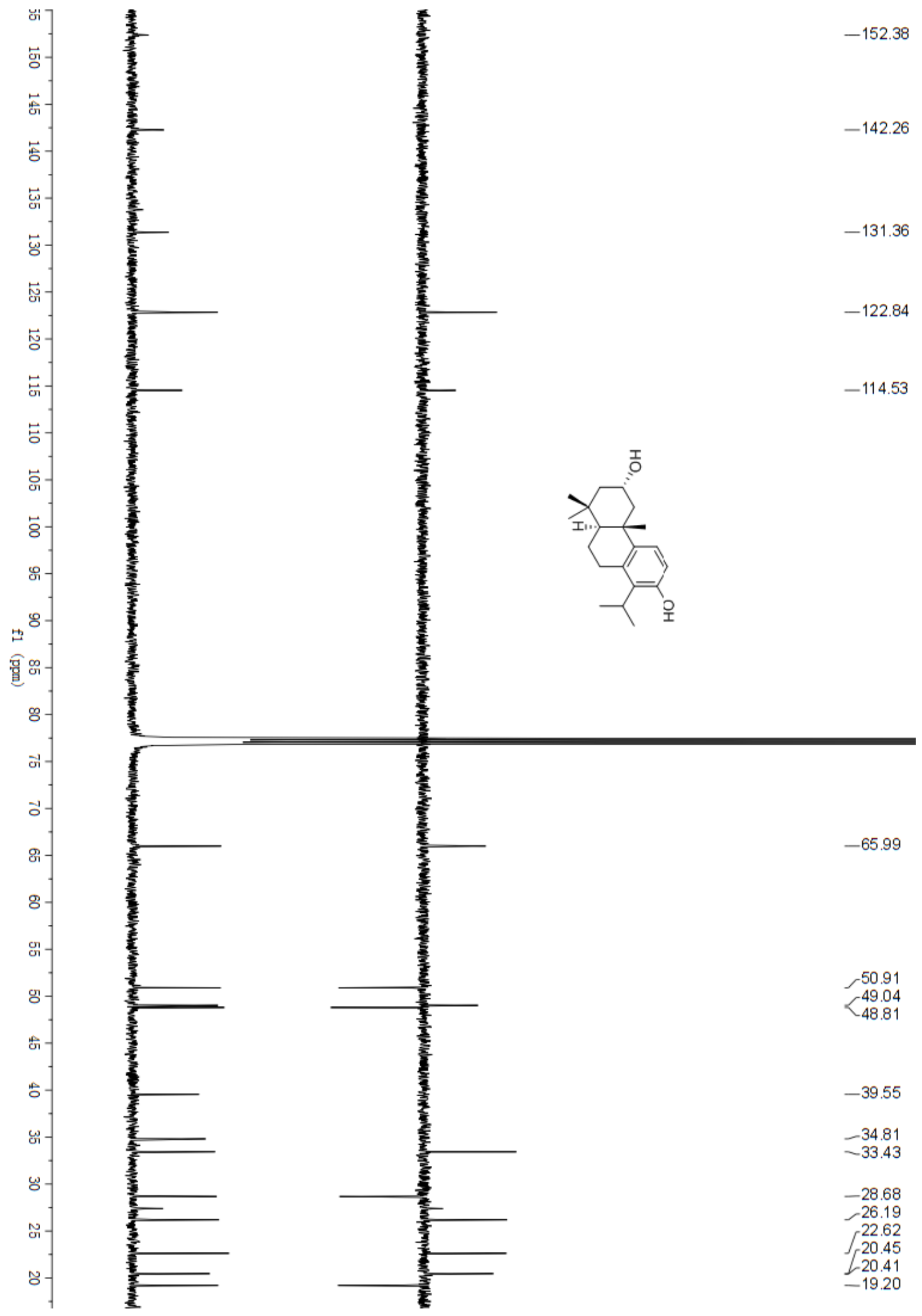


Figure S91. HSQC spectrum of $2 \alpha$-hydroxytotarol (11) in $\mathrm{CDCl}_{3}$

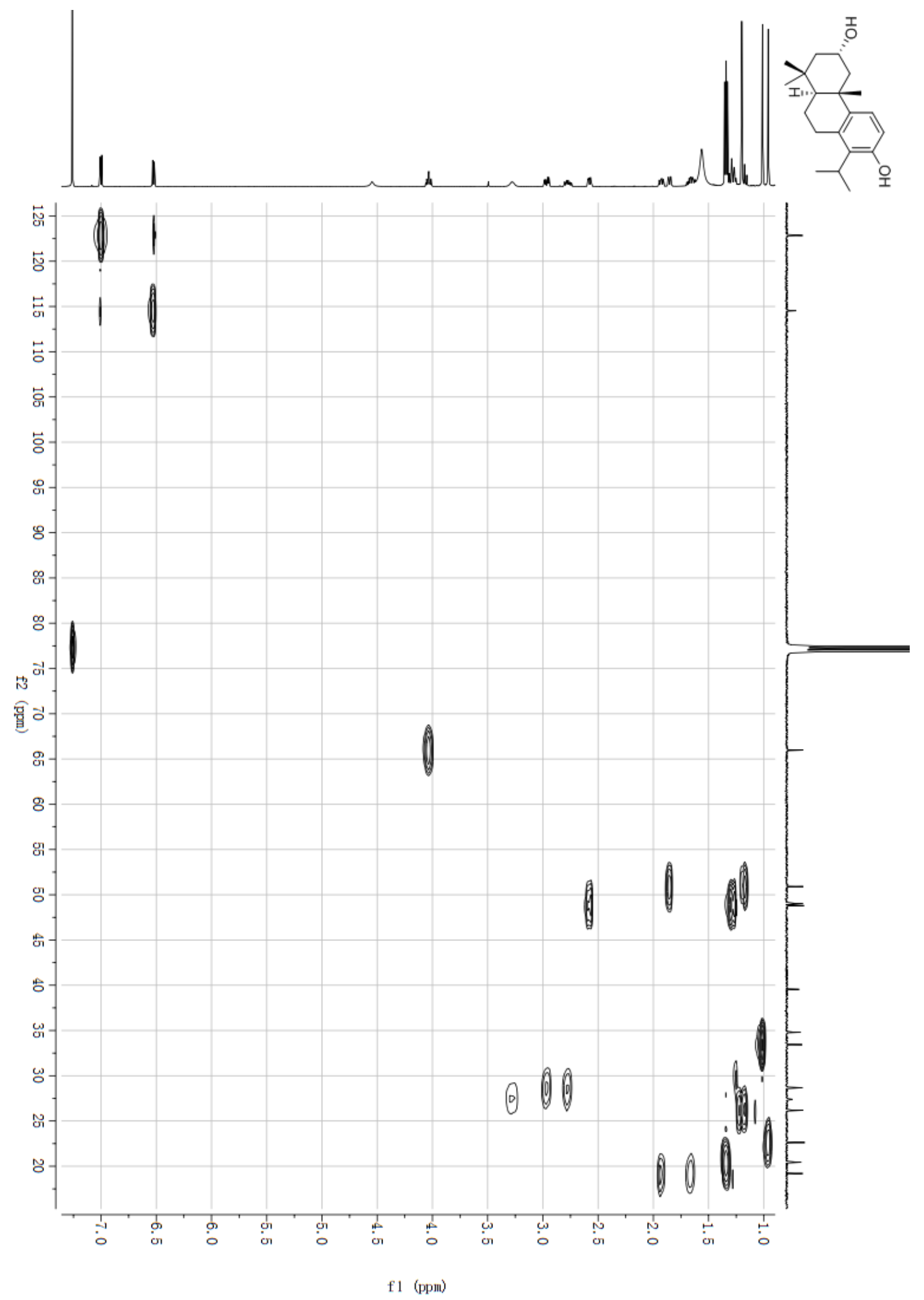


Figure S92. HMBC spectrum of $2 \alpha$-hydroxytotarol (11) in $\mathrm{CDCl}_{3}$

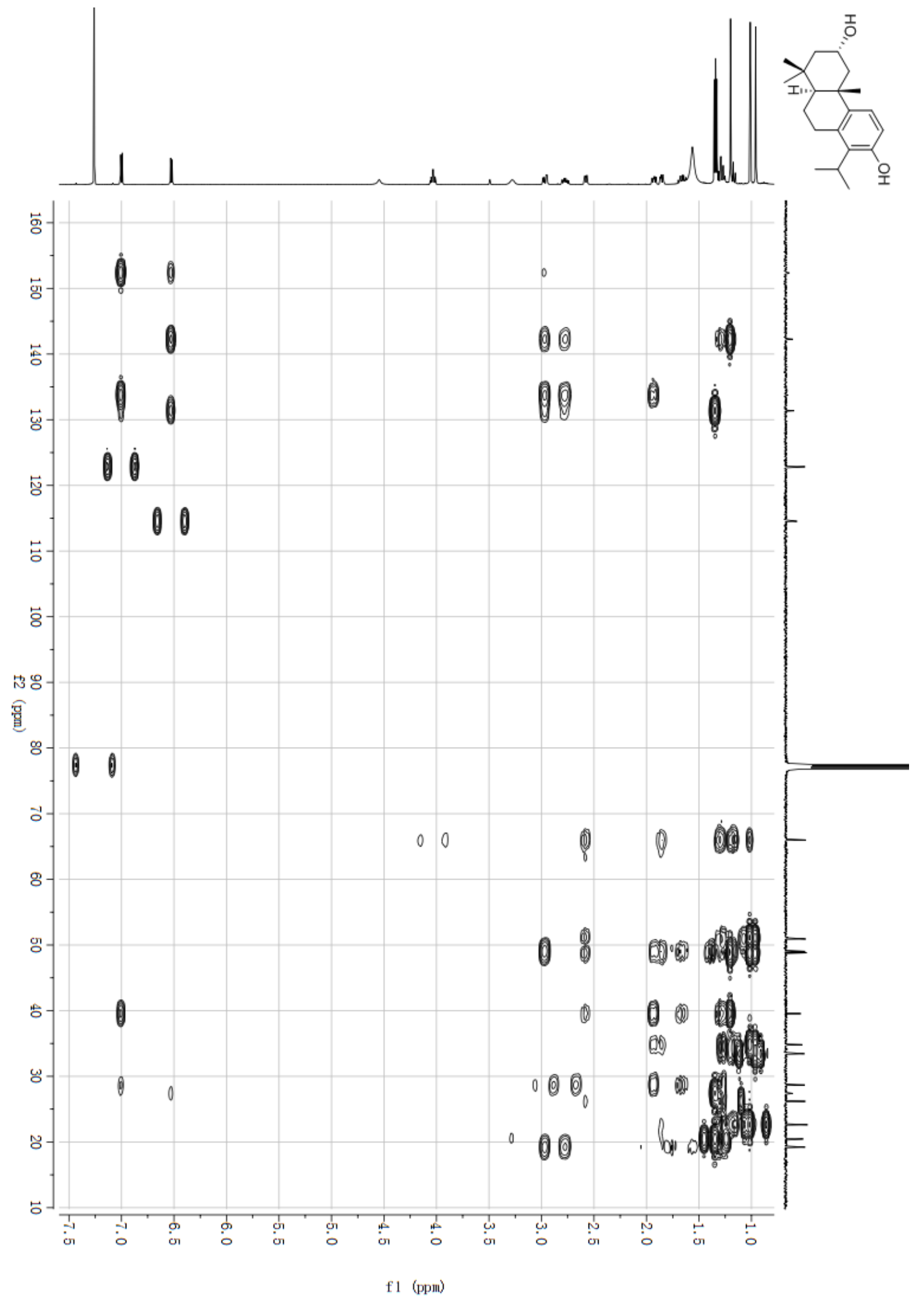


Figure S93. NOESY spectrum of $2 \alpha$-hydroxytotarol (11) in $\mathrm{CDCl}_{3}$

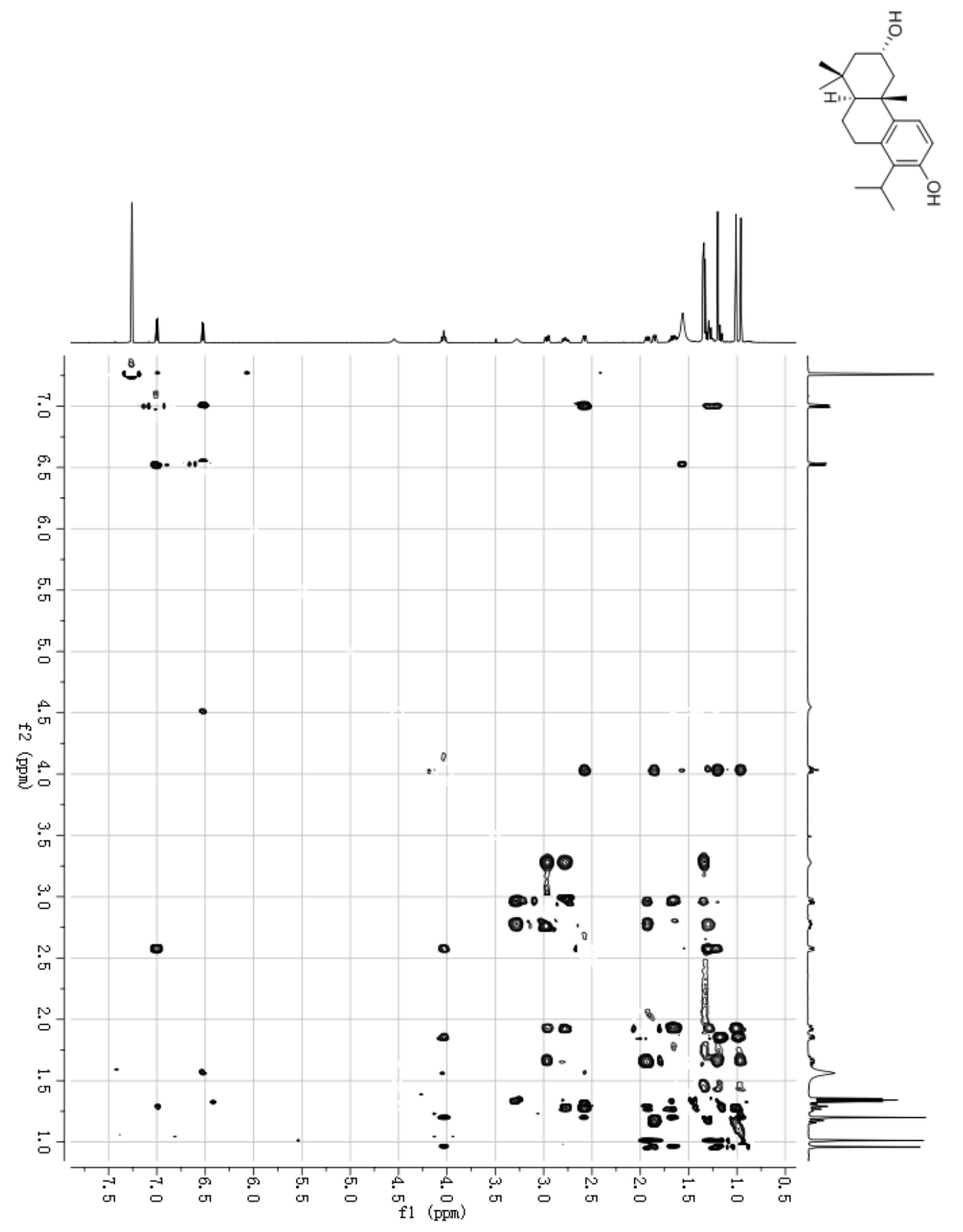


Figure S94. (+)-ESIMS spectrum of $2 \alpha$-hydroxytotarol (11)

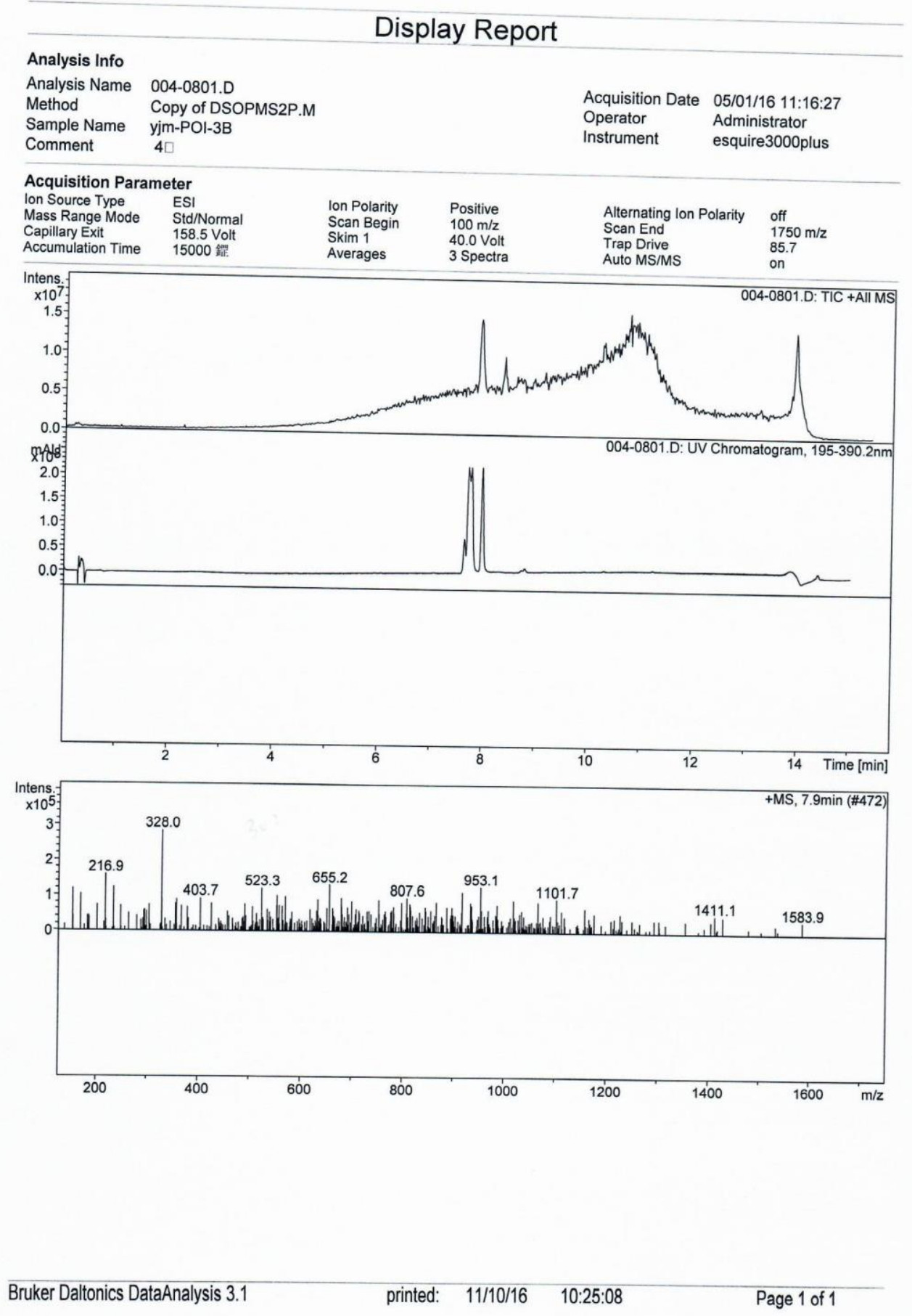


Figure S95. (-)-ESIMS spectrum of $2 \alpha$-hydroxytotarol (11)

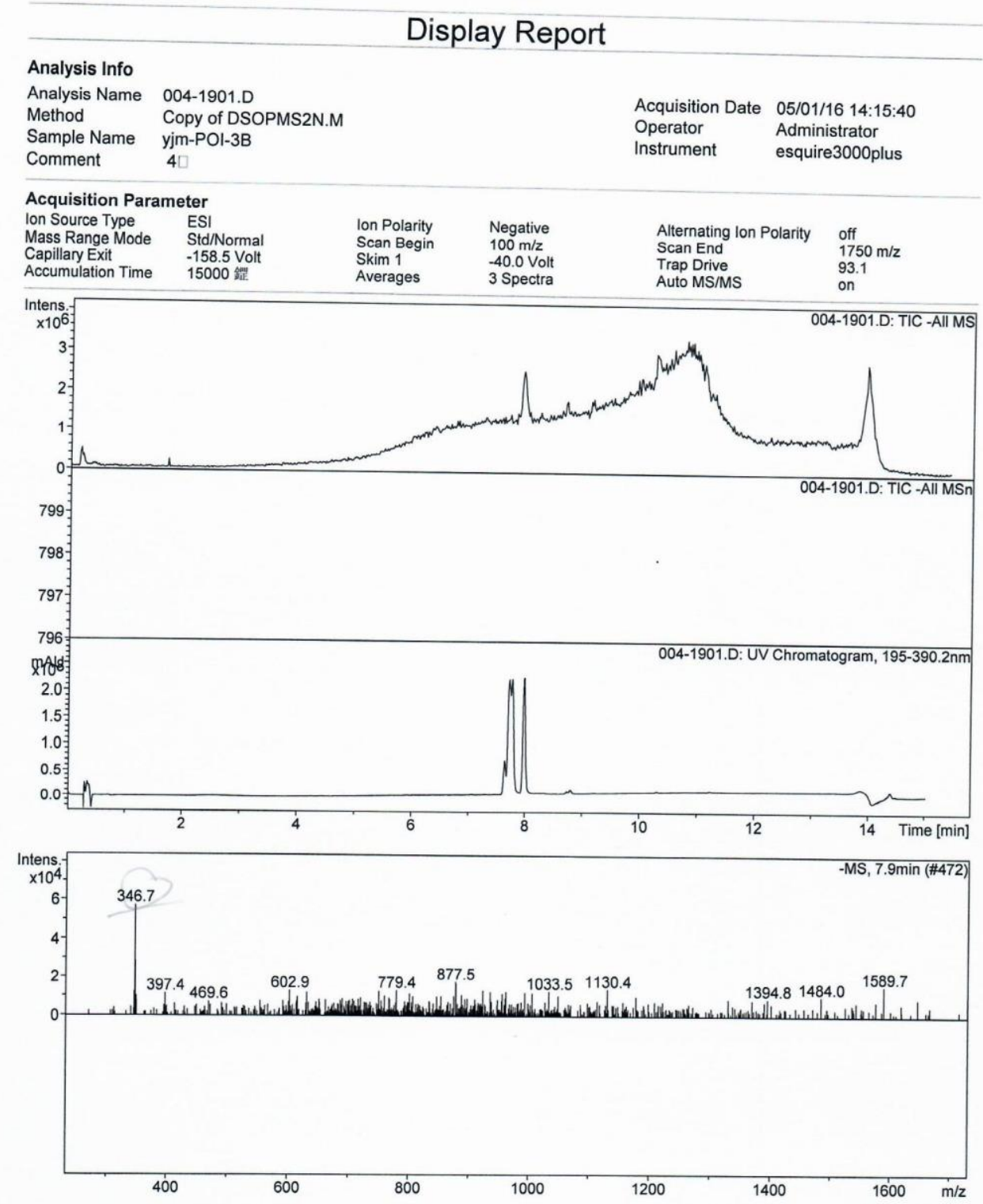


Figure S96. (-)-HRESIMS spectrum of $2 \alpha$-hydroxytotarol (11)

Elemental Composition Report

Page 1

Single Mass Analysis

Tolerance $=3.0$ PPM I DBE: $\min =-1.5, \max =50.0$

Element prediction: Off

Number of isotope peaks used for i-FIT $=3$

Monoisotopic Mass, Even Electron lons

116 formula(e) evaluated with 1 results within limits (up to 50 closest results for each mass)

Elements Used:

$\begin{array}{llll}\text { C: } 5-80 & \text { H: } 2-120 & \text { O: } 0-30 & \mathrm{Na}: 0-1\end{array}$

POI-3B

LCT PXE KE324

29-Oct-2016

TOF MS ES-
$1.42 \mathrm{e}+003$

POI-3B 6 (0.124) AM2 (Ar, 10000.0,0.00,1.00); ABS; Cm (5.6)

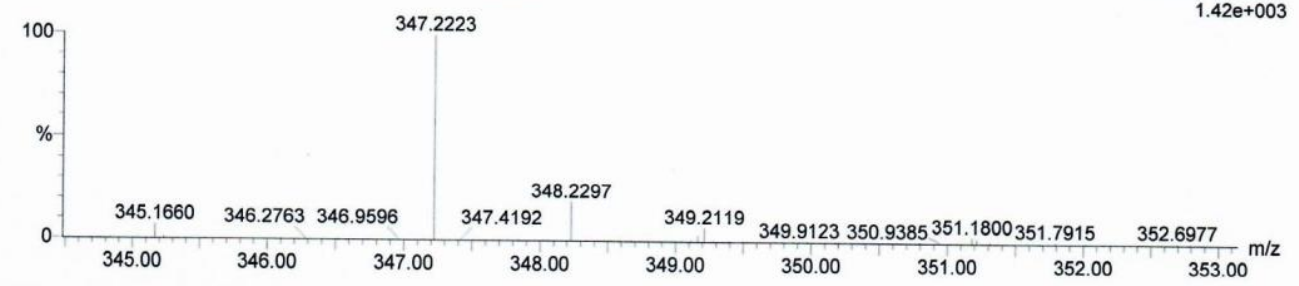

Minimum:

Maximum:

$\begin{array}{lll}5.0 & 3.0 & -1.5 \\ & & 50.0\end{array}$

Mass Calc. Mass mDa PPM DBE

347.2223

347.2222

0.1

0.3

6.5

i-FIT

i-FIT (Norm) Formula

$100.7 \quad 0.0$

C21 H31 04 
Figure S97. IR spectrum of $2 \alpha$-hydroxytotarol (11)

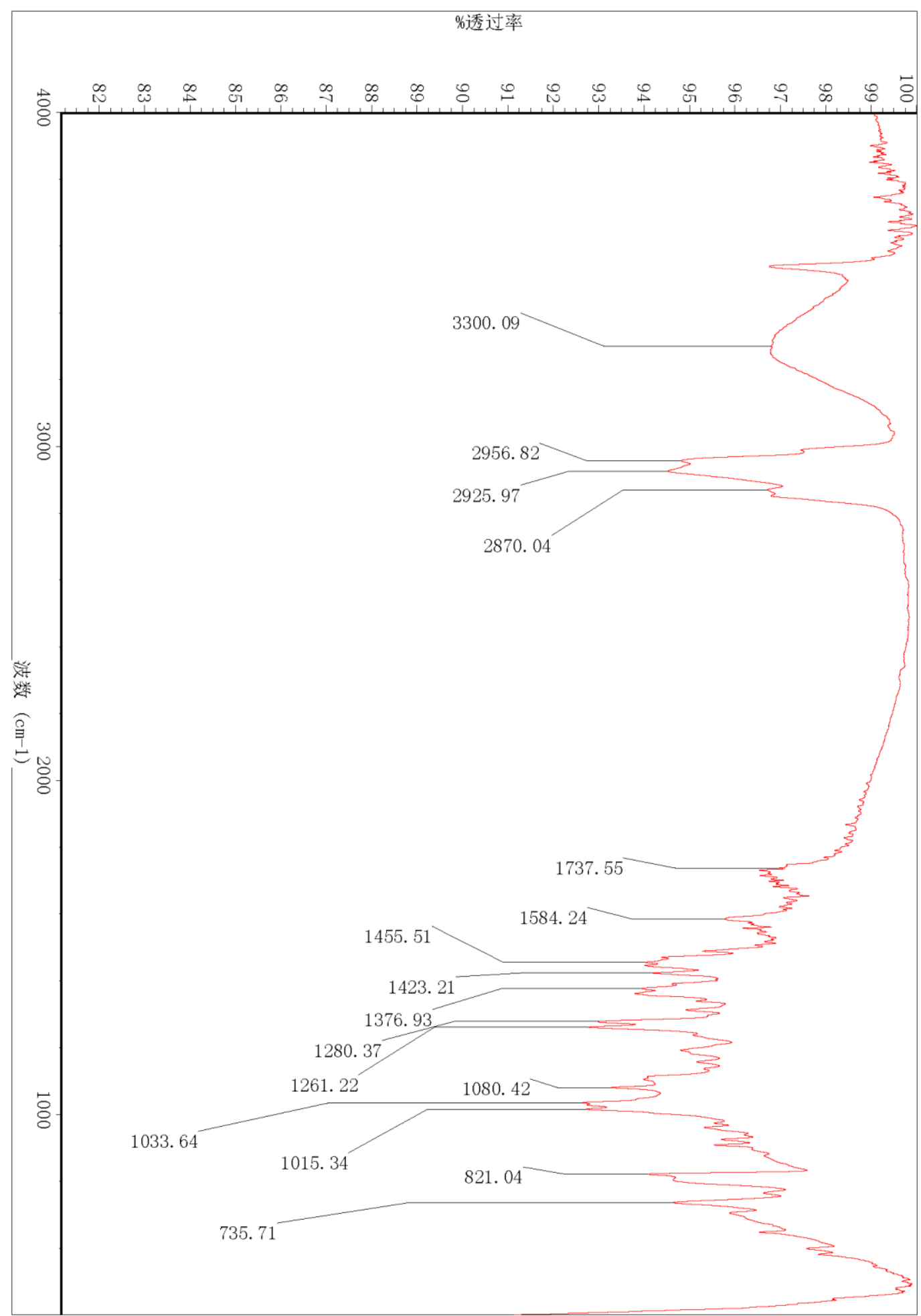


Figure S98. ${ }^{1} \mathrm{H}$ NMR spectrum of $1 \beta$-hydroxytotarol (12) in $\mathrm{CDCl}_{3}$

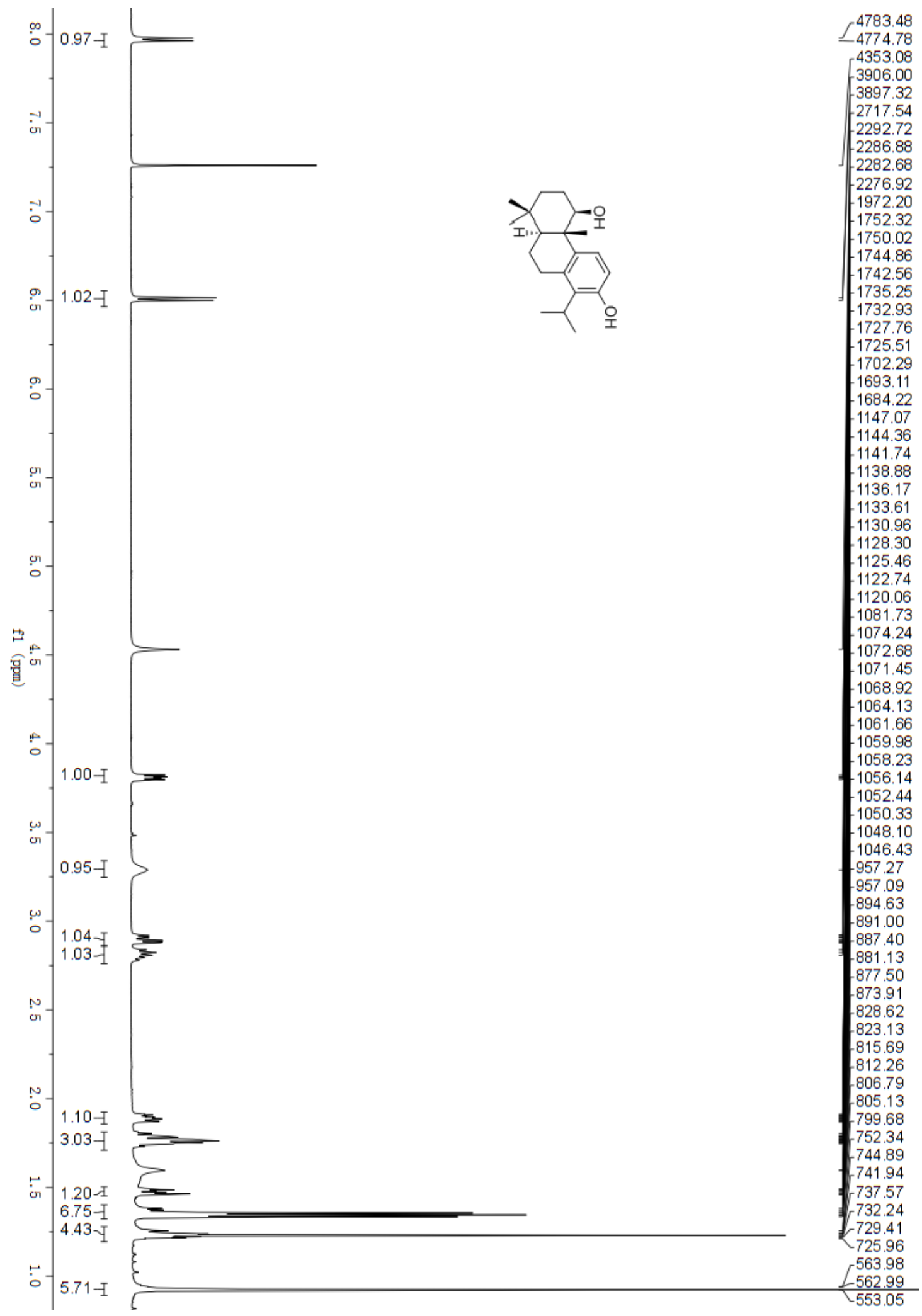


Figure S99. ${ }^{13} \mathrm{C}$ NMR spectrum of $1 \beta$-hydroxytotarol (12) in $\mathrm{CDCl}_{3}$

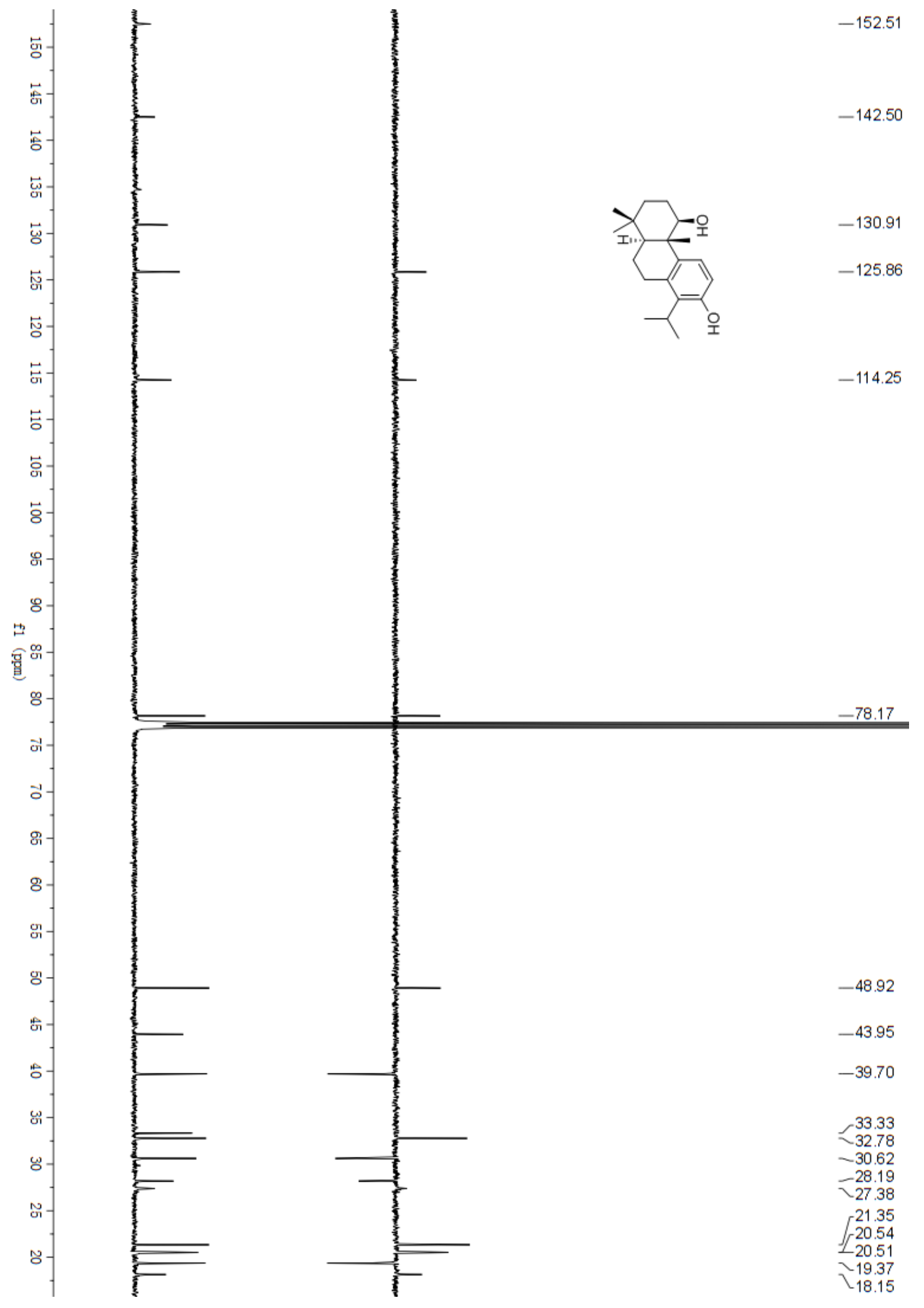


Figure S100. HSQC spectrum of $1 \beta$-hydroxytotarol (12) in $\mathrm{CDCl}_{3}$

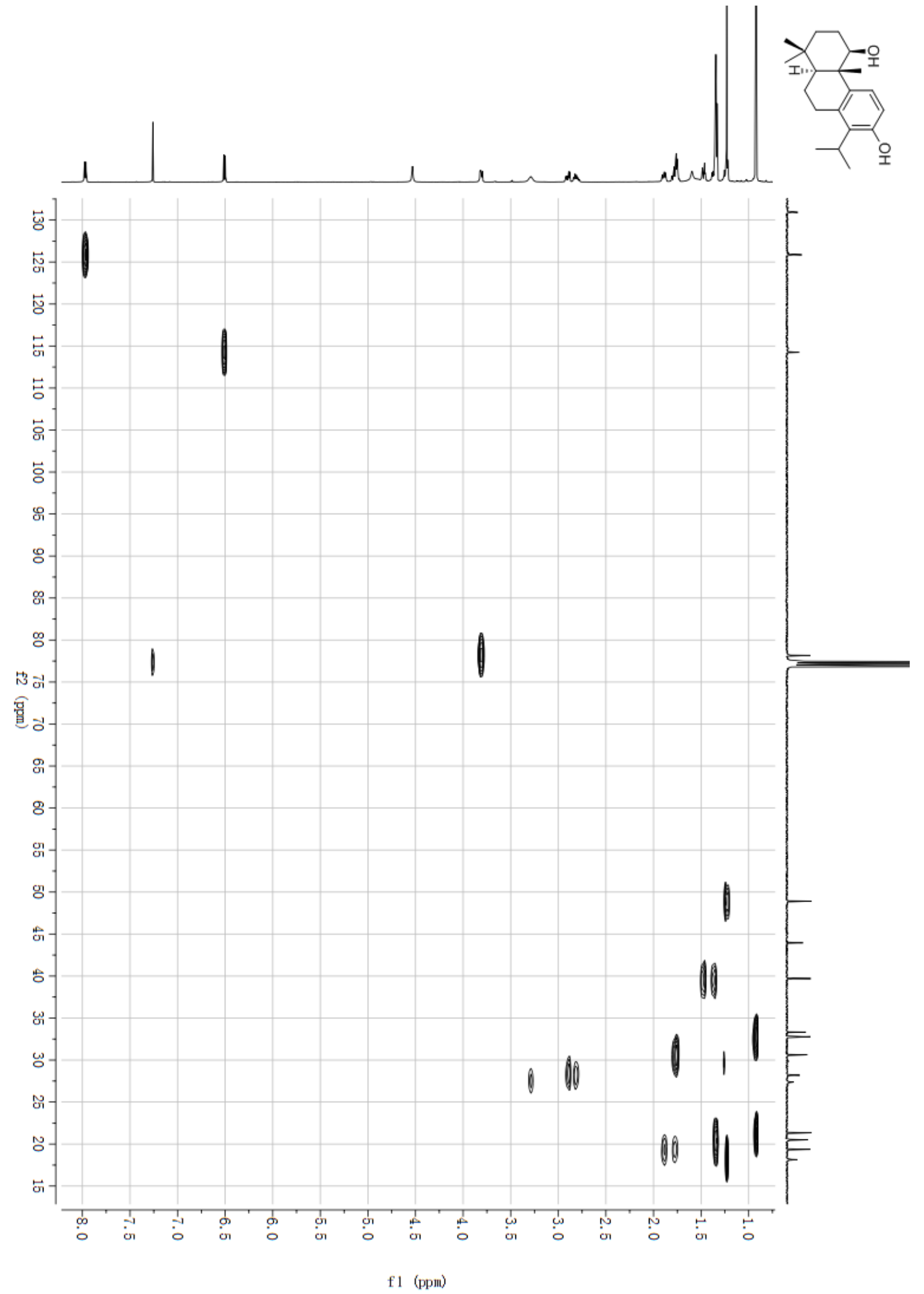


Figure S101. HMBC spectrum of $1 \beta$-hydroxytotarol (12) in $\mathrm{CDCl}_{3}$

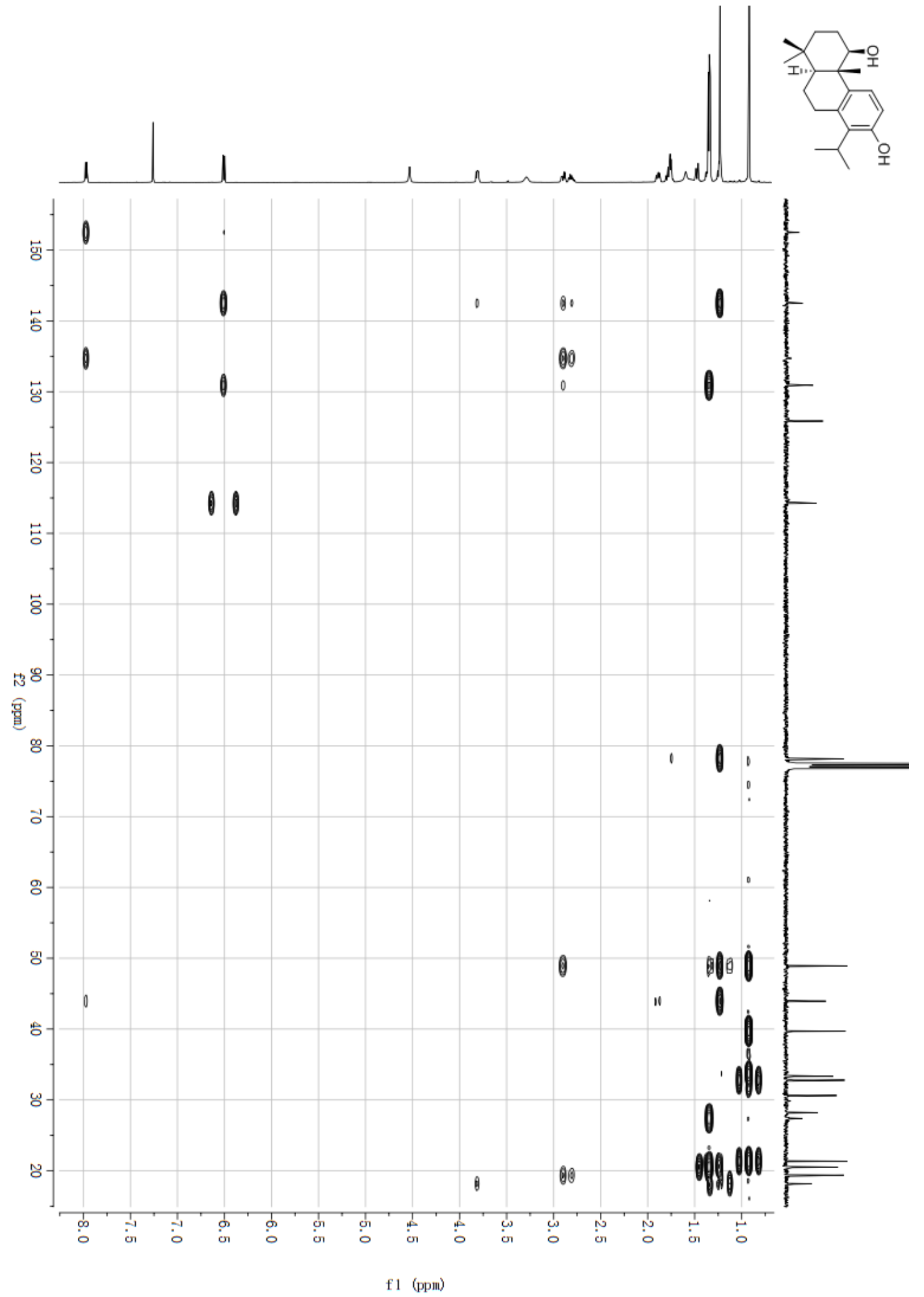


Figure S102. NOESY spectrum of $1 \beta$-hydroxytotarol (12) in $\mathrm{CDCl}_{3}$
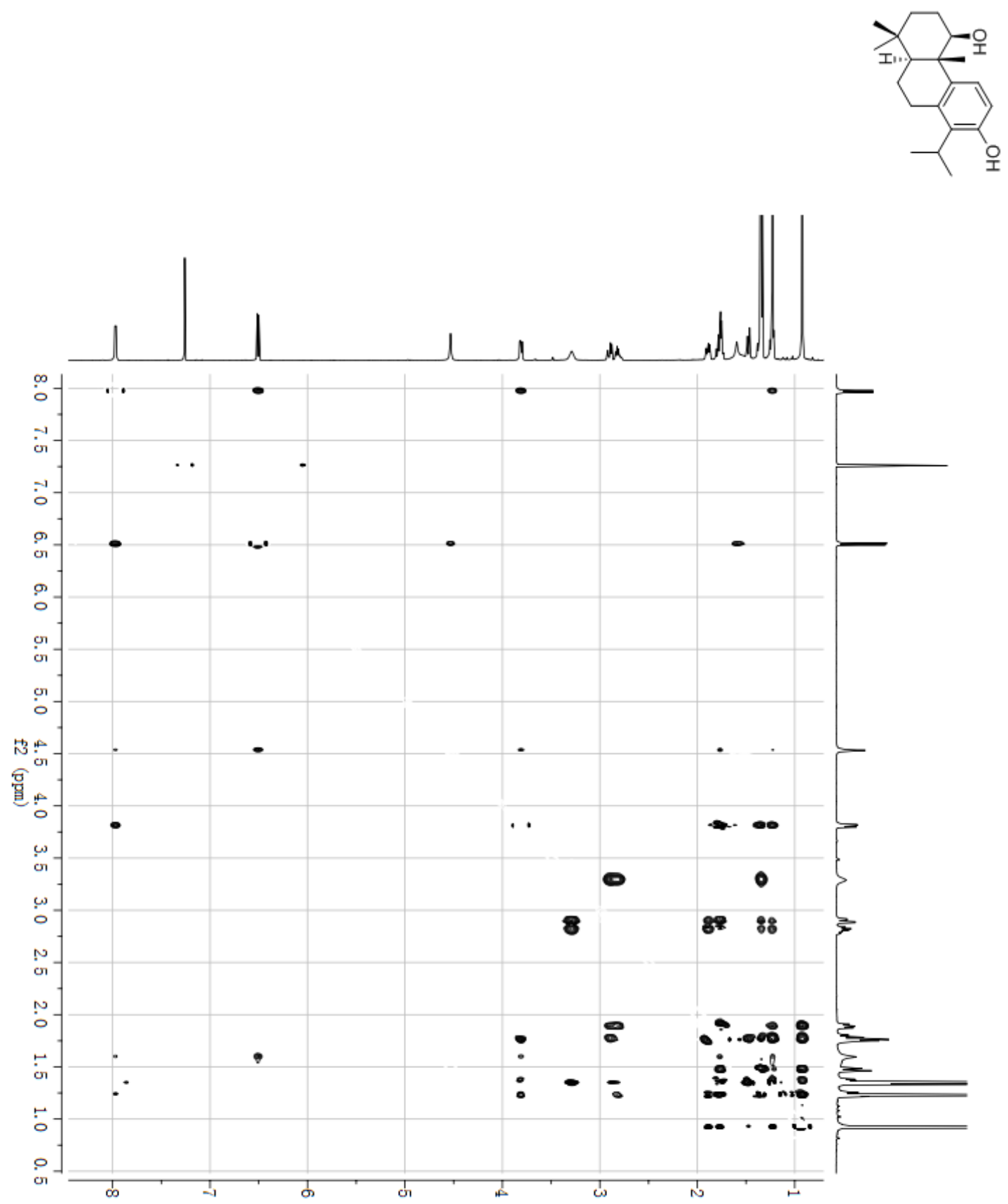

f1 (ppmi) 
Figure S103. (+)-ESIMS spectrum of $1 \beta$-hydroxytotarol (12)

\section{Display Report}

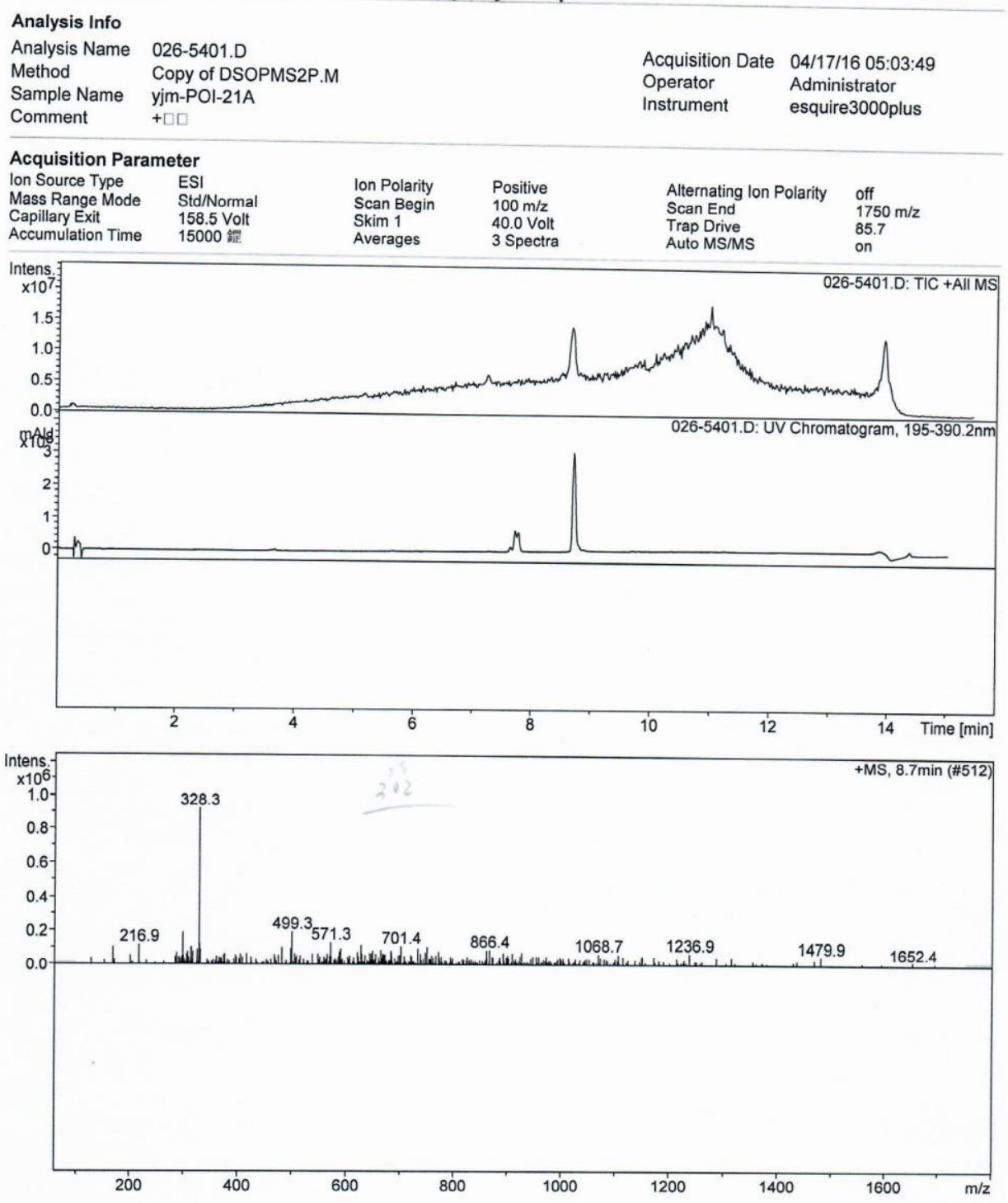


Figure S104. (-)-ESIMS spectrum of $1 \beta$-hydroxytotarol (12)

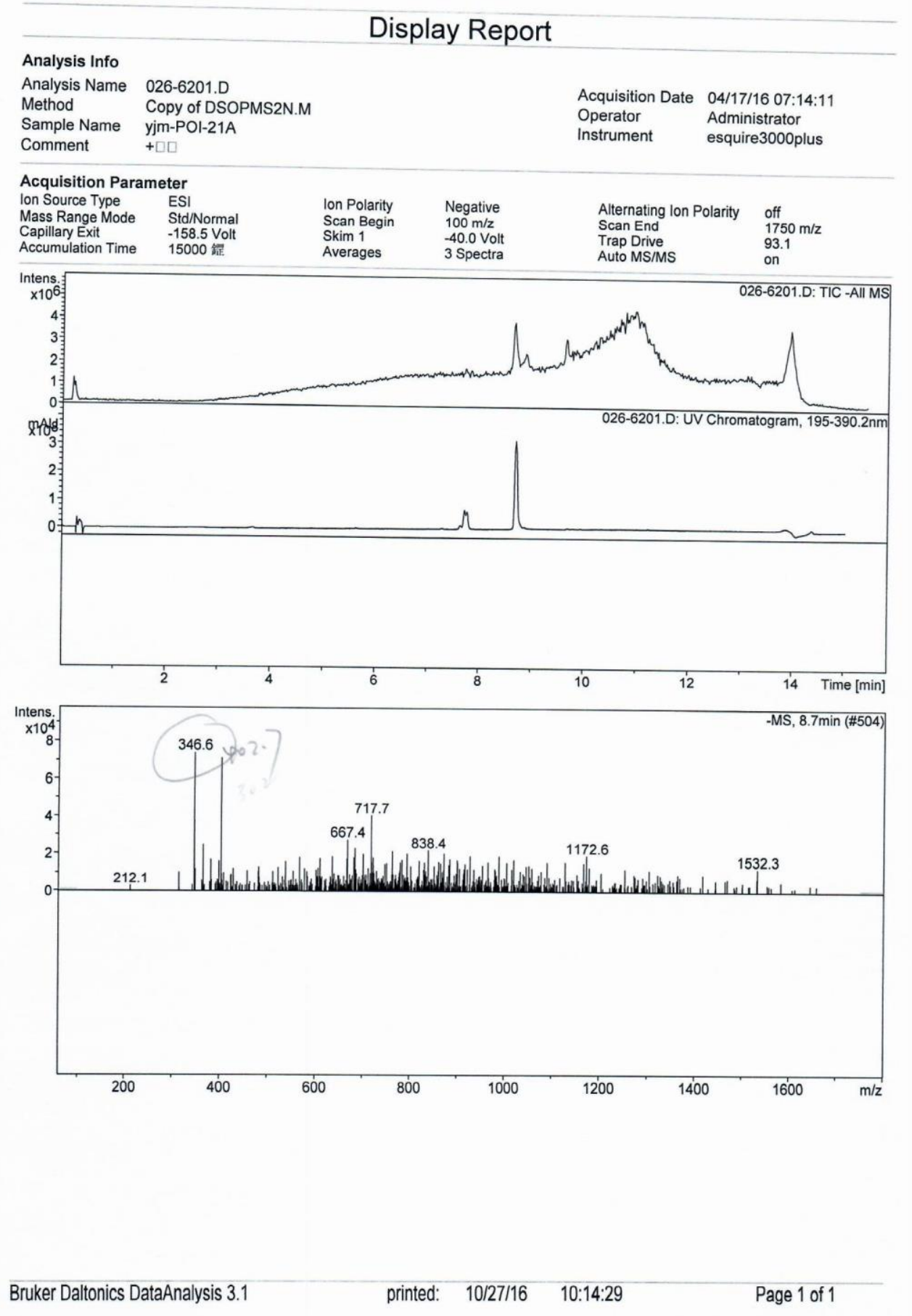


Figure S105. (+)-HRESIMS spectrum of $1 \beta$-hydroxytotarol (12)

Elemental Composition Report

Page 1

Single Mass Analysis

Tolerance $=2.0$ PPM / DBE: $\min =-1.5, \max =50.0$

Element prediction: Off

Number of isotope peaks used for i-FIT $=3$

Monoisotopic Mass, Even Electron lons

321 formula(e) evaluated with 1 results within limits (up to 50 closest results for each mass)

Elements Used:

$\begin{array}{llll}\text { C: } 5-80 & \text { H: } 2-120 & \text { O: } 0-30 & \mathrm{Na}: 0-1\end{array}$

POI-13A

LCT PXE KE324

29-Oct-2016

POI-13A 38 (0.831) AM2 (Ar, 12000.0,0.00,0.70); ABS; Cm (27:41)

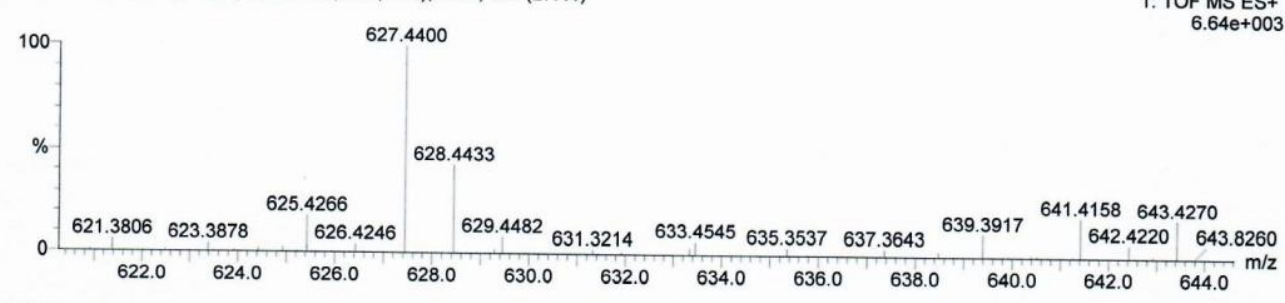

Minimum:

Maximum:

$\begin{array}{lll}5.0 & 2.0 & -1.5 \\ 50.0\end{array}$

Mass Calc. Mass mDa PPM DBE

$\begin{array}{lllllllllll}627.4400 & 627.4389 & 1.1 & 1.8 & 10.5 & 64.5 & 0.0 & \text { C40 } & \text { H60 } & 04 & \mathrm{Na}\end{array}$ 
Figure S106. IR spectrum of $1 \beta$-hydroxytotarol (12)

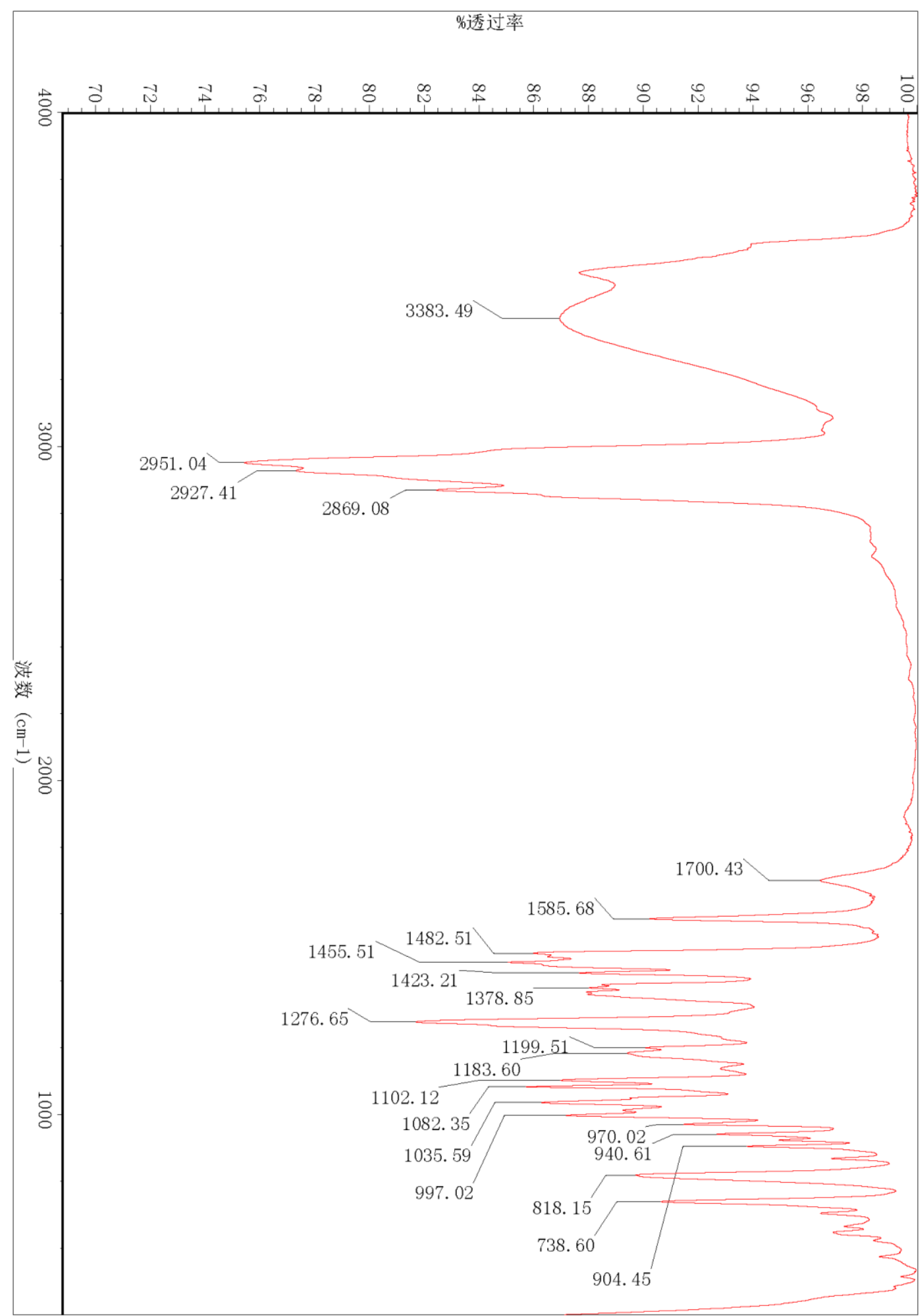


Figure S107. ${ }^{1} \mathrm{H}$ NMR spectrum of 16-hydroxy-17-norlambertic acid (13) in $\mathrm{CDCl}_{3}$

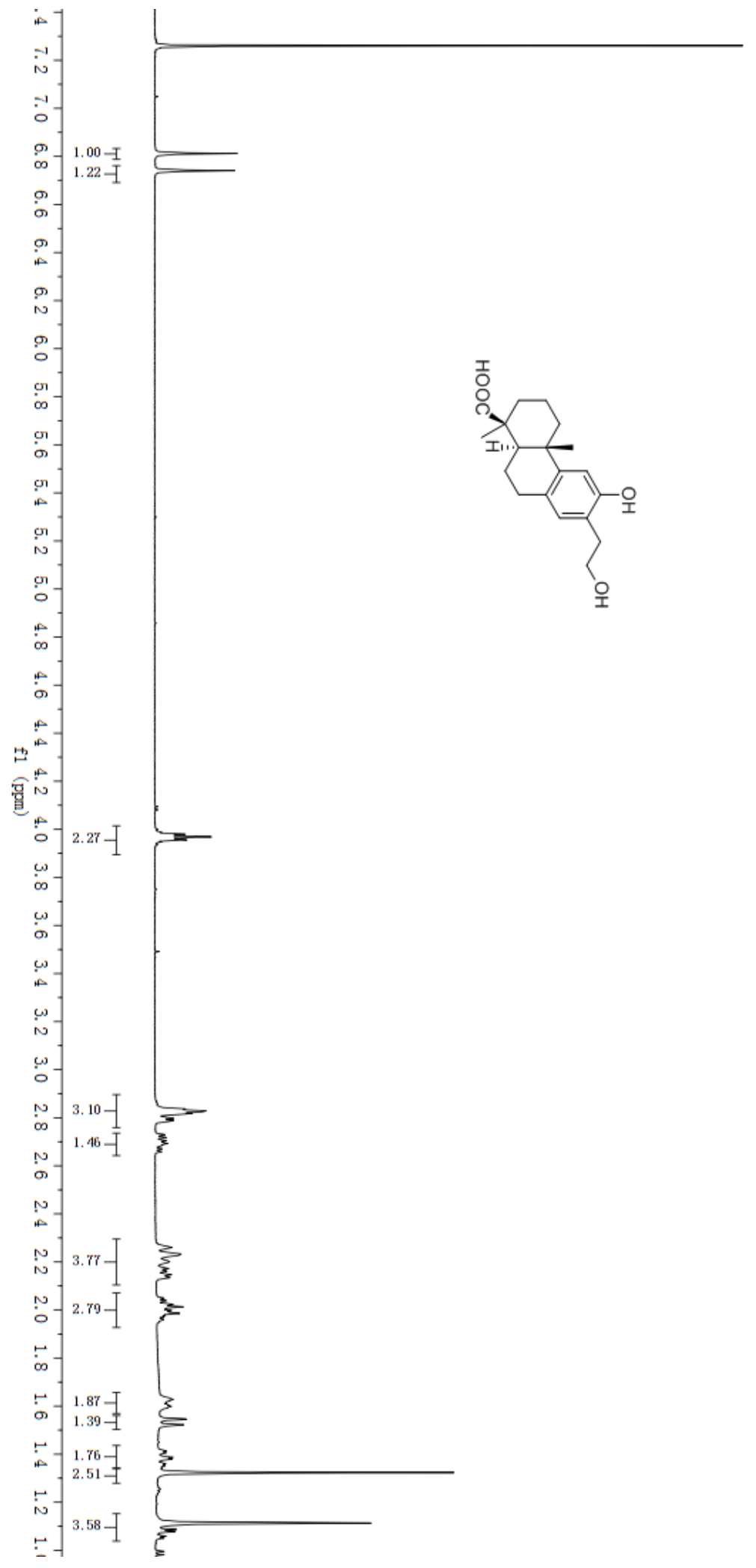

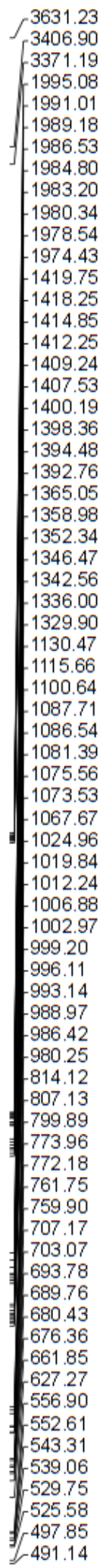


Figure S108. ${ }^{13} \mathrm{C}$ NMR spectrum of 16-hydroxy-17-norlambertic acid (13) in $\mathrm{CDCl}_{3}$

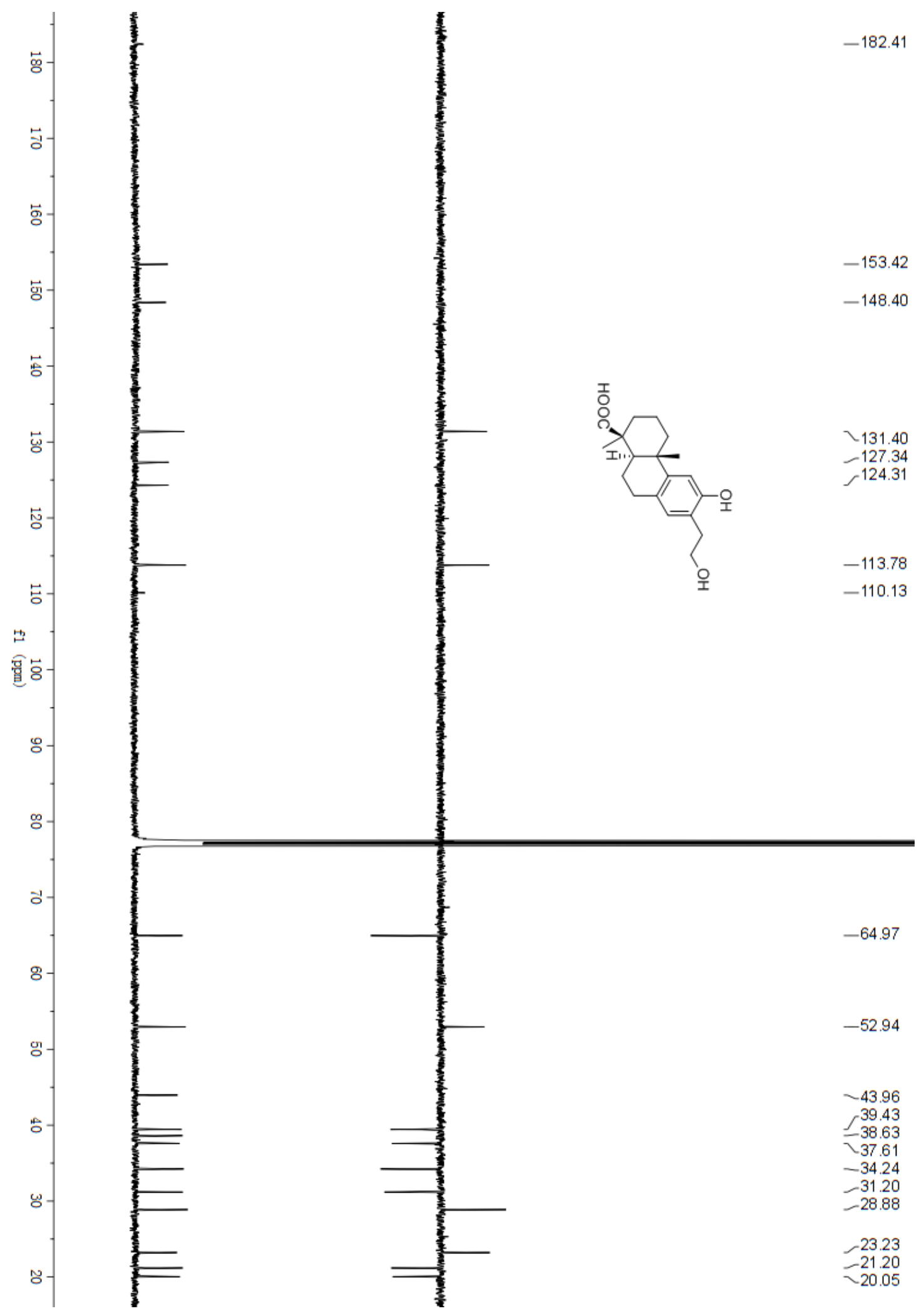


Figure S109. HSQC spectrum of 16-hydroxy-17-norlambertic acid (13) in $\mathrm{CDCl}_{3}$

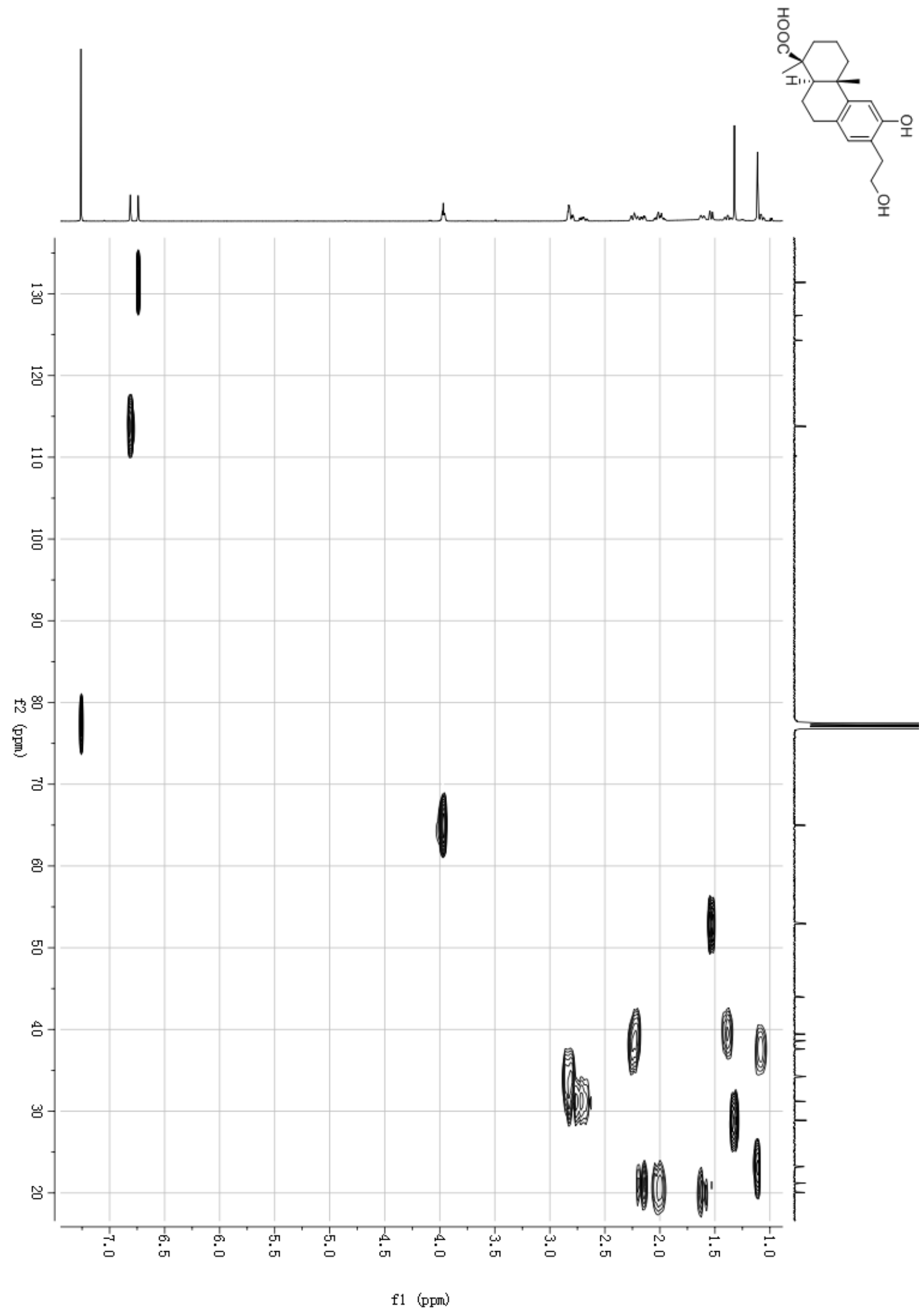


Figure S110. HMBC spectrum of 16-hydroxy-17-norlambertic acid in $\mathrm{CDCl}_{3}$

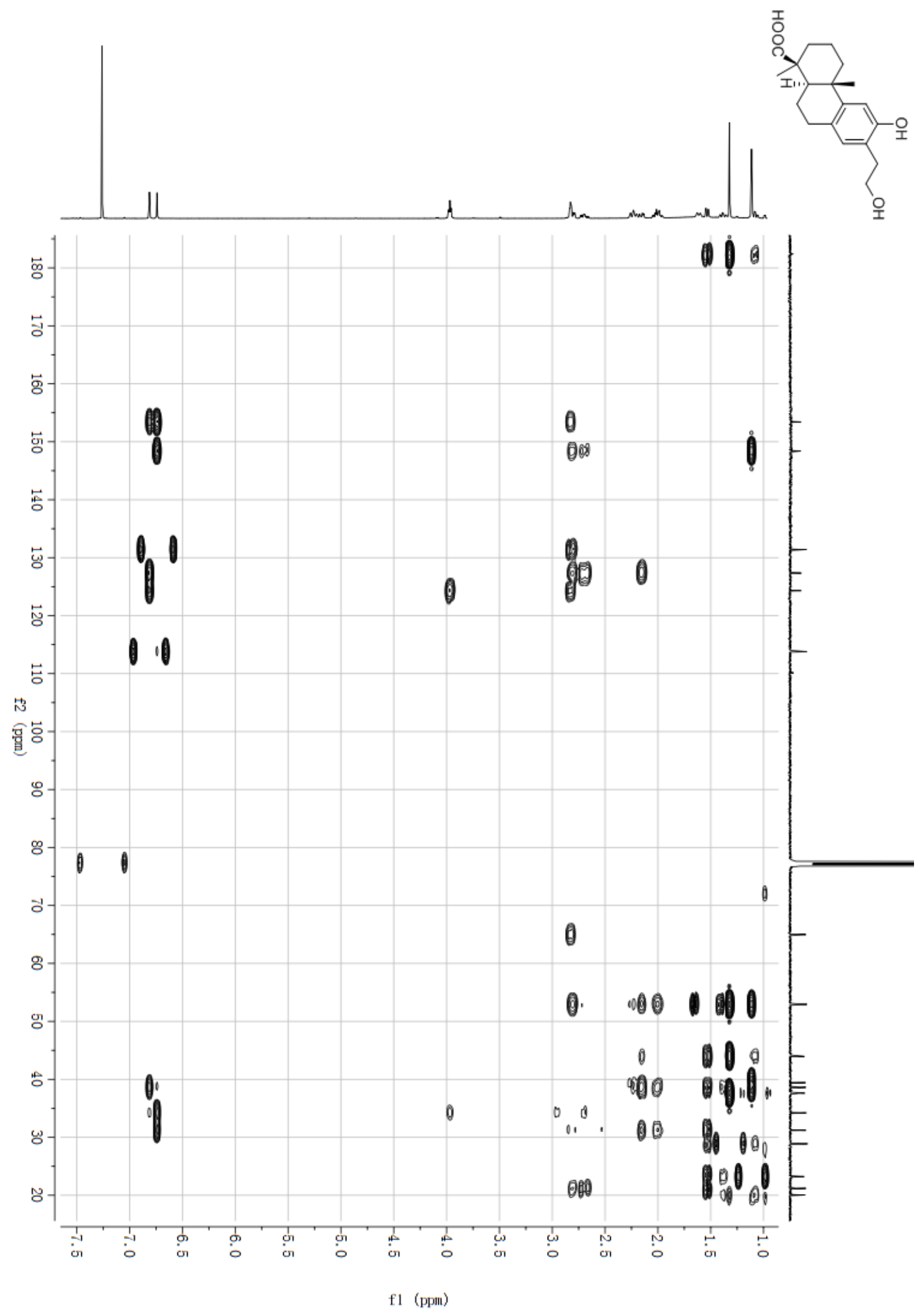


Figure S111. NOESY spectrum of 16-hydroxy-17-norlambertic acid (13) in $\mathrm{CDCl}_{3}$

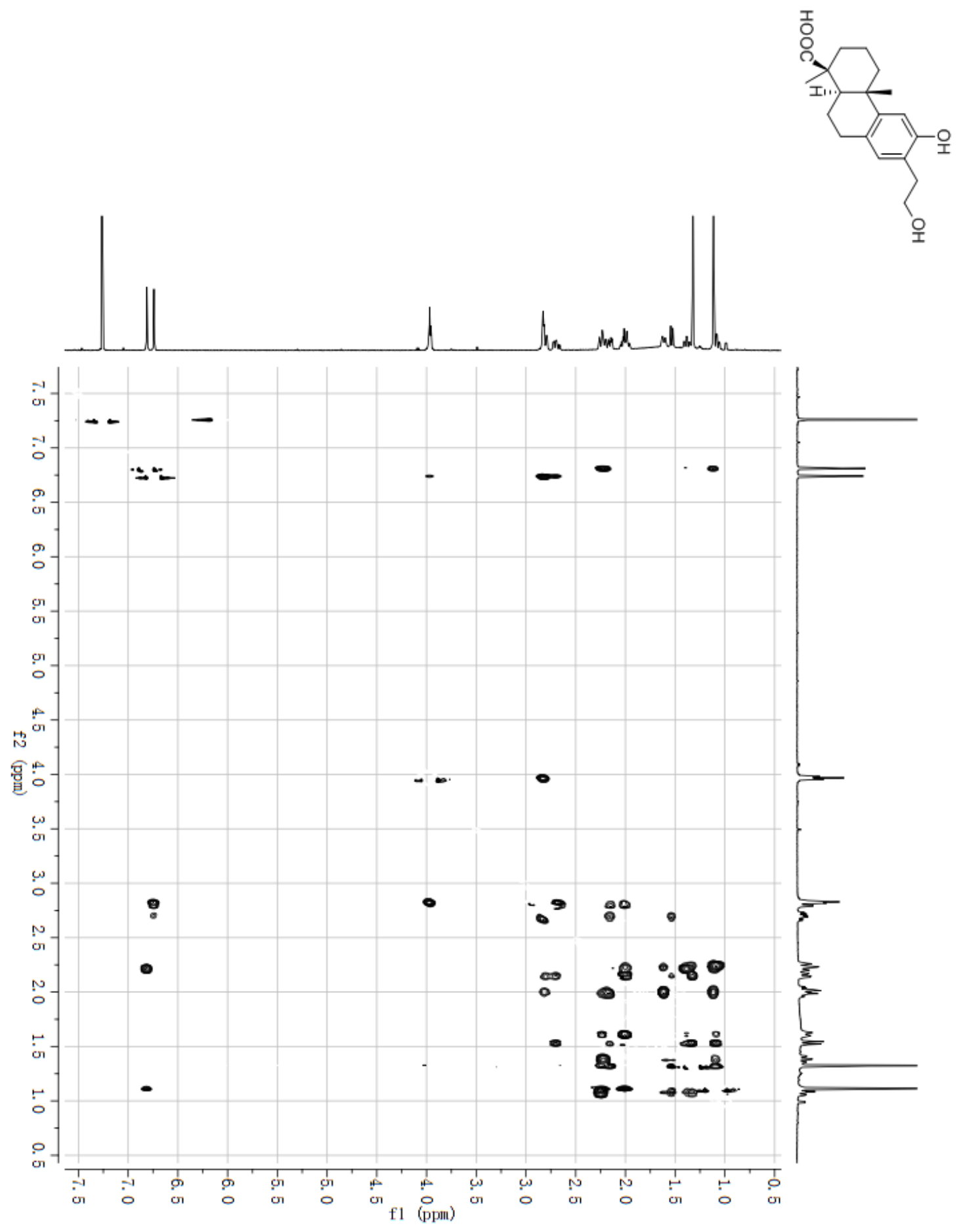


Figure S112. ESIMS spectrum of 16-hydroxy-17-norlambertic acid (13)

2017/7/16 21:08:54 2/ 2
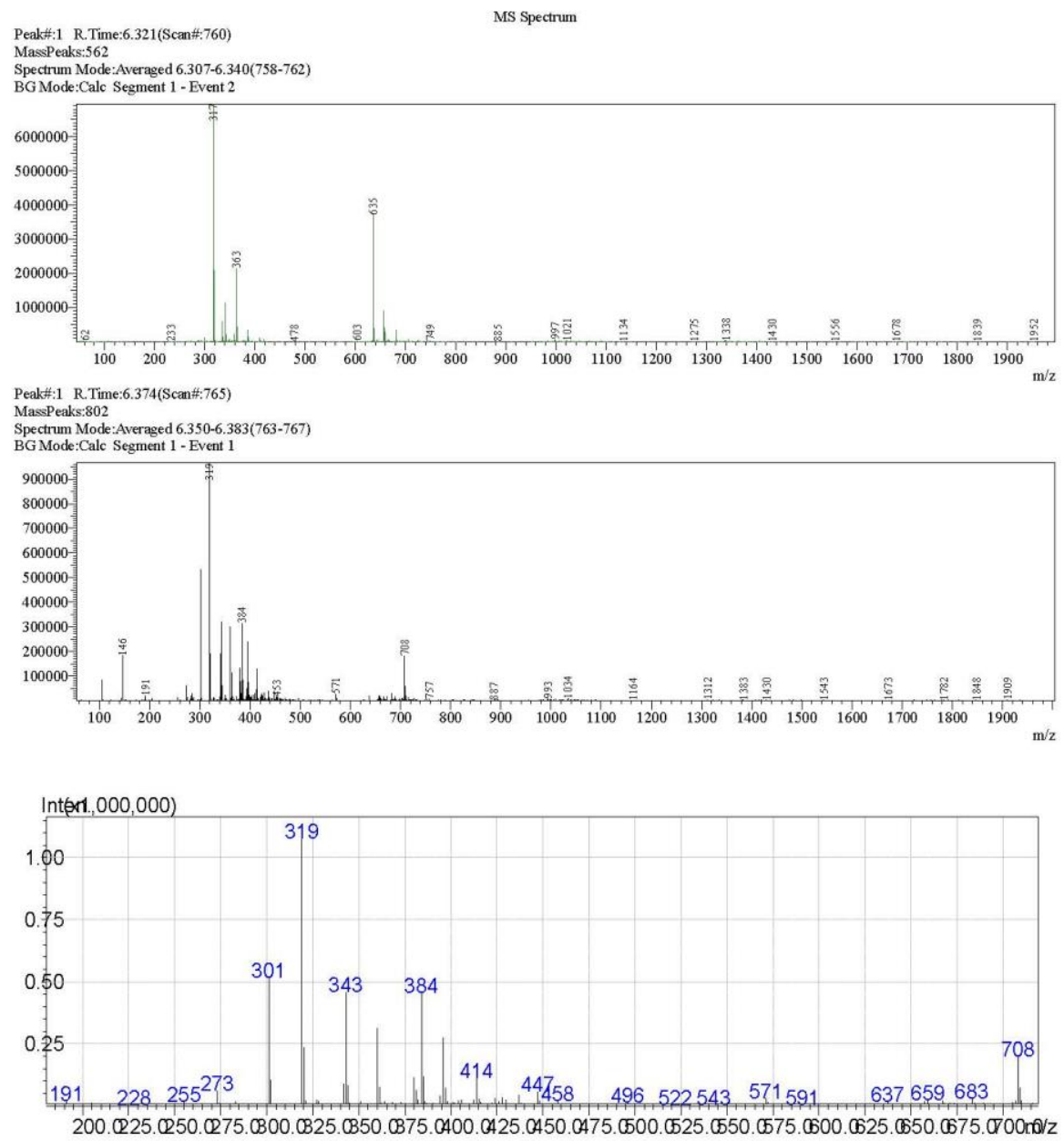
Figure S113. (-)-HRESIMS spectrum of 16-hydroxy-17-norlambertic acid (13)

Elemental Composition Report

Page 1

Single Mass Analysis

Tolerance $=3.0$ PPM / DBE: $\min =-1.5, \max =50.0$

Element prediction: Off

Number of isotope peaks used for i-FIT $=3$

Monoisotopic Mass, Even Electron lons

98 formula(e) evaluated with 1 results within limits (up to 50 closest results for each mass)

Elements Used:

$\begin{array}{llll}\text { C: } 5-80 & \text { H: } 2-120 & \text { O: } 0-30 & \mathrm{Na}: 0-1\end{array}$

POI-10C

LCT PXE KE324

29-Oct-2016

POI-10C 90 (1.974) AM2 (Ar, 12000.0,0.00,0.70); ABS; Cm (89:90)

1: TOF MS ES-

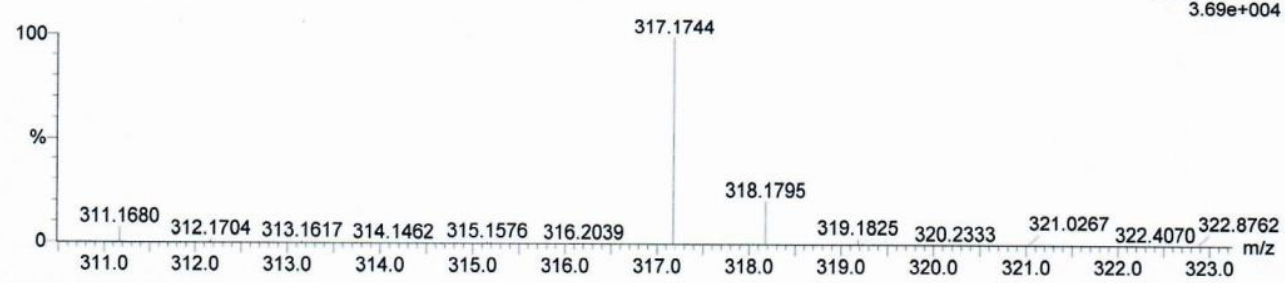

Minimum:

$\begin{array}{lll}5.0 & 3.0 & 50.0\end{array}$

Mass Calc. Mass mDa PPM DBE i-FIT i-FIT (Norm) Formula

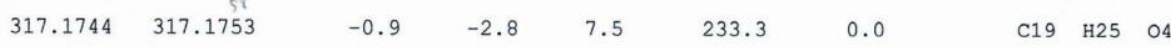


Figure S114. IR spectrum of 16-hydroxy-17-norlambertic acid (13)

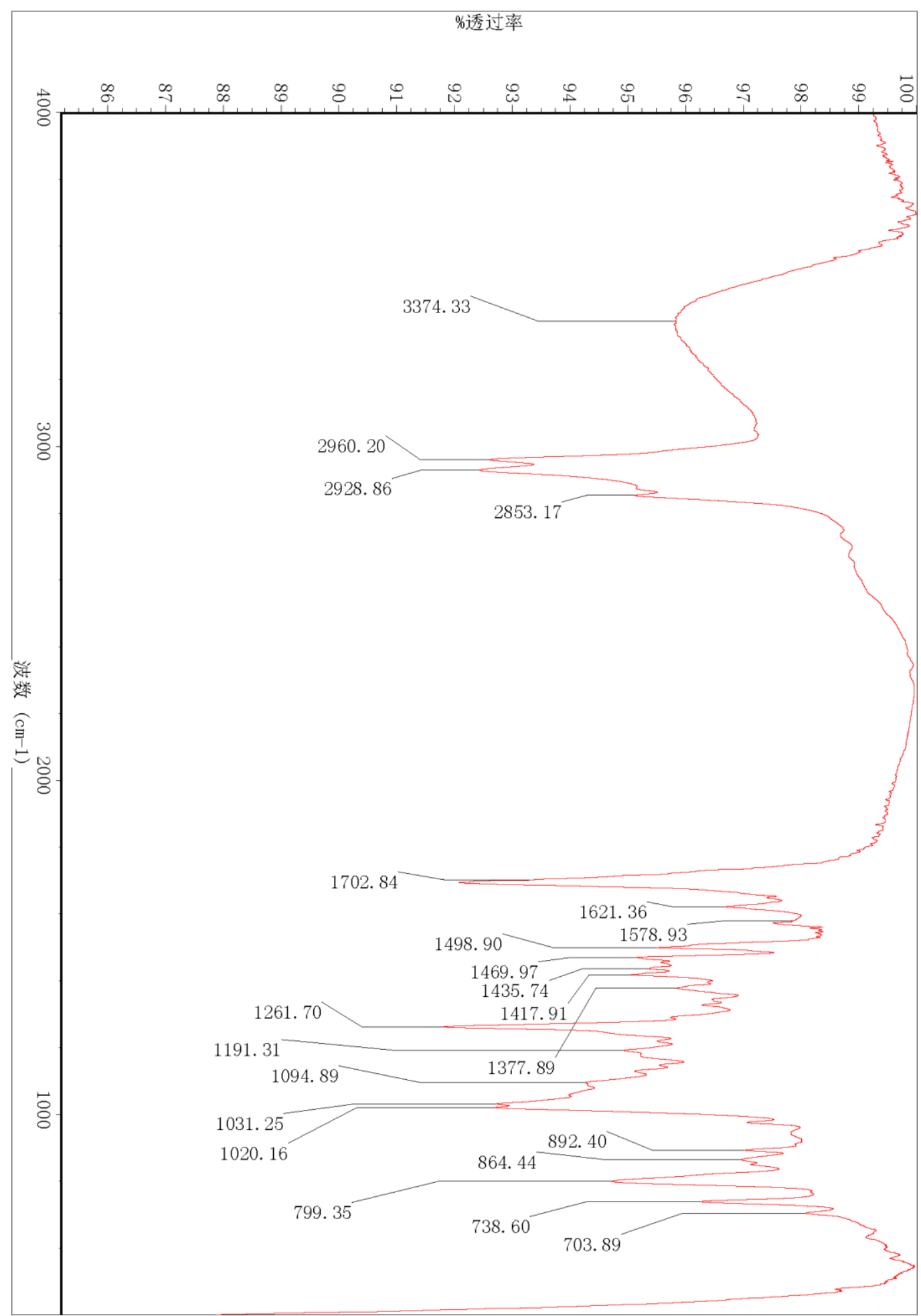


Figure S115. ${ }^{1} \mathrm{H}$ NMR spectrum of 3-oxopisiferanol (14) in $\mathrm{CDCl}_{3}$

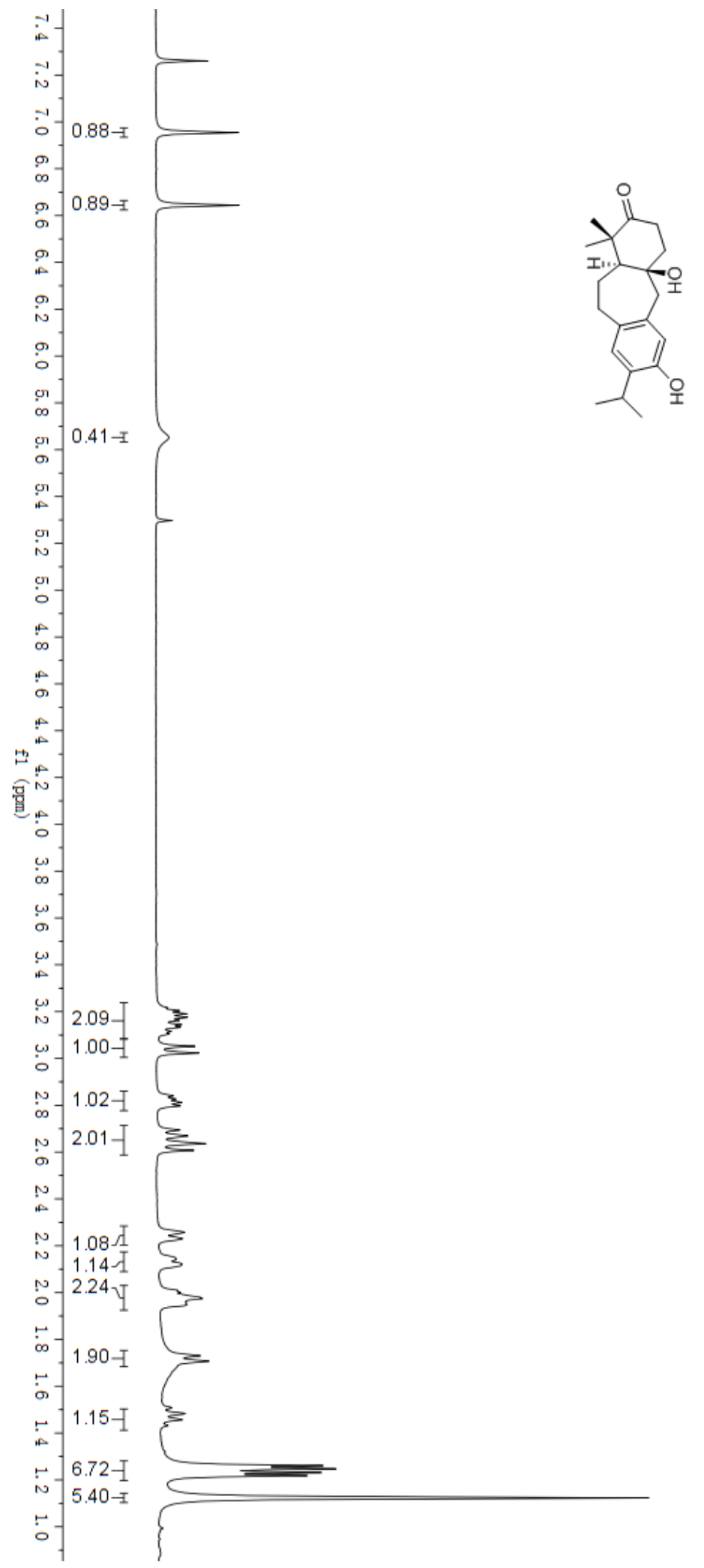

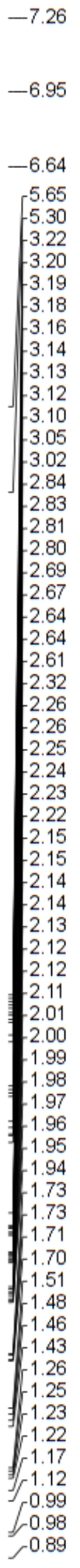


Figure S116. ${ }^{13} \mathrm{C}$ NMR spectrum of 3-oxopisiferanol (14) in $\mathrm{CDCl}_{3}$

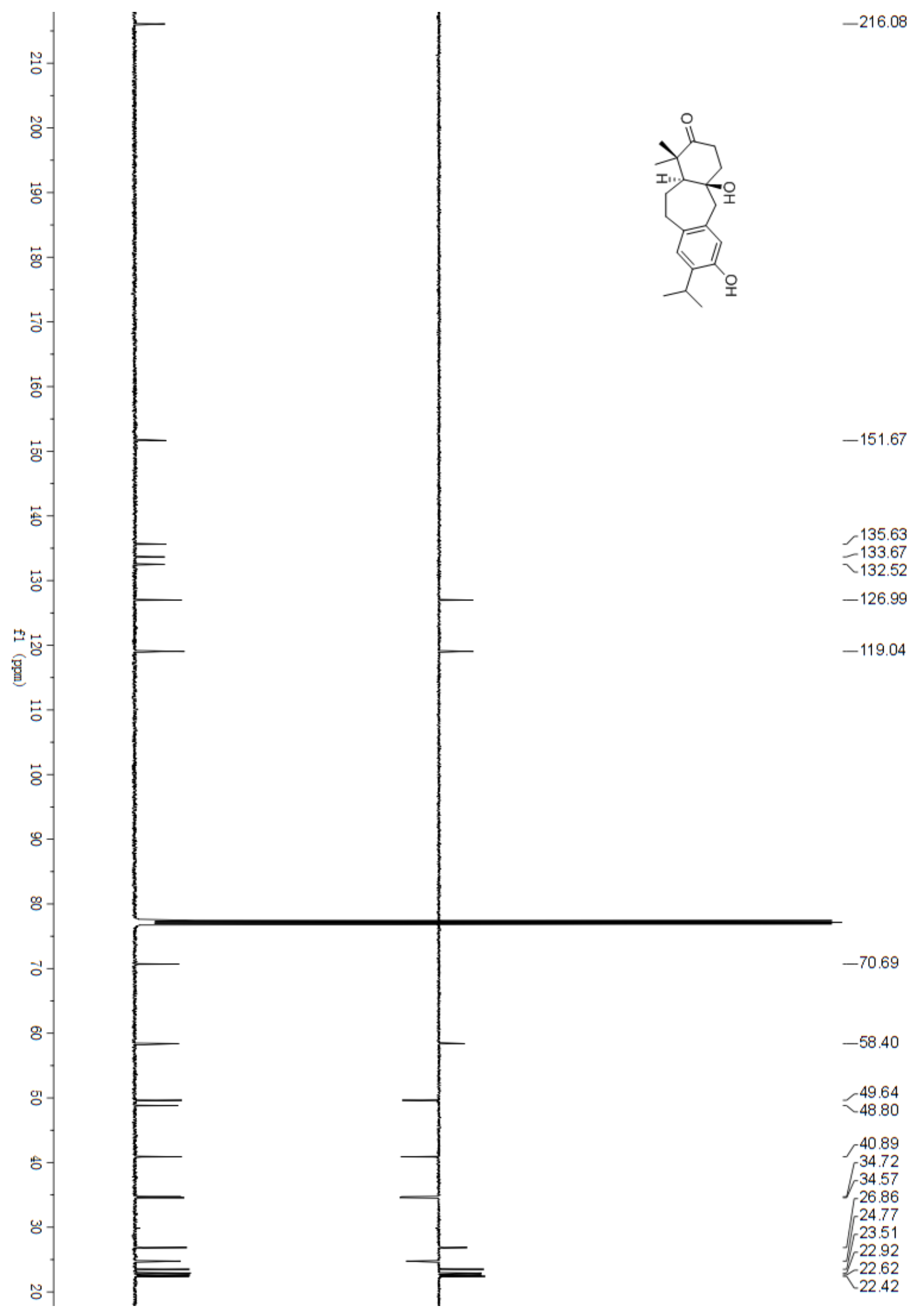


Figure S117. HSQC spectrum of 3-oxopisiferanol (14) in $\mathrm{CDCl}_{3}$

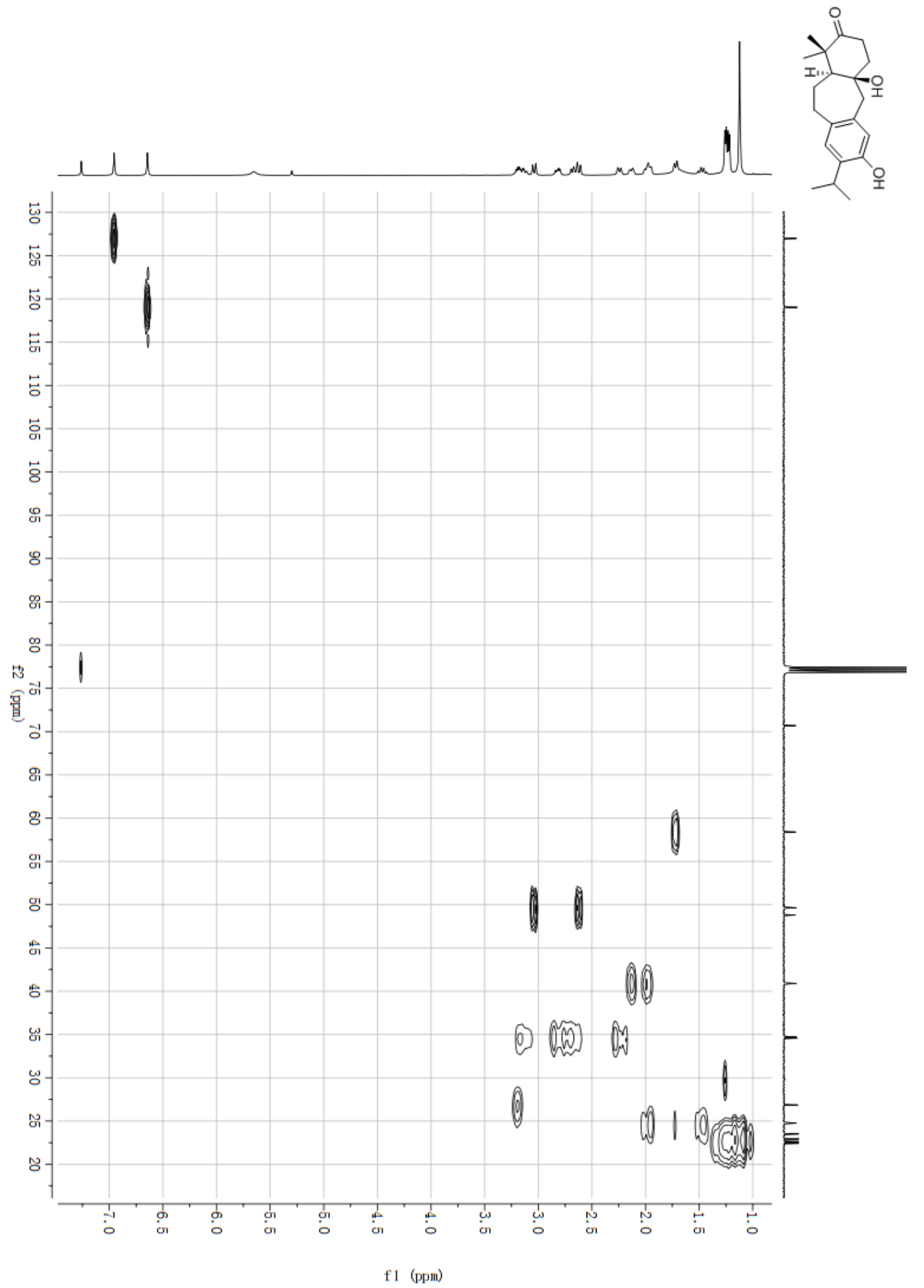


Figure S118. HMBC spectrum of 3-oxopisiferanol (14) in $\mathrm{CDCl}_{3}$

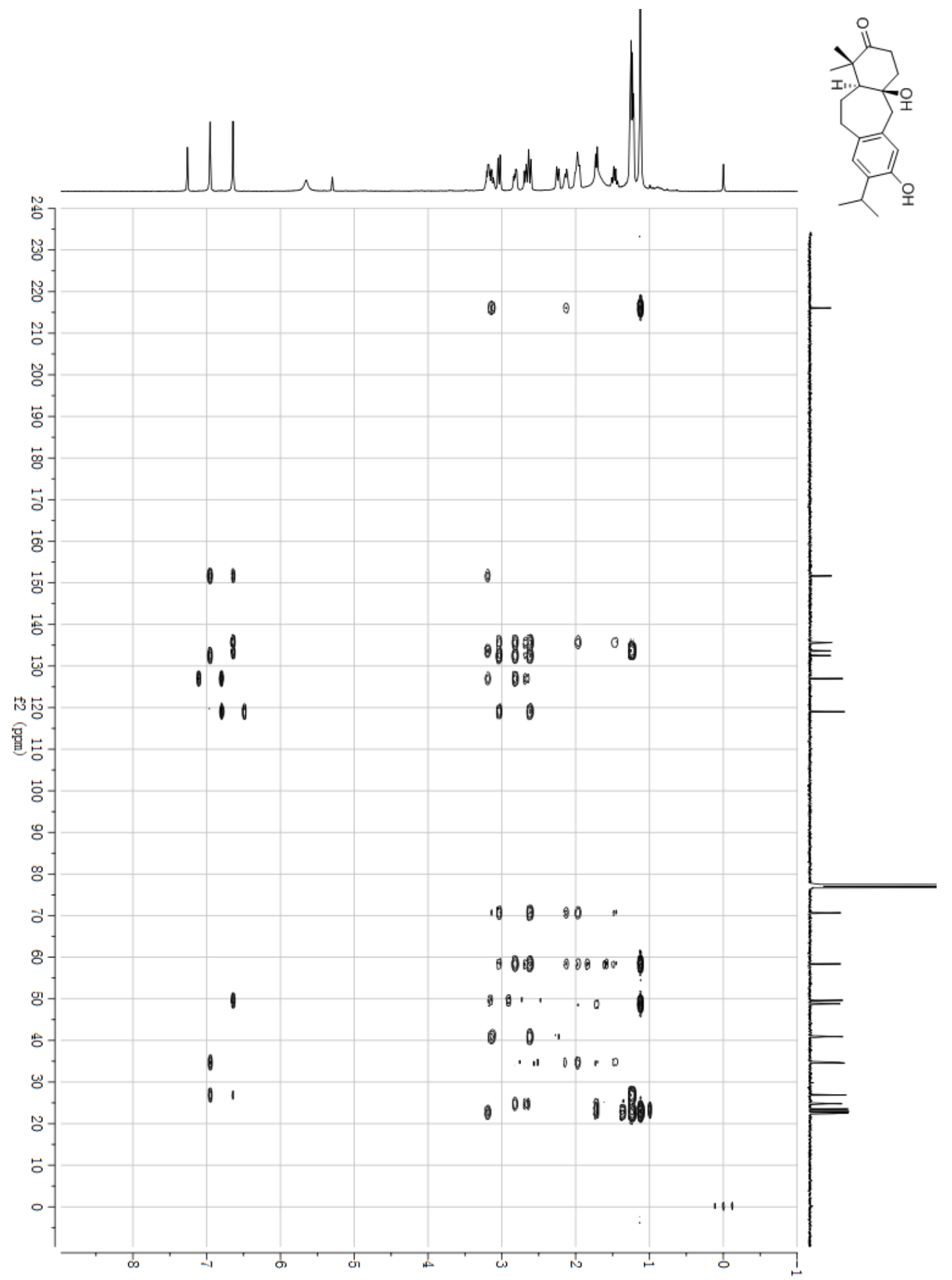

f1 (ppin) 
Figure S119. NOESY spectrum of 3-oxopisiferanol (14) in $\mathrm{CDCl}_{3}$

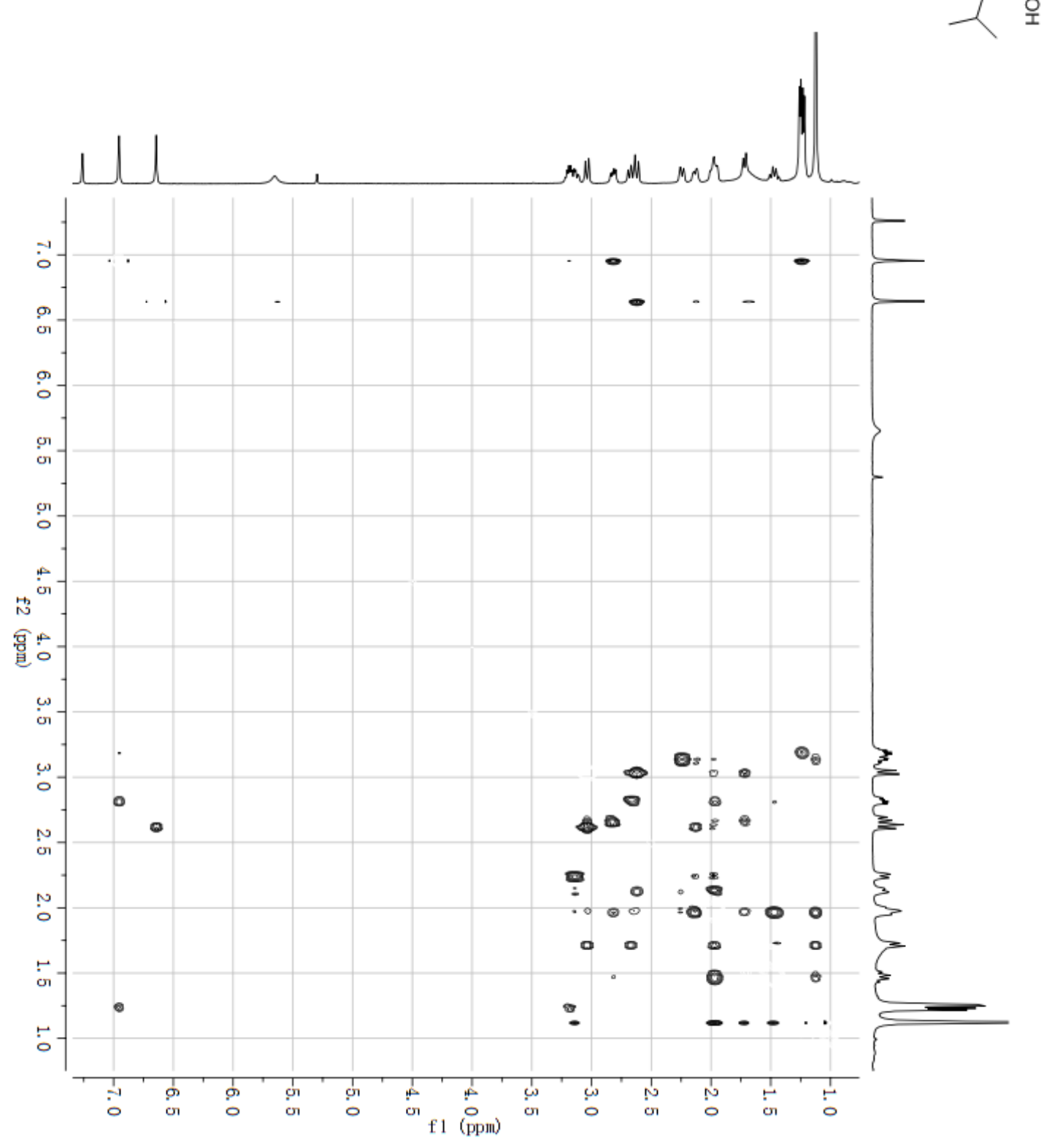

120 
Figure S120. ESIMS spectrum of 3-oxopisiferanol (14)

$2017 / 7 / 1621: 25: 482 / 2$
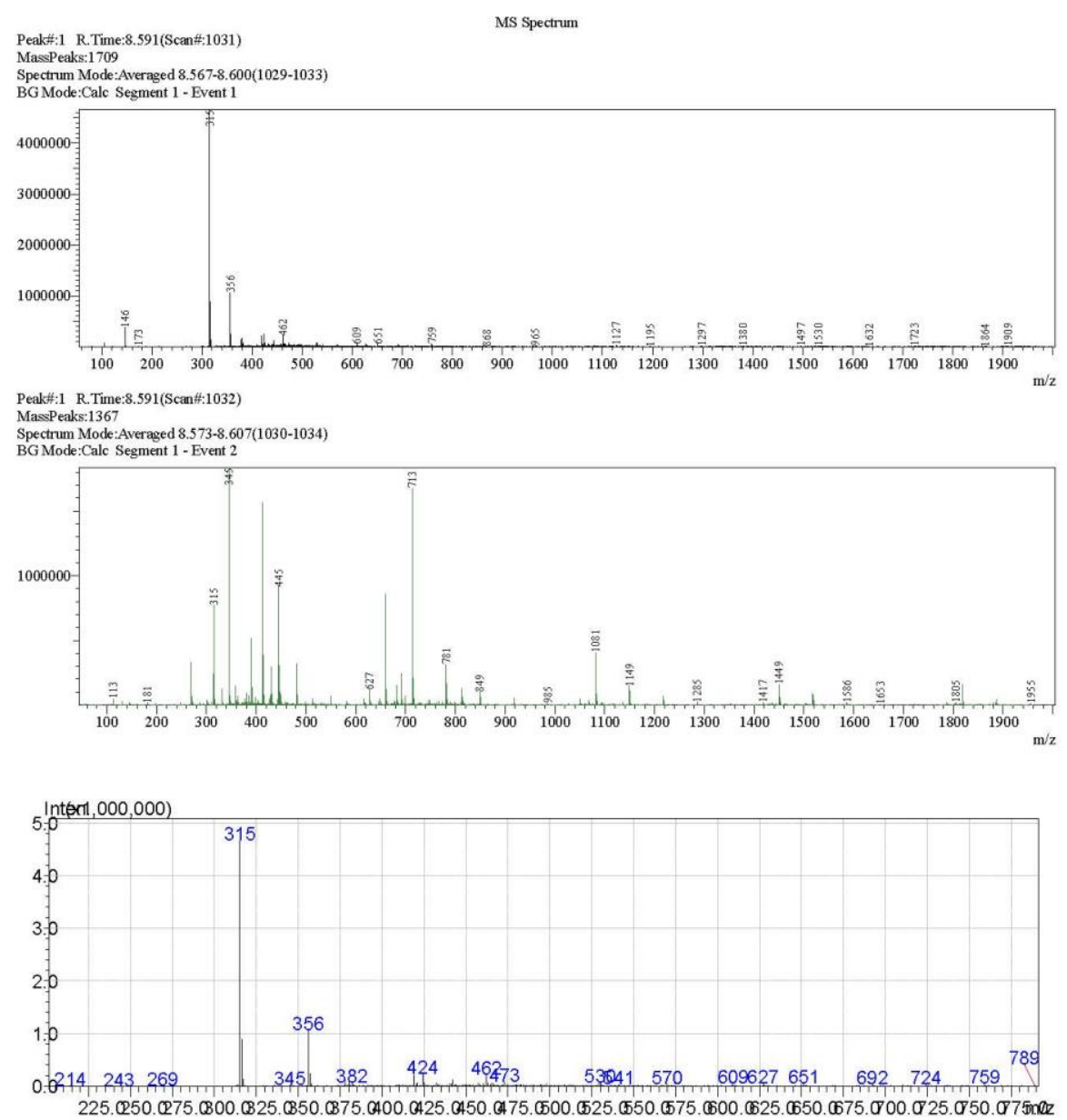
Figure S121. (-)-HRESIMS spectrum of 3-oxopisiferanol (14)

\section{Elemental Composition Report}

Page 1

Single Mass Analysis

Tolerance $=3.0$ PPM / DBE: $\min =-1.5, \max =50.0$

Element prediction: Off

Number of isotope peaks used for i-FIT $=3$

Monoisotopic Mass, Even Electron lons

323 formula(e) evaluated with 1 results within limits (up to 50 closest results for each mass)

Elements Used:

$\begin{array}{llll}\text { C: } 5-80 & \text { H: } 2-120 & \text { O: } 0-30 & \mathrm{Na}: 0-1\end{array}$

POI-12C LCT PXE KE324

LCT PXE KE324 29-Oct-2016

POI-12C 43 (0.919) AM2 (Ar, 10000.0,0.00,1.00); ABS; Cm (33:45)

$15: 20: 25$ 1: TOF MS ES-

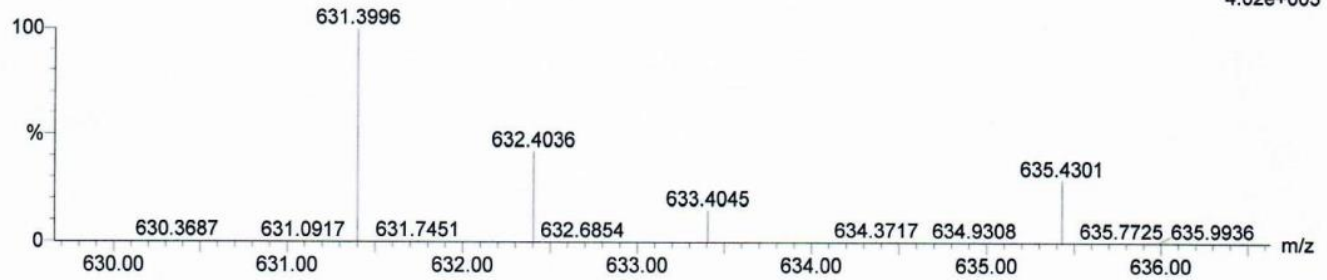

$-1$.

$\begin{array}{llll}\text { Minimum: } & 5.0 & 3.0 & -1.5 \\ \text { Maximum: } & 50.0\end{array}$

Mass Calc. Mass $\mathrm{mDa}$ PPM DBE i-FIT i-FIT (Norm) Formula

$\begin{array}{llllllllll}631.3996 & 631.3999 & -0.3 & -0.5 & 13.5 & 45.4 & 0.0 & \text { C40 } & \text { H55 } & \text { O6 }\end{array}$ 
Figure S122. IR spectrum of 3-oxopisiferanol (14)

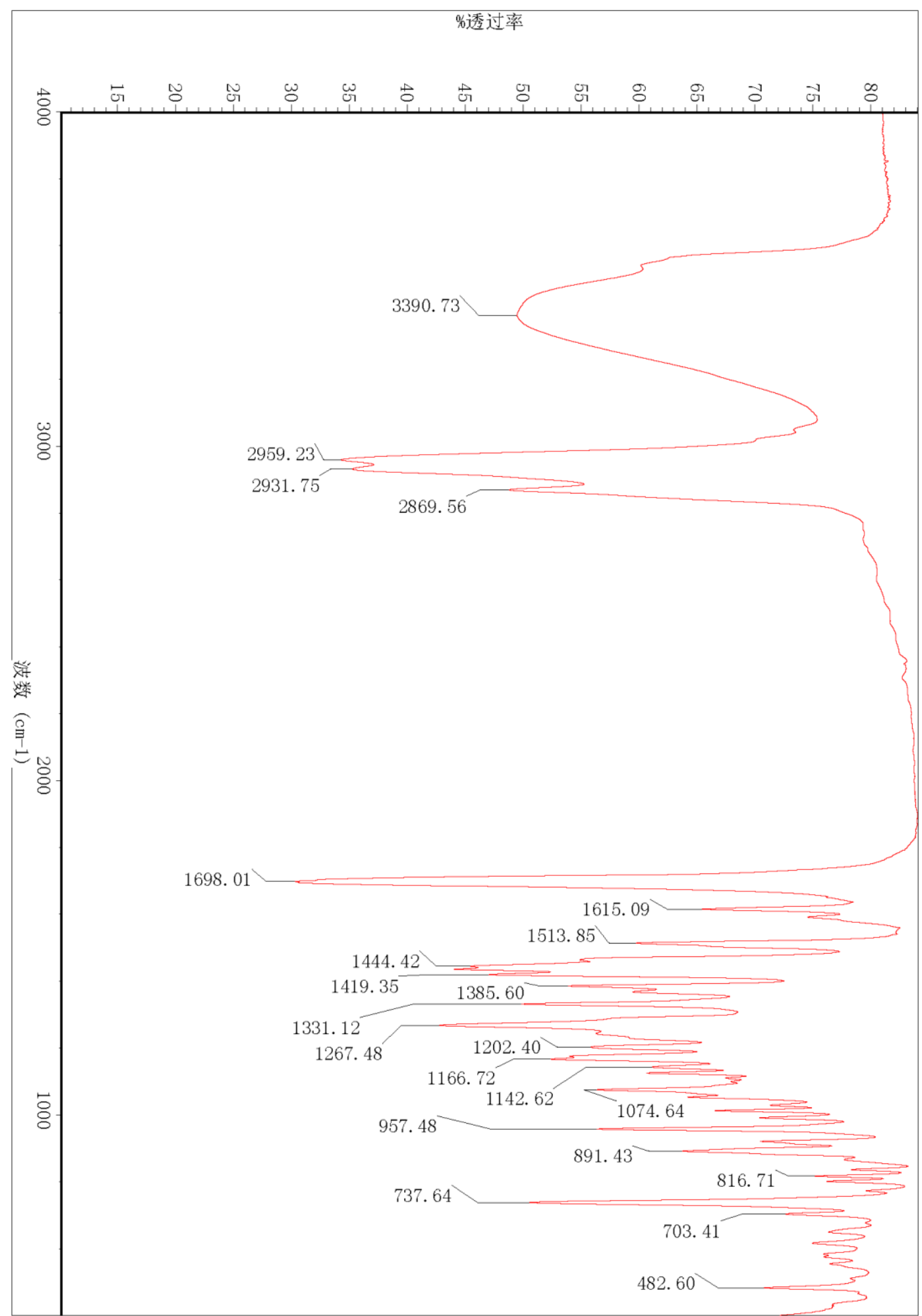

